\title{
Investigations on the Thermal-hydraulic Behavior of Accident Tolerant Fuel Cladding Materials
}

\section{January 2020}

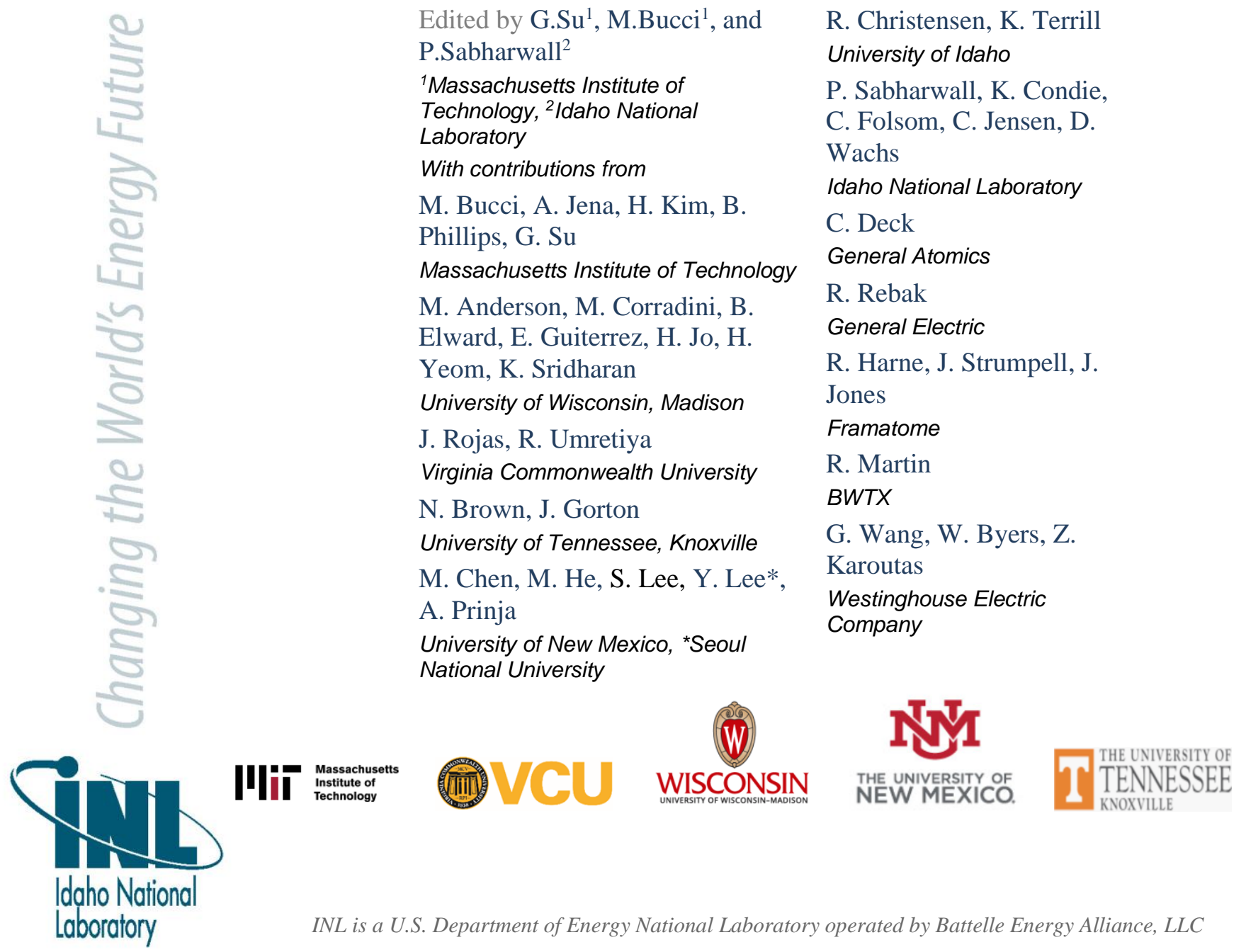




\section{DISCLAIMER}

This information was prepared as an account of work sponsored by an agency of the U.S. Government. Neither the U.S. Government nor any agency thereof, nor any of their employees, makes any warranty, expressed or implied, or assumes any legal liability or responsibility for the accuracy, completeness, or usefulness, of any information, apparatus, product, or process disclosed, or represents that its use would not infringe privately owned rights. References herein to any specific commercial product, process, or service by trade name, trade mark, manufacturer, or otherwise, does not necessarily constitute or imply its endorsement, recommendation, or favoring by the U.S. Government or any agency thereof. The views and opinions of authors expressed herein do not necessarily state or reflect those of the U.S. Government or any agency thereof. 
INL EXT-19-56455

\section{Investigations on the Thermal-hydraulic Behavior of Accident Tolerant Fuel Cladding Materials}

\author{
Edited by G.Su${ }^{1}$, M.Bucci ${ }^{1}$, and P.Sabharwall ${ }^{2}$ \\ ${ }^{1}$ Massachusetts Institute of Technology, \\ 2Idaho National Laboratory \\ With contributions from \\ M. Bucci, A. Jena, H. Kim, B. Phillips, G. Su \\ Massachusetts Institute of Technology
}

M. Anderson, M. Corradini, B. Elward, E. Guiterrez H. Jo, H. Yeom, K. Sridharan

University of Wisconsin, Madison

J. Rojas, R. Umretiya

Virginia Commonwealth University

N. Brown, J. Gorton

University of Tennessee, Knoxville

M. Chen, M. He, S. Lee, Y. Lee*, A. Prinja

University of New Mexico, *Seoul National University
R. Christensen, K. Terrill

University of Idaho

P. Sabharwall, K. Condie, C. Folsom, C. Jensen,

D. Wachs

Idaho National Laboratory

C. Deck

General Atomics

R. Rebak

General Electric

R. Harne, J. Strumpell, J. Jones

Framatome

R. Martin

BWTX

G. Wang, W. Byers, Z. Karoutas

Westinghouse Electric Company

January 2020

Idaho National Laboratory

Idaho Falls, Idaho 83415

http://www.inl.gov

Prepared for the

U.S. Department of Energy

Under DOE Idaho Operations Office

Contract DE-AC07-05ID14517 
Page intentionally left blank 


\section{EXECUTIVE SUMMARY}

In 2018, the Department of Energy launched, through the Nuclear Energy University Program (NEUP) four projects aiming at investigating the thermalhydraulics behavior of ATF cladding materials. These projects have mainly focused on three ATF cladding materials, i.e., Cr-coated Zircaloy, FeCrAl, and SiC. Five technical and scientific questions are being addressed:

(a) How do surface properties of ATF cladding materials, e.g., wettability, change at ambient pressure, and under LWR operating condition?

(b) How do ATF cladding materials perform in atmospheric pool boiling tests?

(c) What is the performance of ATF cladding materials in steady-state and transient flow boiling CHF, particularly under LWR pressure, temperature, and mass flux?

(d) How accurately computer codes model flow boiling CHF on ATF materials, particularly in transient conditions?

(e) How do ATF materials perform in quenching heat transfer, and what is the impact of surface properties on the LFP temperature?

In the year of 2018-2019, significant results have been achieved in surface characterization (structure, morphology, roughness, and contact angle, i.e., wettability), testing (including both pool and flow boiling CHF tests, and droplet quenching tests), and modeling. Lesson learned and near term activities (i.e., to be carried out within the last year of the four NEUP projects) are briefly summarized in four topics, i.e., surface characterization, boiling, modeling and simulation, and quenching.

\section{Surface characterization}

Many groups have measured the contact angle (CA) of ATF materials in the air at atmospheric pressure. However, there seems to be some disagreement on the measured CA from the same material with similar surface roughness. These differences may arise from the sample cleaning protocol, or the surface itself. The CA variation from ambient pressure and temperature to LWR operating conditions has been partially clarified by MIT' tests. Systematic CA measurements on ATF materials (from the four projects) with different surface roughnesses could be conducted in LWR conditions using the MIT facility.

\section{Boiling}

An analysis of the impact of surface characteristics on CHF has been conducted. However, more experiments should be run before definite conclusions could be drawn.

In pool boiling conditions at atmospheric pressure, the CHF values measured by UWM-1 suggest that Zirlo, FeCrAl, and Cr-coated Zirlo have very similar CHF and that the CHF limit can be captured by a modified version of the Kandlikar correlation.

However, UNM performed flow boiling CHF tests at atmospheric pressure and observed that $\mathrm{FeCrAl}$ has a higher CHF limit compared to Zircaloy or $\mathrm{Cr}$ - 
coated Zircaloy at the same operating conditions. UNM also observed that surface degradation (e.g., increase of surface roughness and wettability) does not affect the CHF limit. UNM has also conducted a test with a transient power pulse on $\mathrm{FeCrAl}$ tubes and observed that the transient $\mathrm{CHF}$ value is higher than the steady-state value.

UWM-2 has carried out studies on steady-state flow boiling on Cr-coated and bare Zirlo claddings, and have observed that the $\mathrm{Cr}$-coated cladding has a higher boiling heat transfer coefficient and a slightly higher CHF compared uncoated claddings

WEC conducted several flow boiling CHF tests at PWR operating conditions, showing no difference in the CHF values of bare, Cr-coated and cruded Zirlo claddings.

More tests will be carried out in the third year of the project by WEC and UWM-2, with a specific focus on high pressures, ideally covering both PWR $\left(15.5 \mathrm{MPa}, 344{ }^{\circ} \mathrm{C}\right)$ and $\mathrm{BWR}\left(7.6 \mathrm{MPa}, 291{ }^{\circ} \mathrm{C}\right)$ conditions.

\section{Modeling and simulation}

UTK has generated a computational framework to simulate flow boiling until post-CHF. UTK also quantified the uncertainty and sensitivity of the CHF value and the post-CHF temperature excursion. According to the UTK analysis, there is a need to improve the modeling of post-CHF heat transfer during power transients. However, the development and validation of these models require more experimental data, particularly for high-pressure conditions.

\section{Quenching}

MIT has developed a facility to study droplet quenching, producing demonstrative results on Cr-coated surface. A systematic study will be carried out to quantify the LFP temperature of potential ATF materials. For each material, different surface finish from nano-smooth to PWR cladding-roughness should be tested. The impact of droplet Weber number and subcooling should also be investigated.

On August 13th, 2019, MIT hosted a workshop aiming at sharing the progress of the four projects, summarizing the main findings of the research activities, identifying the challenges and the path forward, and coordinating the efforts from different research teams. Nine technical presentations were given by different organizations involved in the projects. The agenda and the presentation slides are attached in the appendix.

Note: This is a status report and there is additional work to be performed in 2020 prior to completing the projects. 
Page intentionally left blank 


\section{CONTENTS}

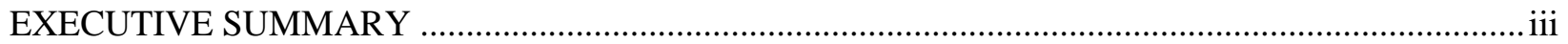

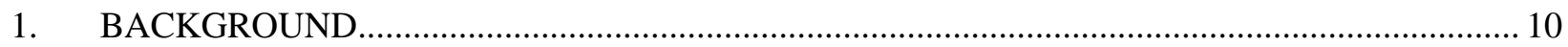

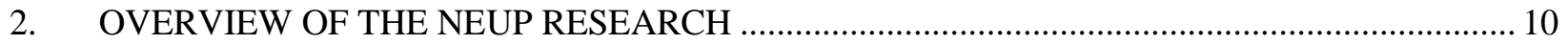

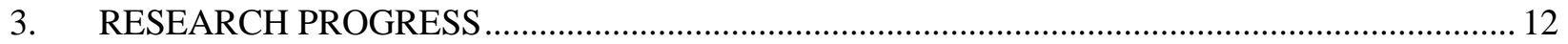

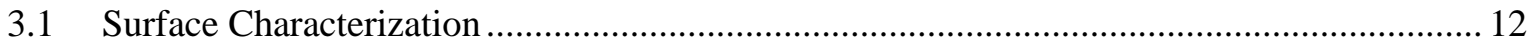

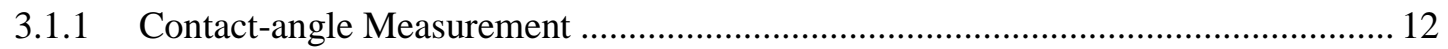

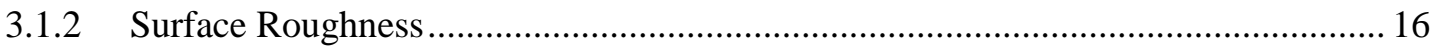

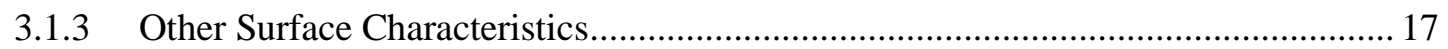

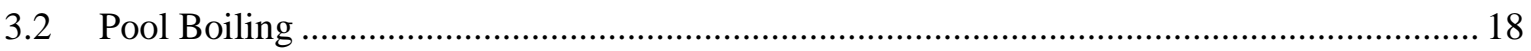

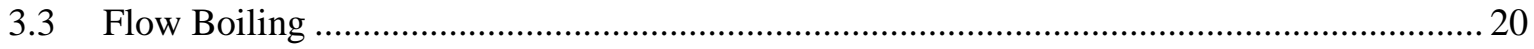

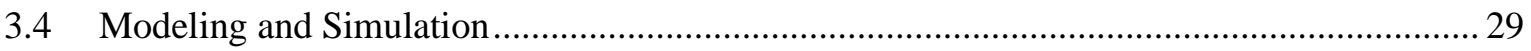

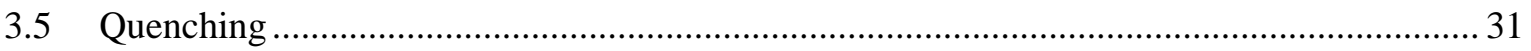

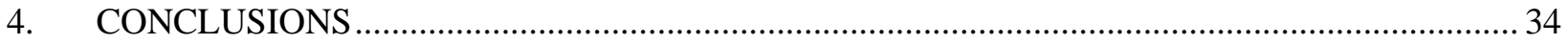

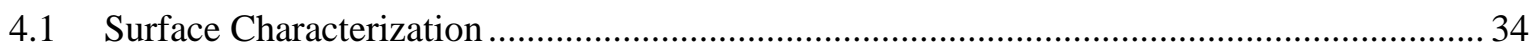

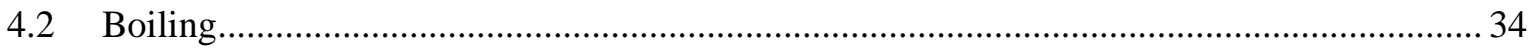

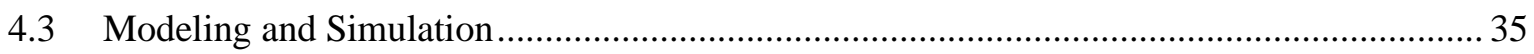

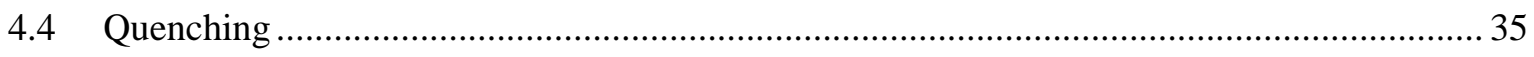

Appendix A Program: Thermal-Hydraulics of ATF Cladding Materials ............................................... 37

Appendix B Critical Heat-Flux Studies of Advanced Accident-Tolerant Fuel-Cladding Concepts.......... 41

Appendix C Summary of ATF Testing at the University of Wisconsin ................................................59

Appendix D Wettability of ATF Cladding Materials in Nuclear-Reactor Conditions .......................... 71

Appendix E Sensitivity of Critical Heat Flux for ATF FeCrAl Alloy Using RELAP5-3D and RAVEN . 82

Appendix G Progress on the Surface Characterization of ATF and Preliminary Results on CHF ........... 96

Appendix H Investigation of Droplet Quenching on Accident Tolerant Coating Using Infrared

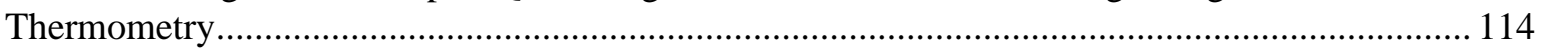

Appendix I CHF and CRUD WALT Loop Measurements for Westinghouse Accident-Tolerant Fuel .. 125

Appendix J In-Pile CHF Experiments at TREAT and Related CHF Activities.................................... 140

Appendix K Thermal-Hydraulics of ATF Cladding Materials, NEUP-ATF Meeting........................... 152

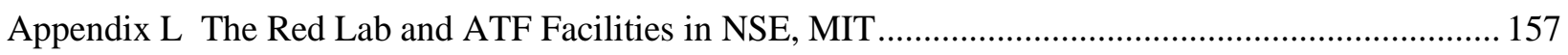




\section{FIGURES}

Figure 1. An overview of the organizations involved in the four projects sponsored by DOE. 11

Figure 2. Comparison of static CA for $\mathrm{Zr}-4$ and $\mathrm{Cr}$-coated $\mathrm{Zr}-4$ with a different surface finish of the substrate (VCU).

Figure 3. CA, roughness, and surface morphology measurements on various materials polished by 600 grit $\mathrm{SiC}$ abrasive paper (UWM-1).

Figure 4. Design of the autoclave (left) and the test section (right) for the CA measurement (MIT).

Figure 5. CA measured on: (top left) as-machined Zr-4, (top right) mirror-polished Zr-4, (middle left) oxidized $\mathrm{Zr}-4$, (middle right) as-machined monolithic $\mathrm{SiC}$, and (bottom) mirrorpolished $\mathrm{FeCrAl}$ (MIT).

Figure 6. XRD patterns of tested materials (VCU). .17

Figure 7. Element map for APMT (left) and SEM micrographs of etched FeCrAl (right) (VCU). 18

Figure 8. Illustrations of the pool-boiling facility designed and constructed for this study:

(a) heater block and sample specimen, (b) assembly of the sample holder and heater block part, and (c) full assembly of the facility (UWM).

Figure 9. Pool-boiling $\mathrm{CHF}$ at atmospheric pressure and saturation temperature as a function of CA and their comparison with modified Kandlikar's model (UWM).

Figure 10. CHF results as a function of the sample thermal activity (UWM). 20

Figure 11. (a) Flow loop diagram, (b) test section cross-sectional view (UNM).

Figure 12. (a) Repeated CHF measurements on the FeCrAl alloy, (b) CHFs compared to the lookup table at corresponding equilibrium quality (UNM).

Figure 13. (a) Experimental measurement of transient pulsed power input, (b) CHF determination, and (c) rewetting-point determination (pulsed power: $1 \mathrm{~s}$ width and peak at 8088.78 watts, $\mathrm{FeCrAl}$ alloy) (UNM).

Figure 14. FeCrAl: obtained boiling curves for steady-state (1) ONB, (2) CHF) and transient flow boiling (300 kg/m² $-\mathrm{s}$ mass flow, $\mathrm{Xe}=-0.0068$, dashed line to (3) $\mathrm{CHF}$, then to (7)) (UNM).

Figure 15. Image of heater rod for low-pressure tests (top), and the design of an internally heated rod for high-pressure tests (bottom) (UWM)..

Figure 16. Low-pressure test section (left) and low-pressure flow loop (right) (UWM-2).

Figure 17. Comparison of rod-average HTC of Cr-coated (PVD) and bare Zircaloy heater rods (UWM-2).

Figure 18. Heat flux values at CHF for bare Zircaloy and two types (PVD and cold spray) of Crcoated Zircaloy.

Figure 19. Boiling curves for bare Zircaloy and two types (PVD and cold spray) of Cr-coated Zircaloy. Pressure and subcooling were maintained at $115 \mathrm{kPa}$ and $75^{\circ} \mathrm{C}$, respectively. .26

Figure 20. Photograh (left) and schematic representation (right) of WALT loop (WEC). 
Figure 21. Comparison of CHF values from different surfaces at similar thermohydraulic conditions. Top left: yellow group; top right: green group; bottom: orange group (WEC).

Figure 22. (a) Experimental heat flux and tube temperature and (b) simulated heat flux and tube temperature. (UTK)

Figure 23. (a) CHF prediction with 12 evenly distributed educated data and (b) comparison of machine-learning prediction to true CHF (UNM).

Figure 24. (a) High-pressure extrapolation strategy and (b) SVM supported extrapolation at $\mathrm{Xe}=-0.05(\mathrm{UNM})$.

Figure 25. Schematics of the droplet quenching experiment (MIT).

Figure 26. Droplet quenching at transition boiling $\left(240^{\circ} \mathrm{C}\right)$. Temperature color scale in ${ }^{\circ} \mathrm{C}(\mathrm{MIT})$.

Figure 27. Droplet quenching at film boiling $\left(520^{\circ} \mathrm{C}\right)$. Temperature color scale in ${ }^{\circ} \mathrm{C}$ (MIT).

Figure 28. Schematic illustration of the quench-test facility to evaluate boiling heat transfer of various ATF cladding surfaces under high-pressure and subcooled-water conditions (UWM).

\section{TABLES}

Table 1. Comparison of roughness and CA between $\mathrm{Zr}-2$ and APMT and C26M grade $\mathrm{FeCrAl}$

(VCU). .13

Table 2. Summary of the measured Ra from different samples .13

Table 3. Surface roughness and wettability: as-received/post-CHF experiment (UNM). .14

Table 4. Summary of CHF results from different metallic test samples (UWM) ...................................20

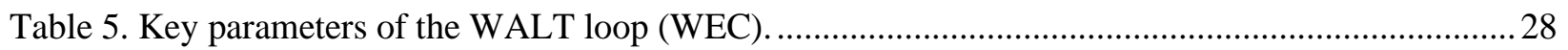

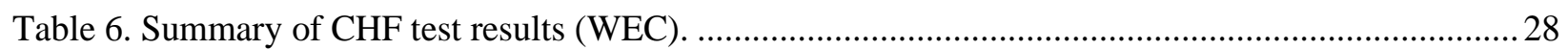

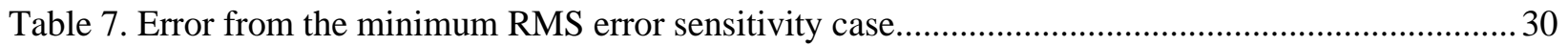


Page intentionally left blank 


\section{Investigations on the Thermal-hydraulic Behavior of Accident Tolerant Fuel Cladding Materials \\ 1. BACKGROUND}

Since the 2011 Fukushima accident, significant research has been devoted to developing accidenttolerant fuel (ATF) cladding materials. These investigations have mostly focused on the ability to resist runaway steam oxidation and retain mechanical strength and structural integrity under thermal shocks. However, much remains unknown about the materials' thermal-hydraulic behavior, particularly under light-water reactor (LWR) operating conditions. Two phenomena that determine safety margins in both normal and off-normal operating conditions - i.e., the critical heat flux (CHF) and Leidenfrost point (LFP) temperature - have not been investigated thoroughly for ATF materials.

Surface properties, such as wettability and roughness, are known to influence pool and flow boiling CHF, as well as the LFP temperature. However, little is known about the surface wettability of ATF materials, particularly at LWR pressure and temperature. Little has been done on flow-boiling CHF and quenching heat transfer, especially for droplet quenching.

Nonetheless, it is known that CHF in transient conditions, e.g., an exponentially escalating power transient, can be significantly different from that expected in steady-state operation. Very few studies have investigated transient CHF, either on ATF materials or under LWR pressure and temperature. The thorough understanding of transient CHF under prototypical reactor conditions will benefit not only the deployment of ATF but also the upcoming national efforts to study transient ATF behavior in the Transient Reactor Test Facility (TREAT) at Idaho National Laboratory.

In summary, as a part of ATF development efforts, there is an urgent need to understand how and how much these materials may affect two-phase heat transfer phenomena in nuclear reactor conditions.

\section{OVERVIEW OF THE NEUP RESEARCH}

In 2018, the Department of Energy launched, through the Nuclear Energy University Program (NEUP), four projects aimed at investigating thermal-hydraulic behavior of ATF cladding materials. These projects involve many organizations, as shown in Figure 1, and are structured as follow:

- Project 17-12549: "Critical Heat Flux Studies for Innovative Accident Tolerant Fuel Cladding Surfaces," led by the University of Wisconsin at Madison (UWM)-1 in collaboration with Westinghouse Electric Company, LLC (WEC) and General Atomics (GA).

- Project 17-12647: "Determination of Critical Heat Flux and Leidenfrost Temperature on Candidate Accident Tolerant Fuel Materials," led by the Massachusetts Institute of Technology (MIT) in collaboration with UWM-2, WEC, and GA.

- Project 17-12688: “An Experimental and Analytical Investigation into Critical Heat Flux Implications for Accident Tolerant Fuel Concepts," led by the University of New Mexico (UNM) in collaboration with the University of Tennessee at Knoxville (UTK), Oregon State University (OSU), Framatome, General Electric (GE), and Idaho National Laboratory (INL).

- Project 17-13019: "Evaluation of Accident Tolerant Fuels Surface Characteristics in Critical Heat Flux Performance," led by Virginia Commonwealth University (VCU) in collaboration with UWM-2, BWX, Framatome, and GE. 


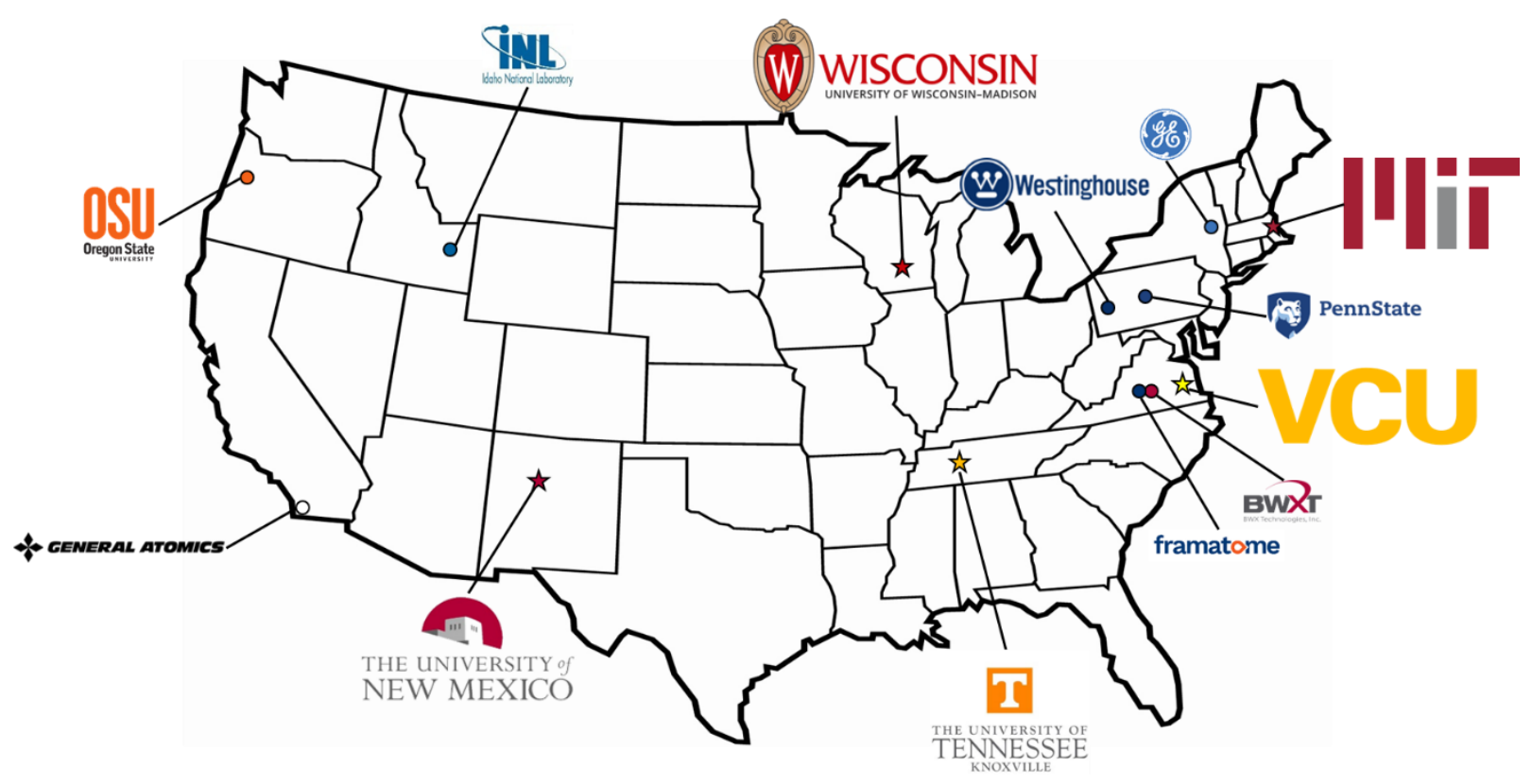

Figure 1. An overview of the organizations involved in the four projects sponsored by DOE.

The list of PIs (in bold) and collaborators at the different organizations include (in alphabetical order):

- BWXT: J. Miller

- GA: C. Deck

- GE: R. Rebak

- Framatome: J. Strumpell (UNM lead project), R. Harne, J. Jones (VCU lead project)

- INL: C. Jensen

- $\quad$ MIT: M. Bucci, G. Su, B. Phillips

- OSU: W. Marcum

- UTK: N. Brown (previously at PennState)

- UNM: A. Prinja (previously Y. Lee)

- UWM-1: M. Corradini, K. Sridharan, S. Yeom, H. Jo (now at Postech, South Korea)

- UWM-2: M. Anderson, B. Elward

- VCU: V. Rojas

- WEC: Z. Karoutas (MIT lead project only), Q. Wang (MIT lead project only), P. Xu, W. Byers.

These projects have mainly focused on three ATF cladding materials-i.e., Cr-coated Zircaloy, $\mathrm{FeCrAl}$, and SiC. Five technical and scientific questions are being addressed:

(a) How do surface properties of ATF-cladding materials, e.g., wettability, change at ambient pressure and under LWR operating condition?

(b) How do ATF-cladding materials perform in atmospheric pool boiling tests?

(c) What is the performance of ATF-cladding materials in steady-state and transient flow-boiling CHF, particularly under LWR pressure, temperature, and mass flux? 
(d) How accurately do computer codes model flow-boiling CHF on ATF materials, particularly in transient conditions?

(e) How do ATF materials perform in quenching heat transfer, and what is the impact of surface properties on the LFP temperature?

In the year 2018-2019, significant results have been achieved in surface characterization (structure, morphology, roughness, and contact angle (i.e., wettability)), testing (including both pool- and flowboiling $\mathrm{CHF}$ and droplet-quenching tests), and modeling.

In this report, we discuss the contributions and accomplishments of all the organizations involved in these projects in the effort to answer these five technical and scientific questions.

\section{RESEARCH PROGRESS}

\subsection{Surface Characterization}

Surface wettability - i.e., the surface contact angle with water - is known to affect boiling heat transfer (e.g., increasing CHF) and quenching heat transfer (e.g., increasing the LFP temperature). The apparent surface wettability depends on surface roughness and intrinsic surface wettability-i.e., the contact angle that one would measure on an ideally smooth surface.

It is essential to characterize the intrinsic wettability of these materials as well as the roughness and the apparent wettability of actual ATF cladding samples to understand how they will affect boiling and quenching heat transfer. Ideally, one would quantify wettability (i.e., static, advancing, and receding contact angles) up to LWR operating conditions-i.e., in fully degassed water at high pressure and temperature.

\subsubsection{Contact-angle Measurement}

The sessile-drop method is the most-common approach to measure contact angles (CAs). This measurement typically requires an optical goniometer and a high-definition (HD) camera. The HD camera is used to take a magnified, backlit image of a sessile water drop on the test sample. Then, a postprocessing algorithm is used to calculate the tangent of the droplet outline at the point of contact with the sample surface. The CA value is then back-calculated from the tangent.

VCU, UWM-1, UNM, and MIT have done CA measurements using goniometers on various ATF materials and surface finishes. Most of these tests were conducted with water droplets in the air under atmospheric pressure. However, MIT developed and operated a new apparatus that is capable of measuring CA in degassed water up to critical pressure and temperature (i.e., $22.06 \mathrm{MPa}$ and $374^{\circ} \mathrm{C}$, respectively).

VCU measured the CA in the air at atmospheric pressure on various tubular ATF materials including Zr-2, APMT, and C26M-grade FeCrAl from GE, Zr-4 from Framatome, and Cr-coated Zr-4. A comparison between $\mathrm{Zr}-2$ and $\mathrm{FeCrAl}$ is shown in Table 1 (Ra represents the arithmetical-mean deviation of the assessed profile, Rz the average distance between the highest peak and lowest valley in each sampling length, Rsk the skewness of the height measurement, Rku the kurtosis of the height measurement, roughness factor the ratio of the measured area over the projection area, Rsm the rootmean-squared of the assessed height profile). All the samples have a very similar roughness factor, but while the measured CAs on APMT and $\mathrm{C} 26 \mathrm{M}$ grade $\mathrm{FeCrAl}$ are very close, $\mathrm{Zr}-2$ has a lower CA. This seems to indicate that the intrinsic wettability of $\mathrm{FeCrAl}$ is lower than the intrinsic wettability of $\mathrm{Zr}-2$. 
Table 1. Comparison of roughness and CA between $\mathrm{Zr}-2$ and APMT and C26M grade FeCrAl (VCU).

\begin{tabular}{|c|c|c|c|c|c|c|c|}
\hline \multirow{3}{*}{ Material } & \multicolumn{6}{|c|}{ Roughness } & \multirow{3}{*}{$\begin{array}{c}\text { Contact } \\
\text { angle } \\
\text { (degree) }\end{array}$} \\
\hline & \multicolumn{4}{|c|}{ SJ-410 Profilometer } & \multicolumn{2}{|c|}{ AFM } & \\
\hline & $\mathrm{Ra}(\mu \mathrm{m})$ & $\mathrm{Rz}(\mu \mathrm{m})$ & Rsk & Rku & $\begin{array}{c}\text { Roughness } \\
\text { factor (r) }\end{array}$ & $\begin{array}{l}\text { Rsm } \\
(\mu \mathrm{m})\end{array}$ & \\
\hline Zircaloy-2 & $0.36 \pm 0.04$ & $4.46 \pm 1.08$ & $0.01 \pm 0.32$ & $4.46 \pm 1.79$ & 1.02 & 0.18 & $72.33 \pm 4.28$ \\
\hline APMT & $0.68 \pm 0.07$ & $5.94 \pm 0.84$ & $-0.47 \pm 0.12$ & $3.17 \pm 0.29$ & 1.07 & 0.49 & $91.97 \pm 2.78$ \\
\hline C26M & $0.69 \pm 0.07$ & $8.59 \pm 1.34$ & $-1.05 \pm 0.31$ & $6.23 \pm 1.76$ & 1.02 & 0.38 & $90.43 \pm 2.28$ \\
\hline
\end{tabular}

VCU also examined the separate effect of surface finish on CA using Cr-coated $\mathrm{Zr}$-4 samples provided by Framatome and found that the CA sharply decreased after $\mathrm{Zr}-4$ is coated with $\sim 4 \mu \mathrm{m} \mathrm{Cr}$ by physical vapor deposition (PVD), and that surface finish of the substrate has a secondary effect on CA for both Zr-4 and Cr-coated Zr-4, as shown in Figure 2. These results also indicate that Chromium coated surfaces have a higher wettability than Zirconium alloys. The measured Ra of different samples are summarized in Table 2.

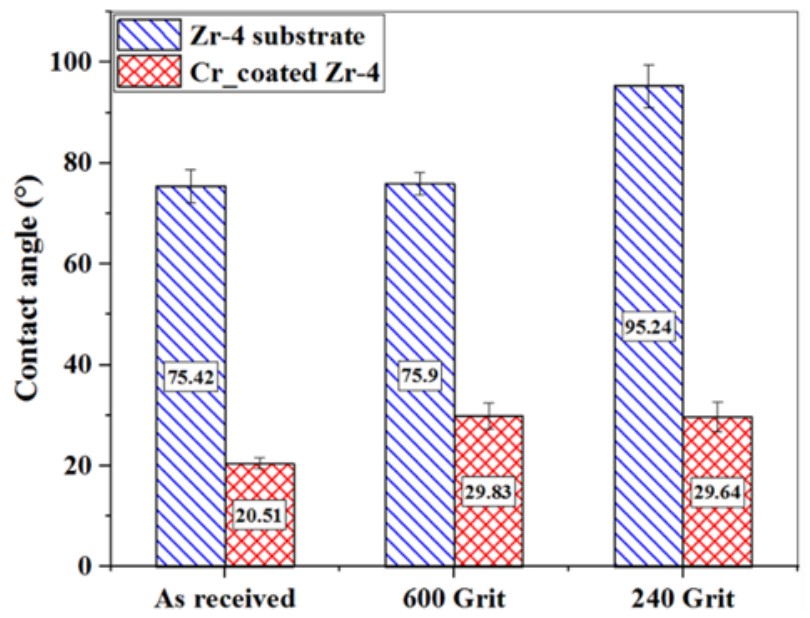

Figure 2. Comparison of static CA for Zr-4 and Cr-coated Zr-4 with a different surface finish of the substrate (VCU).

Table 2. Summary of the measured Ra from different samples.

\begin{tabular}{|l|c|}
\hline \multicolumn{1}{|c|}{ Sample } & Ra $(\boldsymbol{\mu m})$ \\
\hline As received Zr-4 substrate & 0.399 \\
\hline 600 Grit Zr-4 substrate & 0.496 \\
\hline 240 Grit Zr-4 substrate & 0.776 \\
\hline As received Cr-coated Zr-4 & 0.442 \\
\hline 600 Grit Cr-coated Zr-4 & 0.498 \\
\hline 240 Grit Cr-coated Zr-4 & 0.910 \\
\hline
\end{tabular}

UWM-1 measured the CA on flat polished Zirlo, on spray-coated Cr on Zirlo, and spray-coated $\mathrm{FeCrAl}$ on Zirlo samples provided by WEC. The final sample surfaces were all polished by 600 grit SiC abrasive paper to the same roughness and morphology, as shown in Figure 3. The measured CAs on Zirlo and FeCrAl-coated Zirlo are similar to VCU's measurements. However, there is a large discrepancy between the Cr-coated Zirlo from UWM and the Cr-coated Zr-4 from VCU, the latter of which shows a 
much lower CA. Note that the UWM-1 coatings are spray-coated, whereas the VCU coatings are PVDcoated. Thus, the different contact angle may result from different surface morphology.

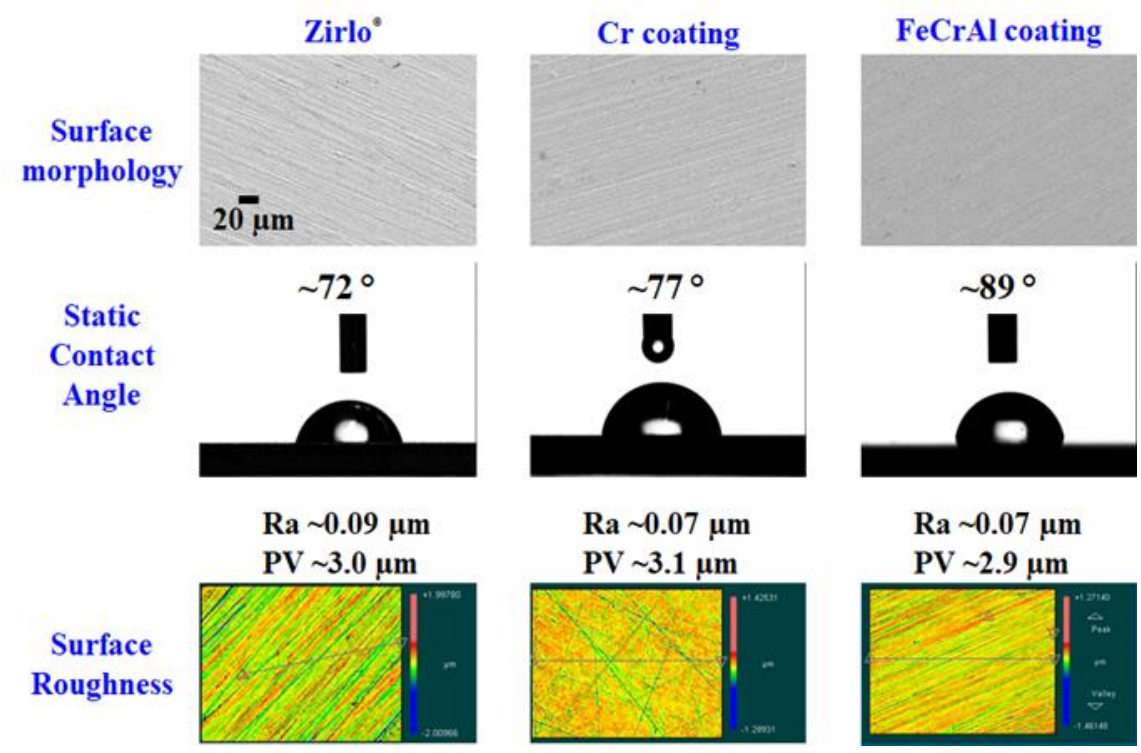

Figure 3. CA, roughness, and surface morphology measurements on various materials polished by 600 grit $\mathrm{SiC}$ abrasive paper (UWM-1).

UNM measured the CA on as-received tubular samples made of $\mathrm{FeCrAl}$, Inconel600, and $\mathrm{Zr}-4$ before and after the CHF tests. The results are summarized in Table 3. The CAs of all the samples increased after the CHF tests. In particular, the CA of fresh FeCrAl measured at UNM is lower than the values reported by UWM and VCU.

Table 3. Surface roughness and wettability: as-received/post-CHF experiment (UNM).

\begin{tabular}{|l|c|c|c|}
\hline & FeCrAl & Inconel600 & Zircaloy-4 \\
\hline Roughness, $\mathbf{R}_{\mathbf{a}}$ & $0.43 \mu \mathrm{m} / 4.53 \mu \mathrm{m}$ & $0.24 \mu \mathrm{m} / 3.13 \mu \mathrm{m}$ & $0.80 \mu \mathrm{m} / 1.61 \mu \mathrm{m}$ \\
\hline Surface Wettability & $53^{\circ} / 69^{\circ}$ & $64^{\circ} / 76^{\circ}$ & $56^{\circ} / 74^{\circ}$ \\
\hline
\end{tabular}

MIT developed an apparatus to measure static, advancing, and receding CAs from subatmospheric conditions up to the critical point of water in a fully degassed, saturated steam-water environment. The configuration of the autoclave-type facility is shown in Figure 4 (left). The autoclave has two sapphire windows at both ends, providing necessary optical access. The two bearings underneath the autoclave enable rotation around the axis of the droplet for measurement of advancing and receding CAs. A natural circulation loop was constructed to supply saturated steam and pressurize the autoclave.

The actual test section for the CA measurement is accommodated inside the autoclave (see Figure 4 [right]), which is equipped with two thermocouples for the temperature measurement of the sample and the autoclave environment. A cartridge heater is imbedded underneath the sample holder in order to maintain the sample temperature and evaporate the residual water after each measurement. The test section can accommodate rectangular samples from $0.5 \times 0.5 \mathrm{~cm}^{2}$ to $12.5 \times 12.5 \mathrm{~cm}^{2}$, and thickness from $1-3 \mathrm{~mm}$. 


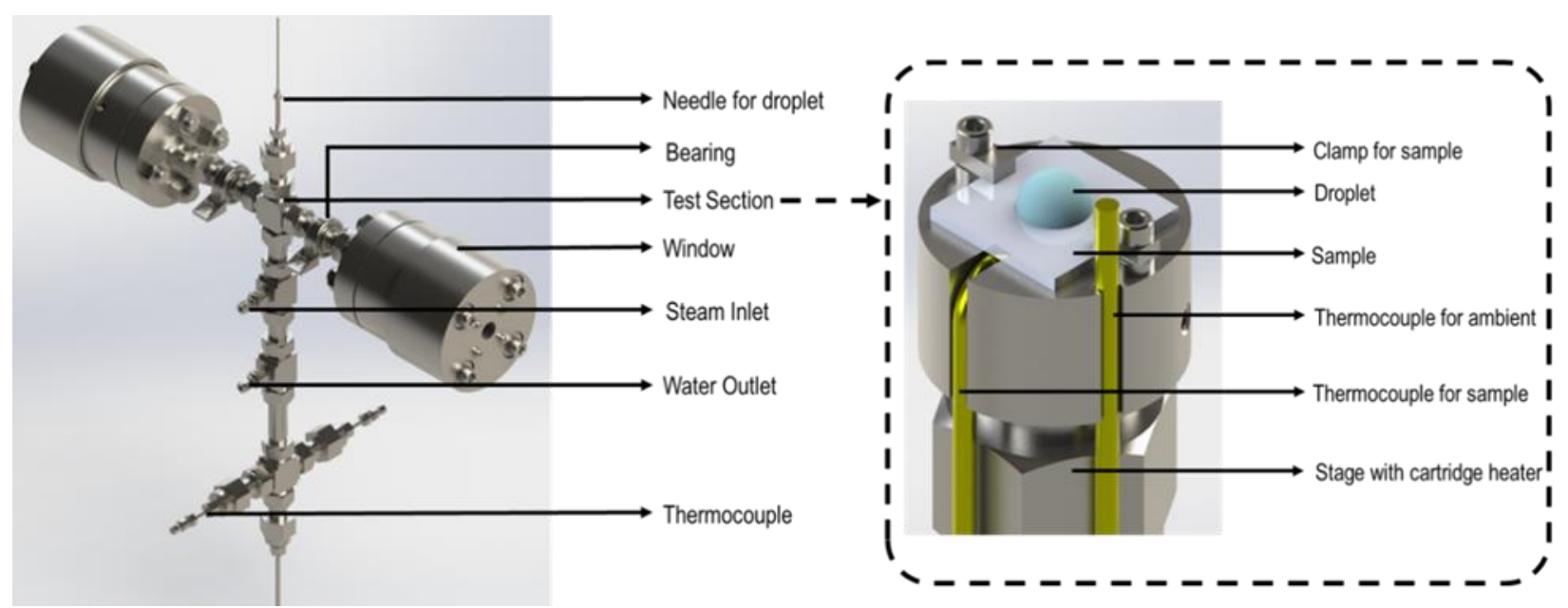

Figure 4. Design of the autoclave (left) and the test section (right) for the CA measurement (MIT).

MIT measured the static CA up to pressurized water reactor (PWR) temperature and pressure on various samples and surface finishes, including as-machined $\mathrm{Zr}-4(\mathrm{Ra}=0.18 \mu \mathrm{m})$, mirror-polished $\mathrm{Zr}-4$ ( $\mathrm{Ra} \sim 0.05 \mu \mathrm{m})$, oxidized $\mathrm{Zr}-4(\mathrm{Ra}=0.2 \mu \mathrm{m})$, as-machined monolithic $\mathrm{SiC}$ received from $\mathrm{GA}$ $(\mathrm{Ra}=0.12 \mu \mathrm{m})$, and mirror-polished APMT-grade mirror-polished FeCrAl purchased from Kanthal $(\mathrm{Ra} \sim 0.05 \mu \mathrm{m})$. MIT conducted the CA measurements while increasing and decreasing the temperature. As shown in Figure 5, the static CA on all surfaces decreases with increasing temperature and pressure. For some surfaces, the CA at high pressure and temperature becomes zero, which indicates that the surface is super-hydrophilic. The CA decreases faster on rough or oxidized surfaces than on mirrorpolished surfaces. On oxidized $\mathrm{Zr}-4, \mathrm{SiC}$, and $\mathrm{FeCrAl}$ surfaces, a large hysteresis was observed. The potential cause of this hysteresis can be different for different surfaces, and more tests are required in order to draw any conclusion. 

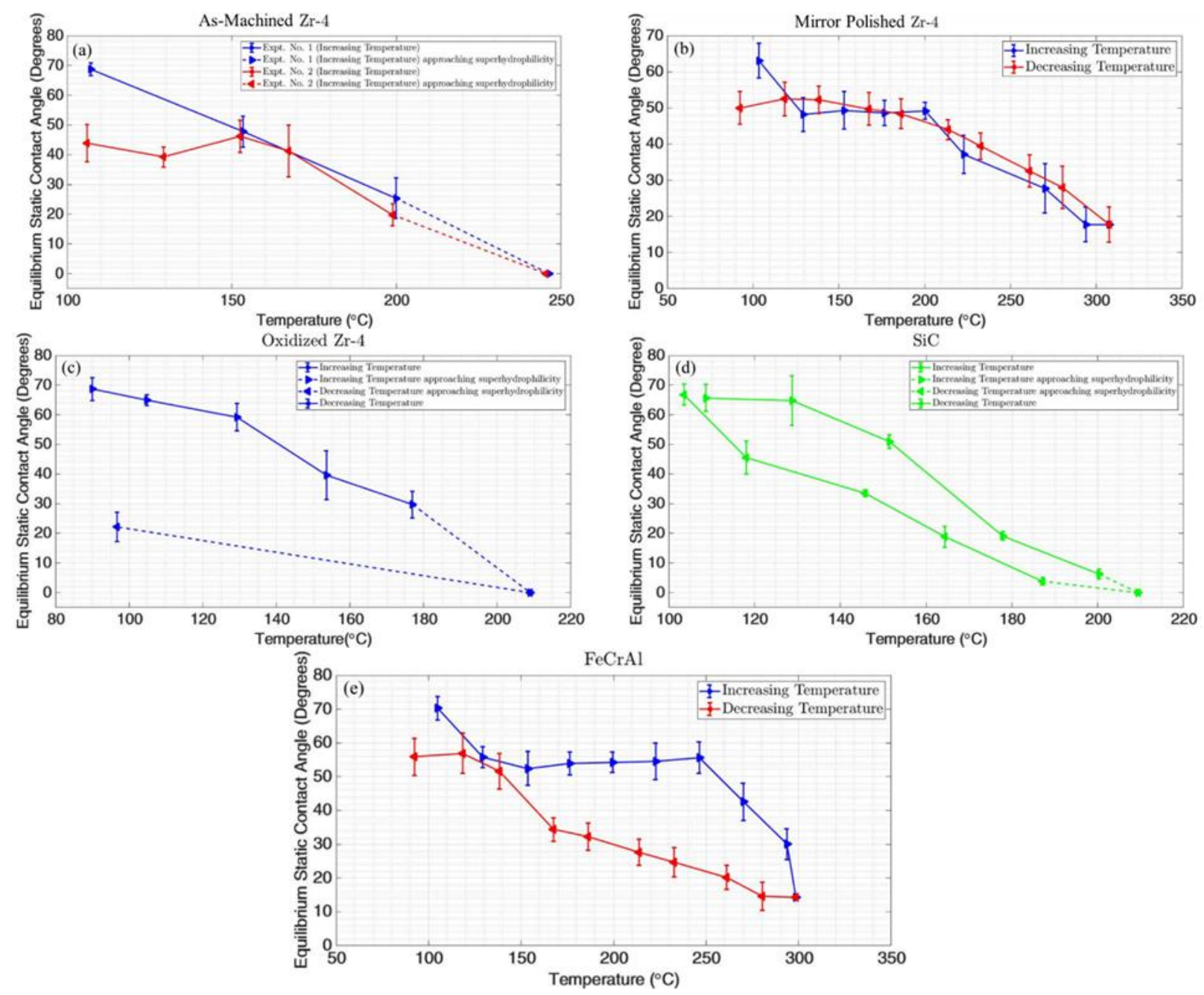

Figure 5. CA measured on: (top left) as-machined Zr-4, (top right) mirror-polished Zr-4, (middle left) oxidized $\mathrm{Zr}-4$, (middle right) as-machined monolithic SiC, and (bottom) mirror-polished FeCrAl (MIT).

\subsubsection{Surface Roughness}

Many approaches can be used to measure and quantify surface roughness. Different methods reveal different kinds of roughness - e.g., stylus-type profilometer for one-dimensional (1D) microscale, optical profilometer for two-dimensional (2D) micro- or nanoscale, atomic force microscopy (AFM) for 2D nanoscale. For most situations, microscale surface roughness is a good indicator of the boiling and quenching heat-transfer behavior. However, on some surfaces with complicated features, such as hierarchical micro- and nanostructures, nanoscale surface roughness is also required.

VCU quantitatively measured surface roughness using a stylus-type profilometer $(2 \mu \mathrm{m}$ stylus-tip radius and 60 degree stylus-tip angle) following International Organization for Standardization (ISO) standards. Twelve different surface-roughness parameters were collected on a $5 \mathrm{~mm}$ sampling length at $0.5 \mathrm{~mm} / \mathrm{s}$ scan rate. They also used tapping mode AFM to reveal nanoscale features as a supplement and validation to the results obtained by stylus-type profilometry. The results are summarized in Table 1 , together with the CA measurements.

UWM-1 used optical profilometry for the surface-roughness measurement. They obtained 2D surface profiles and the associated statistical parameters such as peak-to-valley (PV) distance and root-mean- 
square values of roughness, as shown in Figure 3. The close PV and Ra values from different substrate materials prove the repeatability of their polishing process.

UNM measured the surface roughness, Ra, of the samples before and after CHF tests, as summarized in Table 3. UNM observed a significant increase in surface roughness, as high as 13 times, after the CHF tests. However, the $\mathrm{CHF}$ value on the same rod barely changed test after test, which seems to suggest that surface roughness has a minor effect on CHF.

\subsubsection{Other Surface Characteristics}

In addition to CA and surface roughness, VCU used an X-Ray diffractometer (XRD) to measure the crystal structures of the test samples, as shown in Figure 6. The FeCrAl alloys (APMT, C26M) have body-centered cubic (bcc) crystal structure, while Zircaloy-4 and Zircaloy-2 have a hexagonal closed packed (hcp) crystal structure. For the Cr-coated material, the presence of the Cr layer was confirmed by the presence of its characteristic peaks with a cubic crystal structure. VCU also applied scanning electron microscopy (SEM) and X-ray photoelectron spectroscopy (XPS) to examine microscopic surface morphology and elemental composition, separately, as shown in Figure 7. The SEM micrographs of $\mathrm{C} 26 \mathrm{M}$ and APMT show an average grain size of $27.98 \pm 9.81 \mu \mathrm{m}$ and $41.04 \pm 13.39 \mu \mathrm{m}$, respectively. The smaller grain size of the C26M gives an increase in overall strength, as evidenced in the literature for $\mathrm{FeCrAl}$ alloys. The elements detected by EDS exhibit uniform distribution of the elements with no evidence of second-phase precipitates.
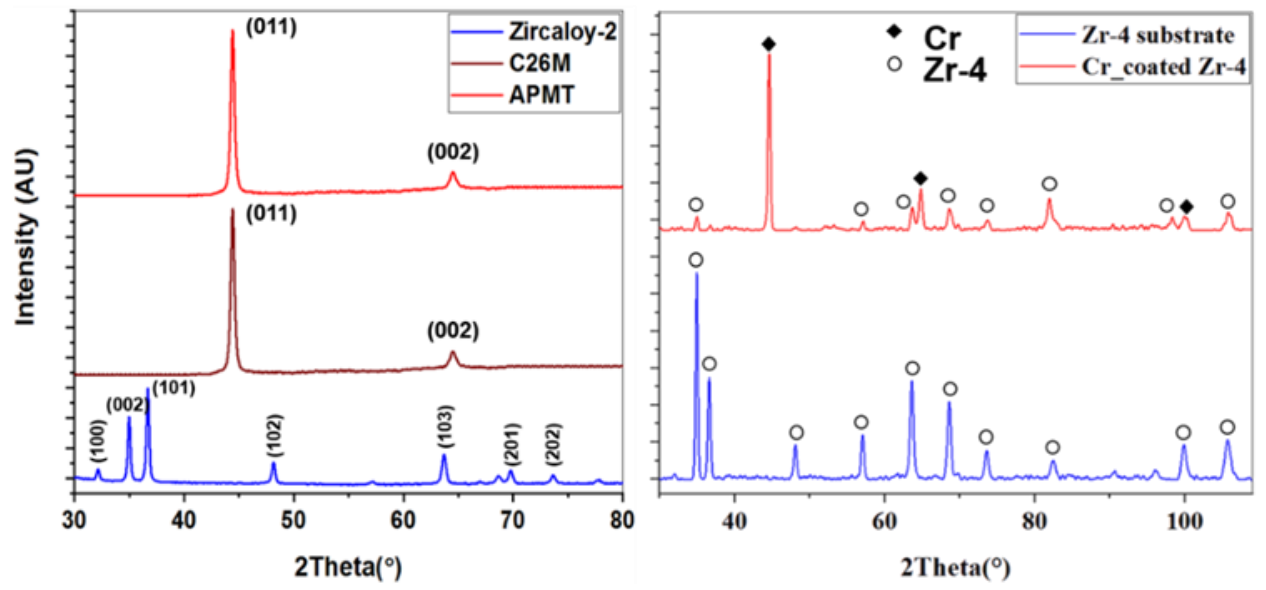

Figure 6. XRD patterns of tested materials (VCU). 

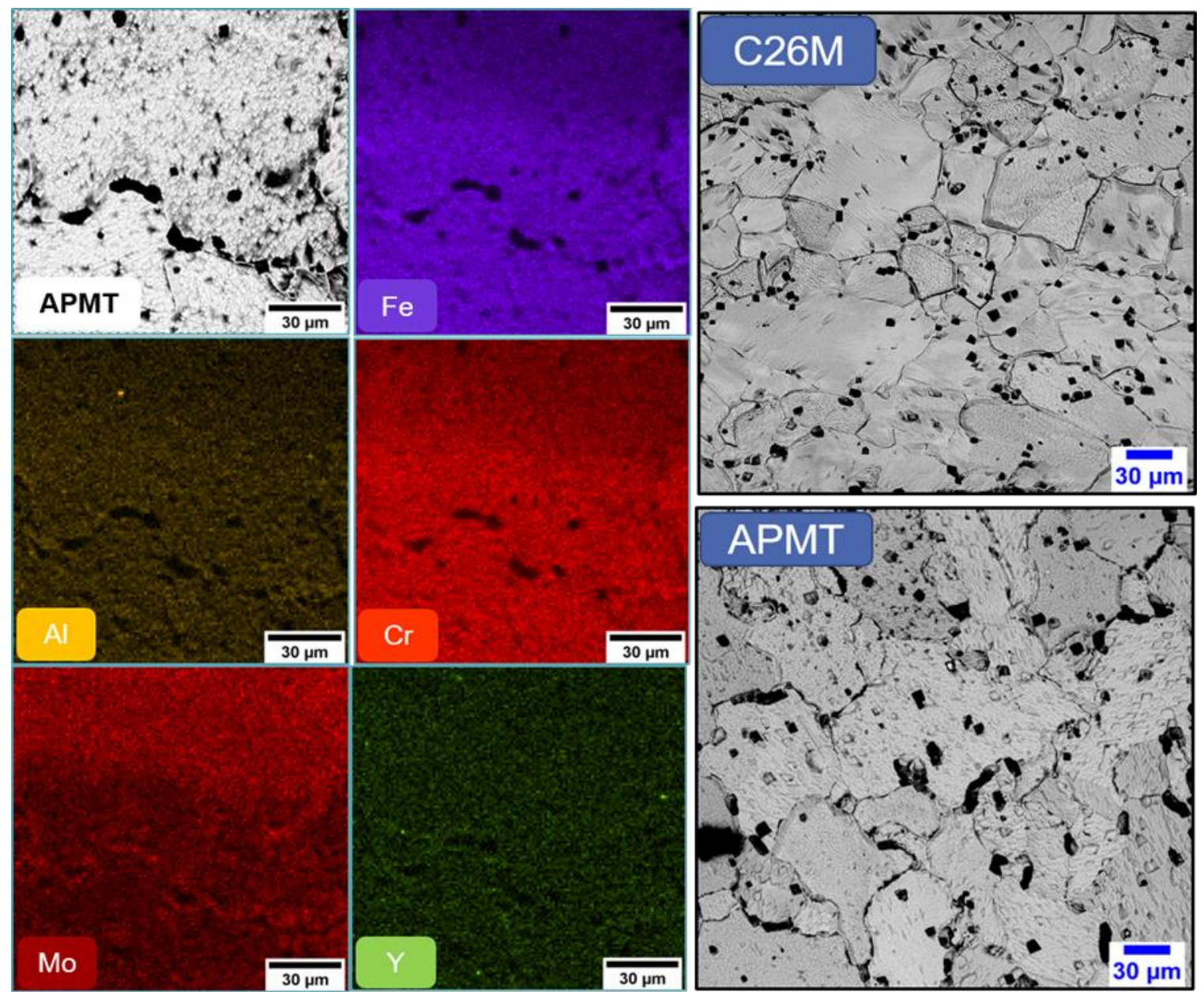

Figure 7. Element map for APMT (left) and SEM micrographs of etched FeCrAl (right) (VCU).

\subsection{Pool Boiling}

Pool-boiling experiments are commonly carried out to investigate the fundamentals of boiling heat transfer (e.g., bubble dynamics) and to quantify boiling parameters (e.g., the CHF value). They also constitute a valuable screening stage to inform the possible outcomes of flow-boiling tests.

UWM-1 conducted pool-boiling tests on flat samples at atmospheric pressure and saturation temperature $\left(100^{\circ} \mathrm{C}\right)$ with deionized water. Material and thickness of the tested samples are listed below:

- 0.4 and $0.8 \mathrm{~mm}$ polished Zirlo

- $0.8 \mathrm{~mm}$ Zirlo with a Cr coating

- $\quad 0.8 \mathrm{~mm}$ Zirlo with a Cr coating polished down to 70 and $30 \mu \mathrm{m}$, respectively

- $0.8 \mathrm{~mm}$ Zirlo with a FeCrAl coating polished down to $40 \mu \mathrm{m}$

- $0.457,0.76,1.52 \mathrm{~mm}$ polished 304 stainless steel

- $\quad 0.508,0.81,1.27 \mathrm{~mm}$ polished brass.

The UWM-1's pool boiling facility for CHF tests of ATF materials is shown in Figure 8. The facility accommodates $2 \times 2 \mathrm{~cm}^{2}$ flat samples of various thicknesses. The top side of the sample is exposed to water, which is heated up by cartridge heaters inserted inside a copper heater block. Temperature and 
subsequent heat-flux measurements were taken using thermocouples located inside the copper heating block at different distances from the boiling surface. The power was slowly increased stepwise through the nucleate-boiling regime until $\mathrm{CHF}$ was reached. $\mathrm{CHF}$ was then determined as the maximum heat flux before the temperature runaway.

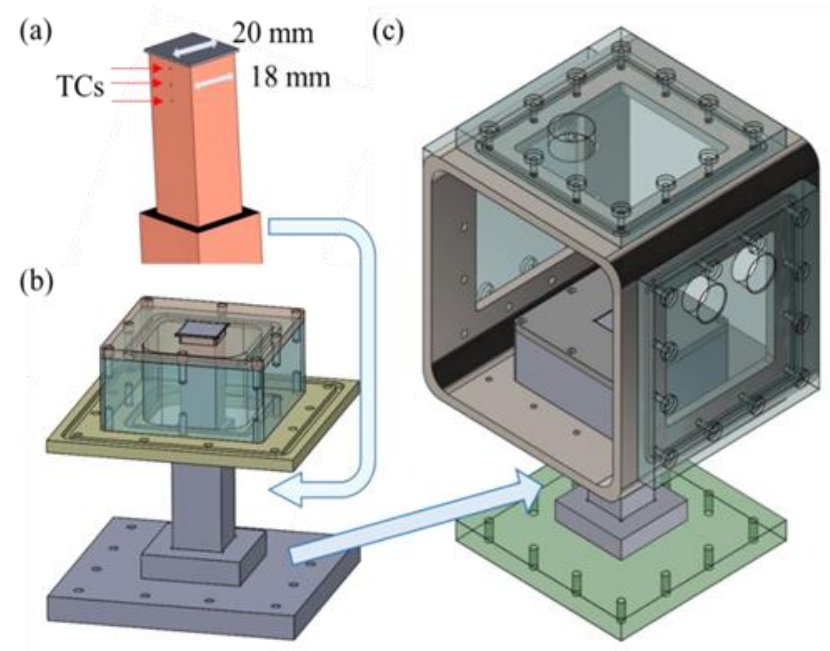

Figure 8. Illustrations of the pool-boiling facility designed and constructed for this study: (a) heater block and sample specimen, (b) assembly of the sample holder and heater block part, and (c) full assembly of the facility (UWM).

UWM-1 observed small differences in wettability on different materials. They attribute such difference to measurement uncertainty and minor inevitable variations resulting from sample surface preparation. However, UWM-1 argued that the effects of these variations on CHF data were not significant. A modified Kandlikar model, taking into account the CA effect with a correction factor for a circular heater (diameter of $10 \mathrm{~mm}$ ), is compared with the experimental results. Although the sample dimension is slightly different in this study, the predicted values using the model are in good agreement with the experimental results, as shown in Figure 9.

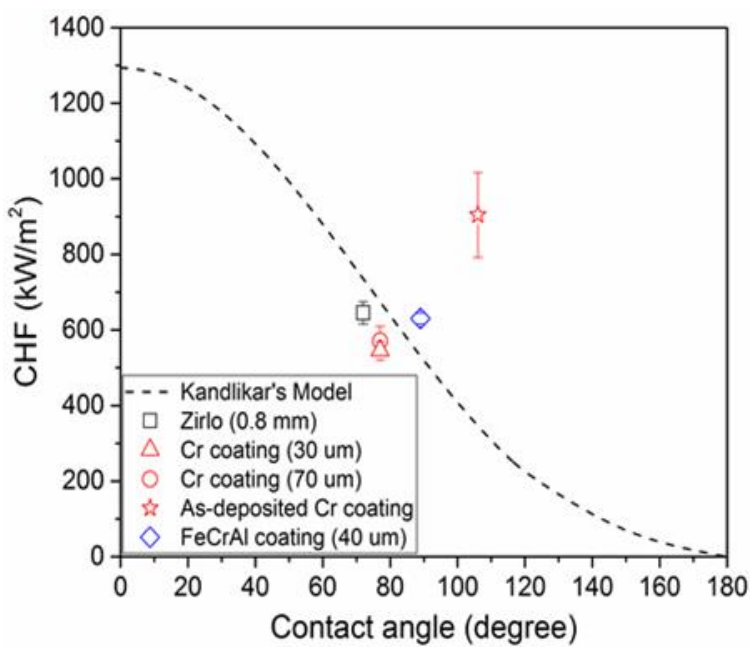

Figure 9. Pool-boiling CHF at atmospheric pressure and saturation temperature as a function of CA and their comparison with modified Kandlikar's model (UWM). 
UWM-1's analysis also suggests that the average pool-boiling CHF is a function of thermal activity for samples with the same surface finish. Thermal activity is defined as the effusivity multiplied by the thickness of the sample. The heater in the Cu block and the test sample are assembled as a single unit. However, thermal paste is inserted between the large $\mathrm{Cu}$ block and the thin-clad test sample $(0.4-0.8 \mathrm{~mm})$ that provides thermal resistance and decouples the thermal response of the sample from the copper block. Thus, while $\mathrm{Cu}$ block provides a constant heat-flux boundary condition, the thermal variation due to boiling phenomena does not occur in the Cu block, but only on the test sample. Figure 10 shows that higher thermal activity leads to enhanced $\mathrm{CHF}$ by allowing more lateral heat conduction within the test sample.

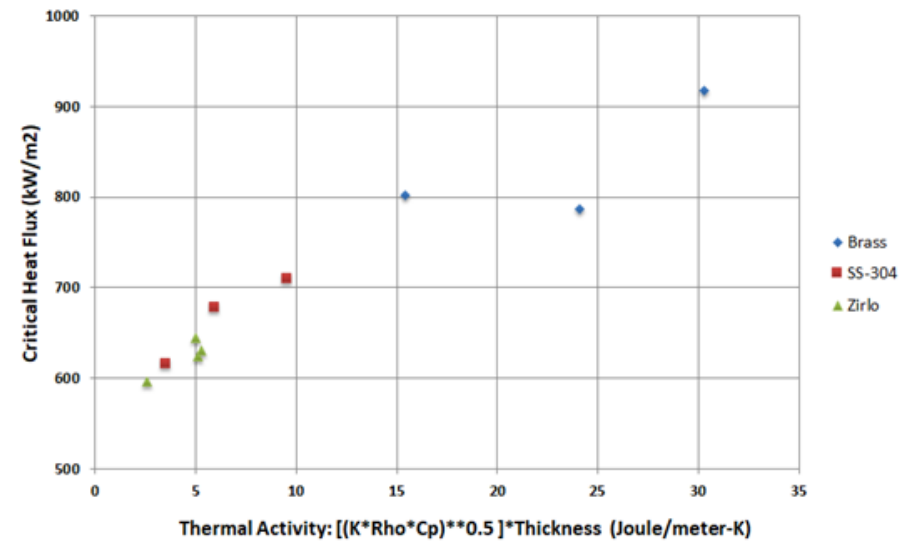

Figure 10. CHF results as a function of the sample thermal activity (UWM).

Table 4 summarizes the CHF data collected from metallic samples (Zirlo [both coated and uncoated], AISI 304 stainless steel, and brass).

Table 4. Summary of CHF results from different metallic test samples (UWM).

\begin{tabular}{|l|c|c|c|c|}
\hline & $\begin{array}{c}\text { CHF Average } \\
{\left[\mathrm{kW} / \mathrm{m}^{2}\right]}\end{array}$ & $\begin{array}{c}\text { CHF Range } \\
{\left[\mathrm{kW} / \mathrm{m}^{2}\right]}\end{array}$ & $\begin{array}{c}\text { Static Contact } \\
\text { Angle } \\
{[\text { degrees }]}\end{array}$ & $\begin{array}{c}\text { Thickness } \\
{[\mathrm{mm}]}\end{array}$ \\
\hline Cr coated Zirlo & 571 & $526-597$ & 77 & 0.87 \\
\hline FeCrAl coated Zirlo & 630 & $614-639$ & 90 & 0.84 \\
\hline Bare Zirlo & 645 & $631-656$ & 72 & 0.8 \\
\hline SS 304 & 709 & $695-724$ & 68 & 0.762 \\
\hline Brass & 803 & $758-979$ & 60 & 0.81 \\
\hline
\end{tabular}

\subsection{Flow Boiling}

In LWRs, fuel bundles are cooled in forced-flow conditions. Thus, systematic flow boiling CHF tests are necessary, in particular at LWR pressure and temperature, to better inform the design and deployment of ATF materials. The CHF margins should be examined under both steady-state heating and in transient heating conditions that are representative of accident scenarios (e.g., reactivity insertion accidents [RIAs]). Many groups have conducted steady-state flow-boiling CHF tests on ATF materials at 
atmospheric or close-to-atmospheric pressures. WEC has also conducted flow-boiling CHF tests at PWR pressure and temperature. UNM has carried out transient flow boiling CHF tests with pulsed-power input.

UNM constructed an atmospheric pressure flow loop and tested steady-state flow boiling CHF on Fe13Cr-6Al, Inconel600, and Zircaloy-4, as well as pulsed-power transient (1 s width and $8088.78 \mathrm{~W}$ peak power) flow-boiling $\mathrm{CHF}$ on $\mathrm{FeCrAl}$. The configuration of the flow loop and the cross-sectional view of the test section are shown in Figure 11. The test section features a tubular flow channel with $9.252 \mathrm{~mm}$ outer diameter and $5.08 \mathrm{~cm}$ heated length. The tests were intentionally repeated on the same sample to investigate the effects of surface conditions on flow CHF.

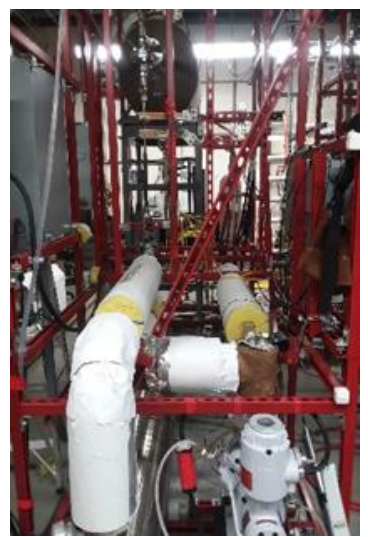

(a)

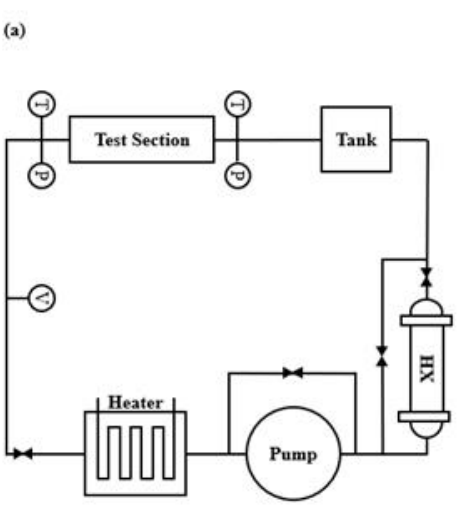

(b)

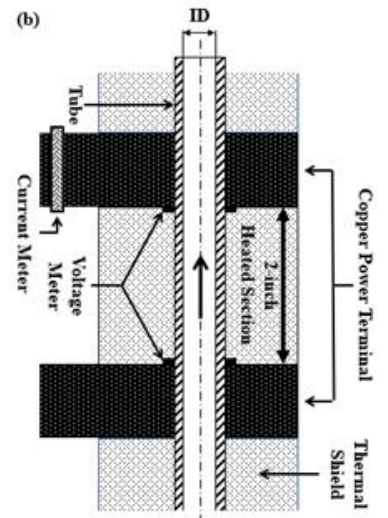

Figure 11. (a) Flow loop diagram, (b) test section cross-sectional view (UNM).

Figure 12 (a) shows several steady-state $\mathrm{CHF}$ values on FeCrAl. Note that the standard deviation is less than $10 \%$ of the average value, confirming the repeatability of the tests. Figure 12 (b) shows the average experimental CHF values of three tested materials compared to the $2006 \mathrm{CHF}$ lookup table at corresponding equilibrium qualities. The $\mathrm{CHF}$ value measured on the $\mathrm{FeCrAl}$ tube is higher than the $\mathrm{CHF}$ measured on Zircaloy and Inconel and the value reported in the Groeneveld lookup tables. This finding suggests that $\mathrm{FeCrAl}$ could lead to larger safety margins - i.e., a higher departure from nucleate boiling (DNB) ratio.
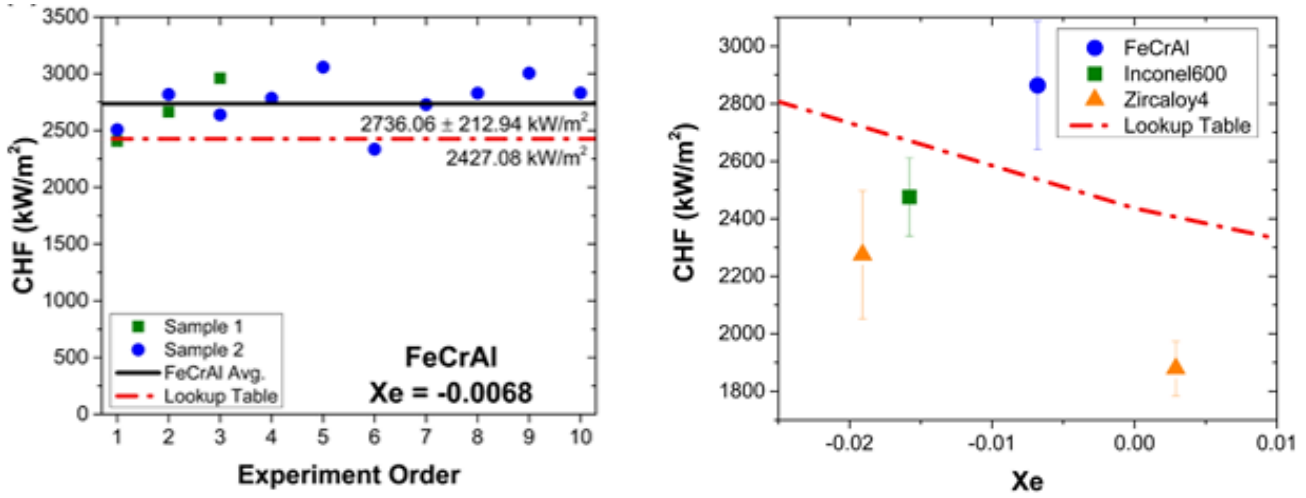

Figure 12. (a) Repeated CHF measurements on the FeCrAl alloy, (b) CHFs compared to the look-up table at corresponding equilibrium quality (UNM).

To address the change in surface characteristics after several experiments on the same tube, UNM measured surface roughness and wettability on post-steady-state CHF surfaces, which showed an increase in both roughness and CA compared to the as-received surfaces, as shown in Table 3 . The results suggest that the effect of surface roughness in the range of $\sim 0.2-5 \mu \mathrm{m}$ and CA in the range of 50-80 degrees has 
limited influence on flow-boiling CHF. This also suggests that, unless materials with extreme roughness or CA are used, the influence on flow-boiling CHF is likely limited for most engineered materials.

Traditionally, thermal parameters (e.g., thermal effusivity, activity, and diffusivity) were used to explain observed CHF differences; however, given the limited range of thermal parameters from three materials, no clear relation of thermal parameters to measured CHF values was observed under the same reference flow condition. UNM plans to carry out material-sensitivity studies in flow-boiling conditions to evaluate the impact of thermal parameters over a broader range. The effect of mass flow on flowboiling $\mathrm{CHF}$ will also be investigated.

In addition to the steady-state tests, transient $\mathrm{CHF}$ experiments were also conducted on the $\mathrm{Fe}-13 \mathrm{Cr}-6 \mathrm{Al}$ tube under the same pressure and mass-flow conditions. The inlet quality was set to that of the steady-state CHF point, assuming that the thermodynamic quality at the instant of DNB does not change significantly in transient condition. By matching every condition (i.e., pressure, flow rate, and quality), a clear comparison between steady-state and transient CHF could be made. Nevertheless, due to limitation of the power supply, the pulsed power input is a much longer pulse than a super-prompt-critical power jump (>\$1 of reactivity) or any hot zero-power RIA.

In UNM's tests, $\mathrm{CHF}$ and post-CHF phenomena are detected through estimates of the cladding inner temperatures. In this aim, UNM used a transient energy balance to calculate heat flux from measured power and outer surface temperature. Then the cladding inner surface temperature was obtained by solving the transient conduction equation with an implicit finite-difference scheme. The experimental results are shown in Figure 13.

As shown in Figure 13 (b), a sharp increase in the temperature is observed at $1.36 \mathrm{~s}$. The heat flux starts to decrease with a cladding-temperature overshoot, which corresponds to the occurrence of CHF. As the power is cut at CHF, the cladding temperature decreases, and the vapor film is no longer sustained. This is the rewetting point shown in Figure 13 (c), coinciding with a sudden temperature drop at the inner cladding wall.

(a)

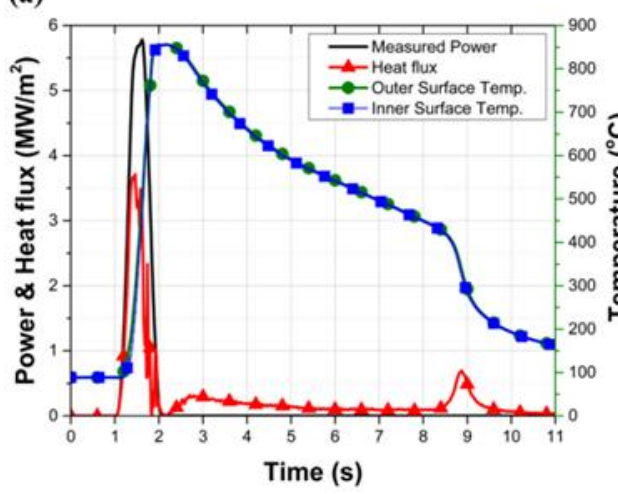

(b)

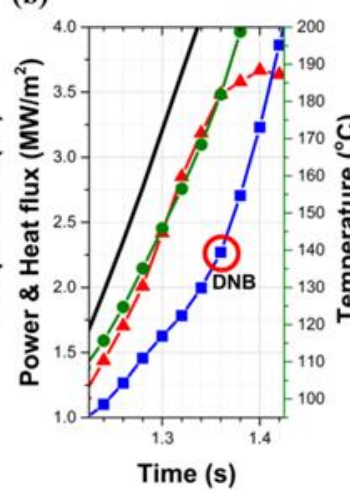

(c)

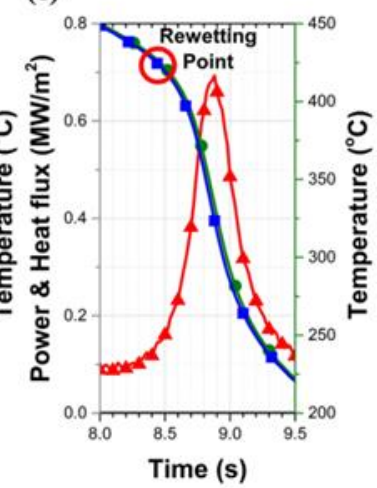

Figure 13. (a) Experimental measurement of transient pulsed power input, (b) CHF determination, and (c) rewetting-point determination (pulsed power: $1 \mathrm{~s}$ width and peak at 8088.78 watts, FeCrAl alloy) (UNM).

Based on the analysis, UNM has proposed a modeling approach for transient boiling that can be implemented in reactor-analysis code, as shown in Figure 14. UNM also found that transient CHF is 39\% and $23 \%$ higher than the lookup table prediction and the steady-state condition experimental result, respectively. 


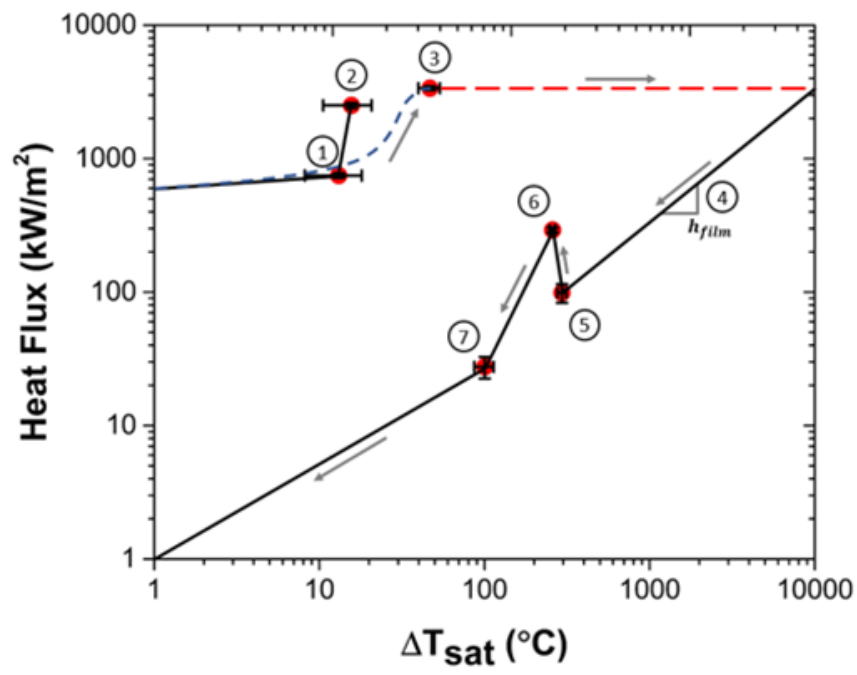

Figure 14. FeCrAl: obtained boiling curves for steady-state (1) ONB, (2) CHF) and transient flow boiling (300 kg/m²-s mass flow, $\mathrm{Xe}=-0.0068$, dashed line to (3) $\mathrm{CHF}$, then to (7) (UNM).

UWM-2 developed and fabricated directly heated rods using ATF material and standard Zircaloy cladding to study flow boiling at atmospheric-pressure conditions. The finished heater rod in the assembly jig is shown in Figure 15 (top). They also collaborated with Stern Labs to design internally heated rods with a cosine power profile for high-pressure flow-boiling tests, as shown in Figure 15 (bottom). 


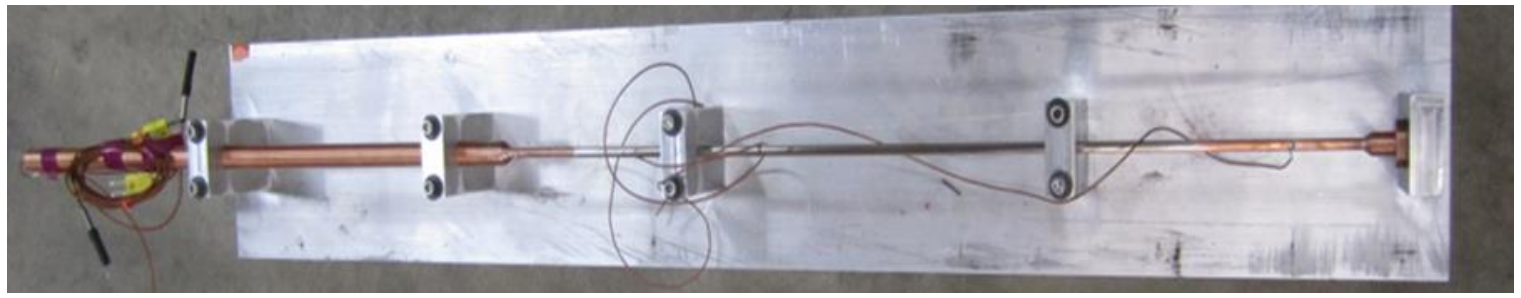

Ref. Number: $N-1320$
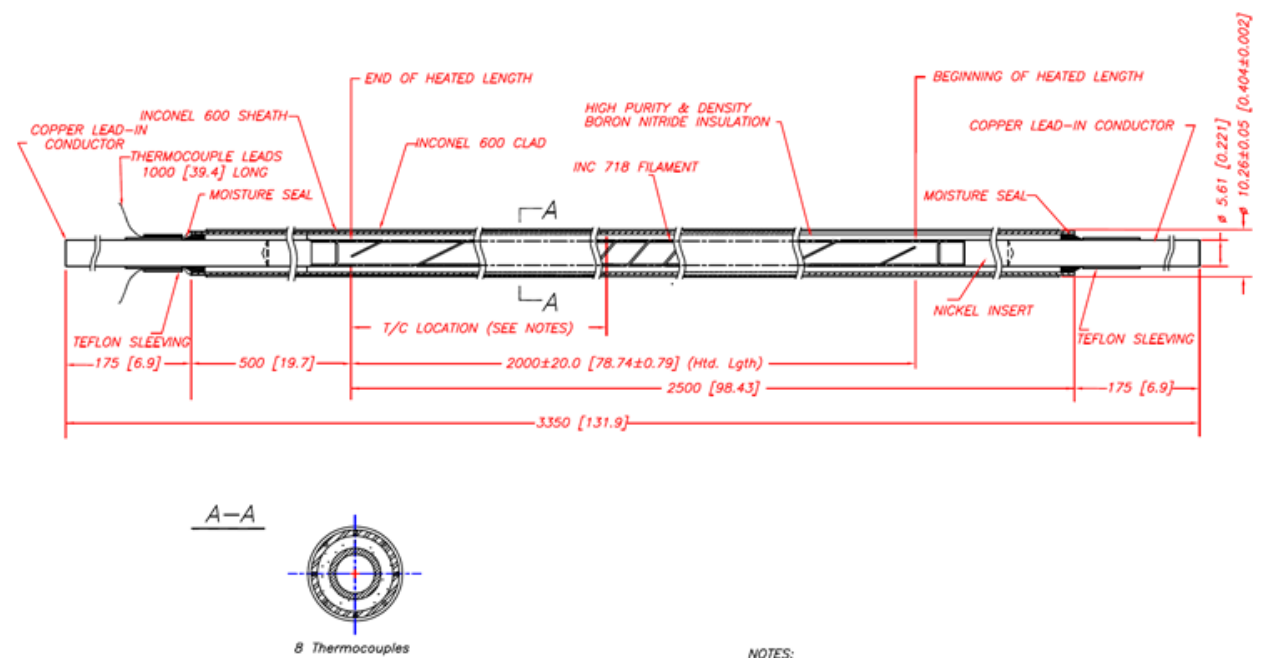

NOTES:
1. All dimensions in milimeters [inches].
2. Upto 10 thermocoupies can be embedded in the sheoth as shown.

Stern Laborotories inc. Hamiton, Ontario, Conado

Updoted: $2018-11-16$

Figure 15. Image of heater rod for low-pressure tests (top), and the design of an internally heated rod for high-pressure tests (bottom) (UWM).

UWM-2 constructed a low-pressure loop and designed a high-pressure loop for flow-boiling tests at different pressures. Until now, UWM-2 has conducted low-pressure tests only while the high-pressure capability is still in the design and construction stages. In the low-pressure test, water with specific subcooling is pumped through an annular flow channel formed by a quartz test section and a directly heated rod located in the center, as shown in Figure 16 (left). The quartz window allows for flow visualization of boiling phenomena and the CHF event via high-speed photography. In steady-state flowboiling tests, the imposed power across the rod is slowly increased until CHF is achieved. 

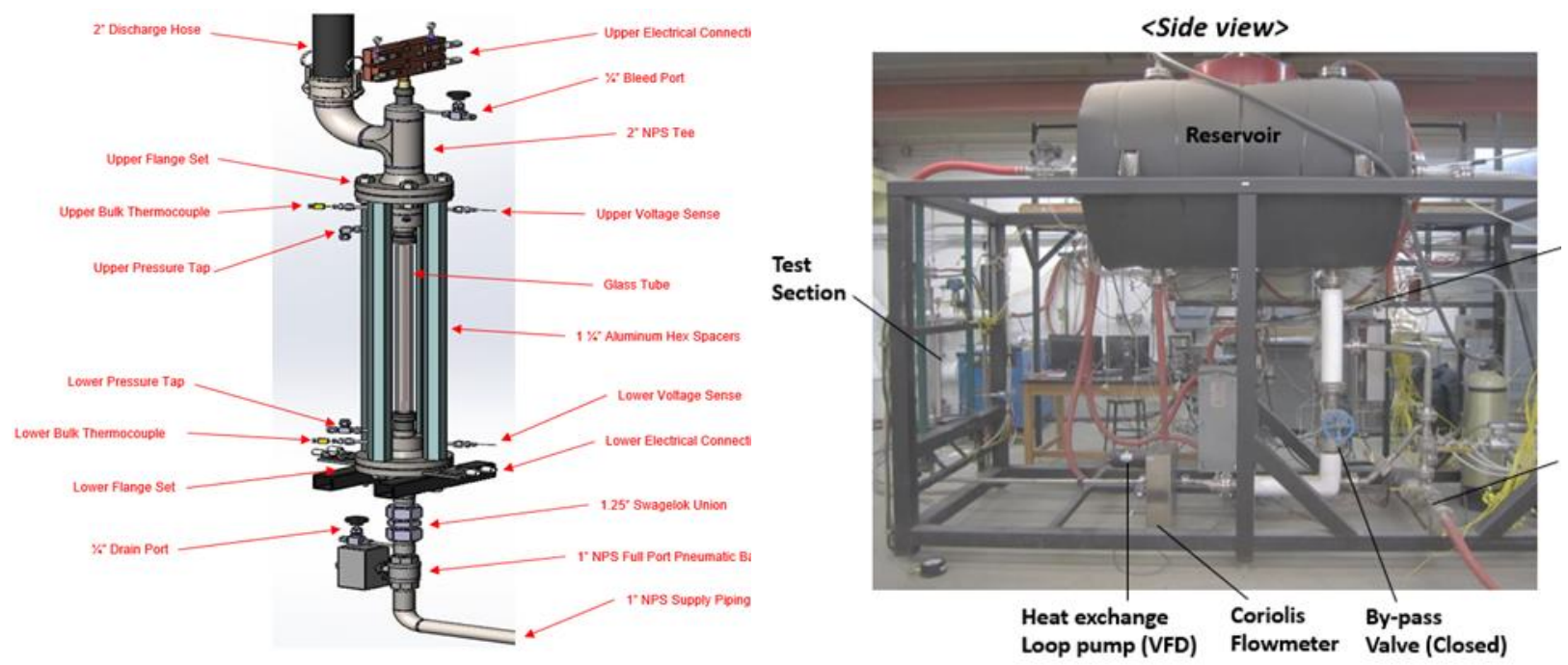

Figure 16. Low-pressure test section (left) and low-pressure flow loop (right) (UWM-2).

To measure the temperature profile along the heated rod, UWM-2 designed and fabricated an opticalfiber sensor and the accompanying data-acquisition system for distributed-temperature measurement. UWM-2 operated the optical-fiber sensor in flow-boiling experiments using Cr-coated and bare Zircaloy heater rods. UWM found that the Cr-coated heater rod has a slightly $(\sim 10 \%)$ higher heat-transfer coefficient (HTC) than Zircaloy heater rod, as shown in Figure 17.

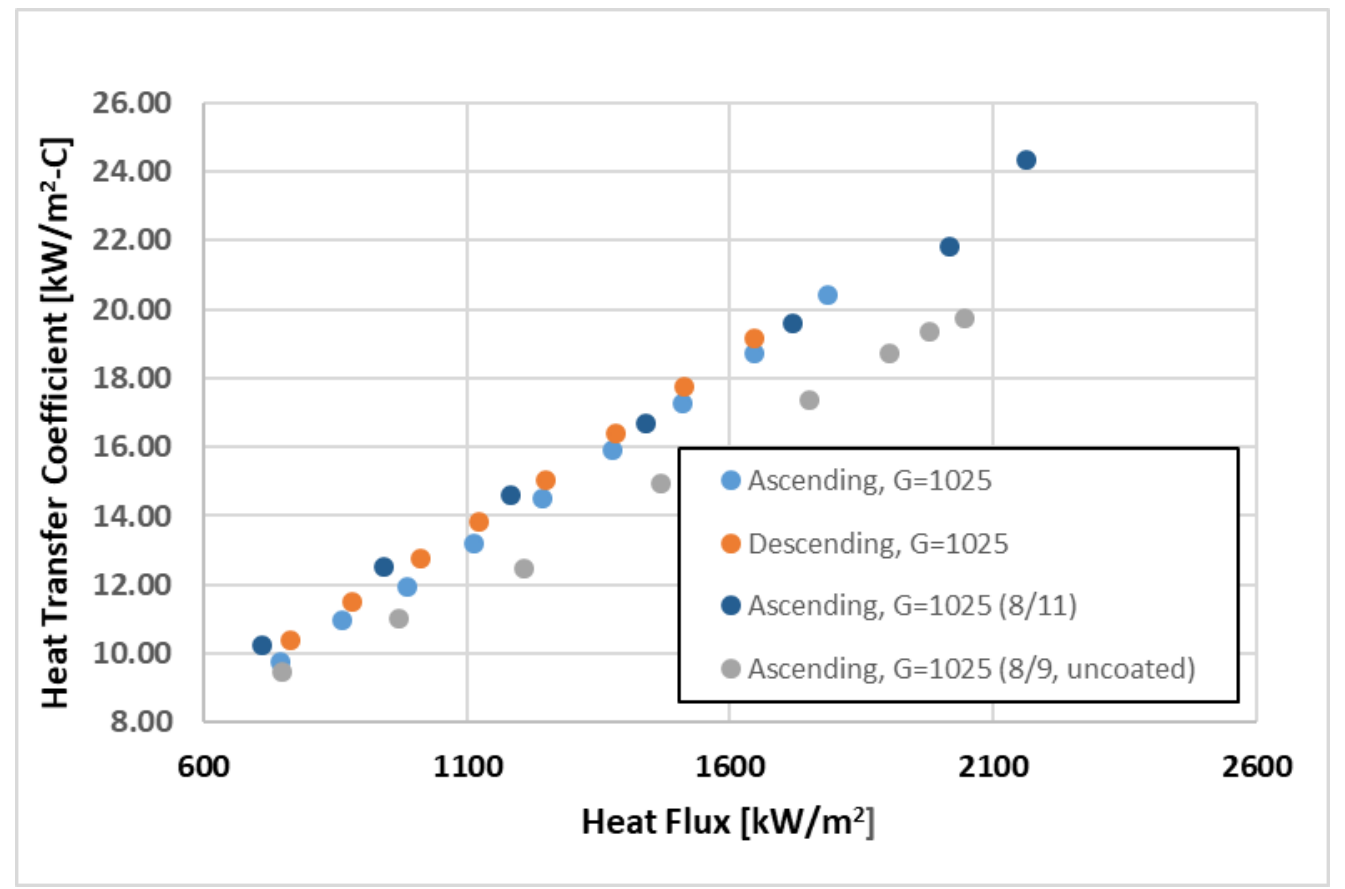

Figure 17. Comparison of rod-average HTC of Cr-coated (PVD) and bare Zircaloy heater rods (UWM-2). Pressure, subcooling, and mass flux are maintained at constant values of $115 \mathrm{kPa}, 75^{\circ} \mathrm{C}$, and 1025 $\mathrm{kg} / \mathrm{m}^{\wedge} 2$-s, respectively. HTCs were studied in both ascending and descending heat flux to check for the presence of hysteresis effects; none were found. The Cr-coated rod exhibits $\sim 10 \%$ improvement in HTC compared to uncoated rods (gray dots). 
UWM-2 has finished initial testing of CHF for bare Zircaloy rods and two types (PVD and cold spray) of Cr-coated rod. Due to power-supply limitations, CHF tests were performed at mass flux of $750 \mathrm{~kg} / \mathrm{m}^{2}-\mathrm{s}, 75^{\circ} \mathrm{C}$ subcooling, and $115 \mathrm{kPa}$ pressure. CHF testing under these conditions (moderate mass flux and high subcooling) results in extreme temperature excursions, which typically destroy the heater rod. The bare zircaloy rod was destroyed during the first CHF test. Both Cr-coated rods survived their first CHF test and a second test was repeated on both, yielding similar CHF values (within $1.7 \%$ of the first CHF result). Figure 18 shows the heat-flux values at CHF, and Figure 19 shows the boiling curves for the three heater rods.

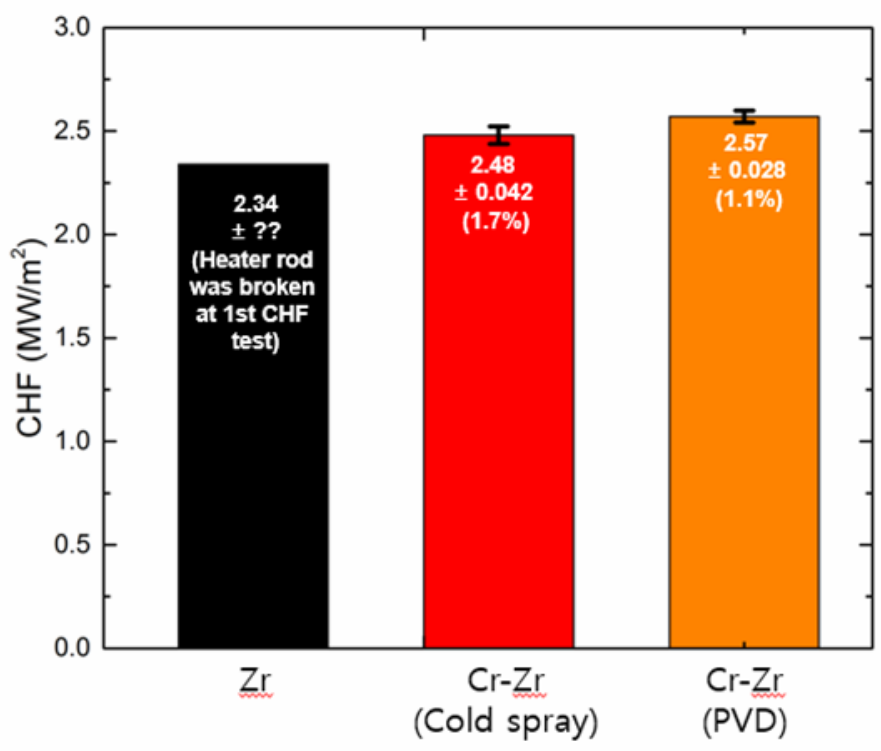

Figure 18. Heat flux values at CHF for bare Zircaloy and two types (PVD and cold spray) of Cr-coated Zircaloy.

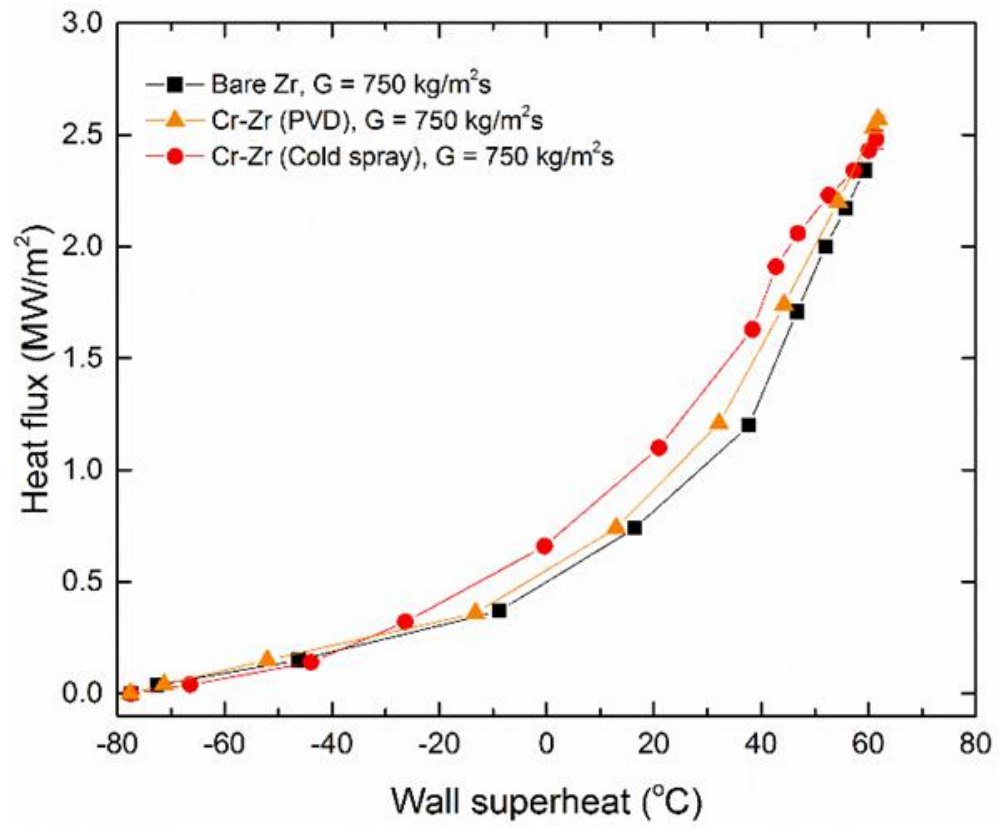

Figure 19. Boiling curves for bare Zircaloy and two types (PVD and cold spray) of Cr-coated Zircaloy. Pressure and subcooling were maintained at $115 \mathrm{kPa}$ and $75^{\circ} \mathrm{C}$, respectively. 
Both UNM and UWM-2 have conducted flow-boiling experiments under atmospheric pressure. Their results provide a precious first look into the performance of ATF material in flow-boiling heat transfer and CHF. However, due to the non-prototypical operating pressure and temperature, it is still unclear whether their conclusions can be directly applied to actual reactor conditions. The main issue comes from the change of thermohydraulic properties - such as surface tension (and thus contact angle), two-phase density ratio, latent heat, thermal diffusivity, thermal effusivity - when pressure and temperature increase.

WEC conducted flow-boiling CHF tests at full PWR pressure and temperature. The coolant used during the CHF tests simulates water chemistry in an actual PWR. It contained $1000 \mathrm{ppm}$ boric acid and $2.2 \mathrm{ppm} \mathrm{LiOH}$, made from high-purity deionized water. WEC believes that water conductivity has a minimal impact on CHF results. The configuration of the flow loop, also known as the WALT loop, is shown in Figure 20. The main parameters of the WALT loop are summarized in Table 5. As shown in Figure 20 (right), the test section features an annular flow channel, which is formed by a direct-heating rod with OD of $9.5 \mathrm{~mm}$ and a test section shroud with inner diameter of $20.96 \mathrm{~mm}$. The heated length is $330 \mathrm{~mm}$.
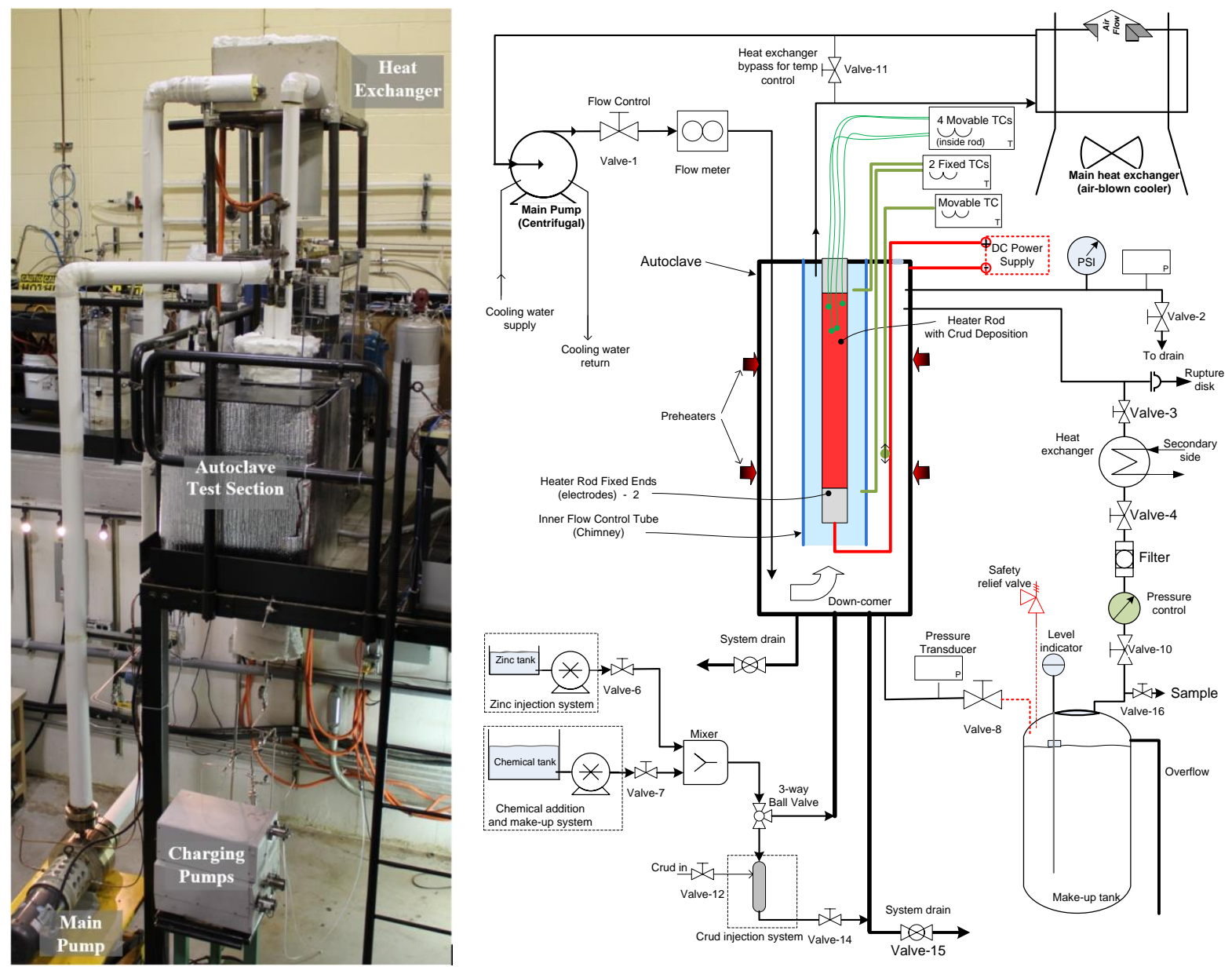

Figure 20. Photograh (left) and schematic representation (right) of WALT loop (WEC). 
Table 5. Key parameters of the WALT loop (WEC).

\begin{tabular}{|l|l|}
\hline Parameters & Upper Limits \\
\hline System pressure, MPa & 17.22 \\
\hline DC power supply, $\mathrm{kW}$ & 90 \\
\hline DC power supply, A & 1800 \\
\hline DC power supply, V & 100 \\
\hline Heat exchanger, $\mathrm{kW}$ & 31.8 \\
\hline Flow velocity, m/s & 6.00 \\
\hline Inlet temperature, ${ }^{\circ} \mathrm{C}$ & $<$ Tsat \\
\hline Axial Power Shape & Uniform \\
\hline Heater rod materials & Inconel, Zr-4, Zirlo ${ }^{\circledR}$ \\
\hline Heater rod length, $\mathrm{m}$ & $<1.35(0.33$ heated typical $)$ \\
\hline Heater rod OD, mm & 9.50 \\
\hline Heater rod ID, mm & $8.35 \sim 9.2$ \\
\hline Test section shroud ID, mm & 20.96 \\
\hline Test section flow area, mm ${ }^{2}$ & 274.0 \\
\hline
\end{tabular}

WEC has tested flow-boiling CHF in the WALT loop using uncoated Zirlo cladding, Cr-coated Zirlo cladding, and Cr-coated Zirlo cladding with crud. They generated crud deposits to the Cr-coated Zirlo by adding FeEDTA, NiEDTA, and colloidal crud precursors in the loop. All CHF test results and associated test conditions are summarized in Table 6.

The CHF test results shown in Table 6 were regrouped according to thermohydraulic conditions of inlet temperature, flow, and pressure, as indicated by yellow, green, and orange colors. Therefore, the separate effect of cladding surfaces, such as Cr-coating and crud deposit, can be examined within the same color group. As shown in Figure 21, the change of CHF due to the Cr-coating and/or crud deposit seems to be within the CHF variation measured from the uncoated surface. The CHF variation in each group is approximately $\pm 6 \%$.

Table 6. Summary of CHF test results (WEC).

\begin{tabular}{|c|c|c|c|c|c|c|c|c|}
\hline Rod & Run & $\begin{array}{c}\mathrm{Cr} \\
\text { Coating }\end{array}$ & $\begin{array}{l}\text { Average } \\
\text { Crud } \\
\text { Thickness } \\
\text { (microns) }\end{array}$ & $\begin{array}{c}\text { Inlet } \\
\text { Temperature } \\
\left({ }^{\circ} \mathbf{C}\right) \\
\end{array}$ & $\begin{array}{c}\begin{array}{c}\text { Flow } \\
\left(\mathbf{m}^{3} / \mathbf{h r}\right)\end{array} \\
\end{array}$ & $\begin{array}{c}\text { Pressure } \\
\text { (bars) }\end{array}$ & $\begin{array}{c}\text { CHF } \\
\left(\mathrm{W} / \mathrm{cm}^{2}\right)\end{array}$ & $\begin{array}{c}\text { Relative } \\
\text { Change in } \\
\text { CHF } \\
\text { Compared } \\
\text { to } \\
\text { Average } \\
\end{array}$ \\
\hline 198 & $1 \mathrm{a}$ & No & 0 & 336.8 & 2.42 & 152.63 & 233.12 & 4.74 \\
\hline 198 & $1 \mathrm{~b}$ & No & 0 & 339.5 & 2.37 & 154.05 & 208.94 & -6.12 \\
\hline 198 & $1 \mathrm{c}$ & No & 0 & 338.7 & 2.42 & 156.58 & 221.22 & -0.60 \\
\hline 193 & $1 \mathrm{a}$ & Yes & 0 & 338.1 & 2.38 & 148.78 & 231.16 & 3.86 \\
\hline 193 & $1 \mathrm{~b}$ & Yes & 0 & 338.1 & 2.40 & 158.99 & 218.37 & -1.86 \\
\hline \multicolumn{4}{|c|}{ Average } & 338.2 & 2.40 & 154.21 & 222.56 & \\
\hline
\end{tabular}




\begin{tabular}{|c|c|c|c|c|c|c|c|c|}
\hline Rod & Run & $\begin{array}{c}\mathrm{Cr} \\
\text { Coating }\end{array}$ & $\begin{array}{l}\text { Average } \\
\text { Crud } \\
\text { Thickness } \\
\text { (microns) }\end{array}$ & $\begin{array}{c}\text { Inlet } \\
\text { Temperature } \\
\left({ }^{\circ} \mathbf{C}\right) \\
\end{array}$ & $\begin{array}{c}\text { Flow } \\
\left(\mathrm{m}^{3} / \mathrm{hr}\right)\end{array}$ & $\begin{array}{c}\text { Pressure } \\
\text { (bars) }\end{array}$ & $\begin{array}{c}\text { CHF } \\
\left(\mathbf{W} / \mathbf{c m}^{2}\right) \\
\end{array}$ & $\begin{array}{c}\text { Relative } \\
\text { Change in } \\
\text { CHF } \\
\text { Compared } \\
\text { to } \\
\text { Average } \\
\end{array}$ \\
\hline 198 & $2 a$ & No & 0 & 333.9 & 3.49 & 156.21 & 245.91 & -1.37 \\
\hline 198 & $2 b$ & No & 0 & 340.6 & 3.49 & 156.72 & 256.16 & 2.74 \\
\hline 194 & $1 \mathrm{a}$ & Yes & 0 & 339.9 & 3.39 & 153.88 & 241.95 & -2.96 \\
\hline 195 & $1 \mathrm{a}$ & Yes & 0 & 339.6 & 3.37 & 151.78 & 249.99 & 0.26 \\
\hline 200 & $1 \mathrm{a}$ & Yes & 0 & 338.8 & 3.39 & 153.46 & 239.53 & -3.93 \\
\hline 200 & $1 \mathrm{~b}$ & Yes & 43 & 341.7 & 3.38 & 155.16 & 249.97 & 0.26 \\
\hline 201 & $1 \mathrm{a}$ & Yes & 0 & 339.2 & 3.38 & 156.94 & 247.82 & -0.61 \\
\hline 201 & $1 \mathrm{~b}$ & Yes & 40 & 339.4 & 3.41 & 156.86 & 263.32 & 5.61 \\
\hline \multicolumn{4}{|c|}{ Average } & 339.9 & 3.41 & 155.13 & 249.33 & \\
\hline 198 & $3 a$ & No & 0 & 329.1 & 3.34 & 128.57 & 258.74 & 0.92 \\
\hline 198 & $3 b$ & No & 0 & 328.3 & 3.41 & 125.08 & 257.88 & 0.58 \\
\hline 199 & $1 \mathrm{a}$ & Yes & 0 & 328.7 & 3.22 & 126.78 & 275.70 & 7.53 \\
\hline 202 & $1 \mathrm{a}$ & Yes & 0 & 330.6 & 3.00 & 127.90 & 238.65 & -6.92 \\
\hline 202 & $1 \mathrm{~b}$ & Yes & 21 & 331.1 & 3.25 & 130.52 & 250.97 & -2.11 \\
\hline \multicolumn{4}{|c|}{ Average } & 329.5 & 3.24 & 127.77 & 256.39 & \\
\hline
\end{tabular}
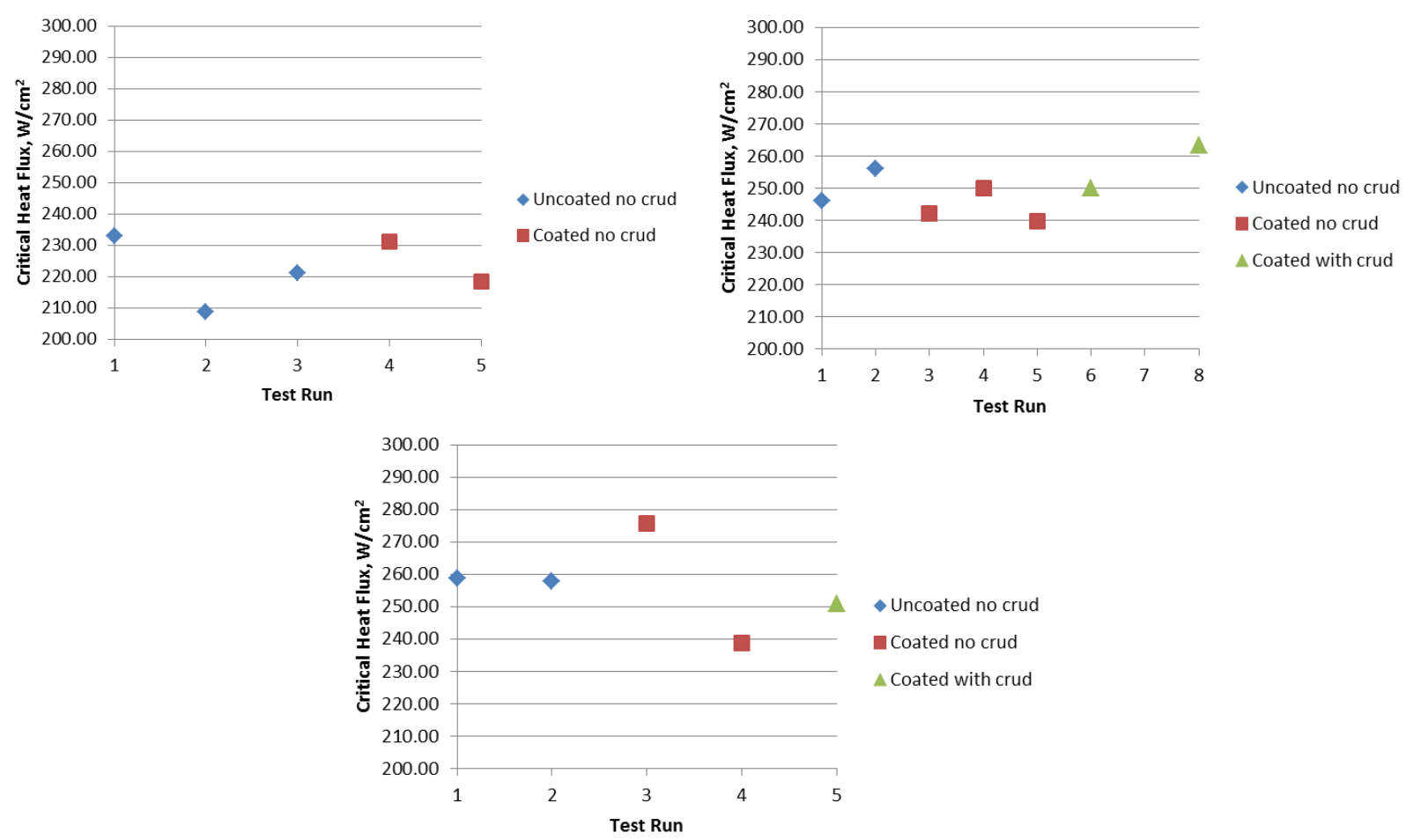

Figure 21. Comparison of CHF values from different surfaces at similar thermohydraulic conditions. Top left: yellow group; top right: green group; bottom: orange group (WEC).

\subsection{Modeling and Simulation}

UTK simulated the UNM experiment using RELAP5-3D and CTF, finding significant discrepancies between calculation and experimental data in terms of CHF and post-CHF tube temperatures for 
Inconel 600, stainless steel 316, and FeCrAl. Parametric studies were carried out to understand the sensitivity of CHF and the post-CHF temperature excursion from HTCs, material thermophysical properties, and a transient CHF multiplier. Sensitivity studies were performed using a RELAP5-3D model of the UNM experiment and the uncertainty quantification code RAVEN. The range of input parameters used in sensitivity studies was chosen based on the measuring uncertainties in material properties and HTCs, as well as the differences in experimentally measured HTCs and the HTCs predicted from the RELAP5 model. Results from the sensitivity study were used to highlight fundamental differences between how CHF is modeled and empirical findings.

The sensitivity cases that best matched the experimental results in terms of maximum heat flux (MHF), integral heat flux, and peak cladding temperature (PCT) were determined, as was a case that gave the minimum RMS error for the three figures of merit. Table 7 summarizes the relative error of the RELAP5 results from the sensitivity case that gave the minimum RMS error.

Table 7. Error from the minimum RMS error sensitivity case.

\begin{tabular}{|c|c|c|c|c|}
\hline Figure of Merit & MHF & PCT & Energy Deposition & RMS Error \\
\hline Relative Error (\%) & 1.24 & 27.02 & 1.70 & 27.10 \\
\hline
\end{tabular}

The parametric study showed that even when the simulated MHF and energy deposition were closely matched with the experimental results, the model still overpredicted PCT. The reason for this remaining discrepancy is attributed to differences in how CHF phenomena are being modeled versus what occurs in reality. Figure 22 (a) shows the experimental heat flux and FeCrAl outer surface temperature around the CHF point. The plot shows that the CHF, determined by an increase in the rate of change in the tube temperature, differs from the MHF. It is possible that this is a product of measurement uncertainty, but it is clear that there is a transition period during which the heat flux remains elevated post-CHF. Computer codes always consider the MHF and CHF to be equivalent, as shown in Figure 22 (b). Once CHF is reached in the models, the heat flux instantaneously and rapidly declines. This leads to a much narrower heat-flux pulse width and the overshoot in PCT predictions.
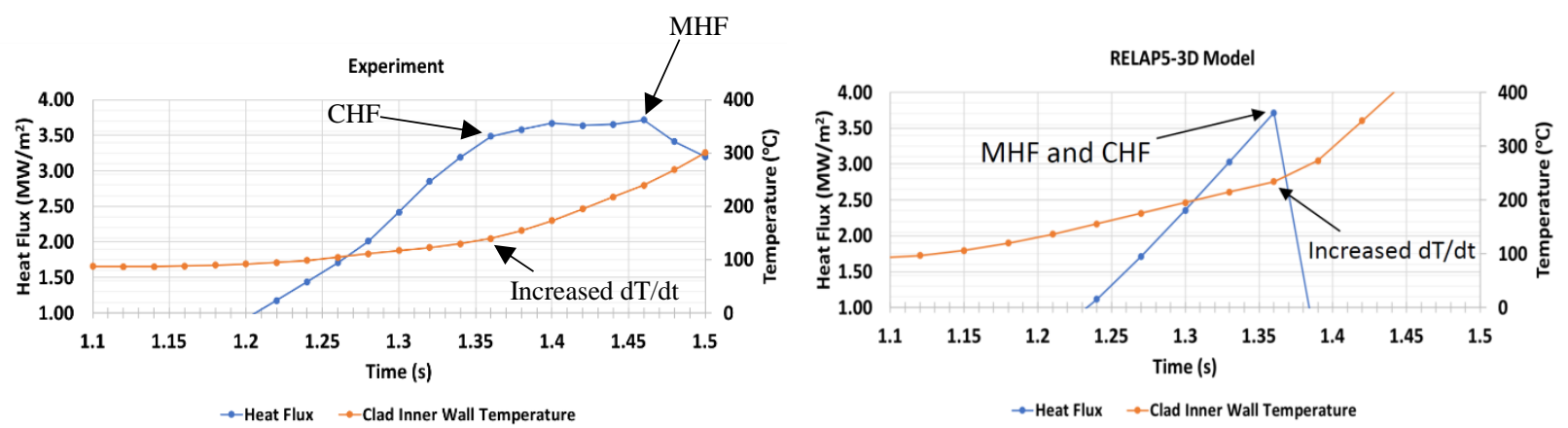

Figure 22. (a) Experimental heat flux and tube temperature and (b) simulated heat flux and tube temperature. (UTK)

Motivated by reducing the high cost of running CHF tests that cover a wide range of operating conditions, UNM explored a machine-learning algorithm for practical interpolation and extrapolation of experimentally measured CHFs so as to inform a strategic scheme of CHF experiment for such technology implementation. Figure 23 demonstrates the capitalization on sparingly distributed experimental data. Machine learning (support vector machine $[\mathrm{SVM}]$ ) shows the capability to accelerate the development of CHF look-up tables or correlations with high accuracy $\left(\mathrm{R}^{2} \geq 0.95\right)$. The rationales behind the CHF predictability of SVM are that the kernel function can map the nonlinear relation of CHF to pressure and mass flux into a linear relation of high-dimensional space. The automatic determination of support vectors can provide the importance weights of training data, and then the prediction of CHF will 
be provided by locally calculating the similarities among the prediction target, training data, and globally summed weighted CHF of training datasets.
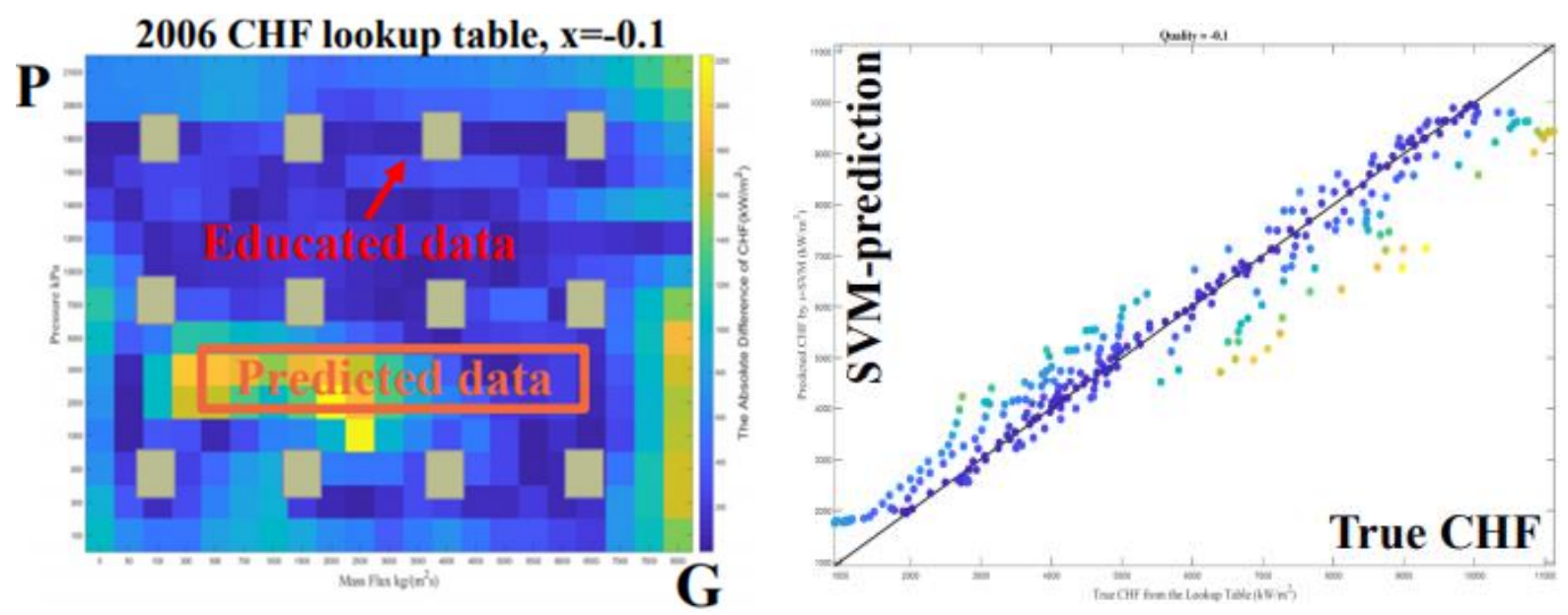

Figure 23. (a) CHF prediction with 12 evenly distributed educated data and (b) comparison of machinelearning prediction to true CHF (UNM).

For pressure-dependent CHF behavior, training data in the proximity of the pressure inflection point that characterizes the maximum allowable CHF for different pressures significantly contribute to the prediction accuracy of the SVM. This implies that experimental CHF data should be procured in the proximity of pressure inflection points, and the prior knowledge of pressure-CHF inflection points can enhance the prediction accuracy of the ATF CHF look-up table. Moreover, the linearity of CHF with respect to mass flux determines prediction accuracy in the absence of a good spread of training data.

Another advantage of the SVM application for CHF prediction is that extrapolation to high pressure from low can be effectively achieved with a few data points in the high-pressure range, as shown in Figure 24. This shows the possibility of strategically integrating high- and low-pressure experimental data to construct a new CHF look-up table while reducing the experimental costs associated with the highpressure testing.
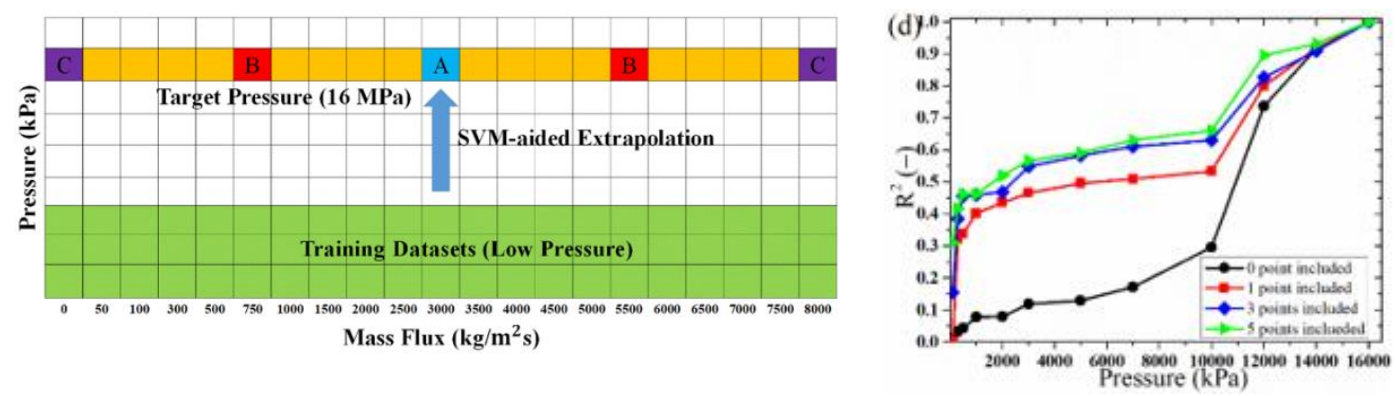

Figure 24. (a) High-pressure extrapolation strategy and (b) SVM supported extrapolation at Xe $=-0.05$ (UNM).

\subsection{Quenching}

Many studies have investigated rewetting of heated samples in reflooding scenarios. Droplet quenching is another important phenomenon that occurs during safety spray cooling-e.g., in a BWR. The spray-cooling system generates tiny droplets on the millimeter scale, which then impinge and quench the fuel-cladding surfaces. Different from pool quenching, droplet quenching is a scarcely investigated phenomenon, especially on ATF materials. 
MIT constructed and operated a test facility for droplet-quenching experiments, as shown in Figure 25. The experimental setup enables the use of synchronized infrared (IR) thermometry and highspeed shadowgraphy, which provides high temporal and spatial resolution for quenching heat-transfer measurement. The test sample is in direct contact with a heater, which is used to control the sample temperature. A through-hole in the center of both the heater and the supporting insulation structure allows IR measurements of time-dependent test-sample temperature and heat-flux distributions. The side view of the droplet-wall collision is recorded by high-speed video (HSV). The IR camera and HSV are carefully synchronized to record the droplet-collision behavior.

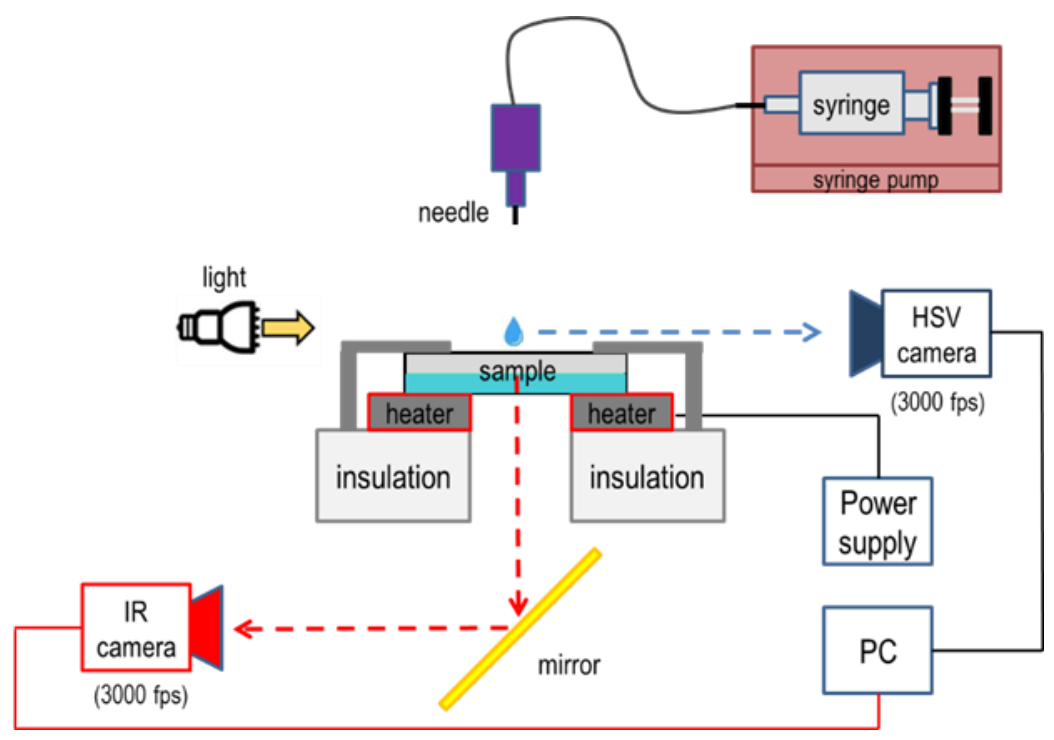

Figure 25. Schematics of the droplet quenching experiment (MIT).

MIT fabricated the test sample by PVD-deposition using different coating materials on circular sapphire substrates. Sapphire is an excellent simulant of Zircaloy, as they have very similar thermal effusivity and diffusivity. In the tests shown in Figure 26 and Figure 27, a $300 \mathrm{~nm} \mathrm{Cr}$ coating was used. The test temperature ranges typically from 100 to $500^{\circ} \mathrm{C}$. After the test sample reaches the desired steadystate temperature, a deionized water droplet, of $2.0 \mathrm{~mm}$ diameter, is released from the needle. It falls by gravity and impinges on the sample. In the reported test, a deionized water droplet with a small Weber number (7.3) at room temperature (75 K subcooling) was used.

IR videos from the droplet-quenching test were post-processed with an in-house MATLAB code to reproduce time-dependent temperature and heat-flux distributions of the sample surface. Figure 26 and Figure 27 show temperature profiles (top row) and high-speed video images (bottom row) during the droplet collision at different sample temperatures. The Leidenfrost temperature can be determined based on shadowgraphy images as well as on the temperature and heat-flux distributions. More tests will be run to fully quantify how the LFP temperature depends on Weber number, droplet temperature and, importantly, surface conditions (i.e., material and roughness). 


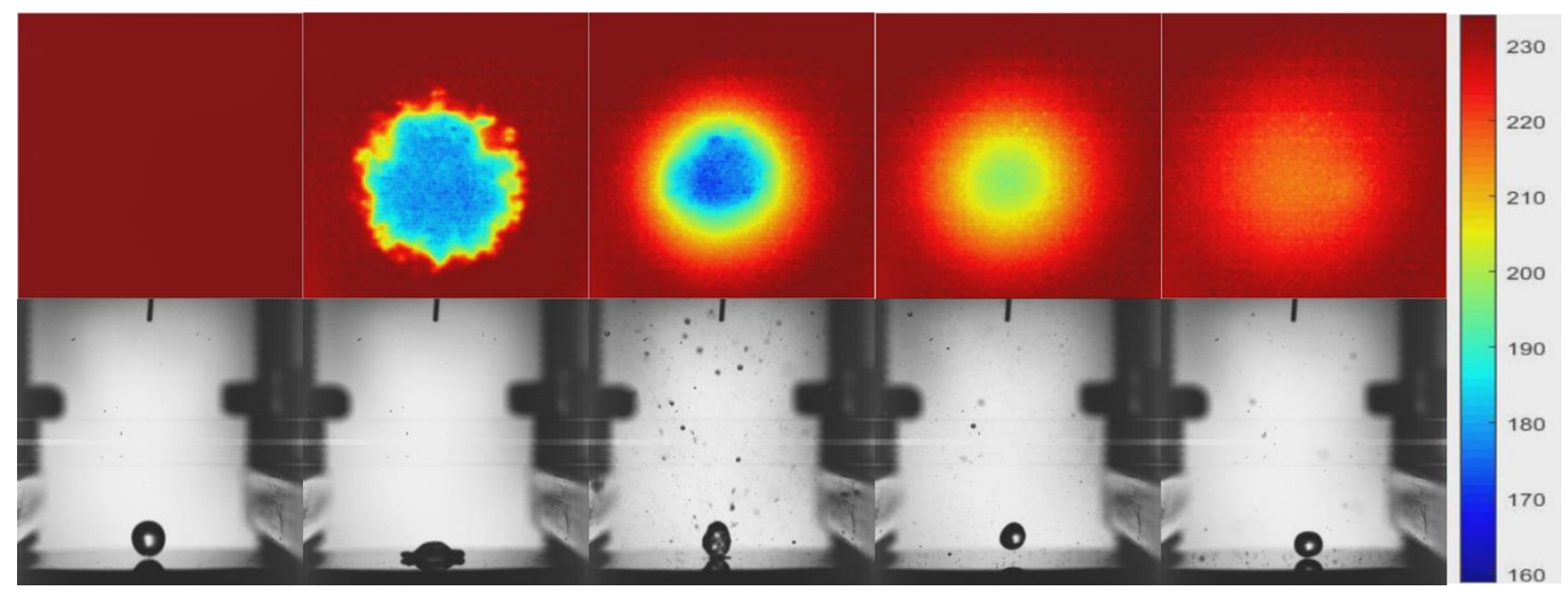

Figure 26. Droplet quenching at transition boiling $\left(240^{\circ} \mathrm{C}\right)$. Temperature color scale in ${ }^{\circ} \mathrm{C}(\mathrm{MIT})$.

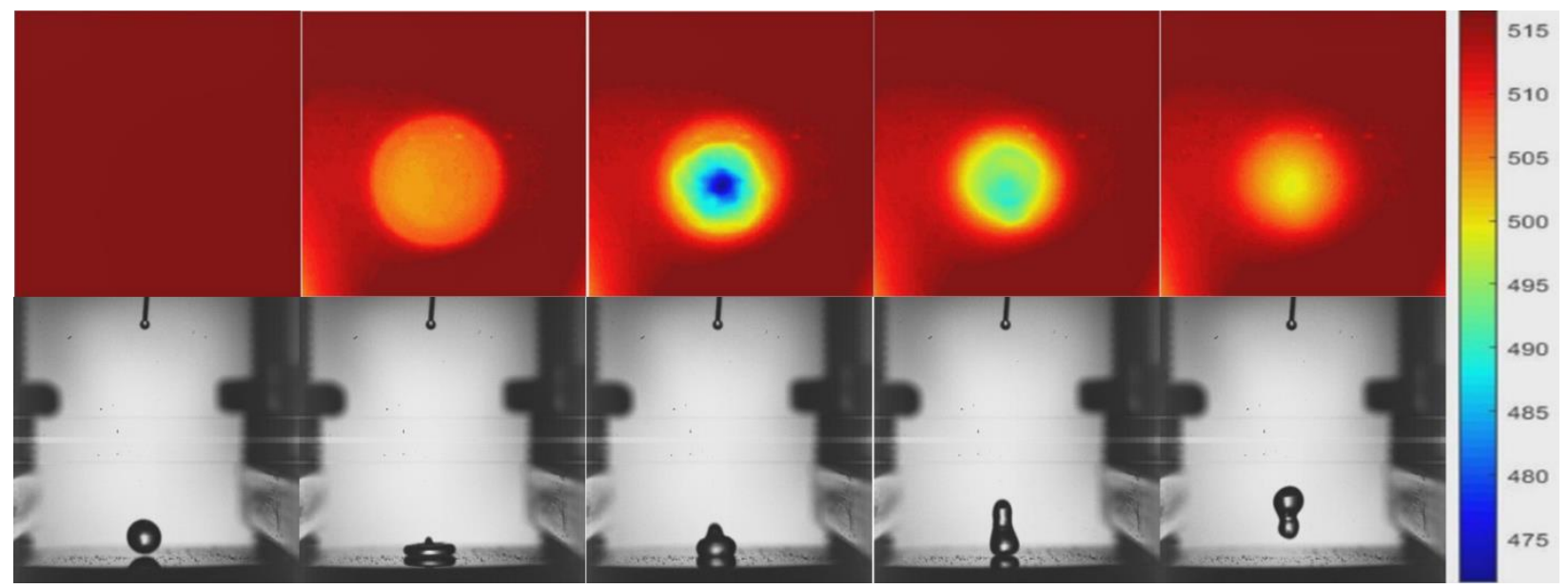

Figure 27. Droplet quenching at film boiling $\left(520^{\circ} \mathrm{C}\right)$. Temperature color scale in ${ }^{\circ} \mathrm{C}$ (MIT).

UWM-1 designed and constructed a quenching test facility that was used to demonstrate boiling heat transfer of modified surfaces under high-pressure and subcooled-water conditions. Figure 28 shows a schematic illustration of the facility. UWM proposed to use such a facility to study the effect of ATF materials' surfaces on the minimum film boiling point and the associated heat-transfer processes. 


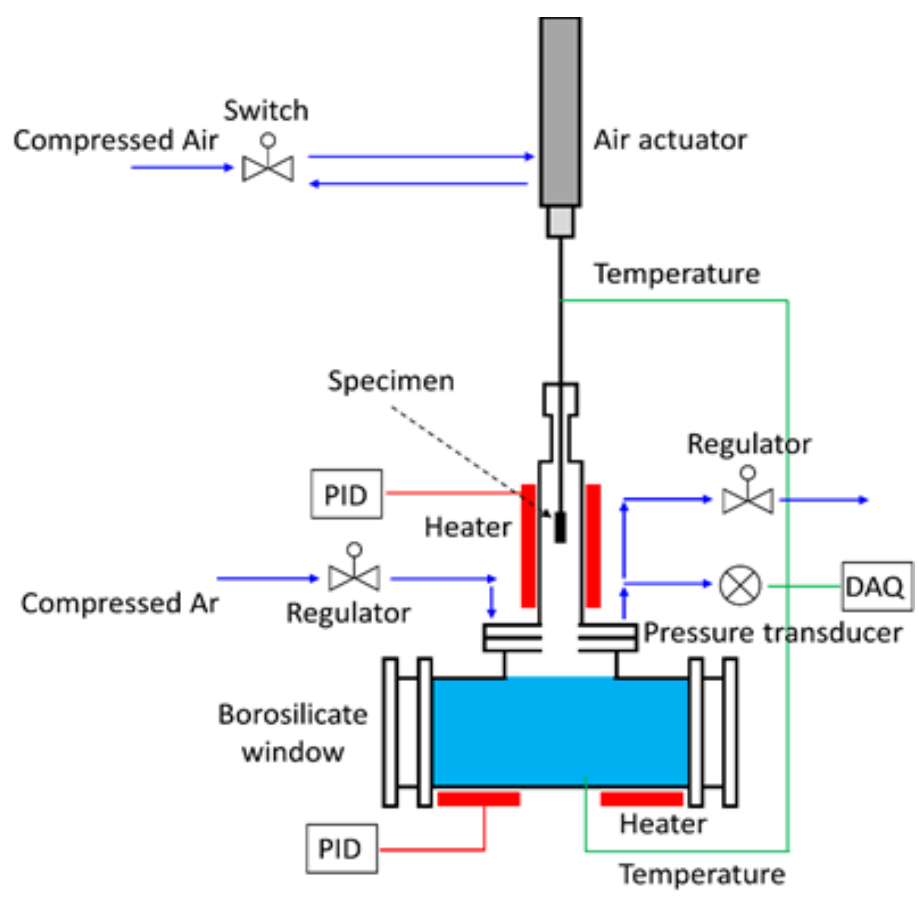

Figure 28. Schematic illustration of the quench-test facility to evaluate boiling heat transfer of various ATF cladding surfaces under high-pressure and subcooled-water conditions (UWM).

\section{CONCLUSIONS}

This report discusses the main achievements of four NEUP projects aimed at investigating the thermal-hydraulic behavior of ATF-cladding materials. Lesson learned and near-term-i.e., to be carried out within the last year of the four NEUP projects - activities are summarized hereafter.

\subsection{Surface Characterization}

Many groups have measured the CAs of ATF materials in the air at atmospheric pressure. However, there seems to be some disagreement on the measured CA from the same material with similar surface roughness. These differences may arise from the sample-cleaning protocol or the surface itself. To address and potentially clarify this issue, samples could be circulated and analyzed by more than one organization.

The CA varies significantly from ambient pressure and temperature to LWR operating conditions. Such variation has been partially clarified by MIT's tests. Systematic CA measurements on ATF materials (from the four projects) with different surface roughness could be conducted under LWR conditions using the MIT facility. The effect of surface degradation during the high-pressure measurements should be evaluated to better understand the CA hysteresis observed with some materials.

\subsection{Boiling}

An analysis of the impact of surface characteristics on CHF has been conducted. However, more experiments should be run before definite conclusions can be drawn.

In pool-boiling conditions at atmospheric pressure, the CHF values measured by UWM-1 suggest that Zirlo, FeCrAl, and Cr-coated Zirlo have very similar CHF and that the CHF limit can be captured by a modified version of the Kandlikar correlation.

However, UNM performed flow-boiling CHF tests at atmospheric pressure and observed that $\mathrm{FeCrAl}$ has a higher CHF limit compared to Zircaloy or Cr-coated Zircaloy at the same operating conditions. 
UNM also observed that surface degradation, e.g., the increase of surface roughness and wettability, does not affect the CHF limit. UNM also conducted a test with a transient power pulse on FeCrAl tubes and observed that the transient $\mathrm{CHF}$ value is higher than the steady-state value.

UWM-2 has carried out studies on steady-state flow boiling on Cr-coated and bare Zirlo cladding, and has observed that the Cr-coated cladding has a higher boiling HTC and a slightly higher CHF compared uncoated claddings.

WEC conducted several flow-boiling CHF tests at PWR operating conditions, showing no difference in the CHF values of bare, Cr-coated, and crud-coated Zirlo claddings.

More tests will be carried out in the third year of the project by WEC and UWM-2, with a specific focus on high pressures, ideally covering both PWR $\left(15.5 \mathrm{MPa}, 344^{\circ} \mathrm{C}\right)$ and $\mathrm{BWR}\left(7.6 \mathrm{MPa}, 291^{\circ} \mathrm{C}\right)$ conditions.

\subsection{Modeling and Simulation}

UTK has generated a computational framework to simulate flow boiling until post-CHF. UTK quantified the uncertainty and sensitivity of the CHF value and the post-CHF temperature excursion. According to the UTK analysis, there is a need to improve the modeling of post-CHF heat transfer during power transients. However, the development and validation of these models require more experimental data, particularly for high-pressure conditions.

\subsection{Quenching}

MIT has developed a facility to study droplet quenching, producing demonstrative results on Crcoated surfaces. A systematic study will be carried out to quantify the LFP temperature of potential ATF

materials. For each material, different surface finish from nanosmooth to PWR-cladding roughness should be tested. The impact of droplet Weber number and subcooling should also be investigated. 


\section{Appendix A}

\section{Program: \\ Thermal-Hydraulics of ATF Cladding Materials}




\title{
Appendix A
}

\section{Program: \\ Thermal-Hydraulics of ATF Cladding Materials}

\author{
Thermal-hydraulics of Accident Tolerant Fuel cladding materials \\ NEUP-ATF meeting
}

Room 24-213

MIT, 77 Massachusetts Avenue, Cambridge, MA 02139

August 13, 2019

Opening 9 AM - Closure 5 PM

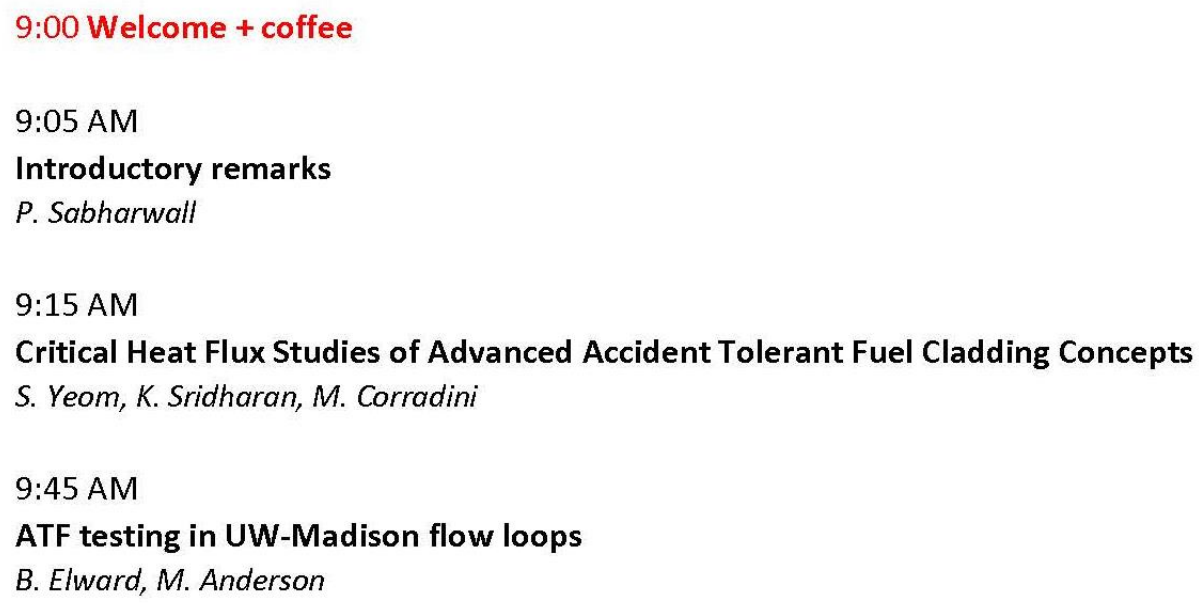


12:30 PM

Investigation of Droplet Quenching on Accident Tolerant Coatings Using Infrared

Thermometry

H. Kim, W. McGee, A. Kossolapov, B. Phillips, M. Bucci

1:00 PM

WALT Loop CHF testing for ATF Cladding

G. Wang, Z. Karoutas

1:30 PM Lunch break

2:15 PM

Tour of The Red Lab and other "ATF" facilities in NSE

The Red Lab

- PEThER loop: $10 \mathrm{bar}, 180^{\circ} \mathrm{C}, 2000 \mathrm{~kg} / \mathrm{m}^{2} / \mathrm{s}$

- LWR loop: full PWR pressure, temperature and mass flux

- Autoclave CA facility: up to 221 bar at steam saturated environment

- Quenching facility: up to $500^{\circ} \mathrm{C}$

The Green Lab

- Oxidation Column: superheated steam up to $1500^{\circ} \mathrm{C}$

- KAPL loop: all flow regimes up to annular flow

3:30 PM

In-Pile CHF Experiments at TREAT and related Activities.

C. Folson, C. Jensen

4:00 PM

Coordination of NEUP projects and proposal for joint publications

P. Sabharwall, M. Bucci

4:15 PM

Discussion

Moderated by P. Sabharwall, M. Bucci

5:00 PM Adjurn 


\begin{tabular}{|c|c|c|}
\hline Participants & & \\
\hline Mark Anderson & UWM & manderson@engr.wisc.edu \\
\hline Nick Brown & UTK & nbrown49@utk.edu \\
\hline Matteo Bucci & MIT & mbucci@mit.edu \\
\hline Barret Elward & UWM & elward@wisc.edu \\
\hline Charlie Folsom & INL & charles.folsom@inl.gov \\
\hline Jake Gorton & UTK & igorton@vols.utk.edu \\
\hline Zeses Karoutas & WEC & karoutze@westinghouse.com \\
\hline Haeseong Kim & MIT & haeseong@mit.edu \\
\hline Youho Lee & SNU & leeyouho@snu.ac.kr \\
\hline Bren Phillips & MIT & bren@mit.edu \\
\hline Jessika Rojas Marin & VCU & jvrojas@vcu.edu \\
\hline Piyush Sabharwall & INL & pivush.sabharwall@inl.gov \\
\hline Kumar Sridharan & UWM & kumar.sridharan@wisc.edu \\
\hline Guanyu Su & MIT & gysu@mit.edu \\
\hline Daniel M. Wachs & INL & daniel.wachs@inl.gov \\
\hline Guoqiang Wang & WEC & wangg@westinghouse.com \\
\hline Sung Yeom & UWM & hveom@wisc.edu \\
\hline
\end{tabular}

WebEx

Christian Deck GA christian.deck@ga.com 


\section{Appendix B}

\section{Critical Heat-Flux Studies of Advanced Accident- Tolerant Fuel-Cladding Concepts}




\section{Appendix B}

\section{Critical Heat-Flux Studies of Advanced Accident- Tolerant Fuel-Cladding Concepts}

$\frac{\text { DEPARTMENT OF }}{\text { ENGINEERING PHYSICS }}$
COLEGE OF ENGINERNG UNNEBSTYY OF WISCONSIN-MADISON

\section{Critical Heat Flux Studies of Advanced ACCIDEnt Tolerant Fuel Cladding ConcePts}

Hwasung Yeom, Emilio Guiterrez, Kumar Sridharan, Hangjin Jo, Yimin Zhou, Michael Corradini*

Nuclear Engineering \& Engineering Physics

University of Wisconsin, Madison WI

NEUP-ATF Meeting at MIT

August 13 $3^{\text {th }}, 2019$ 
1. Introduction

- Project Overview

- Surface Effects on CHF

2. Experimental

3. Results

- Coated Zirlo Samples

- SiC Samples

4. Concluding Remarks

5. Publications

\section{- University of Wisconsin-Madison}

- Dr. Hwasung Yeom

- Emilio Guiterrez

- Yimin Zhou

- Prof. Kumar Sridharan

- Prof. Hangjin Jo (at POSTECH, South Korea)

- Prof. Michael Corradini*

- Westinghouse Electric Company

- Dr. Peng Xu

- Dr. William Byers

- General Atomics

- Dr. Christian Deck 


\section{Introduction}

DEPARTMENT OF

- Objective

- Investigating CHF for surfaces of ATF cladding materials that are presently being considered for implementation jointly by industry, utilities, and DOE.

\section{- Tasks}

- Task 1: Preparation of candidate ATF cladding materials' heat transfer surfaces

- Task 2: Surface characterization of candidate ATF cladding materials

- Task 3: Pool boiling tests of candidate ATF cladding materials

- Task 4: Flow boiling tests of ATF cladding materials under prototypical reactor conditions

- Task 5: Modeling of boiling and CHF for ATF cladding surfaces

\section{- Material of Interest}

- Zirlo ${ }^{\circledR}$, Cr coatings, FeCrAl coatings, CVD SiC, $\mathrm{SiC}_{-} \mathrm{SiC}_{\mathrm{f}}$ composite 


\section{Boiling and Critical heat flux (CHF) \\ DEPARTMENT OF \\ ENGINEERING PHYSICS \\ COLEGE OF ENGINEERING UNIVERSTY OF WISCONSIN-MADISON}

Parameters: Fluid, Pressure, Subcooling, mass flow rate \& surface/material effects [wettability, thermal-physical properties, surface structure/roughness ]

Boiling curve with ONB, CHF, and MHF

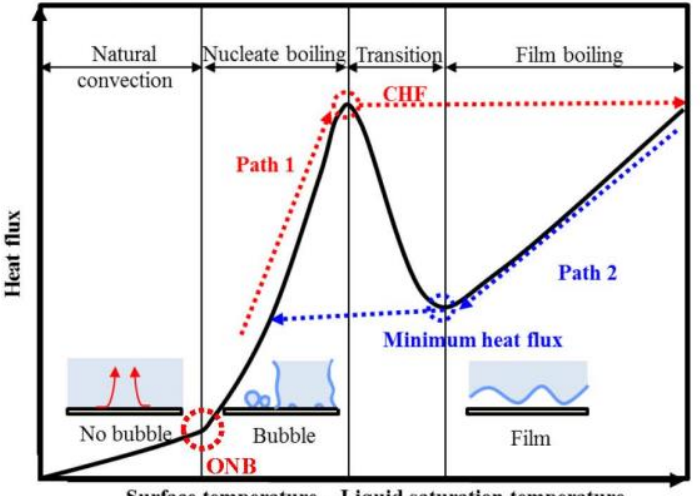

Surface temperature - Liquid saturation temperature
High speed camera visualization (near CHF)

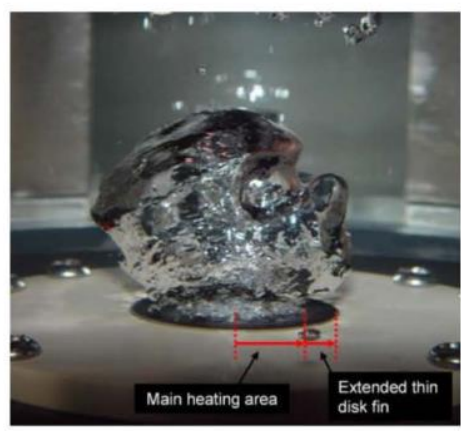

Kim et al., JHT, vol. 132, pp. 061501 (2010)

The surface change could affect boiling associated with TH nuclear reactor limits

\section{Surface parameters with CHF :}

\section{Wettability}

In prior work, heated surface wettability effect has been studied. Receding contact angle (dynamic contact angle) would be the representative contact angle for CHF
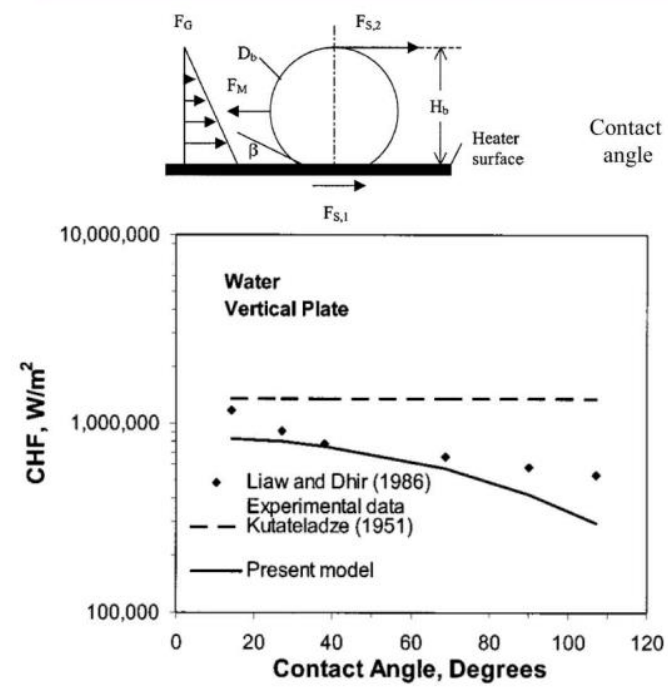

DEPARTMENT OF

ENGINEERING PHYSICS

COLLEGE OF ENGINEERING UNIERSITY OF WISCONSIN-MADISON
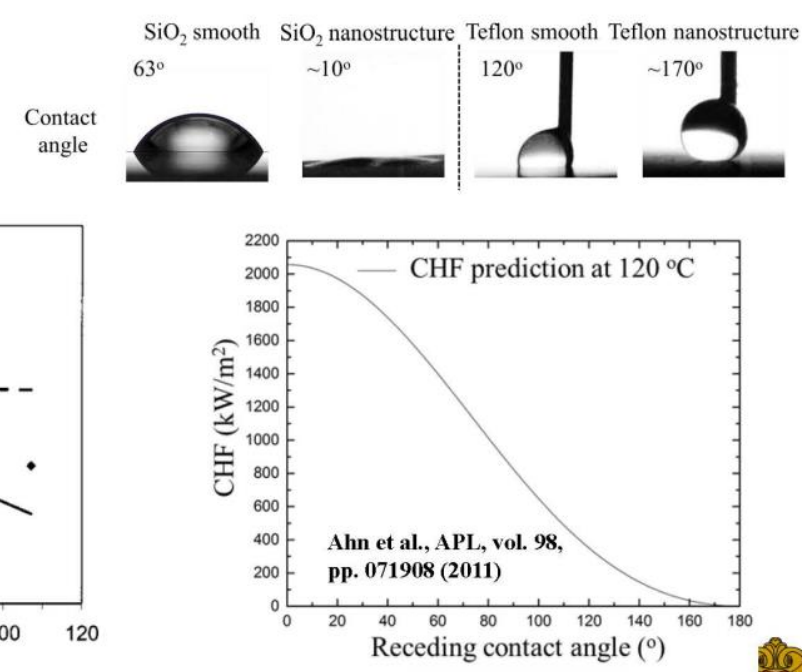

7 Kandlikar, J. Heat Transfer, Vol. 123, pp. 1071 (2001) 
Larger surface thermal conductivity inhibited formation of hot spots, increasing CHF

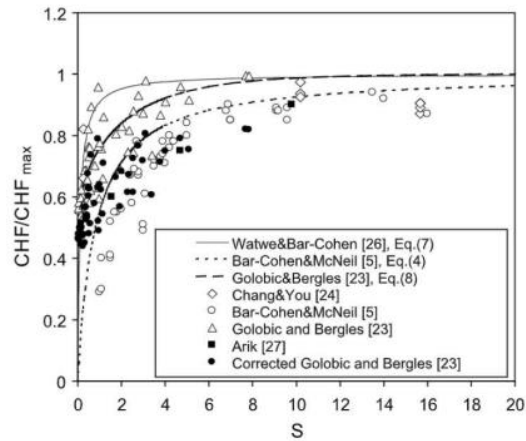

IR images of heating surfaces at boiling at $98 \%$ of the CHF of the bare silicon surface

Fig. 9. Variation of the non-dimensional experimental pool boiling $\mathrm{CHF}$ values with thermal activity parameter.

Thermal activity $=$ Thickness $\mathrm{x}$ thermal effusivity

$$
S=\delta_{w} \sqrt{\rho_{w} C_{p . w} k_{w}} \quad \frac{q_{C H F}^{\prime \prime}}{q_{\max }^{\prime \prime}} \propto \frac{S}{S+C}
$$

Arik, M. \& Bar-Cohen, A. Int. J. Heat and Mass Trans. 46, 3755-3764 (2003).

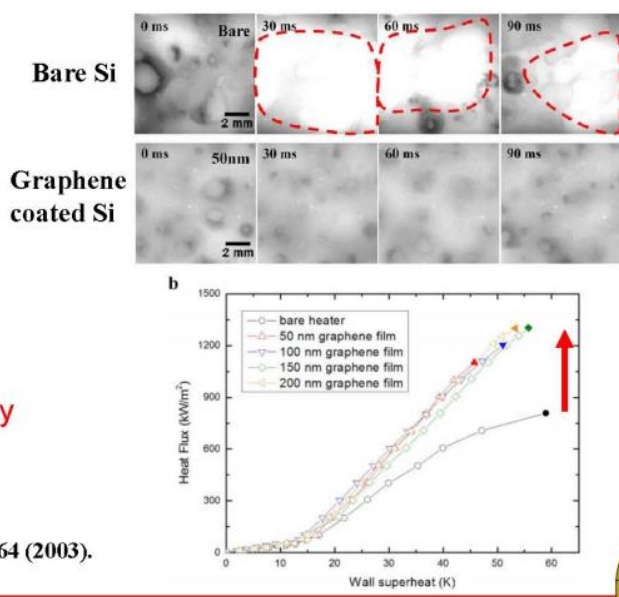

Ahn et al., Scientific Reports, vol. 4, pp. 6276 (2014)

Surface parameters associated with CHF:

DEPARTMENT OF

\section{SuNGINEERING PHYSICS}

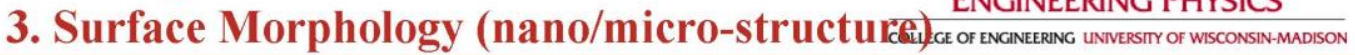

Capillary wicking phenomena enhances CHF on nanostructured surfaces

Nano/Micro (NM)

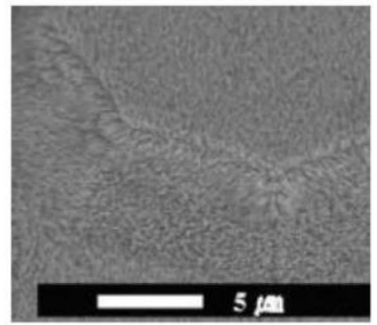

Capillary wicking

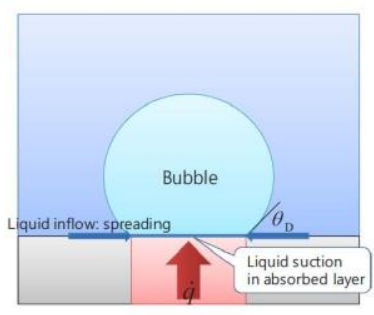

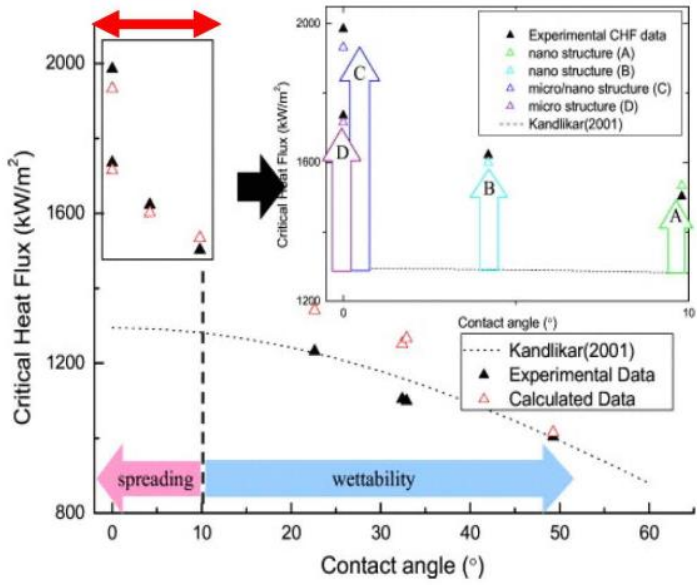

Ahn et al., APL, vol. 98, pp. 071908 (2011) 
Surface parameters associated with CHF: 3. Surface Morphology (e.g, Roughness)

DEPARTMENT OF

ENGINEERING PHYSICS

COLLEGE OF ENGINEERING UNIVERSTTY OF WISCONSIN-MADISON

Increasing surface roughness enhanced $\mathrm{CHF}$, possibly due to capillary wicking effect and enhanced nucleation site density

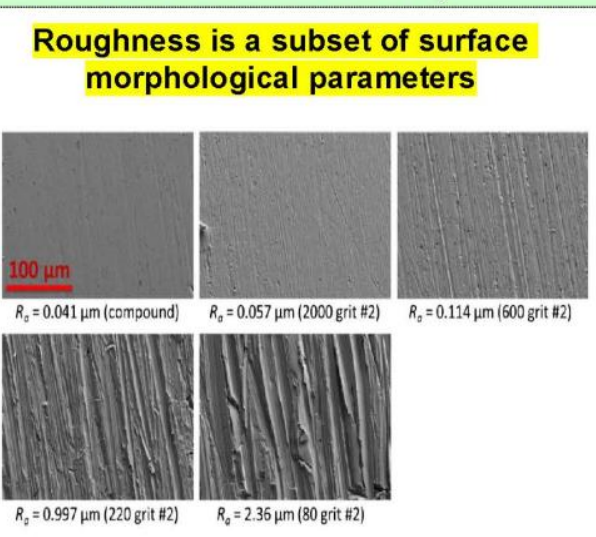

Copper surfaces polished by sand papers

Copper blocks of size $10 \mathrm{~mm} \times 10 \mathrm{~mm} \times 3 \mathrm{~mm}$

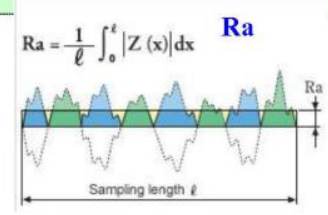

$\mathrm{Rc}=\frac{1}{\mathrm{~m}} \sum_{i=1}^{m} \mathrm{Zti}_{\mathrm{i}}$ Av. Peak-to-Valley

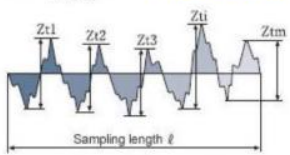

https://www.olympus-ims.com

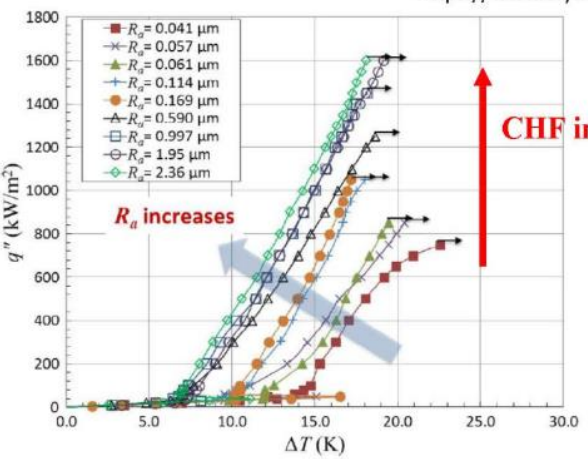

Kim et al., IJHMT, vol. 101, pp. 992-1002 (2016)

DEPARTMENT OF

\section{Pool Boiling Experiment and Surface Characterization at Univ. Wisconsin-Madison}




\section{Pool boiling experiments at UW}

DEPARTMENT OF

Pool boiling facility

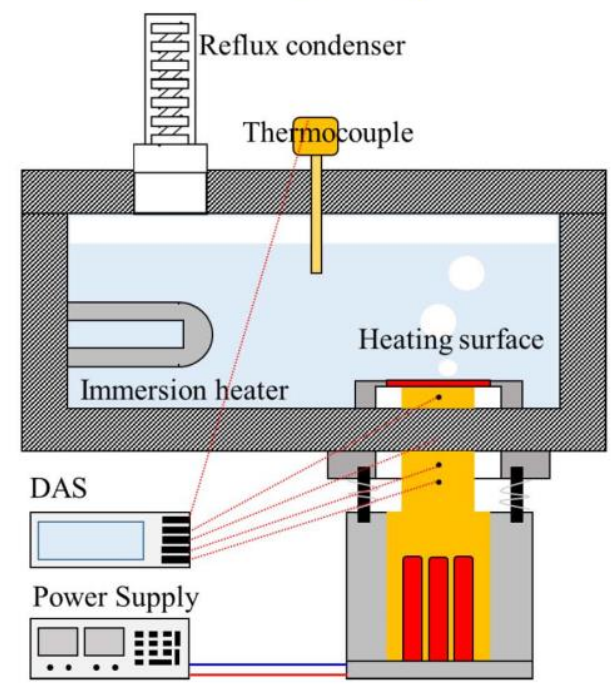

Heater block and sample $(2 \times 2 \mathrm{~cm})$

(a)

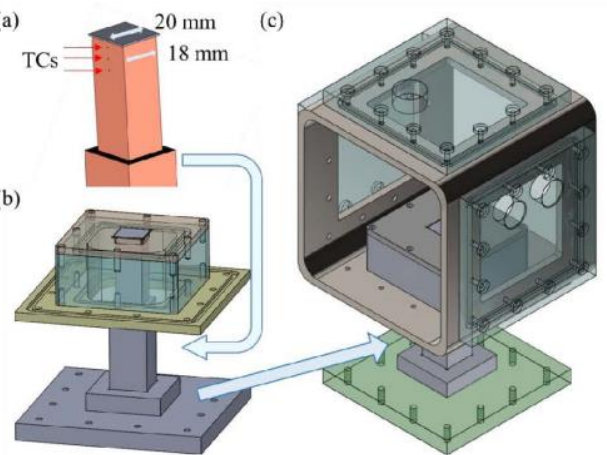

- Heating deionized water in the boiling pool at atmospheric pressure (degassing for one hour)

- Cartridge heaters generate heat embedded in a copper block, transferring heat to a sample flat

- Three thermocouples installed in the copper block measure temperature for heat flux calculation

- The power level was step-wisely increased until the thermocouple temperature abruptly increases and the measured heat flux decreases

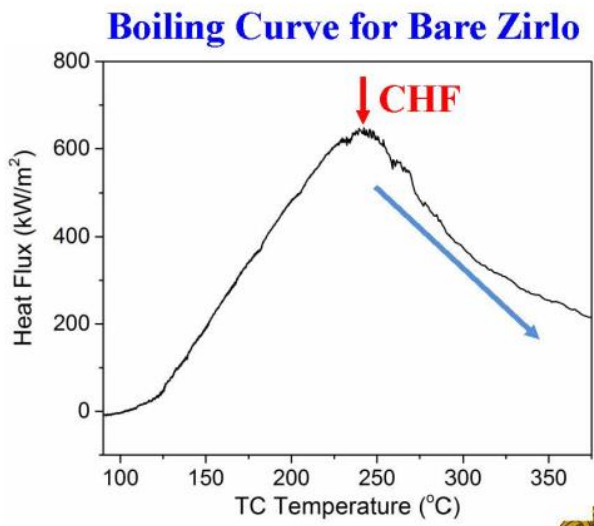




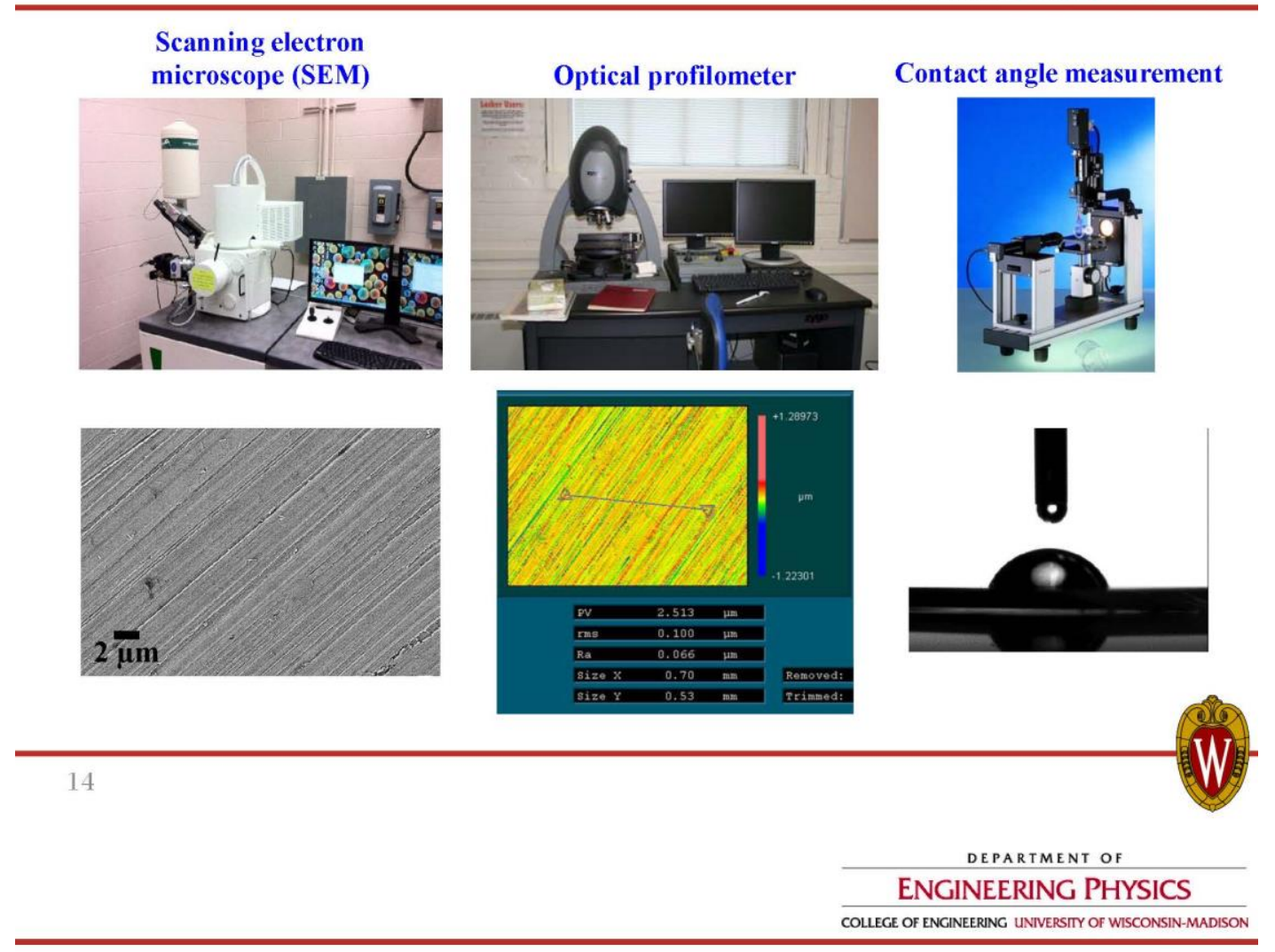

\section{Experimental Results \\ Coated Samples SiC Samples}



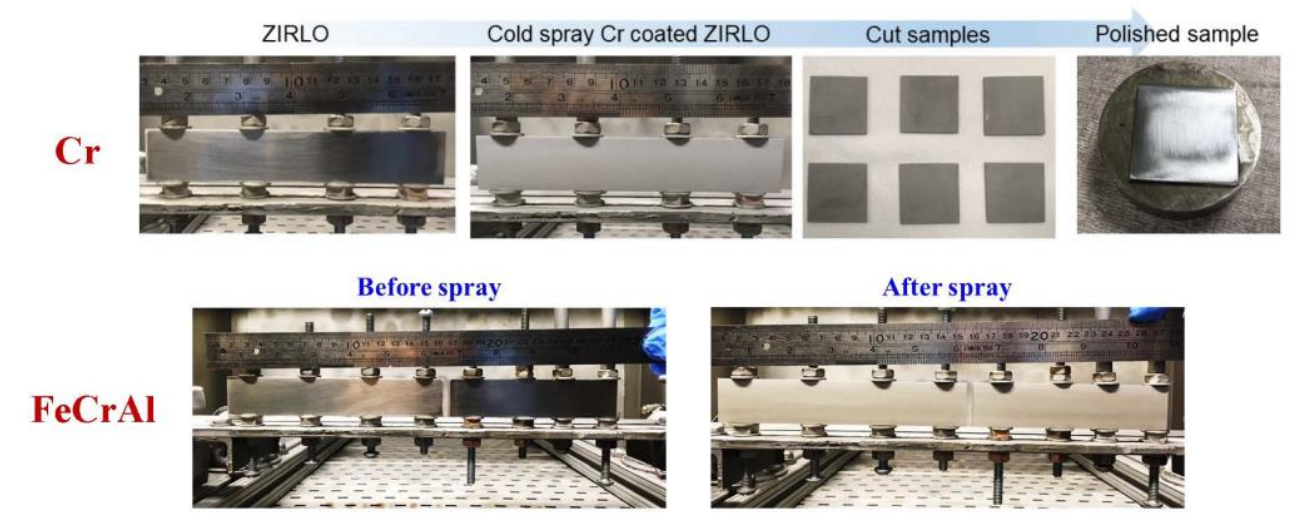

- Substrate: $0.8 \mathrm{~mm}$ Zirlo ${ }^{\circledR}$ Sheet

- Pure Cr powder and Fe20Cr5Al powder

- Surface finishing

- Thickness down to 30 and $70 \mu \mathrm{m}$ using $\underline{600 \text { grit } \mathrm{SiC} \text { abrasive paper }}$

16

Surface Characteristics of Coated Zirlo ${ }^{\circledR}$ Samples

DEPARTMENT OF

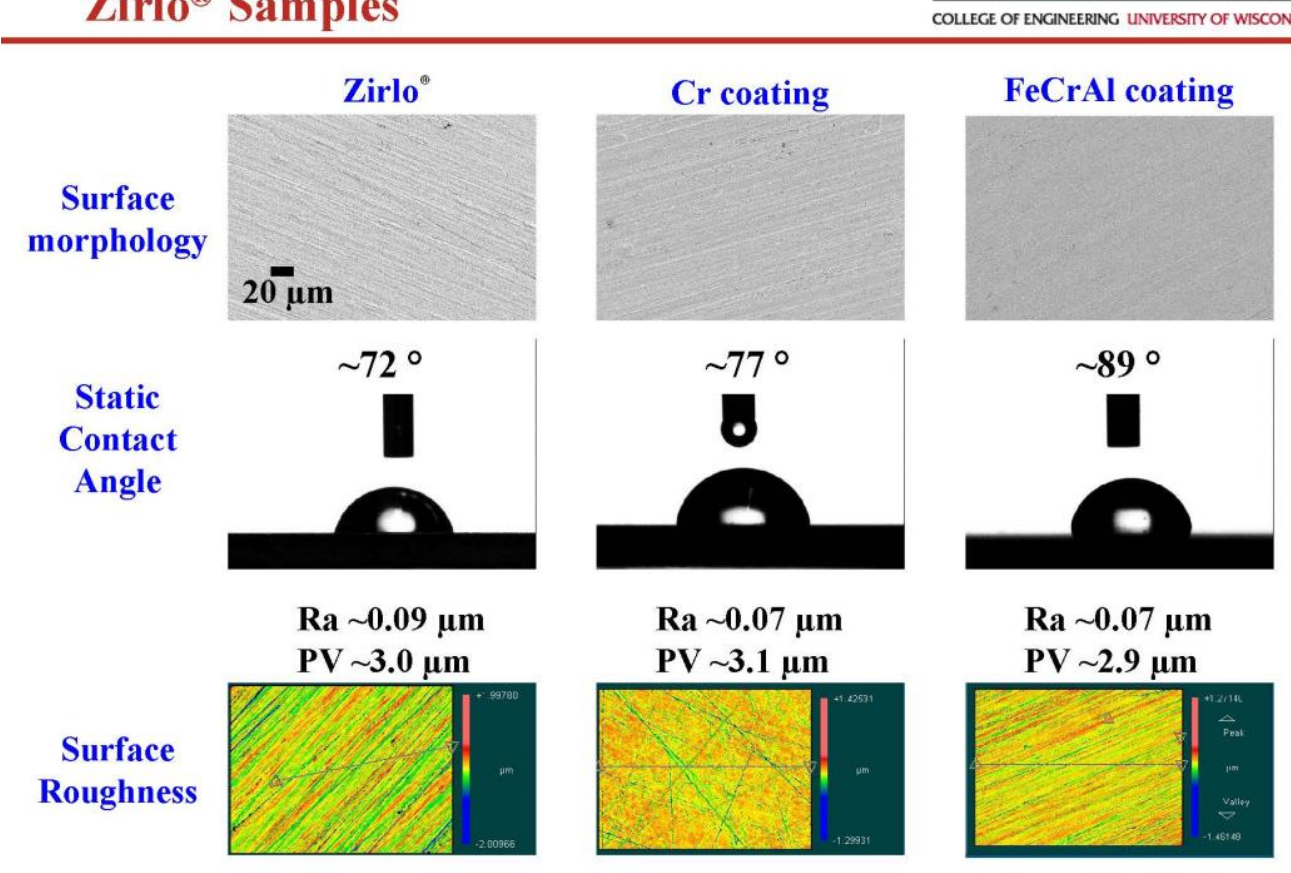

17 
Results for smooth surfaces were well described with contact angle effect on CHF

$$
q_{\text {CHF_Kandikar }}^{\prime \prime}=\rho_{\mathrm{g}}^{0.5} h_{\mathrm{lg}}\left(\frac{1+\cos \beta}{16}\right) \cdot\left[\frac{2}{\pi}+\frac{\pi}{4}(1+\cos \beta)\right]^{0.5}\left[\sigma g\left(\rho_{l}-\rho_{g}\right)\right]^{0.25} * \mathrm{~S}(=0.823)
$$

Modified Kandlikar's model based on Ahn et al., APL, 2011

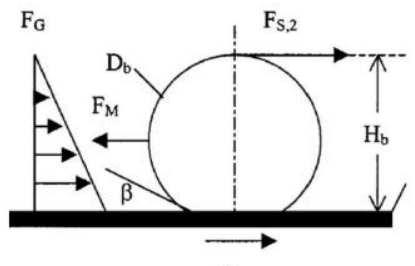

$$
\mathrm{F}_{\mathrm{S}, 1}
$$

Kandlikar, J. Heat Transfer, Vol. 123, pp. 1071 (2001)

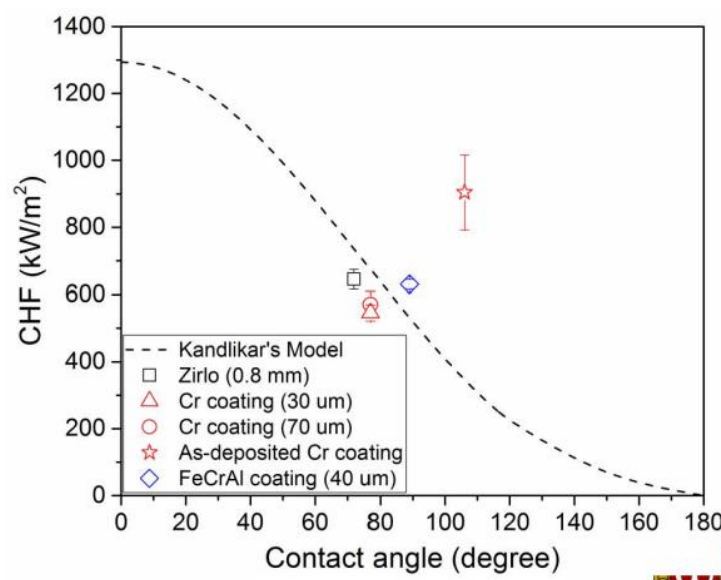

18

Thermo-Physical Measurement

DEPARTMENT OF

- No significant change of thermo-physical properties due to the thin surface coating

- Substrate: $0.8 \mathrm{~mm}$ Zirlo ${ }^{\mathbb{R}}$ Sheet

- Cr coating thickness was $\sim 100 \mu \mathrm{m}$

\begin{tabular}{|c|c|c|c|c|}
\hline Material & $\begin{array}{c}\text { Temperature } \\
\left({ }^{\circ} \mathbf{C}\right)\end{array}$ & $\begin{array}{c}\text { Thermal } \\
\text { conductivity } \\
(\mathbf{W} / \mathbf{m K})\end{array}$ & $\begin{array}{c}\text { Heat capacity } \\
(\mathbf{C a l} / \mathbf{g K})\end{array}$ & Density (g/cc) \\
\hline Zirlo $^{\circ}$ & 24 & $13.5-13.6$ & 0.065 & 6.552 \\
\hline Zirlo $^{\circ}$ & 200 & $15.4-15.7$ & 0.075 & 6.552 \\
\hline $\mathrm{Cr}$ coated Zirlo & 24 & 15.0 & 0.075 & 6.606 \\
\hline $\mathrm{Cr}$ coated Zirlo & 200 & $15.7-16.0$ & 0.081 & 6.606 \\
\hline
\end{tabular}

- Thermal conductivity: Laser flash thermal conductivity method

- Density: Archimedes Principle

- Heat capacity: Differential scanning calorimetry (DSC) 
CHF as a function of heater thermo-physical properties
DEPARTMENT OF

ENGINEERING PHYSICS

COLLEGE OF ENGINEERING UNIVERSTYY OF WISCONSIN-MADISON

Thermo-physical properties of heater affect CHF values

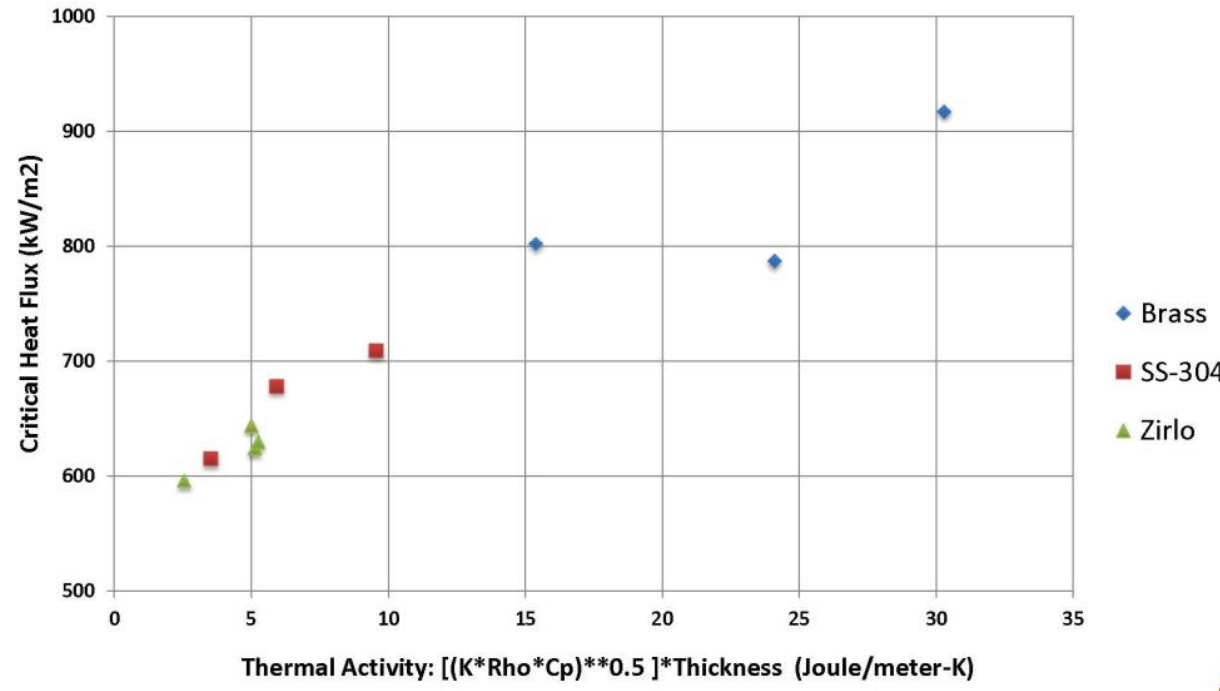

H. Jo, et al, ANS Transactions, Minneapolis MN (2019)

H. Jo, et al, ANS Transactions, Orlando FL (2018)

Comparison with Literature (Pool Boiling Test at DI Water)
DEPARTMENT OF ENGINEERING PHYSICS COLLEGE OF ENGINEERING UNIVERSTYY OF WISCONSIN-MADISON

\section{Other factors (e.g., surface condition, base material, heater size) should be also considered}

\begin{tabular}{|c|c|c|c|c|}
\hline Authors & $\begin{array}{c}\text { Materials } \\
\text { (Coating/Substrate) }\end{array}$ & $\begin{array}{l}\text { Coating } \\
\text { technique }\end{array}$ & $\begin{array}{c}\text { CHF } \\
\text { change }\end{array}$ & Note \\
\hline UW & Cr/Zirlo flat & Cold spray & $-15 \%$ & $\begin{array}{c}30 \mu \mathrm{m} \text { coating } \\
\text { Conduction heating }\end{array}$ \\
\hline UW & $\mathrm{FeCrAl} / \mathrm{Zirlo}$ flat & Cold spray & $-2 \%$ & $\begin{array}{c}40 \mu \mathrm{m} \text { coating } \\
\text { Conduction heating }\end{array}$ \\
\hline $\begin{array}{l}\text { Seo et al, } \\
2016\end{array}$ & $\mathrm{FeCrA1} / \mathrm{SS} 316$ flat & DC sputter & $+40 \%$ & $\begin{array}{c}1 \mu \mathrm{m} \text { coating } \\
\text { Joule heating } \\
\text { Coating cracks }\end{array}$ \\
\hline $\begin{array}{c}\text { Son et al., } \\
2017\end{array}$ & $\mathrm{Cr} / \mathrm{SS} 316$ flat & DC sputter & $+79 \%$ & $\begin{array}{c}1 \mu \mathrm{m} \text { coating } \\
\text { Joule heating } \\
\text { Superhydrophilicity }\end{array}$ \\
\hline $\begin{array}{c}\text { Son et al., } \\
2019\end{array}$ & $\begin{array}{c}\mathrm{Cr} / \mathrm{SS} 316 \text { tube } \\
\text { FeCrA/SS316 tube } \\
\text { (L: } 10 \mathrm{~cm})\end{array}$ & DC sputter & $\begin{array}{c}+27 \% \\
(\mathrm{Cr}) \\
+34 \% \\
(\mathrm{FeCrAl}) \\
\end{array}$ & $\begin{array}{c}1.5 \mu \mathrm{m} \text { coating } \\
\text { Joule heating } \\
\text { Near zero contact angle }\end{array}$ \\
\hline $\begin{array}{c}\text { Kam et al., } \\
2014\end{array}$ & $\begin{array}{l}\mathrm{SiC} / \text { Zircaloy flat } \\
\mathrm{Cr} / \text { Zircaloy flat }\end{array}$ & $\begin{array}{c}\text { DC sputter } \\
\quad(\mathrm{SiC}) \\
\text { Electroplating } \\
(\mathrm{Cr})\end{array}$ & $\begin{array}{c}+56 \%(\mathrm{SiC}) \\
-30 \% \\
(\mathrm{Cr})\end{array}$ & $\begin{array}{l}1 \mu \mathrm{m} \text { coating } \\
\text { Joule heating }\end{array}$ \\
\hline
\end{tabular}


Sputter Cr coating process leaves inherent micron-scale surface structure resulting from coating growth mechanism, likely influencing $\mathrm{CHF}$

SEM images of as-deposited PVD Cr coating developed at UW
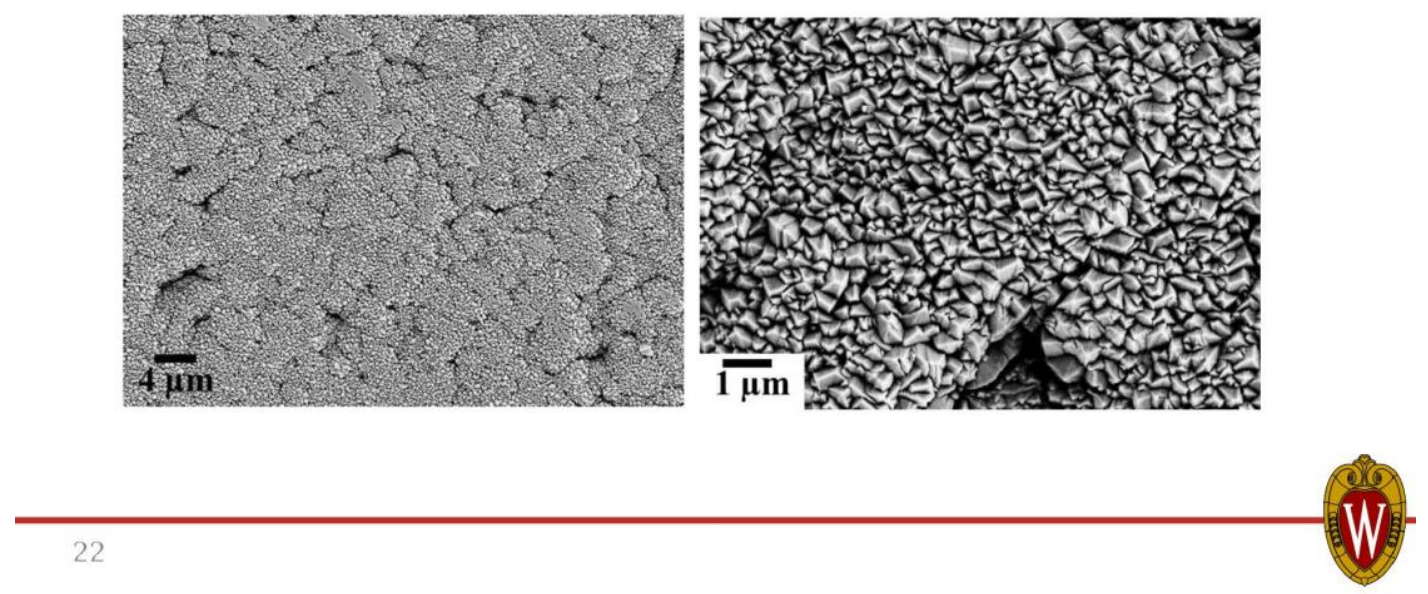

CVD $\mathrm{SiC}$ and $\mathrm{SiC}-\mathrm{SiC}_{\mathrm{f}}$ Samples

DEPARTMENT OF

$\mathrm{CHF}$ tests for $\mathrm{CVD} \mathrm{SiC}$ and $\mathrm{SiC}-\mathrm{SiC}_{\mathrm{f}}$ composite are undergoing

\begin{tabular}{|c|c|c|c|}
\hline Material & $\begin{array}{c}\text { Static } \\
\text { contact } \\
\text { angle }\left(^{\circ}\right)\end{array}$ & $\begin{array}{c}\text { Roughness } \\
\text { (PV, } \mu \mathrm{m})\end{array}$ & $\begin{array}{c}\text { Thickness } \\
\text { (mm) }\end{array}$ \\
\hline $\mathrm{Zirlo}^{\circ}$ & 72 & 4.1 & 0.8 \\
\hline CVD SiC A & 57 & 2.6 & 1 \\
\hline CVD SiC B & 36 & 3.1 & 1 \\
\hline CVD SiC C & 32 & 5.0 & 1 \\
\hline $\mathrm{SiC}-\mathrm{SiC}_{\mathrm{f}} \mathrm{A}$ & 67 & 11 & 1.4 \\
\hline $\mathrm{SiC}-\mathrm{SiC}_{\mathrm{f}} \mathrm{B}$ & 51 & 6 & 1.4 \\
\hline $\mathrm{SiC}-\mathrm{SiC}_{\mathrm{f}} \mathrm{C}$ & 66 & 23 & 1.4 \\
\hline
\end{tabular}
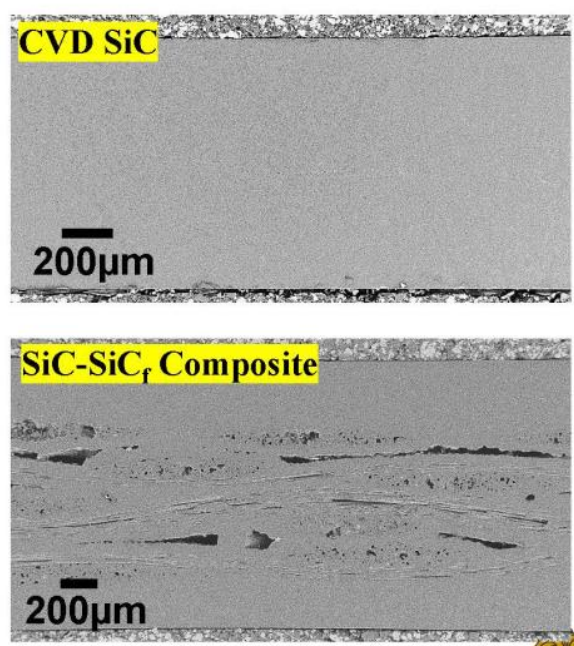
Surface Morphology of As-prepared

SiC Surfaces

ENGINEERING PHYSICS

COLLEGE OF ENGINEERING UNIVERSTIY OF WISCONSIN-MADISON
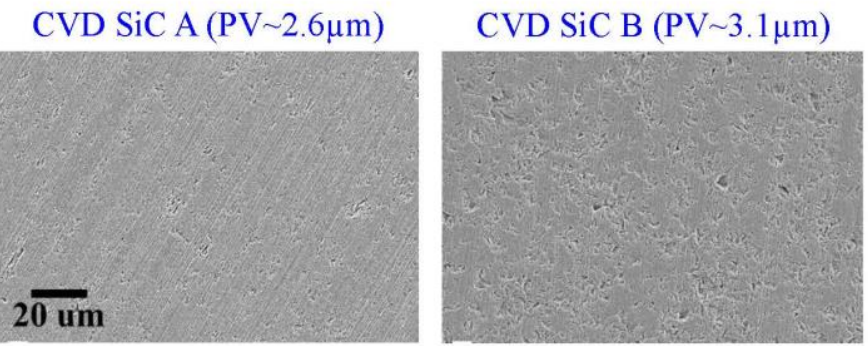

CVD SiC C (PV 5.0 $\mu \mathrm{m})$
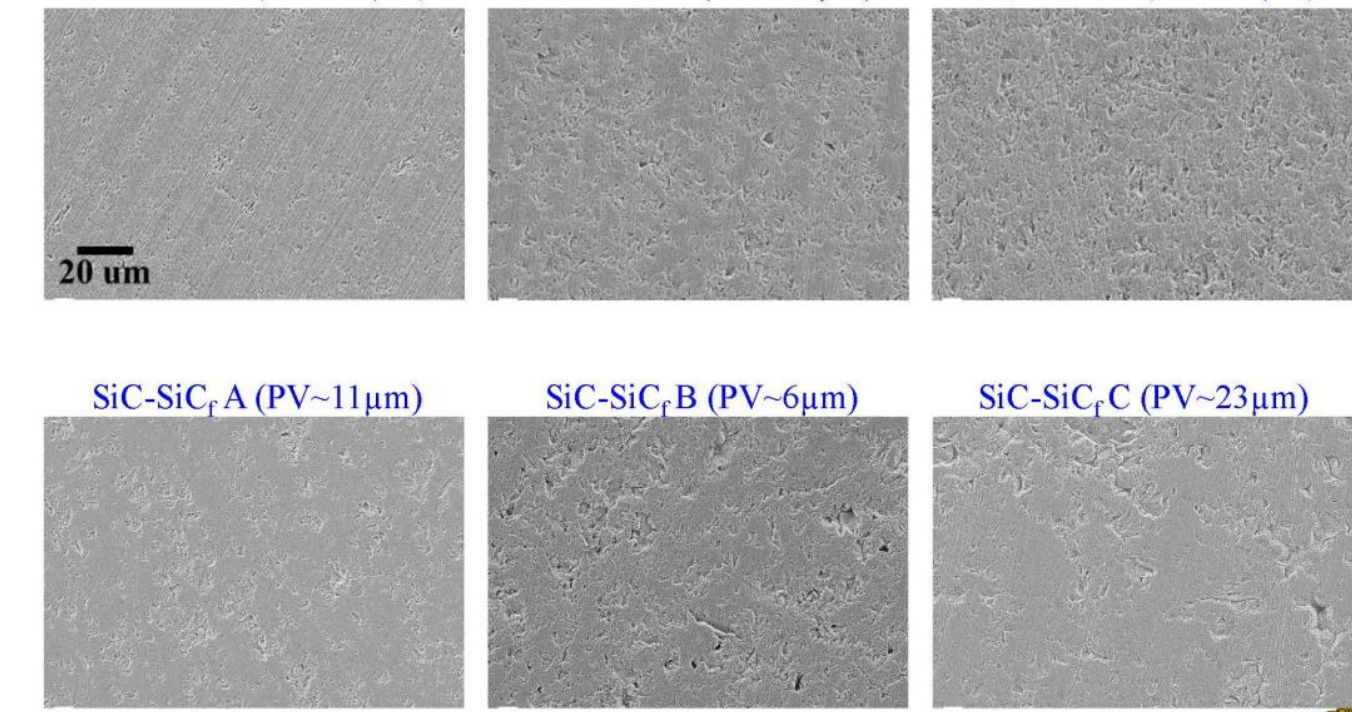

$\mathrm{SiC}-\mathrm{SiC}_{\mathrm{f}} \mathrm{B}(\mathrm{PV} \sim 6 \mu \mathrm{m})$

$\mathrm{SiC}-\mathrm{SiC}_{\mathrm{f}} \mathrm{C}(\mathrm{PV} \sim 23 \mu \mathrm{m})$
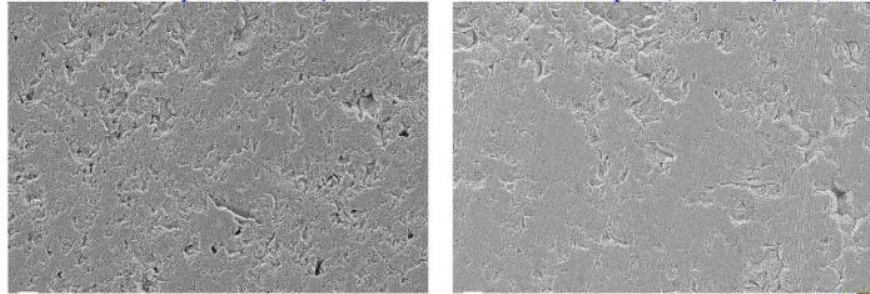

24

Do not distribute

Immediate Future Work

DEPARTMENT OF

- Complete pool boiling tests of $\mathrm{SiC}$ samples and comprehensive understanding of the results

- Investigation of corrosion effects on boiling performance of cladding materials Roughness change during

- CHF test of coated Zirlo fuel cladding and $\mathrm{SiC}-\mathrm{SiC}_{\mathrm{f}}$ composite cladding in prototypical flow boiling conditions (Westinghouse WALT Loop Test) water autoclave test [UW]

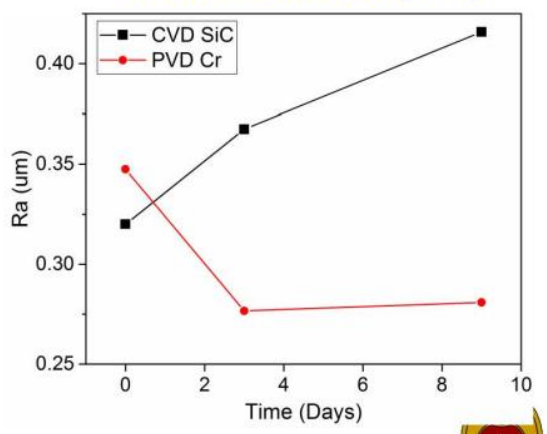




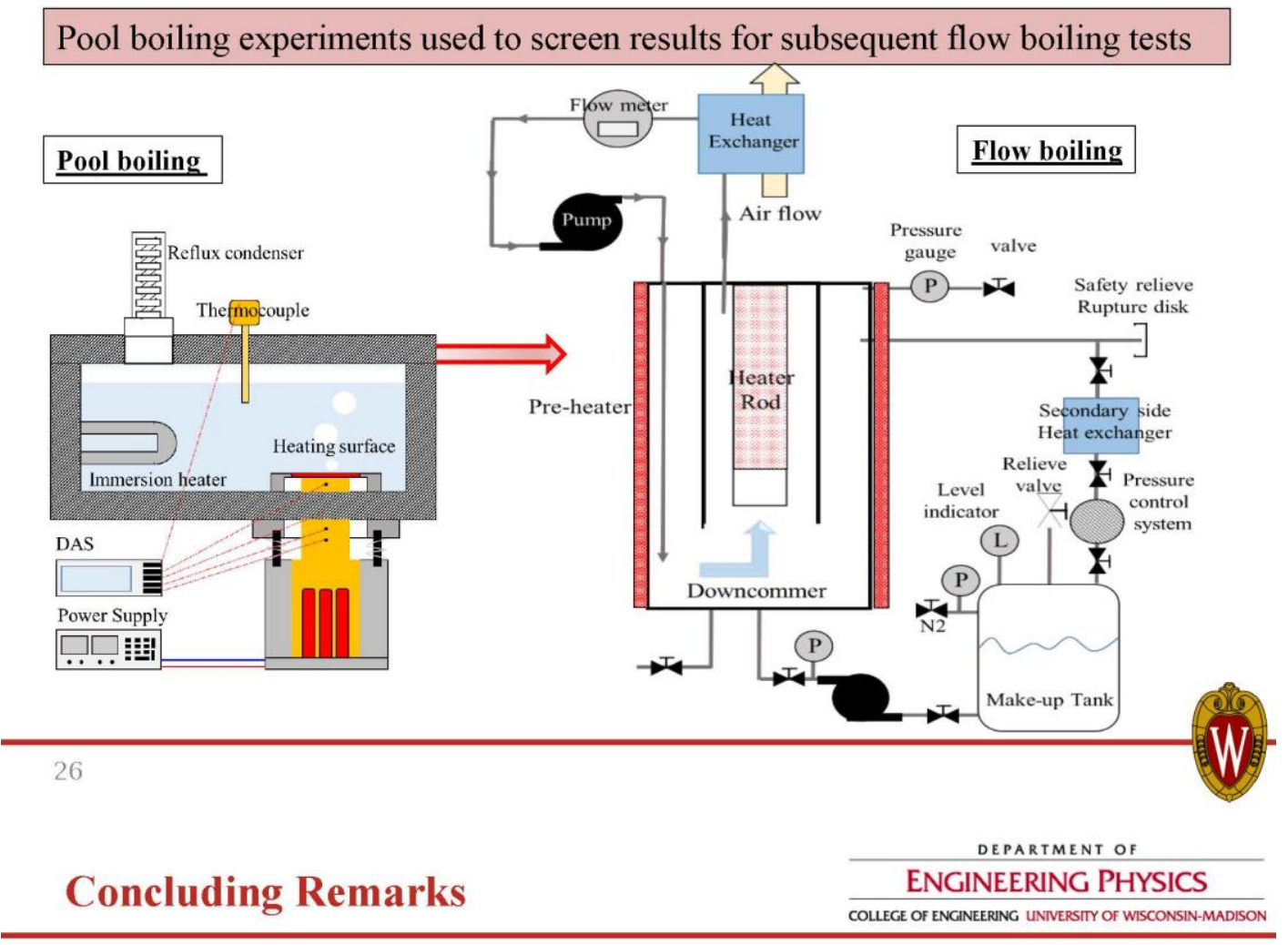

- Pool boiling experiment for potential ATF cladding materials has been performed

- Thermal physical properties and surface characteristics of coated cladding were very similar to uncoated cladding, resulting in insignificant change of CHF values

- Effect of evolution of surface characteristics (due to corrosion/oxidation) under prototypical normal operating conditions on boiling behavior would be considered

- This study will be extended for prototypical flow boiling test to describe the LWR hydraulics conditions 


\section{Publications}

DEPARTMENT OF

- Journal Publication

- H. Jo, H. Yeom, E. Gutierrez, K. Sridharan, M. Corradini, Evaluation of Critical Heat Flux of ATF Candidate Coating Materials in Pool Boiling, Nuclear Engineering and Design, accepted (in press), 2019

- Conference proceedings

- H. Jo, H. Yeom, E. Gutierrez, K. Sridharan, M. Corradini, "Characterization of boiling characteristics of accident tolerant fuel (ATF) cladding surfaces, Proc. 2018 ANS Winter Meeting and Nuclear Technology Expo, Orlando, FL, 2018

- H. Jo, E. Gutierrez, H. Yeom, K. Sridharan, M. Corradini, "Critical Heat Flux Study with Different Substrate Conditions for Accident Tolerant Fuel Cladding Development", Proc. 2019 ANS Annual Meeting, Minneapolis, MN, 2019

\section{Back-up Slides}


Surface/material changes can affect boiling heat transfer limits on heating surfaces

\begin{tabular}{|l|}
\hline Prior work indicates: \\
- Surface wettability \\
- Thermophysical \\
properties \\
- Surface morphology \\
(roughness, capillarity) \\
\hline
\end{tabular}

\section{Current work funded by DOE: ATF effects on boiling \& CHF}

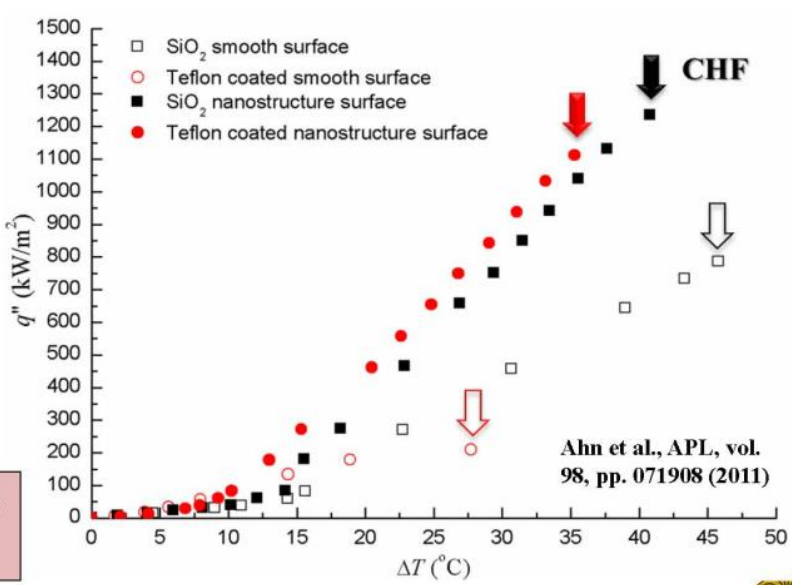

30

Surface parameters associated with CHF: DEPARTMENT OF 3. Surface Morphology

ENGINEERING PHYSICS COLEGE OF ENGINEERNG UNIVESTIY OF WISCONSIN-MADISON Micro/nano-structures on Si surface [Dong et al., IJHM, 2014]
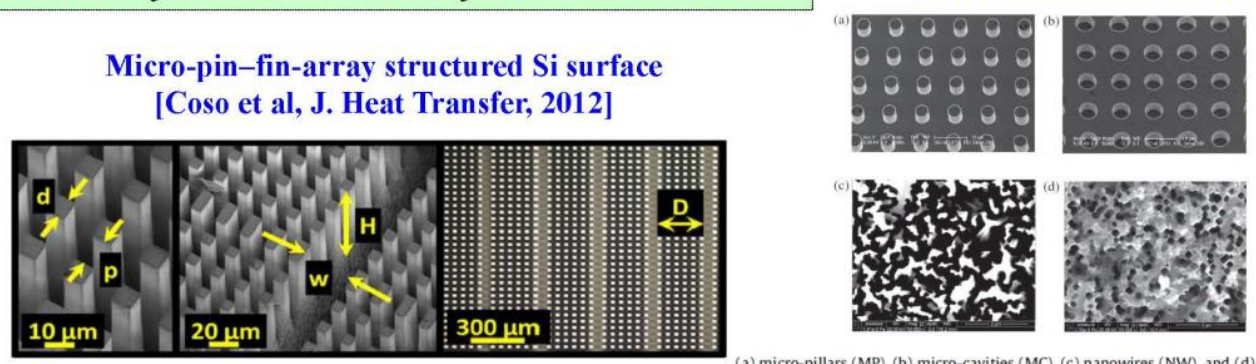

(a) micro-pillars (MP), (b) micro-cavities (MC), (c) nanowires (NW), and (d) nano-cavities (N
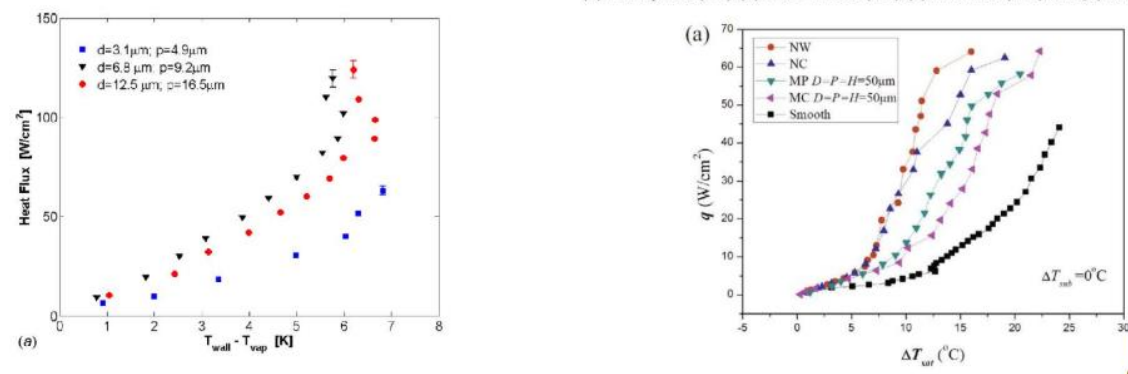


\section{Thickness Effect on CHF}

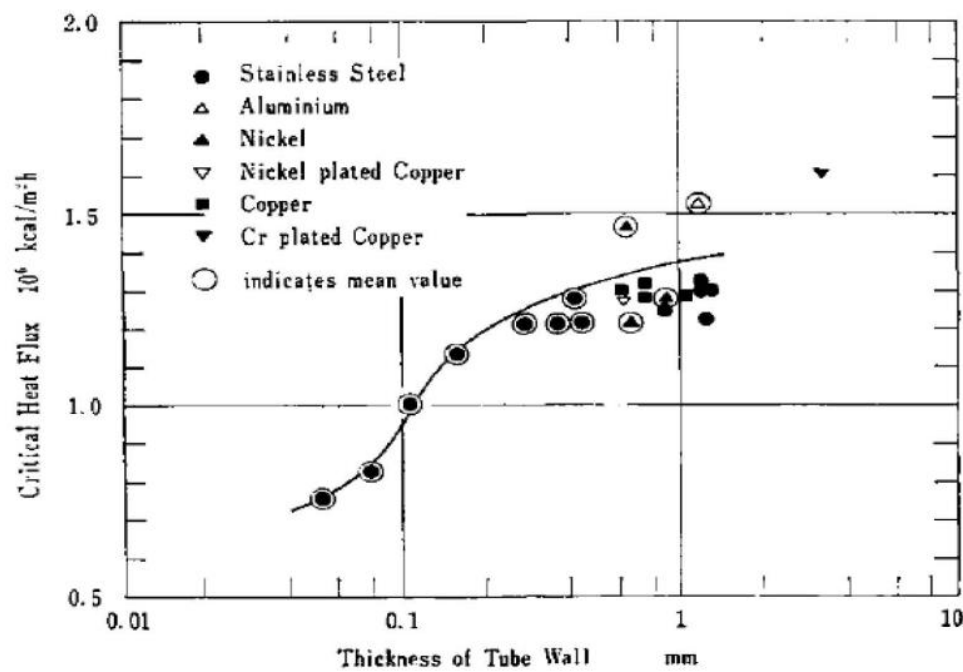

Fig. 2 Critical Heat Flux vs. Thickness of Tube Wall

32 Arik, M. \& Bar-Cohen, A. Int. J. Heat and Mass Trans. 46, 3755-3764 (2003).

\section{Heater Size Effect on CHF}

DEPARTMENT OF ENGINEERING PHYSICS COLLEGE OF ENGINEERING UNIVESTYY OF WISCONSIN-MADISON

Table 1

Summary of experimental results.

\begin{tabular}{|c|c|c|c|c|c|}
\hline & & \multicolumn{4}{|l|}{ Heater size } \\
\hline & & $0.5 \times 0.5\left(\mathrm{~cm}^{2}\right)$ & $1 \times 1\left(\mathrm{~cm}^{2}\right)$ & $1.5 \times 1.5\left(\mathrm{~cm}^{2}\right)$ & $2 \times 2\left(\mathrm{~cm}^{2}\right)$ \\
\hline \multirow[t]{3}{*}{ SiNW } & $\mathrm{CHF}\left(\mathrm{W} / \mathrm{cm}^{2}\right)$ & $223.90 \pm 5.61$ & $150.67 \pm 12.42$ & $124.85 \pm 16.21$ & $125.52 \pm 3.06$ \\
\hline & $\mathrm{HTC}\left(\mathrm{W} / \mathrm{cm}^{2} \mathrm{~K}\right)$ & $9.06 \pm 1.60$ & $4.68 \pm 0.23$ & $3.89 \pm 0.64$ & $4.84 \pm 0.72$ \\
\hline & Conduction loss (\%) & 7.03 & 7.96 & 5.80 & 4.26 \\
\hline \multirow[t]{3}{*}{ Plain Si } & $\mathrm{CHF}\left(\mathrm{W} / \mathrm{cm}^{2}\right)$ & $81.48 \pm 0.87$ & $67.40 \pm 15.52$ & $46.82 \pm 6.46$ & $44.22 \pm 12.33$ \\
\hline & $\mathrm{HTC}\left(\mathrm{W} / \mathrm{cm}^{2} \mathrm{~K}\right)$ & $2.98 \pm 1.01$ & $2.80 \pm 0.47$ & $1.82 \pm 0.29$ & $1.93 \pm 0.73$ \\
\hline & Conduction loss (\%) & 16.21 & 13.46 & 17.88 & 10.08 \\
\hline
\end{tabular}

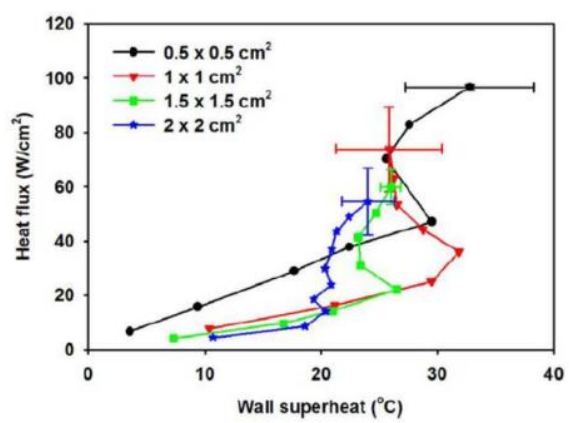

Fig. 8. Boiling curves on plain Si surfaces for different sizes of heaters, which shows that $\mathrm{CHF}$ increases as heater size reduces. 


\section{Appendix C}

\section{Summary of ATF Testing at the University of Wisconsin}




\title{
Appendix C
}

\section{Summary of ATF Testing at the University of Wisconsin}

\author{
SUMMARY OF ATF TESTING AT THE UNIVERSITY \\ OF WISCONSIN
}




\section{ATF Testing Objectives}

- Understand the characteristics and functions of ATF cladding materials

- Overall performance

- Failure modes and CHF performance

- Film stability

- Reflood/rewet conditions

- ATF cladding materials to investigate

- FeCrAl Alloys (APMT and C26M)

- SiC and SiC-SiC Composites

- Coated Zirconium Alloys (PVD and Cold Spray)

- Compare to Zirconium Alloy standard

- Test plan

- Flow visualization, HTC, and CHF measurements at atmospheric pressure

- HTC and CHF performance at prototypic BWR and PWR conditions

\section{UW Madison Team}

- UW's ATF research is a collaboration with MIT, VCU, and industry partners

- Principal Investigators

- Dr. Matteo Bucci (MIT), Dr. Jessika Rojas (VCU), and Dr. Mark Anderson (UW)

- UW Team

- Barret Elward, Research Assistant

- Paul Brooks, Instrumentation/Welding Specialist

- Seth Jones, Machinist/Fabricator

- Brandon, Ian, Jake, and Sid: Undergraduate Hourly Support 


\section{High and Low Pressure Flow Boiling Facilities}

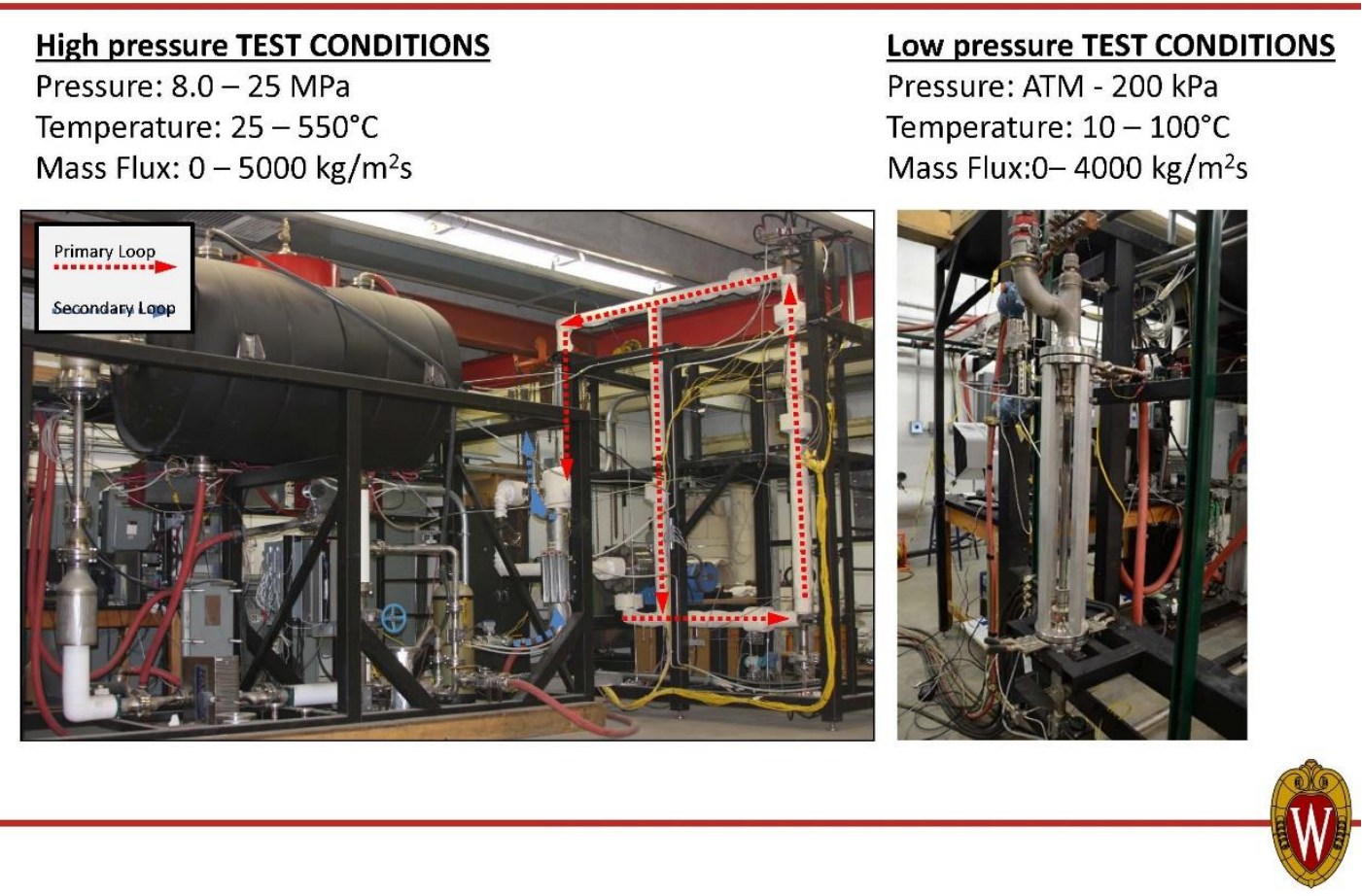

\section{High Pressure Heat Transfer and Flow Boiling}

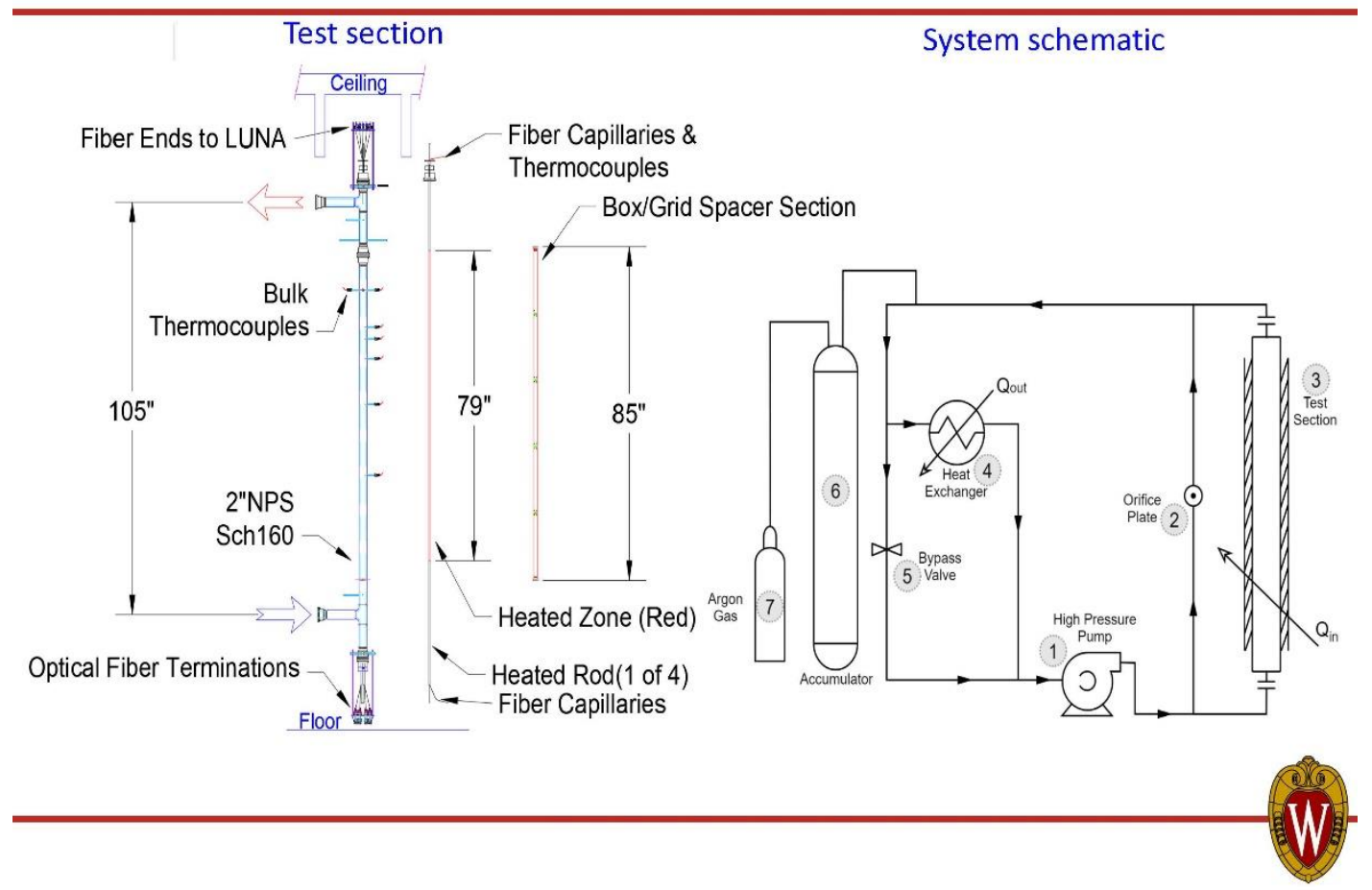




\section{Heater Power Profile and Thermocouples}

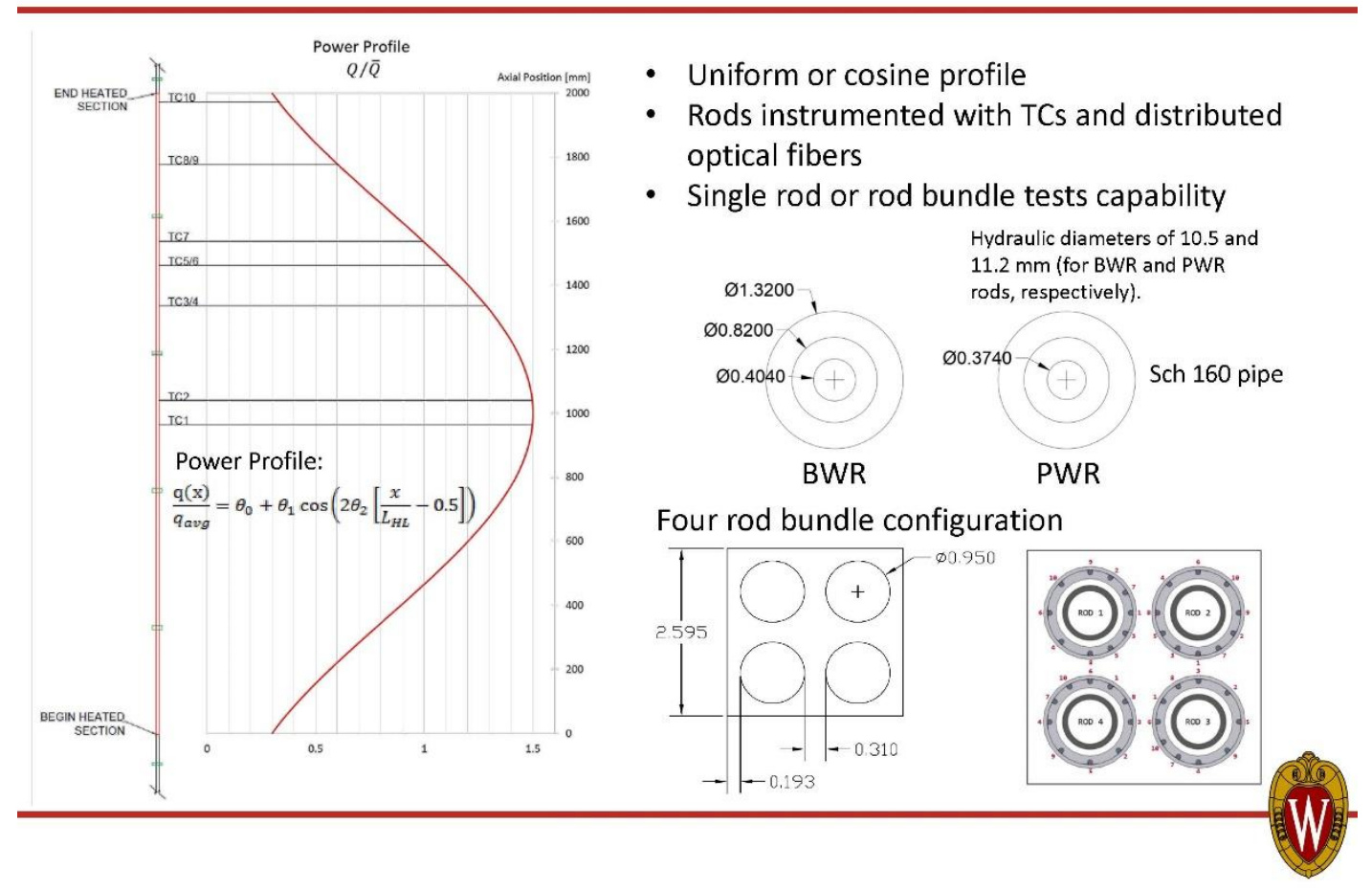

Internally Heated Rod - Stern Labs Design

Ref. Number: $N-1320$
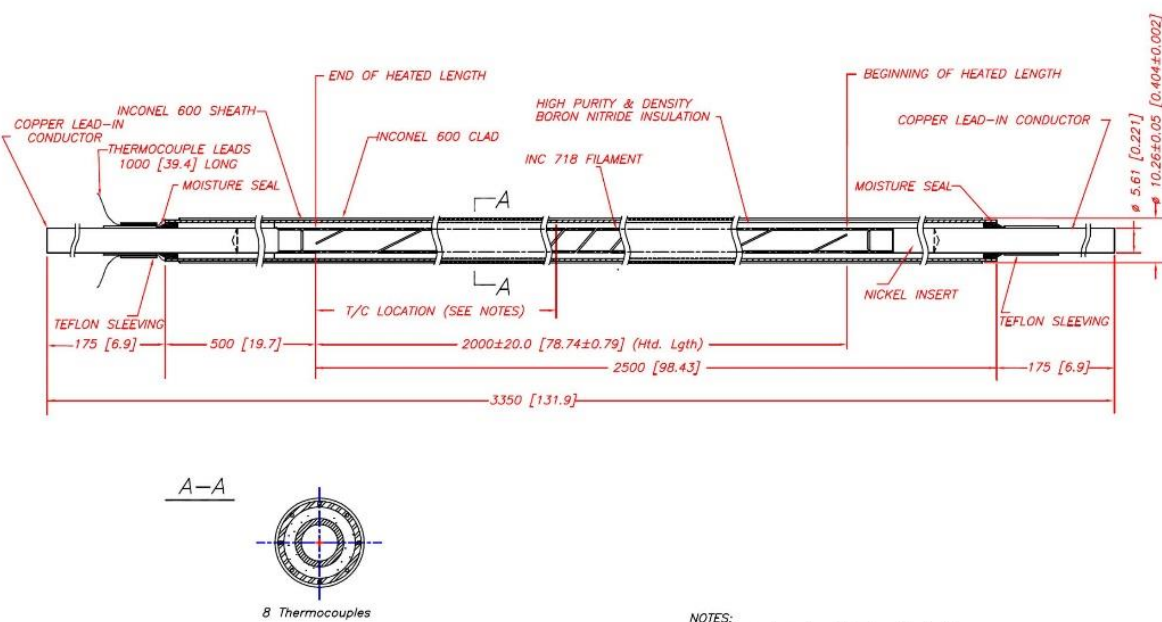

NOTES:
1. Al dimensions in millimeters linches].
2. Upto 10 thermocouples con be embedded in the sheoth as shown. 


\section{Low Pressure System - Instrument Diagram}

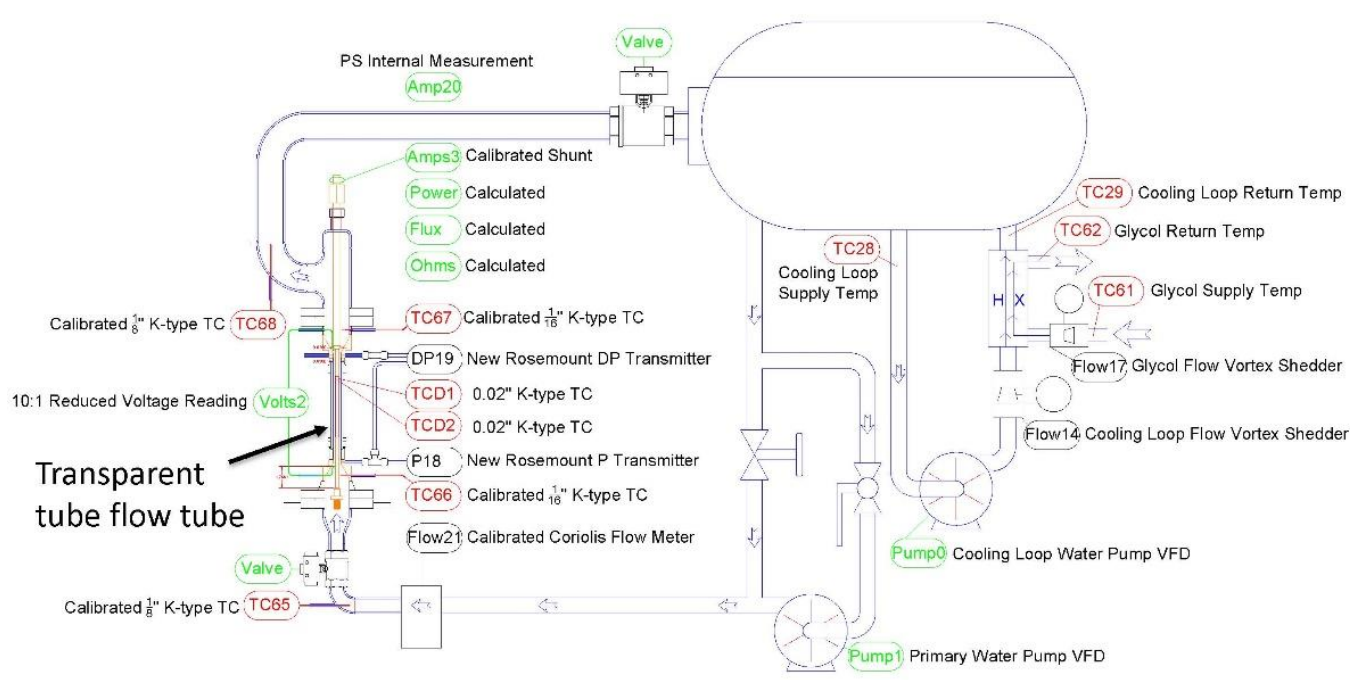

8

Low Pressure System - Flow Boiling
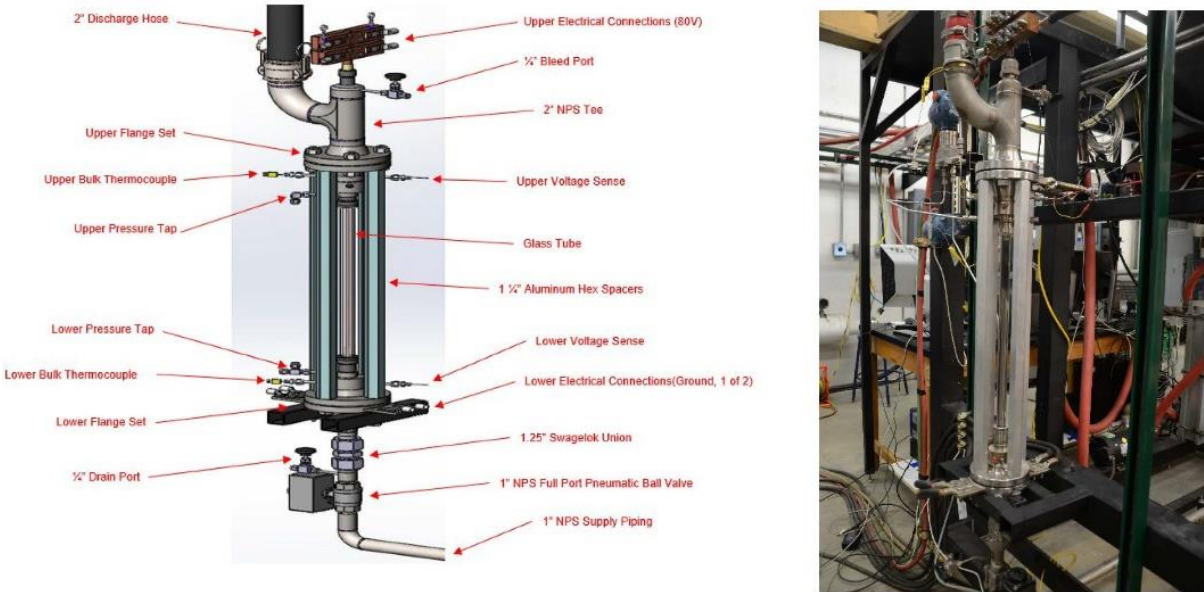

- Simulated fuel pin heated directly via ohmic dissipation

- Steady Uniform heat fluxes up to $2.1 \mathrm{MW} / \mathrm{m}^{2}$ for Zirlo and $3.8 \mathrm{MW} / \mathrm{m}^{2}$ for FeCrAl alloys

- Process data captured w/ LabView DAQ system and LUNA distributed thermal sensing fiber

- High-speed video $(1000 \mathrm{~Hz})$ via Redlake MotionPro and Ametek Phantom cameras 


\section{Test Section Details}

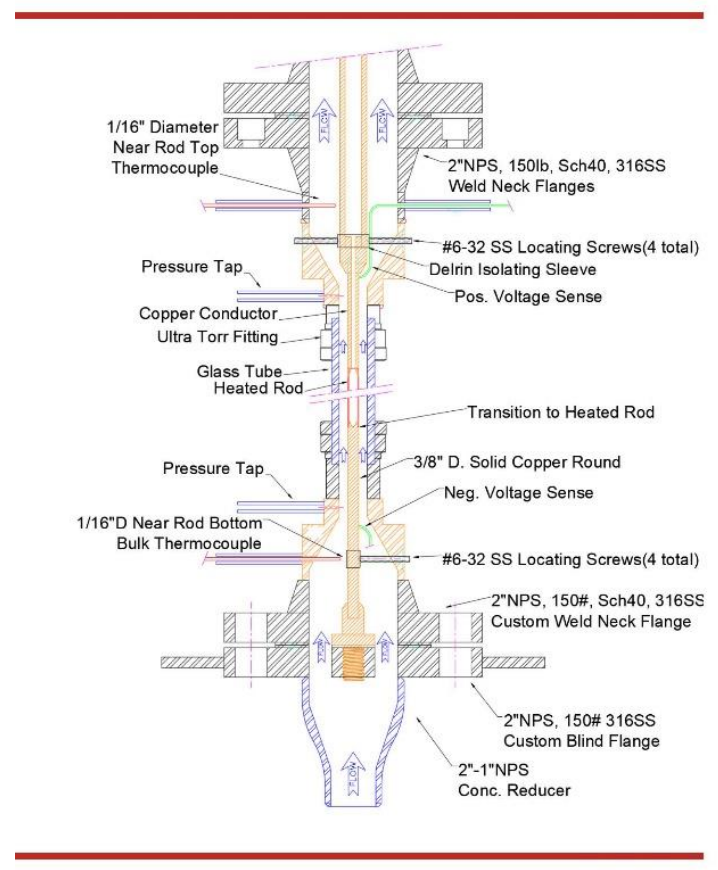

10

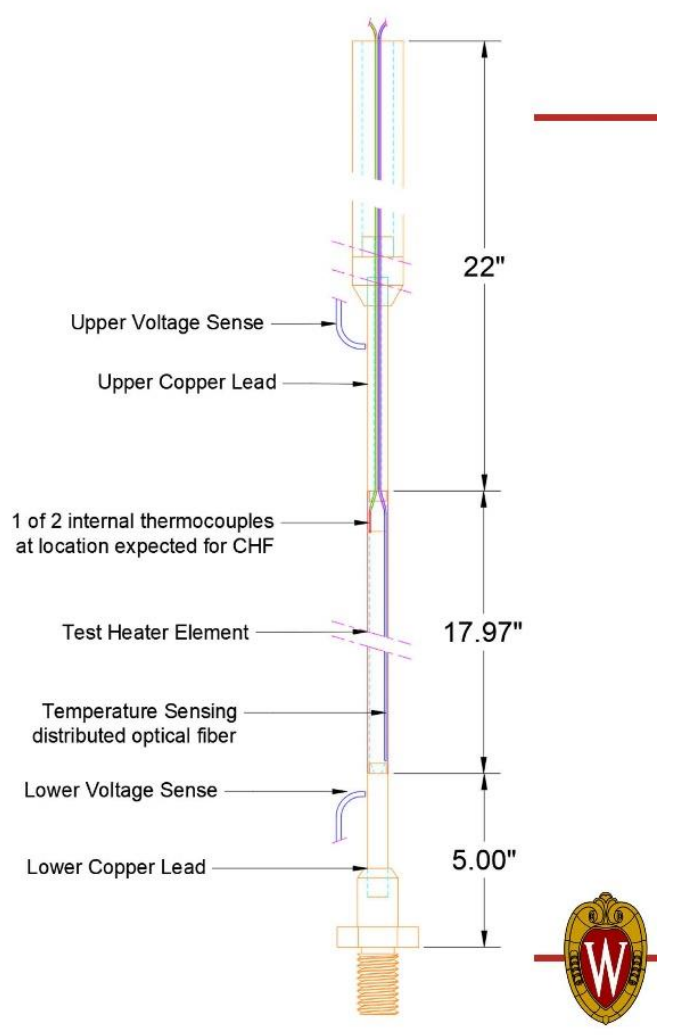

\section{Low Pressure System - Instrumentation}
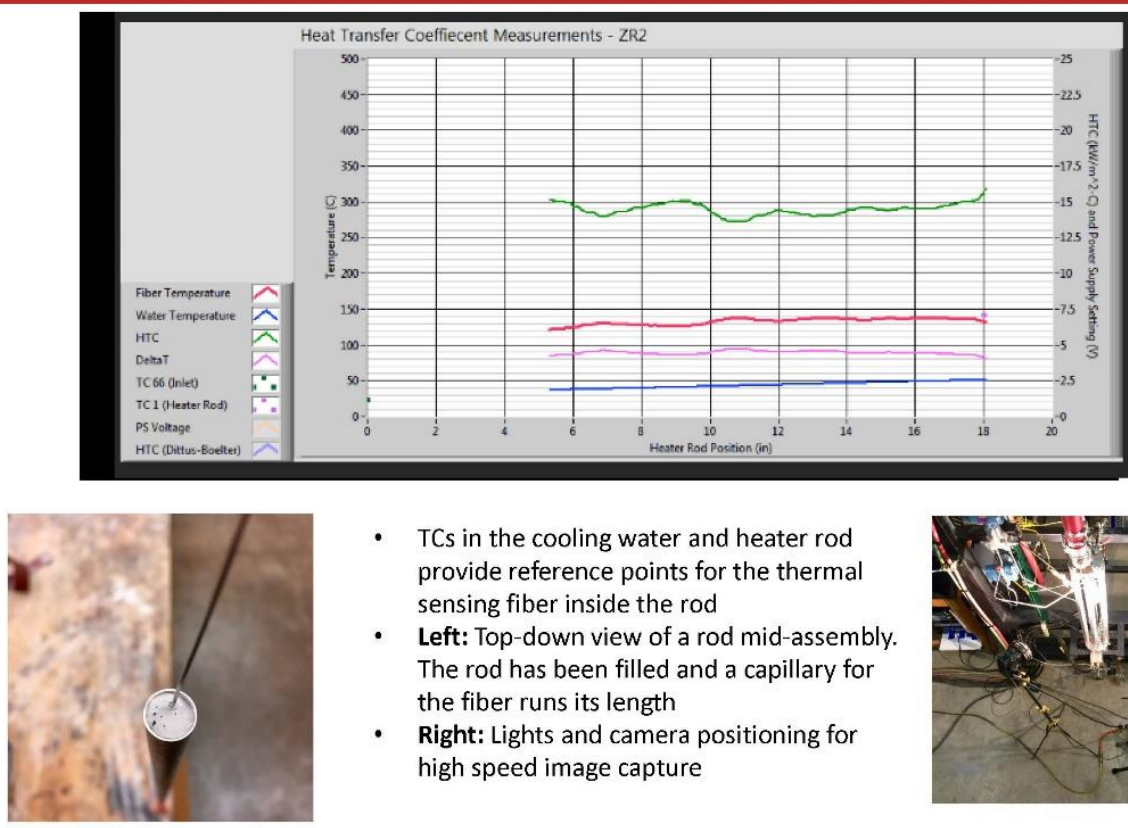

- TCs in the cooling water and heater rod provide reference points for the thermal sensing fiber inside the rod

- Left: Top-down view of a rod mid-assembly The rod has been filled and a capillary for the fiber runs its length

- Right: Lights and camera positioning for high speed image capture

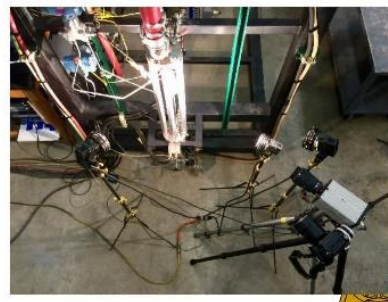




\section{Distributed Thermal Sensing}

- LUNA Systems ODiSI-B fiber interrogator uses Rayleigh backscatter of low energy $(\sim 1550 \mathrm{~nm})$ light to determine temperatures along the length of an optical fiber

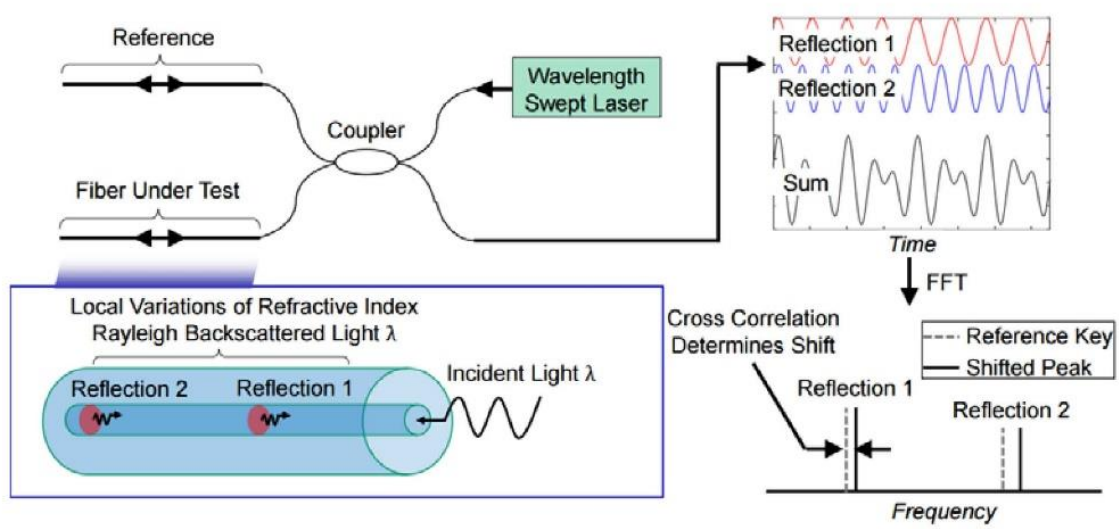

\section{Distributed Thermal Sensing - Reference Key}

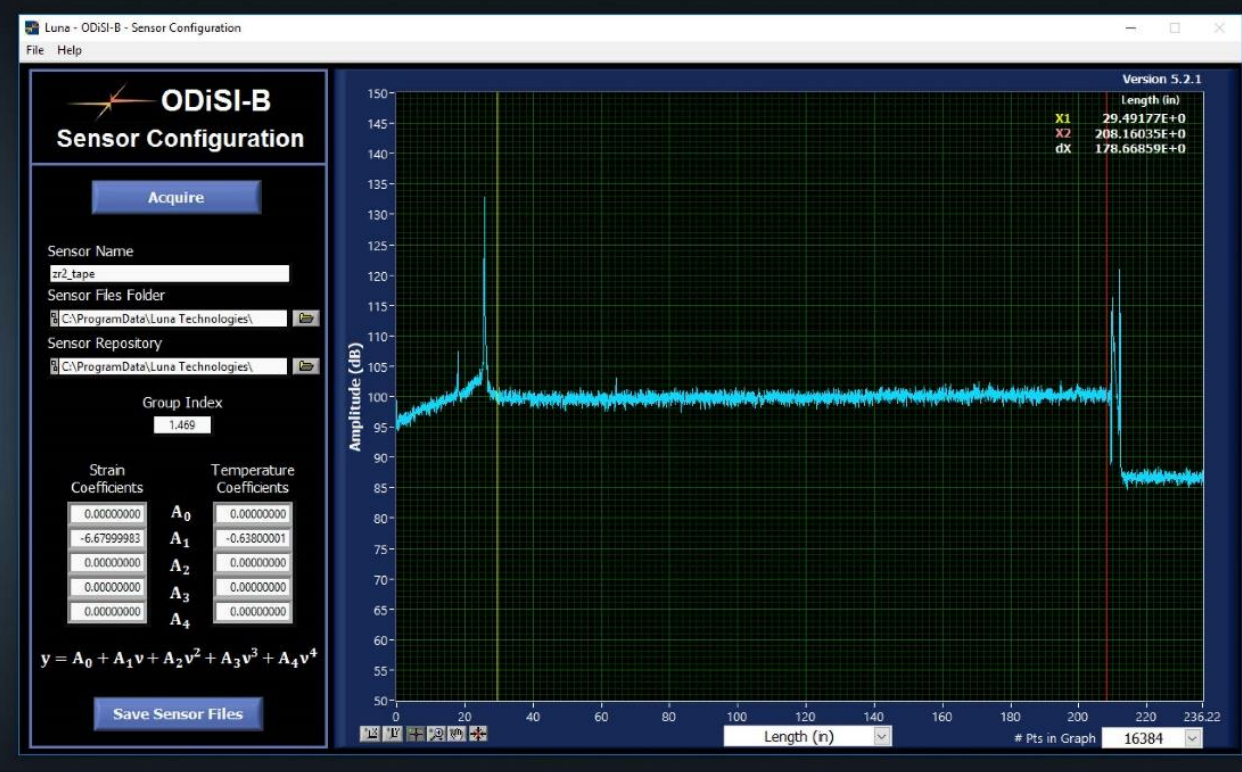


Flow Boiling - Atmospheric Pressure

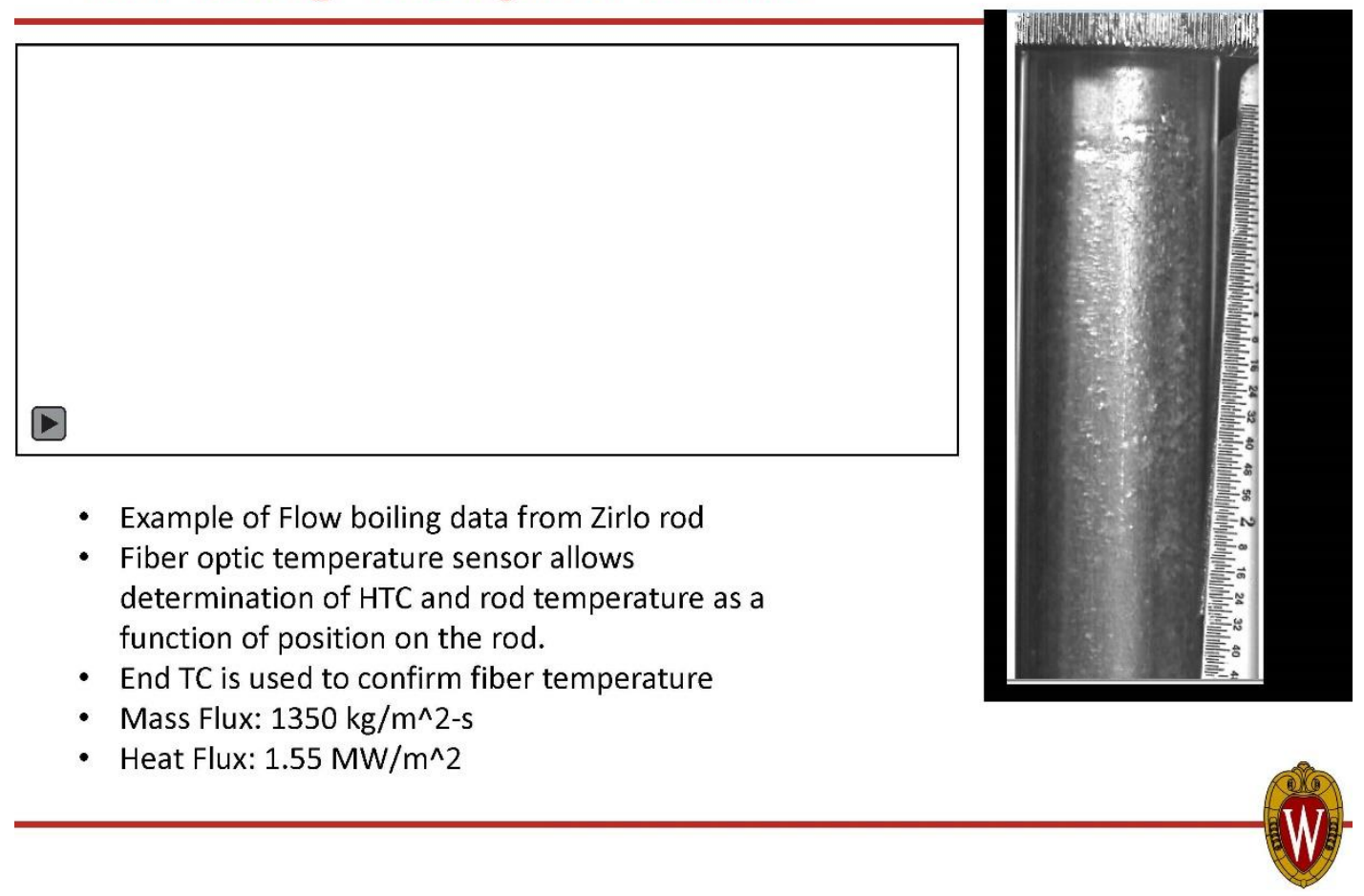

Boiling to CHF - Zirconium Alloy

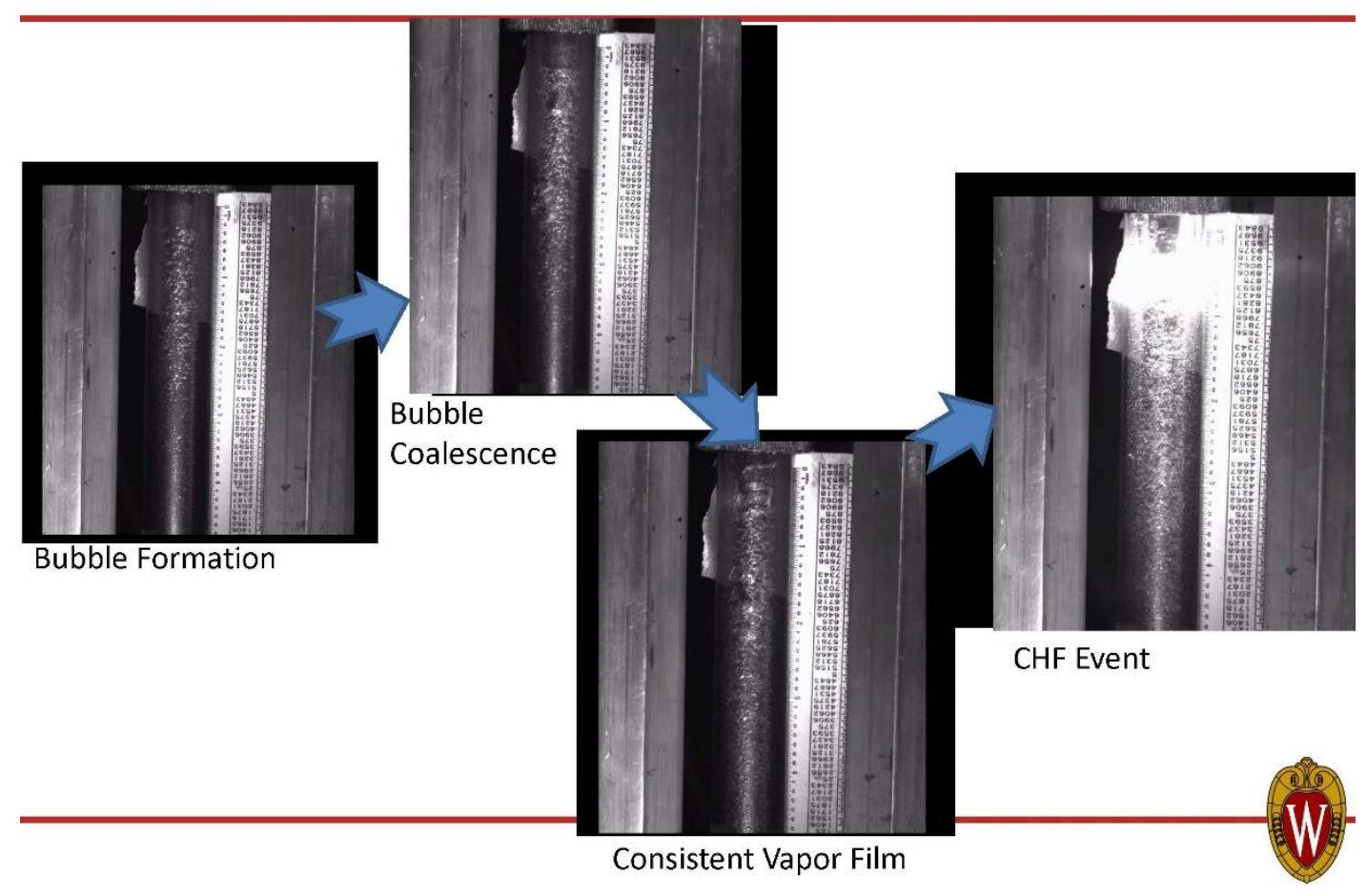




\section{Surface Analysis - ATF Samples}
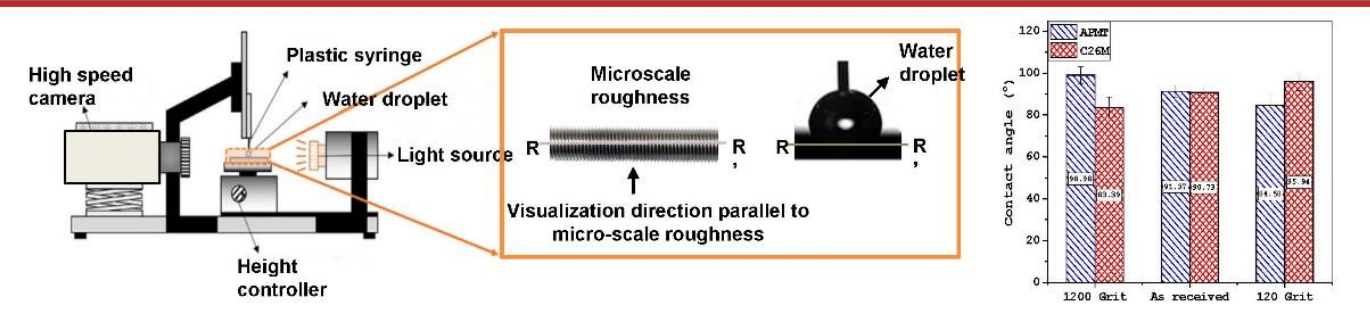

Samples analyzed pre- and post-CHF testing at VCU

- SEM and oxidation measurements

- Surface Roughness

- Wetting angle

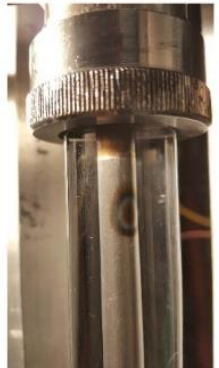

CHF oxidation visible on Incone rod
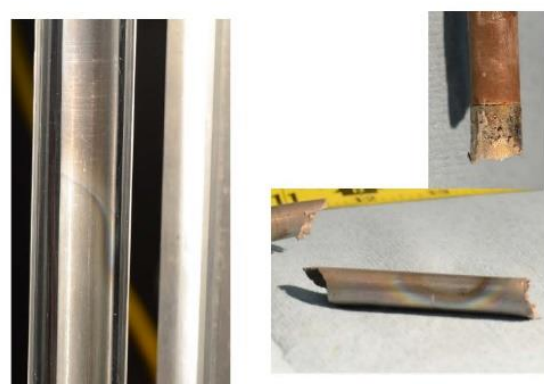

CHF oxidation visible $\mathrm{CHF}$ damage in $\mathrm{FeCrAl}$ rod in top half of image on Zirlo rod

\section{Project Challenges}

- Materials acquisition/properties

- Rare materials

- Resistivity limits for direct heating

- Contact/connection for material heating

- Heater rod assembly

- Preservation of coatings

- Heat generation/transfer within rod

- Instrumentation

- Fiber and TC placement

- Test conditions

- CHF test conditions are harsh

- Heater rod attrition is high 
HTC and CHF Testing - Near and Long Term

- Near term efforts focused on atmospheric pressure testing

- Long term - Internally heated rods for prototypic BWR and PWR testing in high pressure loop

\begin{tabular}{|c|c|c|}
\hline Material & OD & Note \\
\hline$[-]$ & {$[\mathrm{mm}]$} & {$[-]$} \\
\hline Zr Alloys & $10.26,9.6,9.1$ & - \\
\hline Coated Zr Alloys & $9.6,9.1$ & PVD and Cold Spray \\
\hline FeCrAl Alloys & 10.26 & APMT and C26M \\
\hline SiC Ceramics & 9.6 & - \\
\hline
\end{tabular}

\begin{tabular}{|c|c|c|c|c|}
\hline Experiment Conditons & Heat Flux & Mass Flux & Profile & Data Collected \\
\hline$[-]$ & {$\left[\mathrm{MW} / \mathbf{m}^{\wedge} \mathbf{2}\right]$} & {$\left[\mathrm{kg} / \mathbf{m}^{\wedge} \mathbf{2}-\mathrm{s}\right]$} & {$[-]$} & {$[-]$} \\
\hline Atmospheric & $0-2,0-4^{*}$ & $500-2000$ & Uniform & CHF, HTC, Video \\
\hline BWR & $0-2.5$ & $1000-5000$ & Chopped Cosine & CHF, HTC \\
\hline PWR & $0-2.5$ & $1000-5000$ & Chopped Cosine & CHF, HTC \\
\hline
\end{tabular}

\section{Summary}

- Working with MIT, VCU, and industry partners, UW has developed testing methods for heater rods using ATF materials at atmospheric pressure and BWR/PWR conditions

- Heat transfer information and boiling/bubble formation have been captured in low pressure test section for materials available

- BWR/PWR reactor tests will use proven Stern Labs design to mimic cosine power profile and provide meaningful data on ATF materials performance 
Thank you

- Questions 


\section{Appendix D}

\section{Wettability of ATF Cladding Materials in Nuclear-Reactor Conditions}




\section{Appendix D}

\section{Wettability of ATF Cladding Materials in Nuclear-Reactor Conditions}

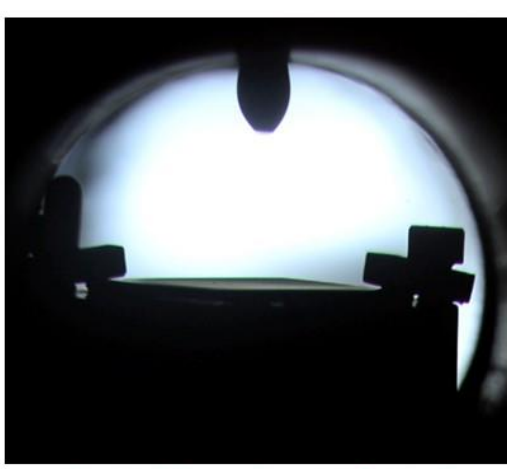

Droplet falling on $\mathrm{Cr}$-coated $\mathrm{Z} r-4$ surface at 6.7 bar $\left(\approx 163^{\circ} \mathrm{C}\right)$ at $25 \mathrm{fps}$
Wettability of ATF cladding materials in nuclear reactor conditions

A. Jena, A. Kossolapov, B. Phillips, M. Bucci

G.Y. Su presents on behalf of A. Jena

Massachusetts Institute of Technology

Department of Nuclear Science and Engineering 


\section{Motivation}

- The surface characteristics have shown to greatly impact both pool and flow boiling heat transfer coefficient and CHF

- There is almost no data available for both the $\mathrm{Zr}-4$ and the candidate ATF cladding materials beyond the atmospheric conditions, nor in a saturated steam environment

\section{Objective}

- Atmospheric Pressure to Critical Pressure (221.1 bar/3206.8 psi, $374^{\circ} \mathrm{C} / 705.2^{\circ} \mathrm{F}$ )

- Saturated Steam Environment

- Static, advancing, and receding contact angle 


\section{Methodology: Contact Angle Facility}

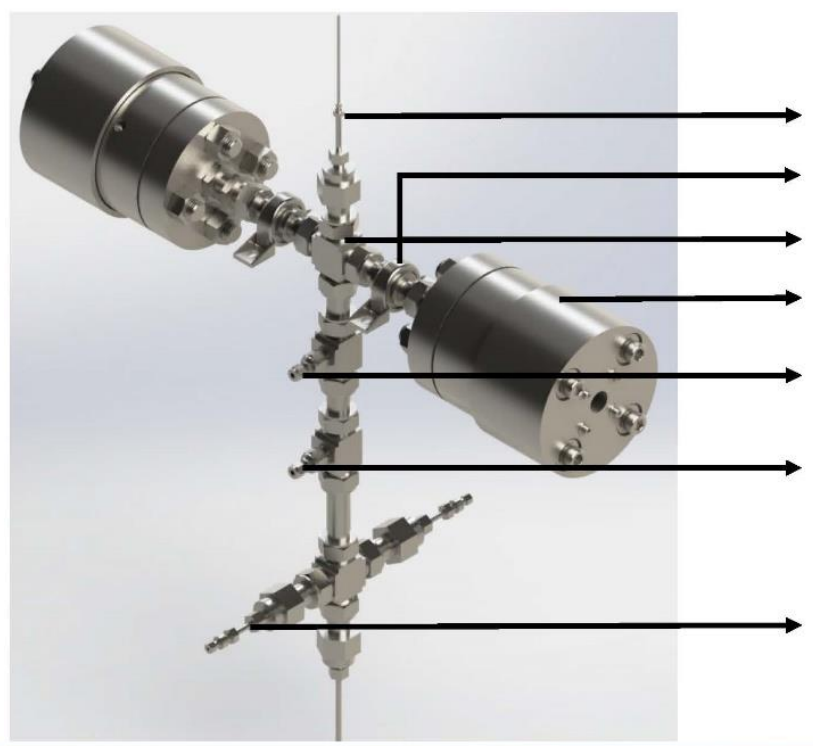

\section{Test Section}

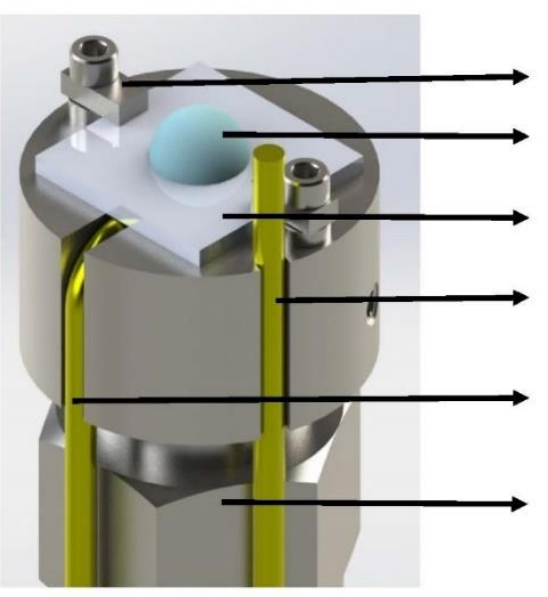




\section{Test Section}
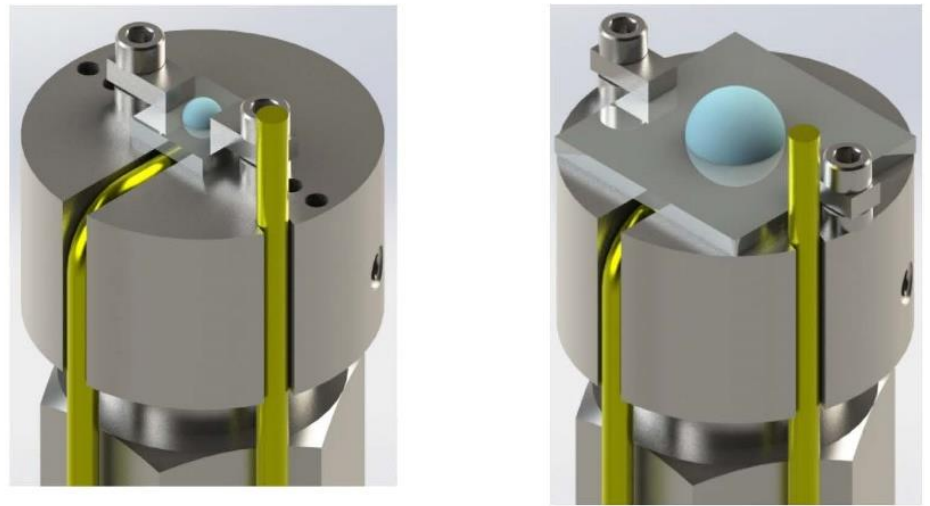

Experimental Facility
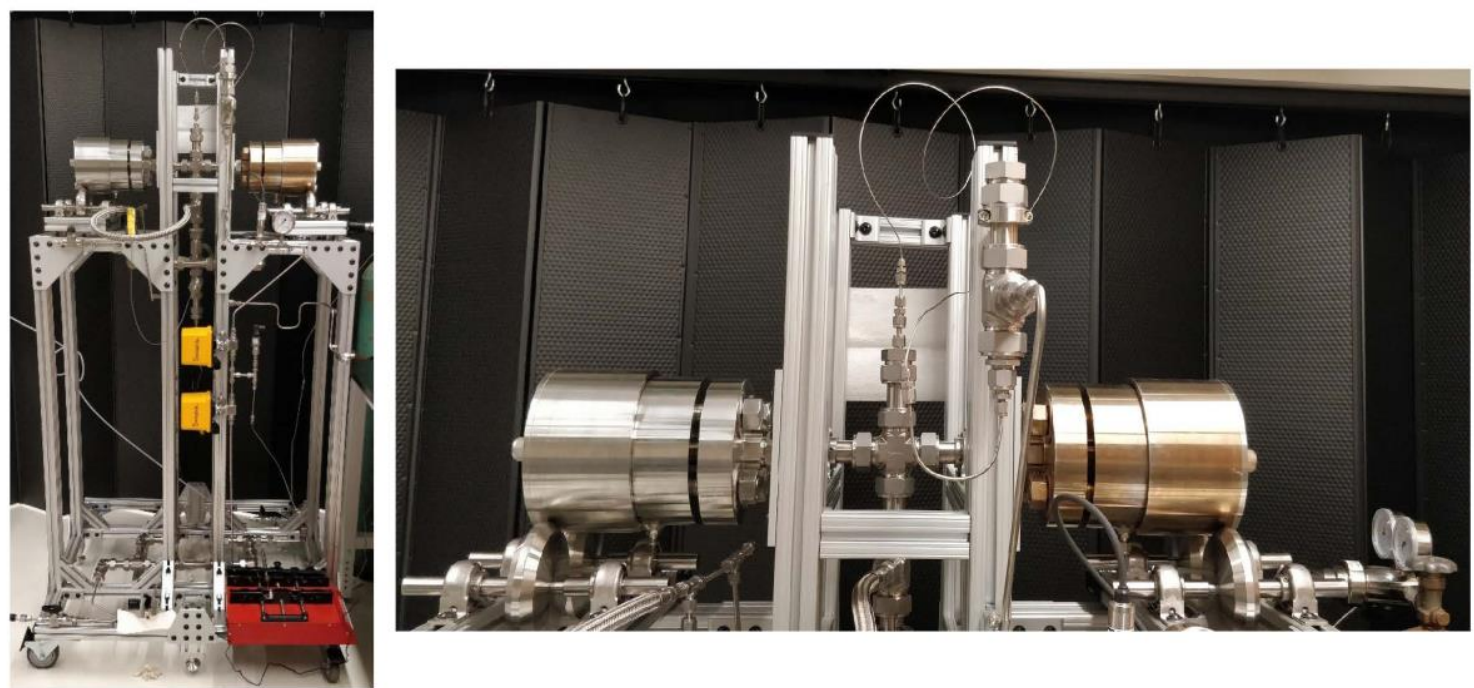


\section{Sample Preparation}

- Before each test, the sample is solvent cleaned in sonicated bath using soapy water, DI water, Acetone, Ethanol and DI water in the respective order and mounted on the stage

\section{Tests and Data Processing (Step 1)}
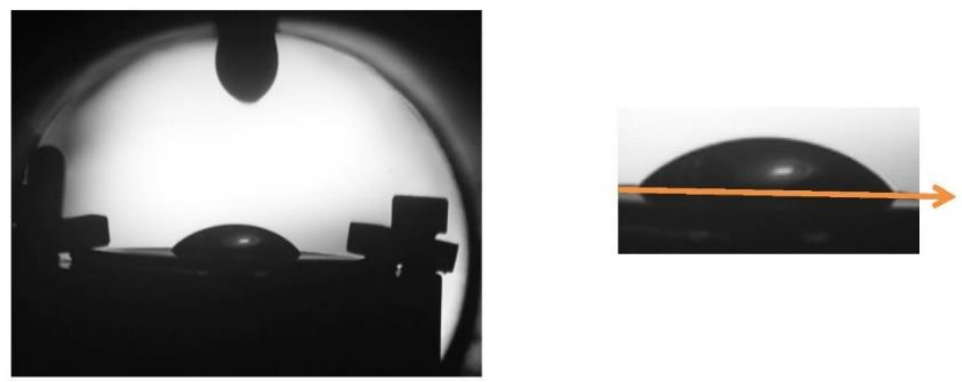


\section{Tests and Data Processing (Step 2)}

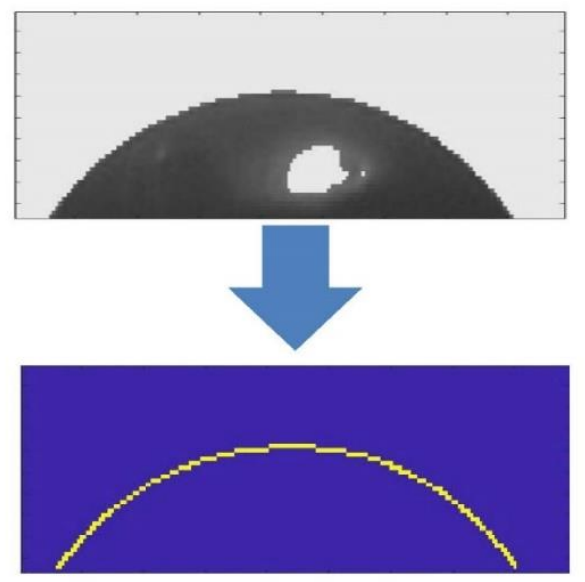

\section{Tests and Data Processing (Step 3)}

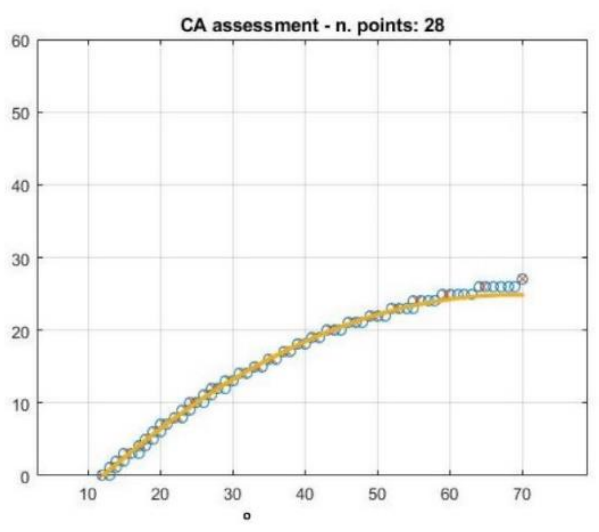




\section{Test Matrix}

\begin{tabular}{l|l|}
\multicolumn{1}{|c|}{ Material } & \multicolumn{1}{c|}{ Surface Finish } \\
\hline Fresh Zr-4 & As machined \\
\hline Fresh Zr-4 & Mirror Polished \\
\hline Oxidized Zr-4 & \\
\hline Cr-coated Zr-4 & Mirror Polished \\
\hline Monolithic SiC & As machined \\
\hline FeCrAl & Mirror Polished \\
\hline
\end{tabular}

- Tests were conducted from ambient condition to PWR pressure and temperature

\section{Fresh Zr-4 As Machined}

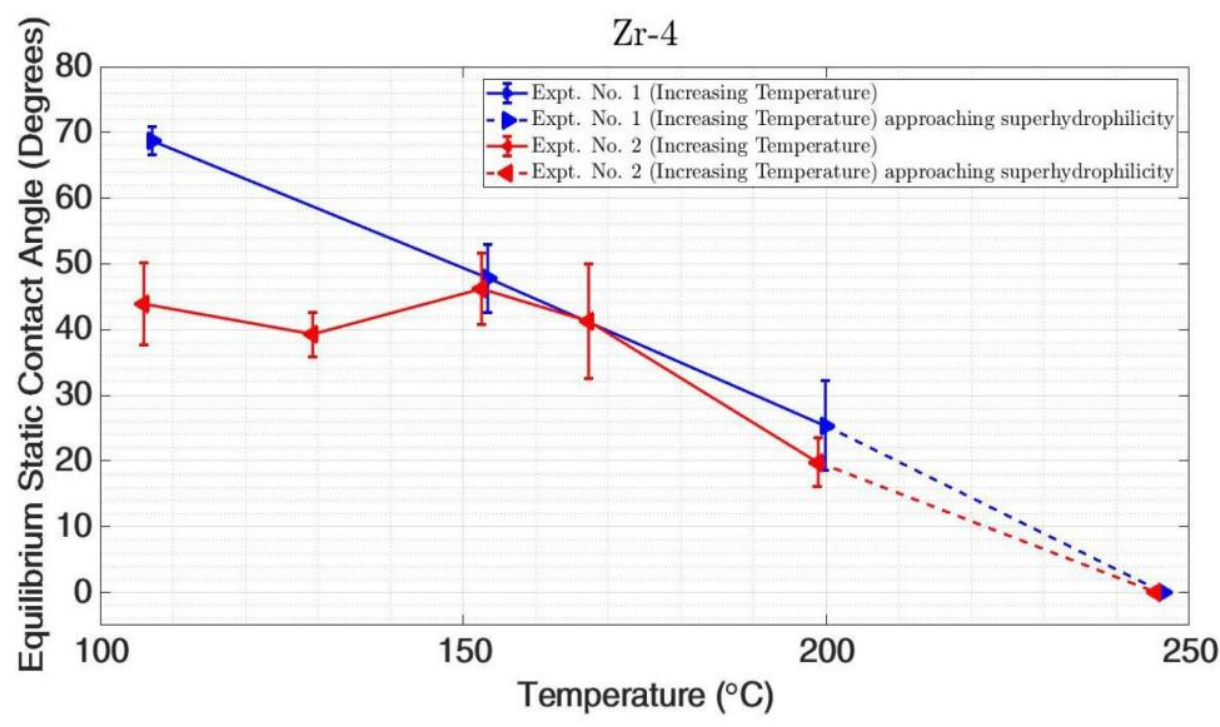




\section{Mirror Polished Fresh Zr-4}

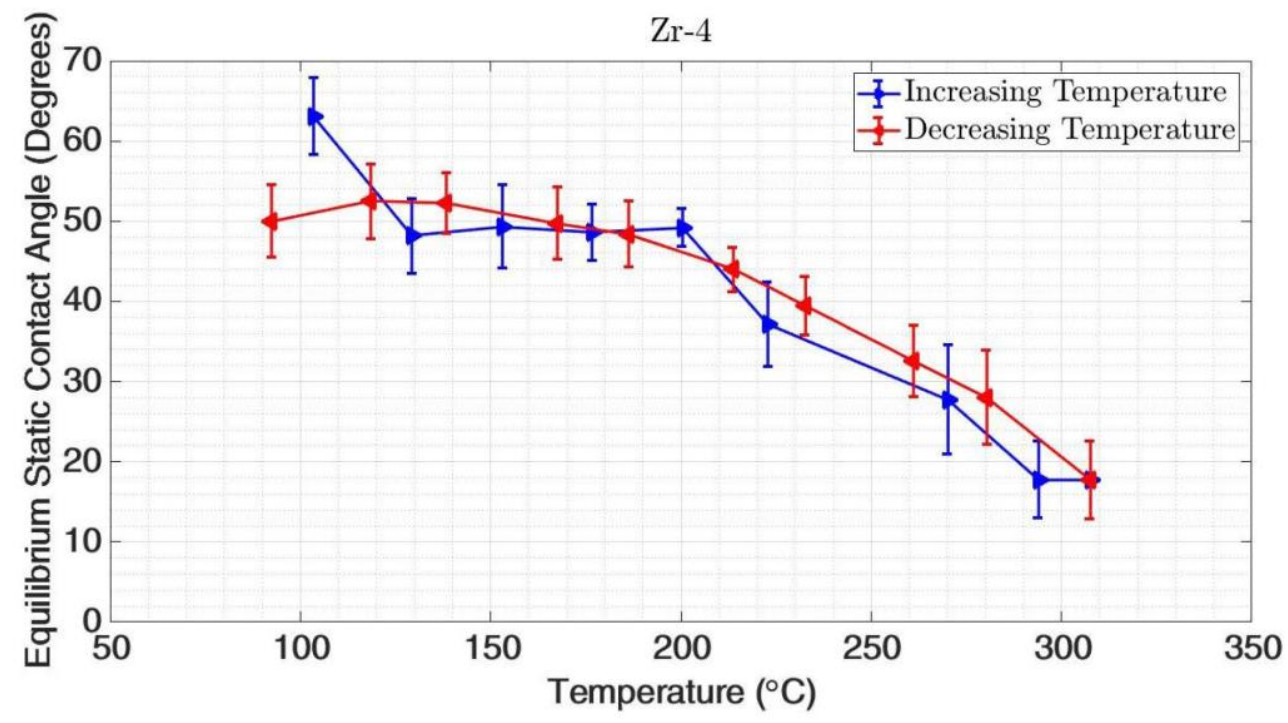

\section{Oxidized Zr-4}

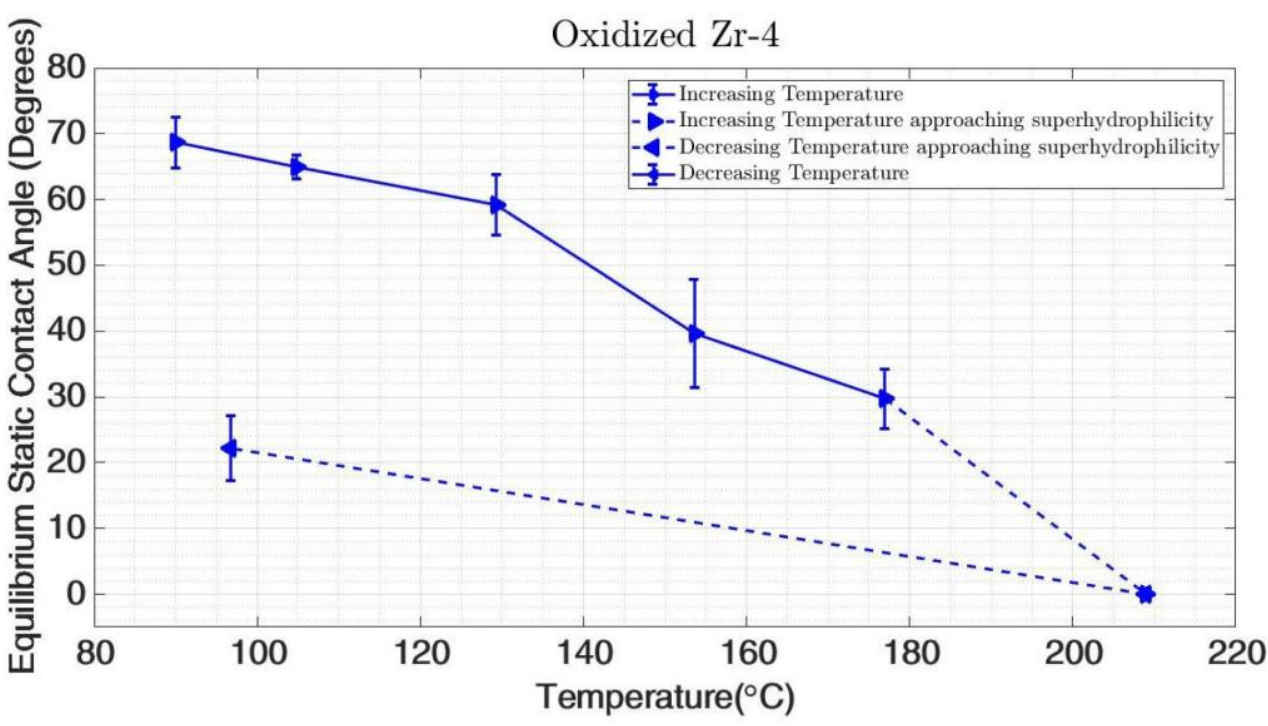




\section{Monolithic SiC As Machined}

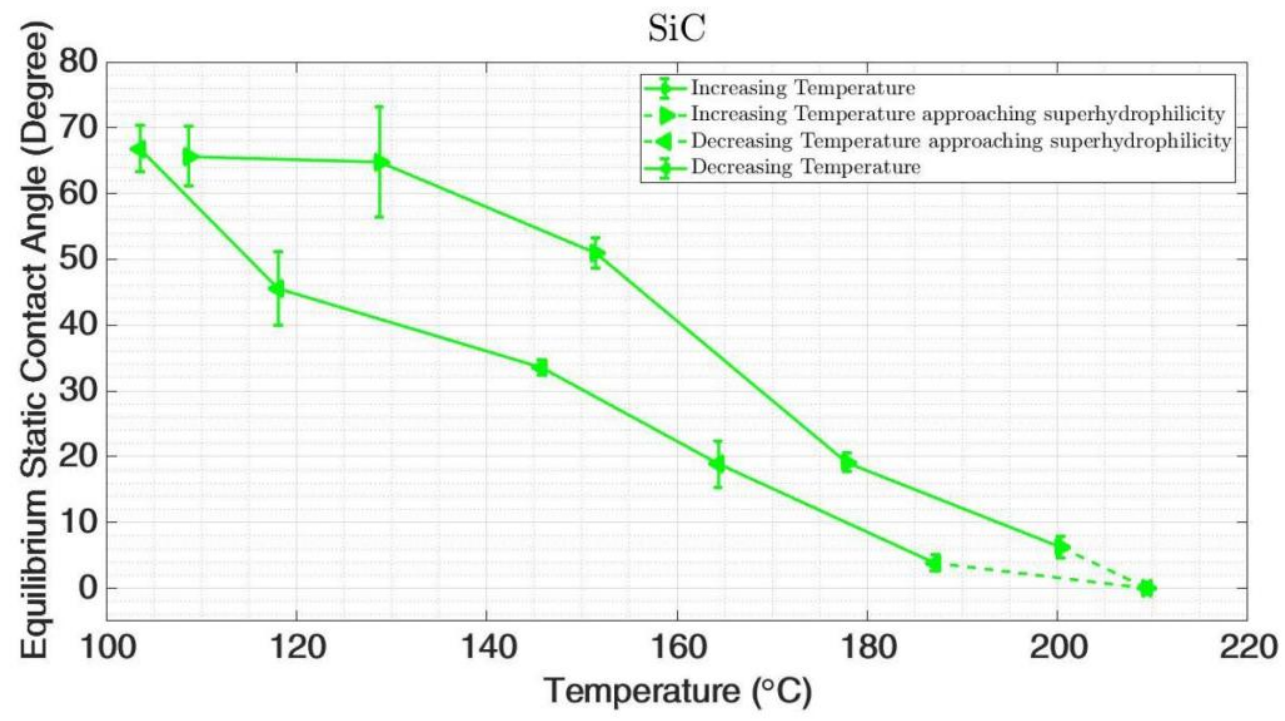

\section{FeCrAl Mirror Polished}

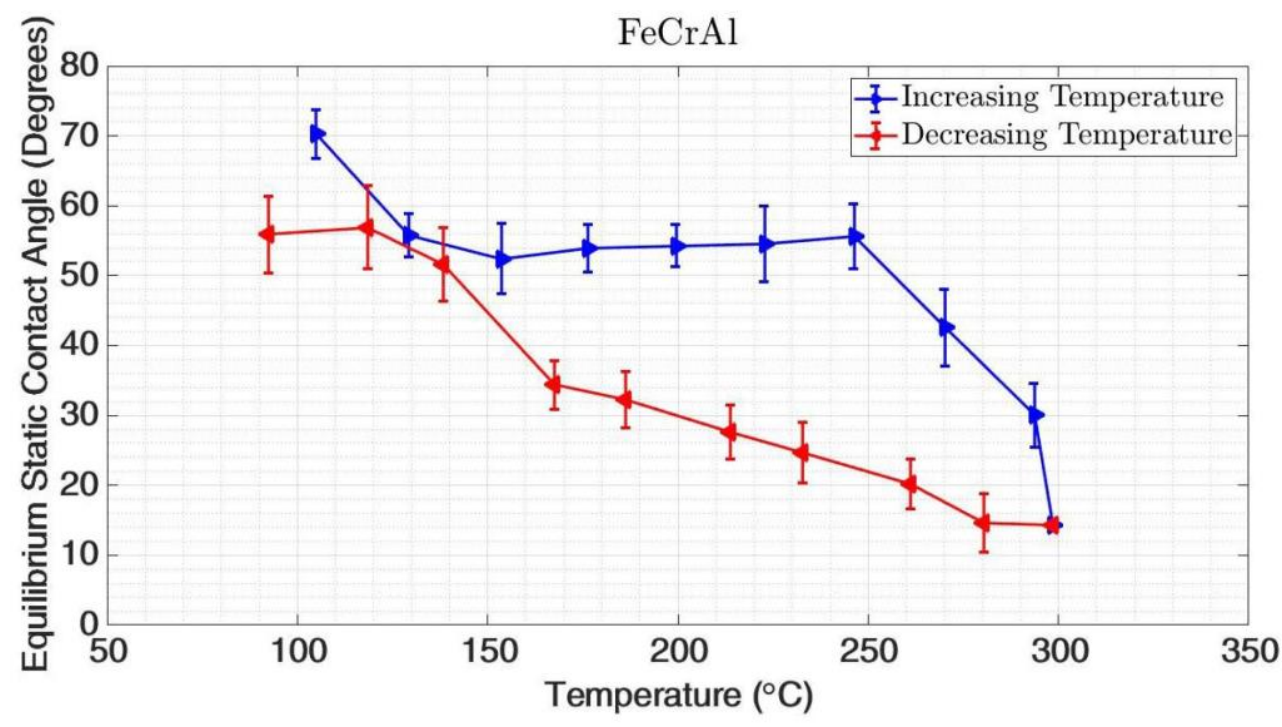




\section{Conclusion}

- Contact Angle decreases with increasing temperature (in some cases the sample attains superhydrophilicity)

- Roughness and oxication plays an important role in wettability

- Samples get oxidized or corroded at high temperature, and thus may bias the trend

- Repeat measurements on samples with no clear trend

\section{Future Work}

Near term:

- Compare data with existing models

- Quantify the effect of roughness on the trend of contact angle

- Figure out the hysteresis (lower contact angle while going down in temperature) and repeat measurements

Long term:

- Measure advancing/receding contact angles

- Measure contact angle of other relevant materials 


\section{Appendix E}

\section{Sensitivity of Critical Heat Flux for ATF FeCrAl Alloy Using RELAP5-3D and RAVEN}




\title{
Appendix E
}

\section{Sensitivity of Critical Heat Flux for ATF FeCrAl Alloy Using RELAP5-3D and RAVEN}

\author{
Sensitivity of Critical Heat Flux for \\ ATF FeCrAl Alloy using RELAP5-3D \\ and RAVEN \\ Jacob Gorton \\ Nicholas Brown \\ TENNESSEE \\ KNOXVILLE
}




\section{Introduction}

- Iron-Chromium-Aluminum ( $\mathrm{FeCrAl}$ ) alloys are potential candidates for replacing zirconium alloys in LWRs as part of the Accident Tolerant Fuel (ATF) program

- Experimental data from a flow-boiling apparatus at the University of New Mexico (UNM) show large discrepancies between measured critical heat flux (CHF) and CHF predicted using the systems code RELAP5-3D

- Code-to-experiment discrepancies in post-CHF tube temperatures also observed

- Sensitivity studies were performed to understand the sensitivity of $\mathrm{CHF}$ and the post-CHF temperature excursion to heat transfer coefficients, material thermophysical properties, and a CHF multiplier

- Sensitivity studies were performed using a RELAP5-3D model of the UNM experiment and the uncertainty quantification code RAVEN

\section{Objectives}

This study has 3 main objectives:

1. To compare best-estimate CHF and temperature predictions from a widely used system analysis code to a simple, well-understood CHF test for an ATF candidate material

2. To enhance understanding of the sensitivity of these models to the shape of the boiling curve and thermophysical properties of the test section

3. To demonstrate an approach to optimize CHF and post-CHF model predictions while highlighting differences between how $\mathrm{CHF}$ is modeled and what occurs in reality 


\section{Experiment Description}

- Low-pressure transient testing performed at UNM using water as the working fluid

- Vertically oriented FeCrAl tubes were placed in the internal flow boiling loop shown

- Test sections were thermally insulated on the outer surface

- Voltage transducers imposed a transient power curve on the tubes similar to a subprompt, hot full power RIA power curve

- A fast-response K-type thermocouple located at the axial center of the tube was used to measure outer surface temperature

- Measured power and temperature were used to calculate inner surface temperature and heat flux

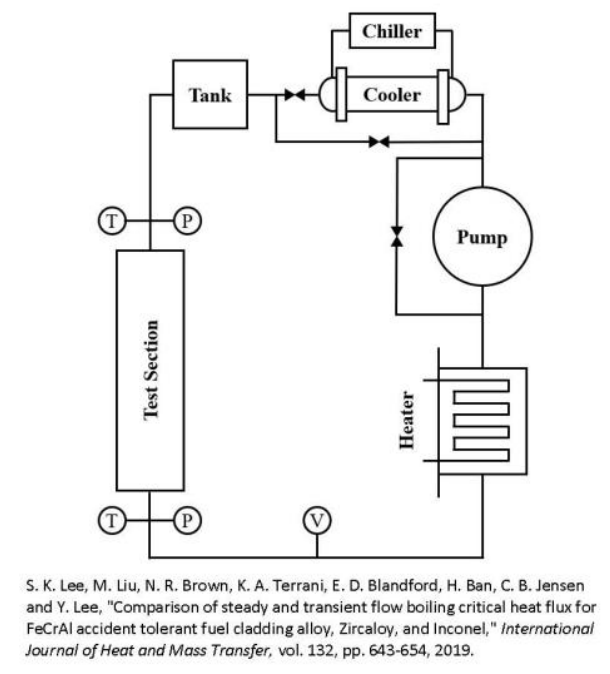

THe

\section{RELAP5-3D Model Description}

- The test section portion of the experiment was modeled in RELAP5-3D using the coolant temperature, pressure, and mass flow rate initial conditions controlled in the experiment

- Model consists of a time-dependent volume, time-dependent junction, the FeCrAl pipe and attached heat structure to apply the power curve, a single junction, and a sink volume

- 50 nodes are used in both the pipe and the heat structure, which has been shown to provide stable results through mesh sensitivity studies

- Thermophysical properties of FeCrAl were used in the model

- Both thermal conductivity and specific heat capacity varied with temperature according to measurements taken at Oak Ridge National Laboratory
170

\begin{tabular}{|l|}
\hline \multirow{1}{*}{$\uparrow 160$} \\
\hline \\
\hline \\
\hline 150 \\
\hline \\
\hline \\
\hline \\
\hline \\
\hline 140
\end{tabular}

130
Model nodalization diagram, geometry, and initial conditions

\begin{tabular}{cc}
\hline Inner Diameter (in.) & 0.345 \\
Outer Diameter (in.) & 0.375 \\
Total Length (in.) & 20 \\
Entrance Length (in.) & 10 \\
Heated Length (in.) & 2 \\
Pressure (kPa) & 84 \\
Mass Flux (kg/m ${ }^{2}$-s) & 300 \\
Inlet Coolant Temperature $\left({ }^{\circ} \mathrm{C}\right)$ & 90 \\
\hline
\end{tabular}

TEMNNESSE: 


\section{Base RELAP5-3D Model Results}

- Experimental results for the measured input power, tube surface temperature, and calculated heat flux are shown and compared to the RELAP5-3D results

- Compared to the experiment and for the same input power curve, RELAP5-3D predicted:

- smaller CHF (2.1 MW/m² vs 3.7 $\mathrm{MW} / \mathrm{m}^{2}$ )

- narrower heat flux pulse width

- greater peak cladding temperature (PCT) $\left(1361^{\circ} \mathrm{C}\right.$ vs $\left.856^{\circ} \mathrm{C}\right)$

- Discrepancies serve as motivation behind performing sensitivity studies

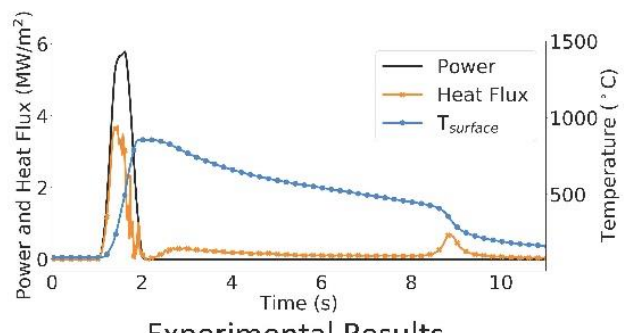
Experimental Results

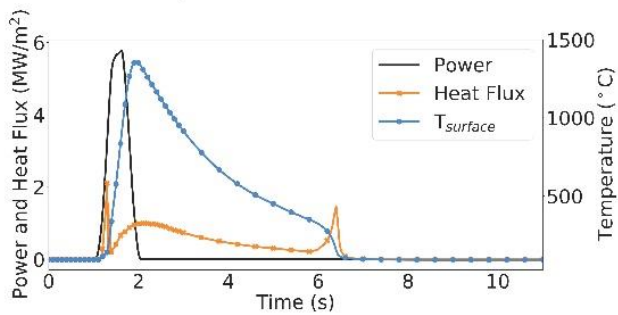

RELAP5-3D Results

\section{Coupling of RAVEN and RELAP5-3D}

- Risk Analysis and Virtual Environment (RAVEN) is an uncertainty quantification tool developed by Idaho National Laboratory

- Used to vary heat transfer coefficient multipliers and CHF multiplier in the first sensitivity study and thermal conductivity $(k)$, volumetric heat capacity $(\rho C p)$, and CHF multiplier in the second sensitivity study

- RAVEN acts as a driver to simultaneously vary the desired values in the RELAP5 input deck

- Emphasis is placed in this presentation on the second sensitivity study involving $k, \rho C p$, and CHF multiplier 


\section{Sensitivity Study Methodology}

- $\quad C p$ and $k$ were varied within the uncertainties of the measurements taken at ORNL

- $\rho$ was varied within the theoretical limit of possible densities using

$\rho=1 / \sum x_{i} / \rho_{i}$ and $\rho=\sum x_{i} \rho_{i}$, where $x_{i}$ is the weight fraction of each constituent in an alloy and $\rho_{i}$ is the density of each constituent

- CHF multiplier was varied from 1.0 to 2.0 based on experimental data that showed that transient CHF may be as much double the CHF predicted in steady-state conditions

- Each parameter was varied uniformly within the uncertainty ranges provided by their respective sources

- Impact on CHF and the maximum tube temperature, analogous to PCT in a reactor, was considered
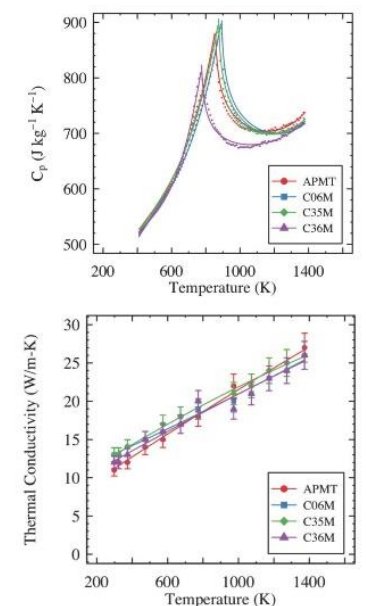

K. G. Field, M. A. Snead, Y. Yamamoto and K. A. Terrani, "Handbook on the Material Properties of FeCrAl Alloys for Nuclear Power Production Applications," ORNL/TM2017/186, 2017

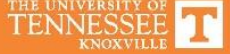

\section{Sensitivity of CHF to Material Properties and CHF Multiplier}
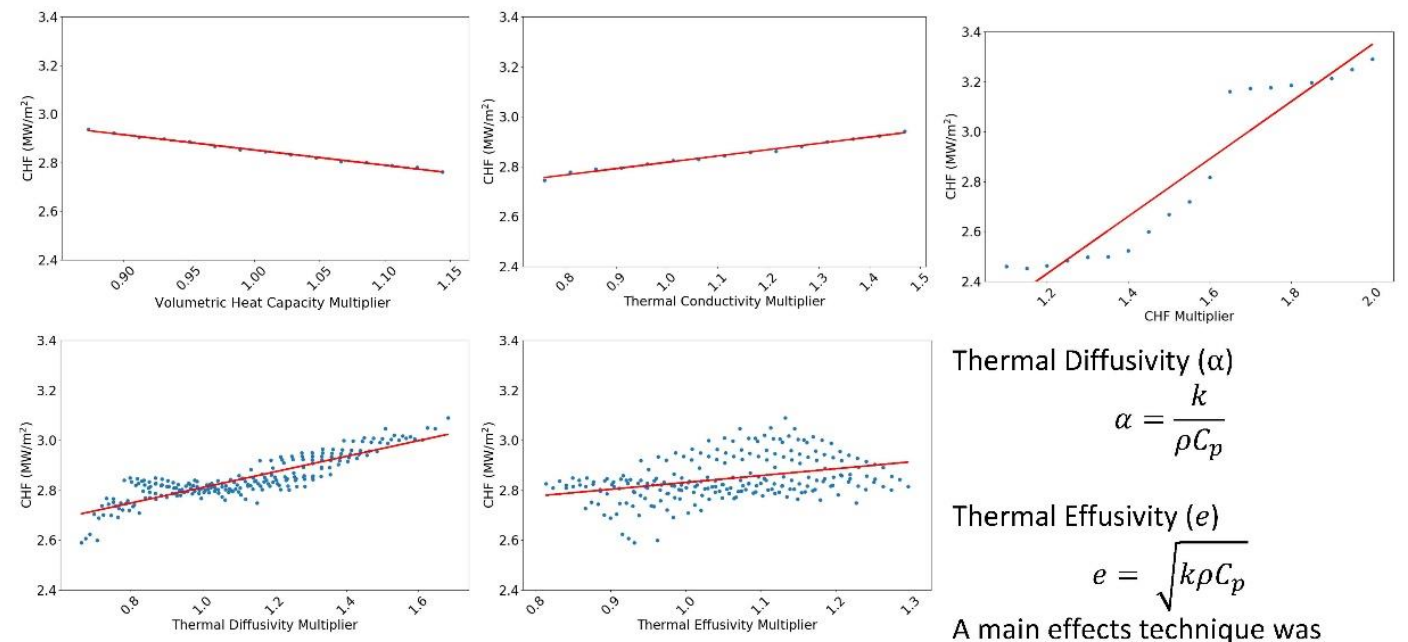

Thermal Diffusivity $(\alpha)$

$$
\alpha=\frac{k}{\rho C_{p}}
$$

Thermal Effusivity $(e)$

$$
e=\sqrt{k \rho C_{p}}
$$

A main effects technique was used in which the output for a single variable was averaged across all other variables 


\section{Sensitivity of PCT to Material Properties and CHF Multiplier}
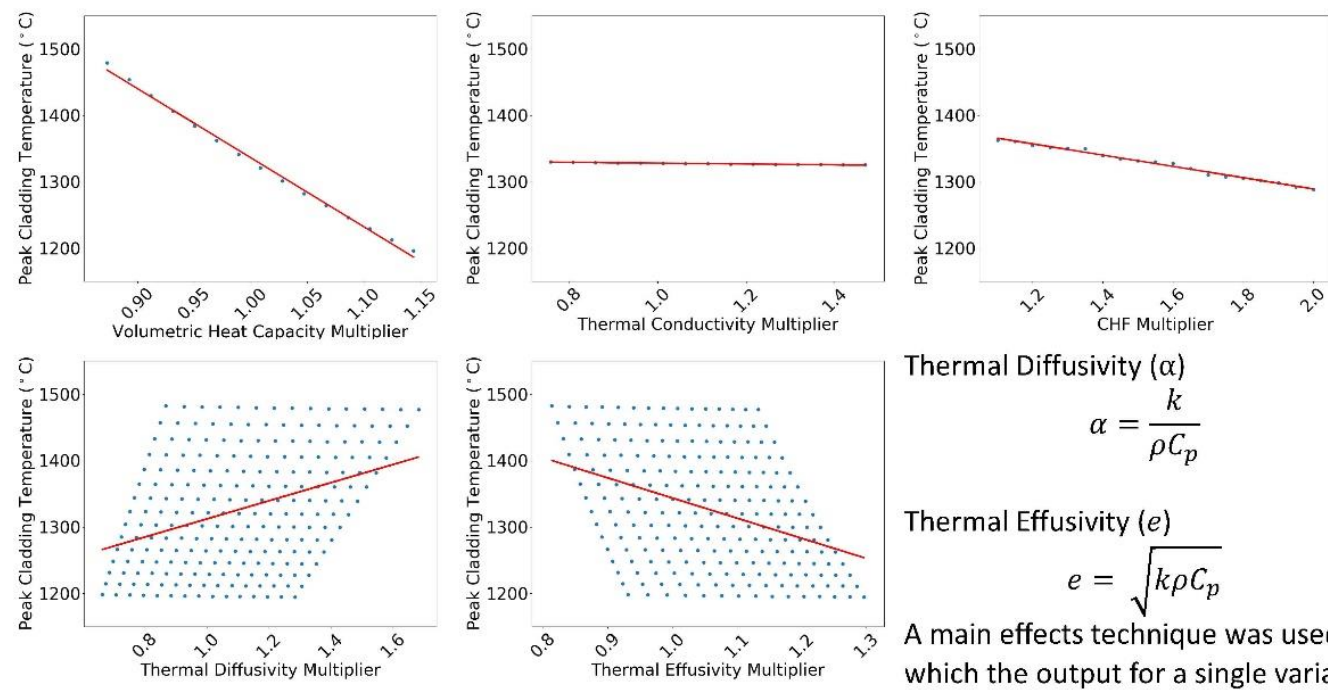

Thermal Diffusivity $(\alpha)$

$$
\alpha=\frac{k}{\rho C_{p}}
$$

Thermal Effusivity $(e)$

$$
e=\sqrt{k \rho C_{p}}
$$

A main effects technique was used in which the output for a single variable was averaged across all other variables

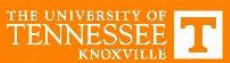

\section{Summary of Material Property and CHF Multiplier Study}

- CHF was sensitive to all parameters and increased with each of them except for the volumetric heat capacity

- PCT was insensitive to thermal conductivity, but was sensitive to each of the other parameters 


\section{Separation of CHF and Maximum}

\section{Heat Flux}

- From the UNM experimental results, it was shown that $\mathrm{CHF}$ was reached at a heat flux value lower than the maximum heat flux (MHF)

- CHF was determined by the increased rate of change of cladding temperature, which indicates DNB

- This observation may be caused by uncertainties in the measurements

- Even if the effect is a product of measurement uncertainty, it is clear that the heat flux stays elevated for a period of time before significantly dropping in the experiment
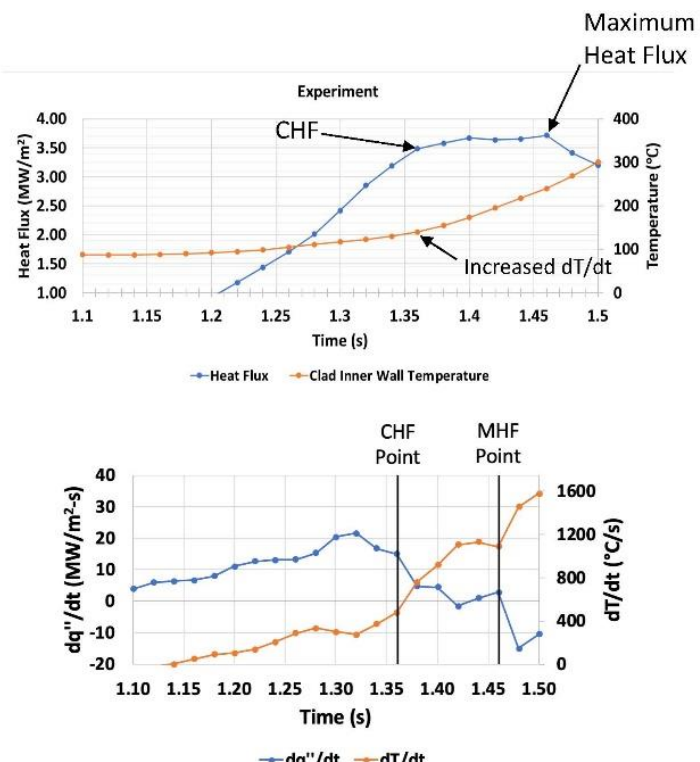

TEN UNESERSEE OR

\section{Separation of CHF and Maximum}

\section{Heat Flux}

- By the classic definition, RELAP assumes CHF and MHF are one in the same, and the heat flux drops immediately and at a much faster rate after $\mathrm{CHF}$ is reached compared to the experiment

- The more drastic drop in heat flux predicted by RELAP after $\mathrm{CHF}$ is reached is a main factor in causing the overprediction of PCT

- Key takeaway: post-CHF phenomena is being modeled differently from what occurs in reality
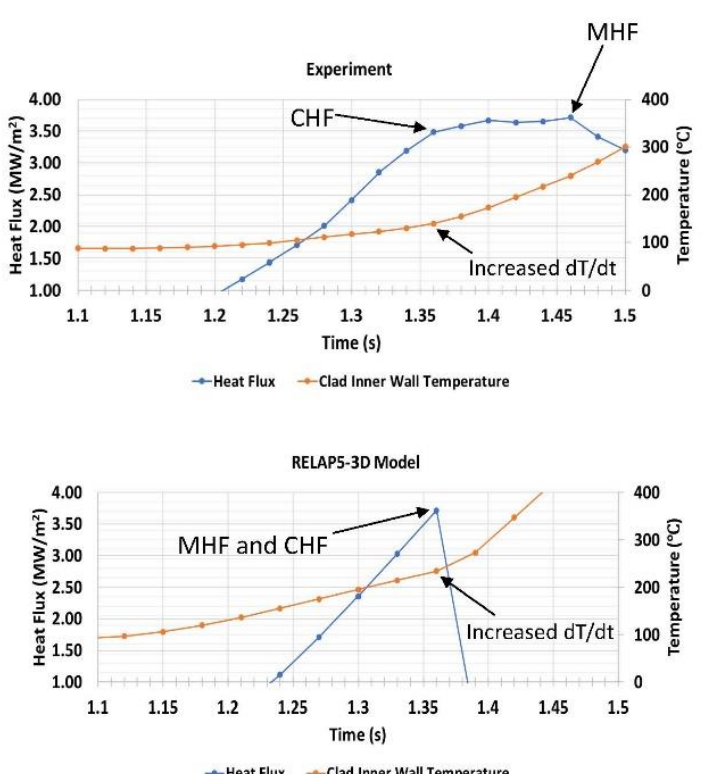

THE UNIYRSSTY OR $\mathbf{T}$ 


\section{Best Match Parameters}

- The combination of parameters from each sensitivity study that provided the best match to the experimental data was determined

- RELAP5 runs with the smallest relative error to the experimental results for each of three figures of merit, MHF, PCT, and integral energy deposition per unit area, were identified

- An overall best match run was identified by finding the run with the minimum RMS value of the three errors

\section{TENNSSSEE T}

\section{Best Match Parameters - Material Property and CHF Multiplier Study}

- The runs with the minimum relative error from the experimental data in terms of MHF, PCT, and integral heat flux were identified

- The run with the minimum RMS of the three error values was also identified Parameters used in Run \#4155 (RMS error of $27.10 \%$ )

\begin{tabular}{cc}
\cline { 2 - 2 } Parameter & Value \\
\cline { 2 - 3 } k multiplier & 1.06 \\
$\rho \mathrm{C}_{\mathrm{p}}$ multiplier & 1.14 \\
$\boldsymbol{e}$ multiplier & 1.10 \\
$\alpha$ multiplier & 0.93 \\
$\mathrm{CHF}$ multiplier & 2.0 \\
\hline & \\
\hline Figure of Merit & Relative Error (\%) \\
\hline MHF & 1.24 \\
PCT & 27.02 \\
Energy Deposition & 1.70 \\
\hline
\end{tabular}

\begin{tabular}{cc}
\cline { 2 - 2 } Parameter & Value \\
\cline { 2 - 3 } k multiplier & 1.06 \\
$\rho \mathrm{C}_{\mathrm{p}}$ multiplier & 1.14 \\
$\boldsymbol{e}$ multiplier & 1.10 \\
$\alpha$ multiplier & 0.93 \\
$\mathrm{CHF}$ multiplier & 2.0 \\
\hline & \\
\hline Figure of Merit & Relative Error (\%) \\
\hline MHF & 1.24 \\
PCT & 27.02 \\
Energy Deposition & 1.70 \\
\hline
\end{tabular}
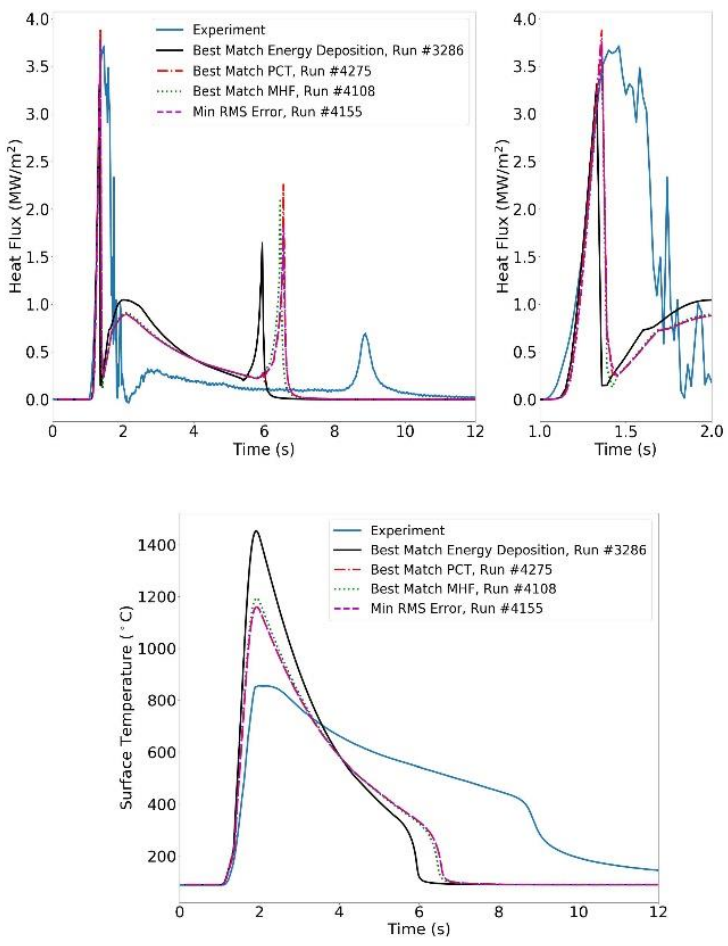


\section{Summary and Conclusions}

- Two parametric studies were performed to determine the impact of heat transfer coefficients, material thermophysical properties, and a $\mathrm{CHF}$ multiplier on CHF and PCT

- The combination of input parameters that gave the best match to experimental data in terms of MHF, PCT, and integral heat flux

- Even when the experimental MHF and integral heat flux were able to be matched within several percent difference, the PCT was still $\sim 27 \%$ greater in the RELAP results

- Differences in PCT are caused by the different pulse widths of the heat flux

- The pulse width during the transient was much narrower in all RELAP runs compared to the experiment, meaning less heat is able to be transferred from the tube to the coolant

- Current modeling of post-CHF phenomena differs from phenomena recorded in experiments

\section{Acknowledgments}

\section{This work was partially financially supported by the Department of Energy NEUP award 17-12688.}




\section{QUESTIONS?}

\section{BACKUP: HEAT TRANSFER COEFFICIENT AND CHF MULTIPLIER SENSITIVITY STUDY}




\section{Sensitivity Study Methodology}

- Heat transfer coefficients were varied based on the data collected by UNM or from the experiments from which the correlations were developed

- The following flow regimes are entered during the transient:

- Forced Laminar Flow (no impact expected; arbitrarily varied from 0.7 to 1.3)

- Forced Turbulent Flow (no impact expected; arbitrarily varied from 0.7 to 1.3)

- Nucleate Boiling (UNM measured $h_{\text {nucl }}$ to be double the $h_{\text {nucl }}$ predicted by the RELAP5-3D base model; varied from 1.0 to 2.0 )

- Transition Boiling (The Chen-Sundaram-Ozkaynak correlation used in RELAP5-3D is based on experimental data with an error up to approximately $100 \%$; varied from 1.0 to 2.0 )

- Film Boiling (UNM measured $h_{\text {film }}$ to be approximately $1 / 3$ the $h_{\text {film }}$ predicted by the RELAP5-3D base model, varied from 0.3 to 1.0 )

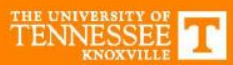

\section{Sensitivity of CHF to Heat Transfer Coefficient and CHF Multipliers}
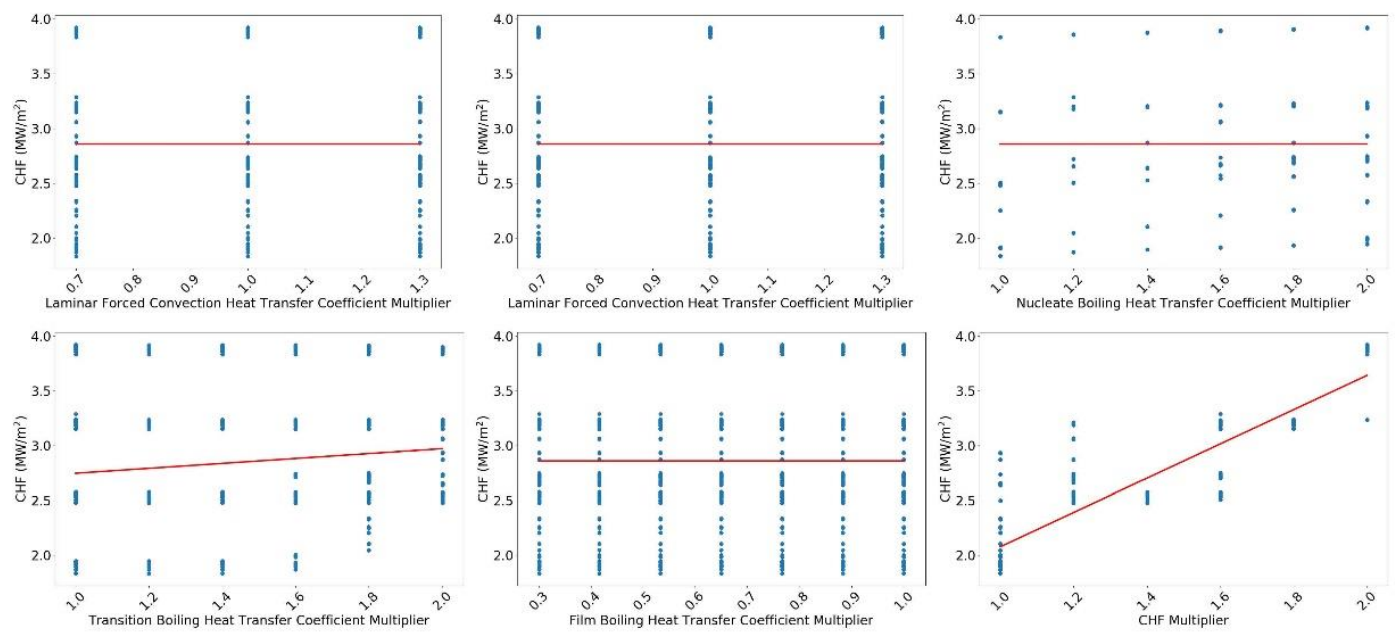


\section{Sensitivity of PCT to Heat Transfer Coefficient and CHF Multipliers}
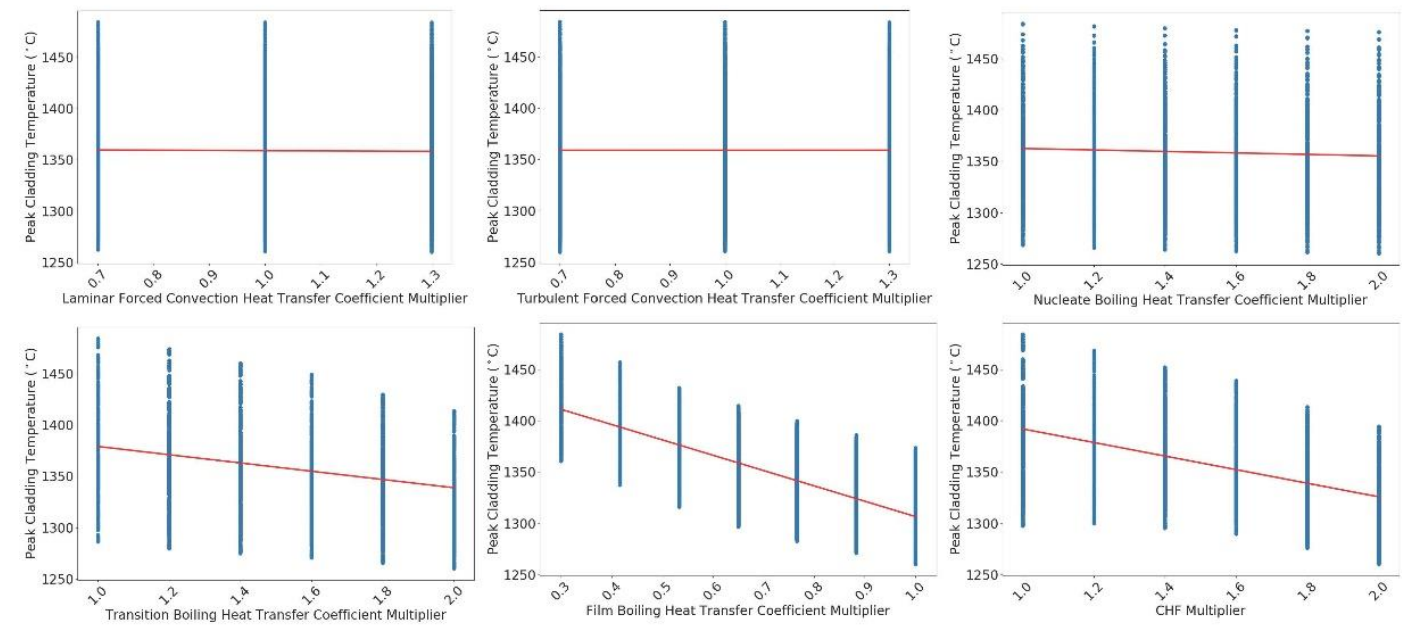

TENNESS T

\section{Summary of Heat Transfer and CHF Multiplier Study}

- Results confirm there is no sensitivity of CHF or PCT on the laminar or turbulent heat transfer multiplier since these regimes are entered prior to the transient

- $\mathrm{CHF}$ is most sensitive to the CHF multiplier and somewhat sensitive to the $h_{\text {trans }}$ multiplier

- PCT decreases slightly as $h_{\text {nucl }}$ increases and more noticeably so when $h_{\text {trans }}, h_{\text {film }}$, and CHF multipliers increase 


\section{Best Match Parameters - Heat Transfer Coefficient and CHF Multipliers Study}

- The runs with the minimum relative error from the experimental data in terms of MHF, PCT, and integral heat flux were identified

- The run with the minimum RMS of the three error values was also identified

Parameters used in Run

\#756 (RMS error of $36.74 \%$ )

\begin{tabular}{cc}
\hline Parameter & Value \\
\hline $\mathrm{h}_{\text {larminar }}$ multiplier & 1.3 \\
$\mathrm{~h}_{\text {turbulent }}$ multiplier & 0.7 \\
$\mathrm{~h}_{\text {nucleate }}$ multiplier & 1.0 \\
$\mathrm{~h}_{\text {transition }}$ multiplier & 2.0 \\
$\mathbf{h}_{\text {film }}$ multiplier & 1.0 \\
CHF multiplier & 2.0 \\
\hline Figure of Merit & Relative Error (\%) \\
\hline MHF & 3.22 \\
PCT & 36.52 \\
Energy Deposition & 2.52 \\
\hline
\end{tabular}
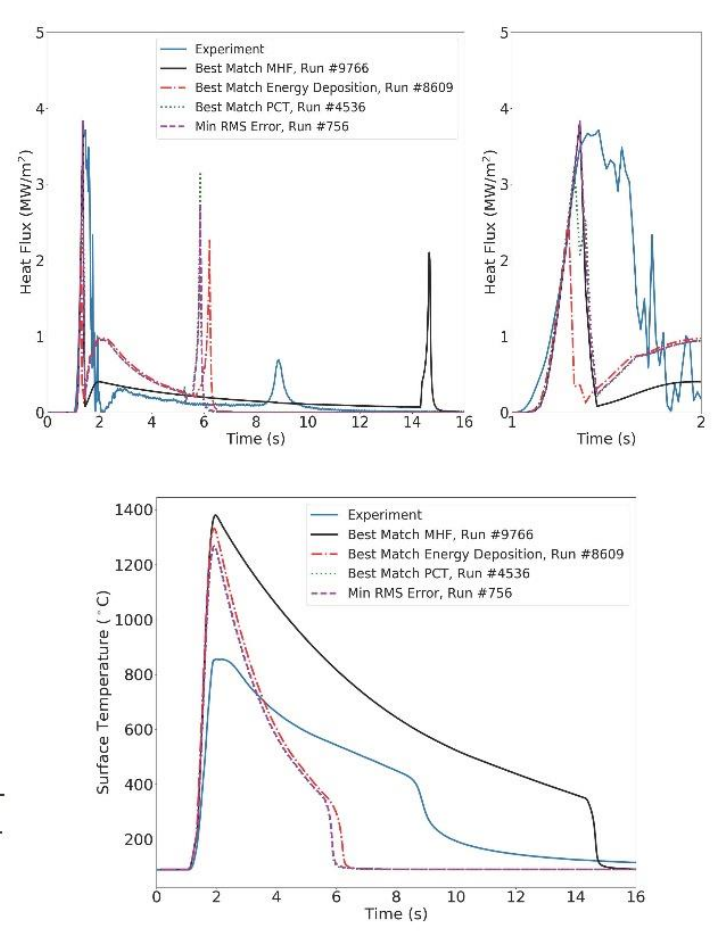


\section{Appendix G}

\section{Progress on the Surface Characterization of ATF and Preliminary Results on CHF}




\section{Appendix G}

Progress on the Surface Characterization of ATF and Preliminary Results on CHF

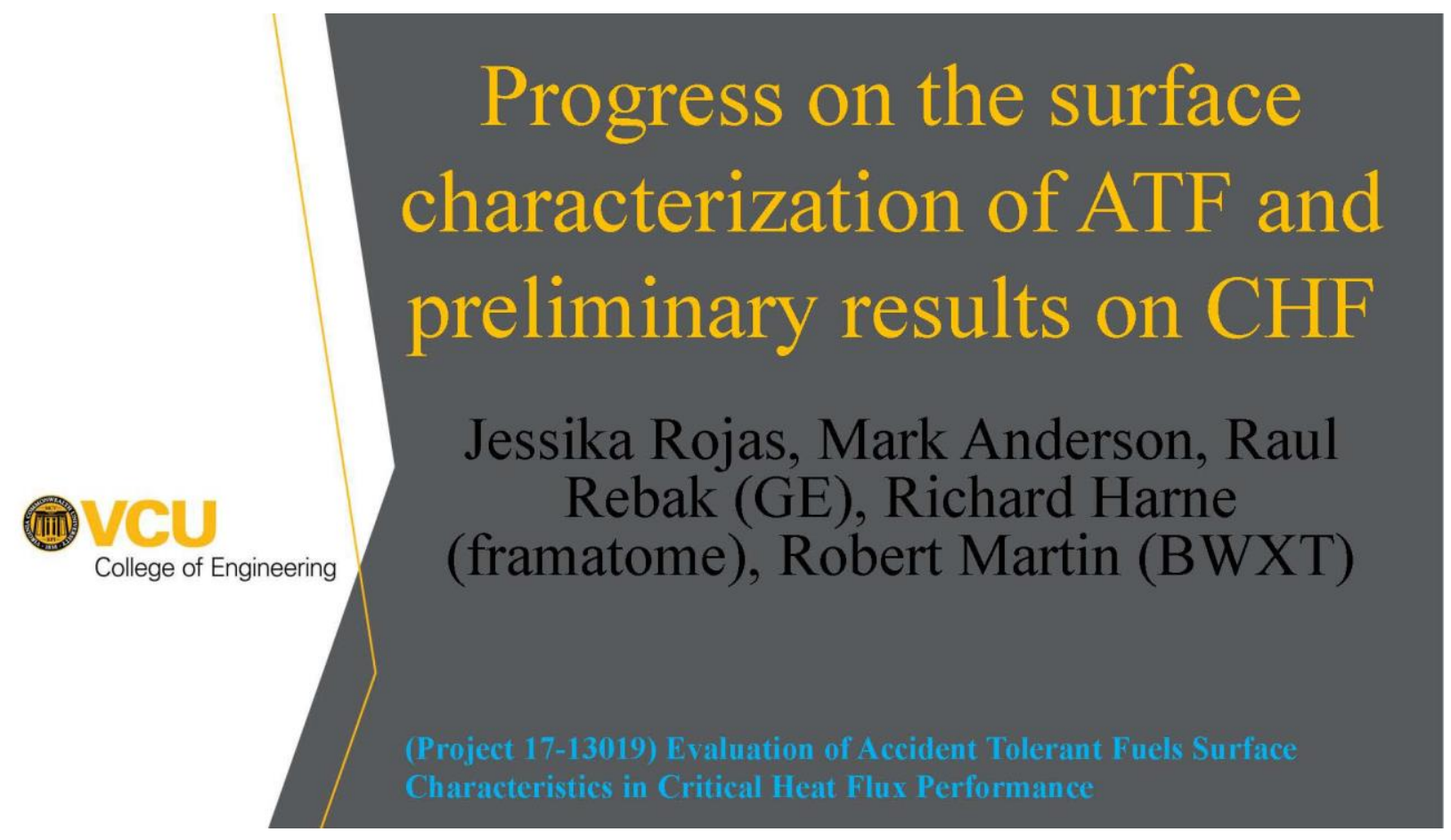




\section{$\underline{\text { Overall Goal }}$}

This project will perform separate-effects tests of several of the ATF concepts under consideration to investigate the impact of cladding surface characteristics in CHF under normal and anticipated off-normal conditions. The experimental results will be used to develop enhanced models or correlations for the prediction of CHF that will be implemented in the various subchannel analysis codes currently licensed for core thermal-hydraulics analysis (VIPRE, LYNXT, FRACG, COBRA) as appropriate

(iii) $V C U_{\text {College of Engineering }}$

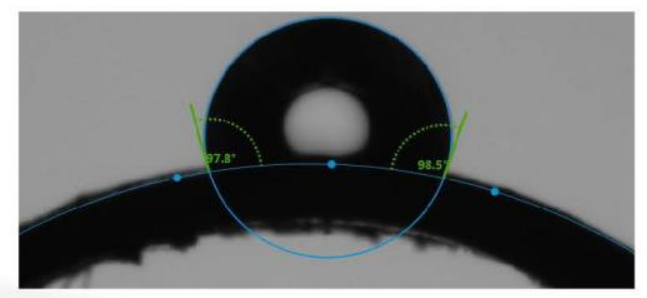

\section{$\underline{\text { Objectives }}$}

- Characterize the surfaces of the ATF concepts under study.

- Conduct CHF experiments to obtain high fidelity qualitative and quantitative measurements for the thermal-hydraulic behavior of the ATF claddings

- Design a series of high fidelity full-scale experiments of the ATF concepts as independent data for the verification and validation of the new CHF models.

- Develop new or enhanced CHF models in accordance with the behavior observed in the CHF experiments

(iii) $\mathbf{V} \mathrm{CU}_{\text {College of Engineering }}$ 


\section{Team and Tasks}

-Conceptual design of an

\section{BWXT}

instrument assembly to investigate

surface impacts of ATF samples.

-system-scale validation plan

intended for future use in pilot-

scale T-H experimental facilities

-Robert Martin

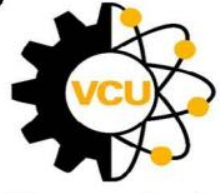

-Surface Characterization of ATF, that includes SEM, profilometry, AFM, contact angle, surface chemistry, before and after CHF. -Development and Implementation of Models in Suitable Subchannel and System Codes

\section{framatome}

-Provide Zr-4 cladding material and technical support on coating characteristics

-Provide COBRA-U (university package) Richard Harne

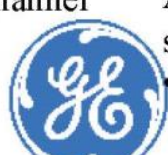

-Provide $\mathrm{FeCrAl}$ tubes, both APMT and C26M grade. Provide technical support on materials characterization

-Dr. Raul Rebak
-Performing CHF experiments of the ATF concepts using both high pressure vertical forced circulation test loop and Atmospheric pressure test section Dr. Mark Anderson thes

WISCONSIN 


\section{Scanning Electron Microscopy (SEM)}

- Phenom ProX Scanning Electron Microscope used to image sample surfaces

- sample preparation

- Material sectioning

- Epoxy Molding

- Grinding \& Polishing

- Ultrasonic Cleaner

- Completed SEM analysis of Zr-2, Zr-4, C26M, and APMT

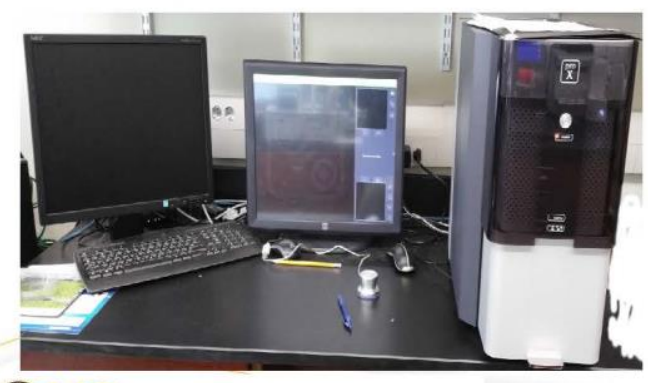

(iii) V/C Phenom ProX SEM

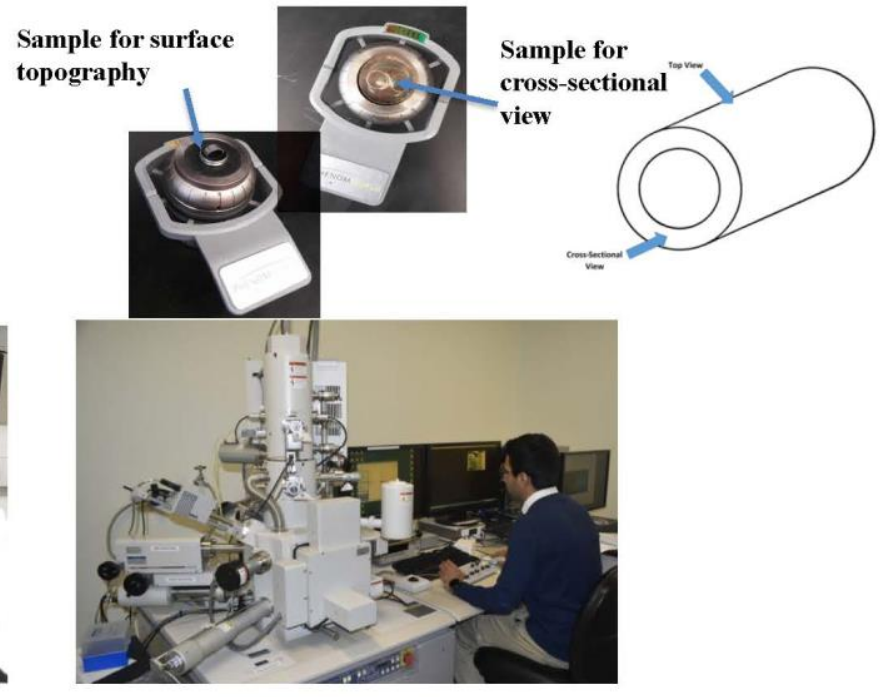

Hitachi SU-70 FE-SEM

\section{X-Ray Diffraction (XRD)}

- Finalized sample preparation procedure

- Polymeric powder (PVP) used with spinner stage

- Completed preliminary XRD scans of Zr-2, Zr-4, C26M and APMT

- Finalized and submitted XRD Test Procedure

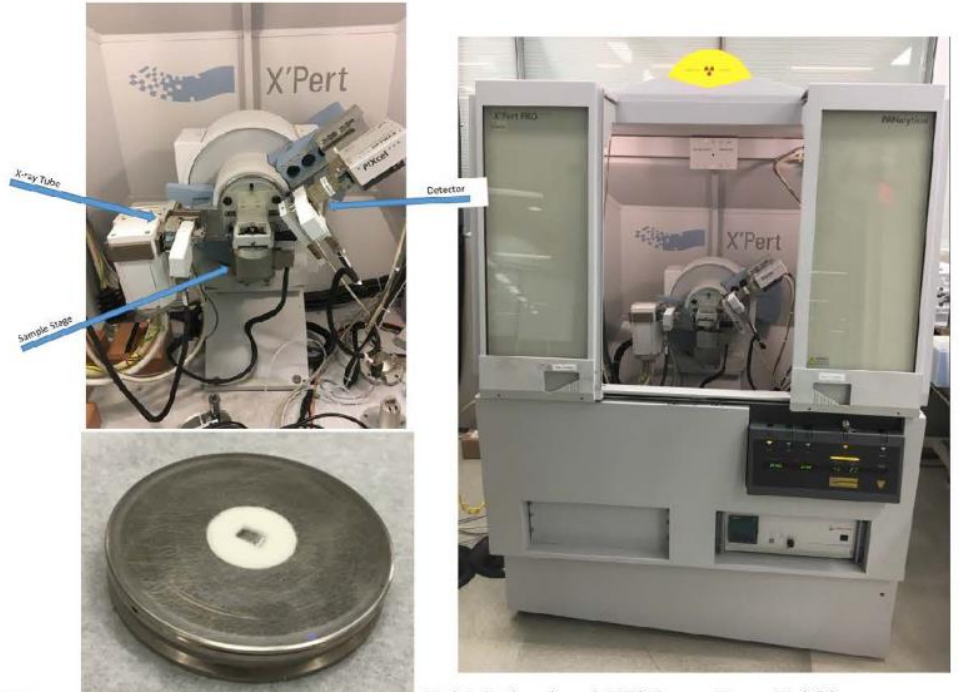




\section{Contact Angle}

- Rame-hart Contact Angle Goniometer is used to measure wettability of surface

- Completed Contact Angle measurements of $\mathrm{Zr}-2, \mathrm{Zr}-4$, $\mathrm{FeCrAl} \mathrm{C26M}$, and APMT

- $5 \mu \mathrm{L}$ droplet was used with plastic needle

- Followed American Society for Testing and Materials (ASTM Designation D7334-08) standards

- 50 measurements taken over totality of surface

- Finalized and submitted Test Procedure
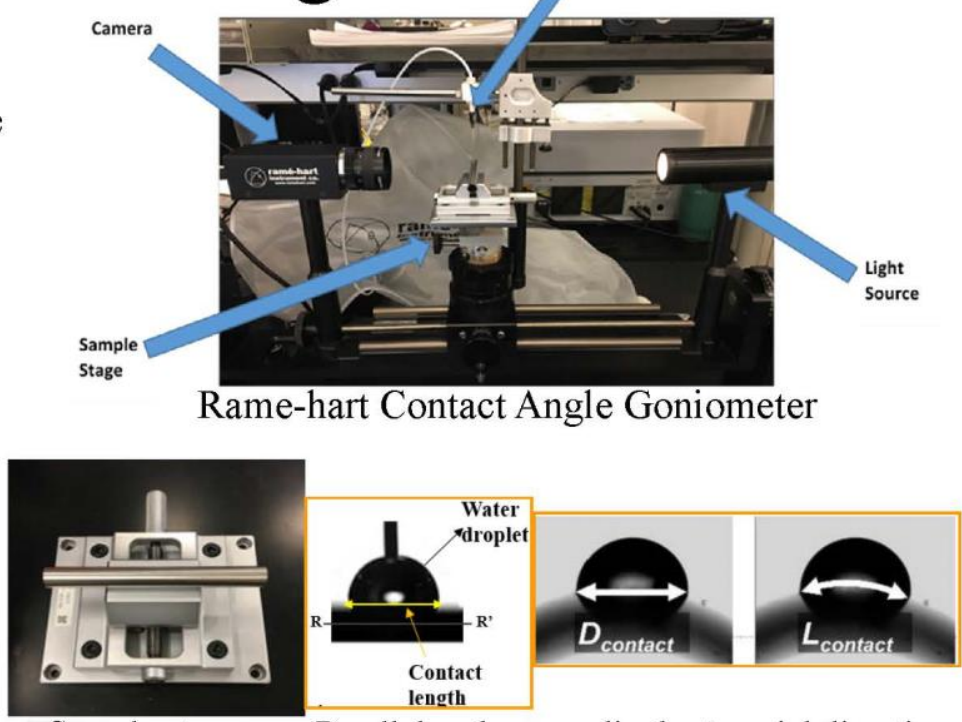

Sample stage Parallel and perpendicular to axial direction

\section{Surface Roughness}

- Measure surface roughness parameters

- Completed Surface Roughness measurements of $\mathrm{Zr}-2, \mathrm{Zr}-4, \mathrm{C} 26 \mathrm{M}$, and APMT

- $5 \mathrm{~mm}$ sampling length measurements

- Followed the International Organization for Standardization (ISO4288) standards

- 100 measurements taken over totality of surface

- Finalized and submitted Test Procedure

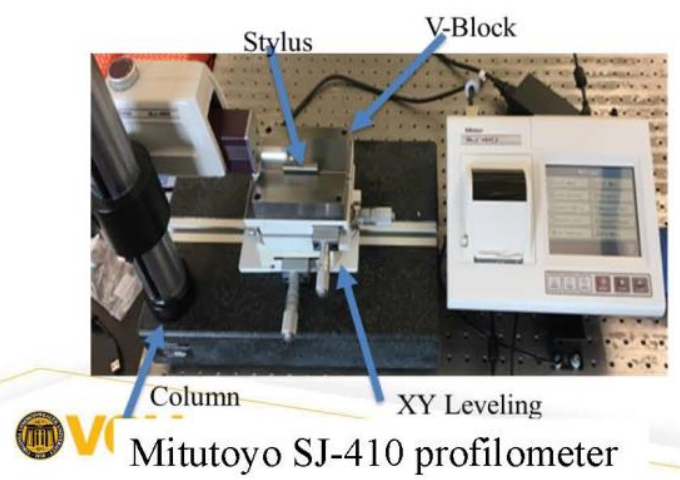

- Bruker Dimension Icon Atomic Force Microscope used to scan sample surface

- Completed preliminary AFM scans of Zr2, Zr-4, C26M, and APMT

- Maximum scan size measured was $90 \mu \mathrm{m}$ x $90 \mu \mathrm{m}$

- Tapping Mode used to generate high resolution images, while minimizing damage to the surface

- Between 3-5 scans for each sample

- Finalized and submitted Test Procedure

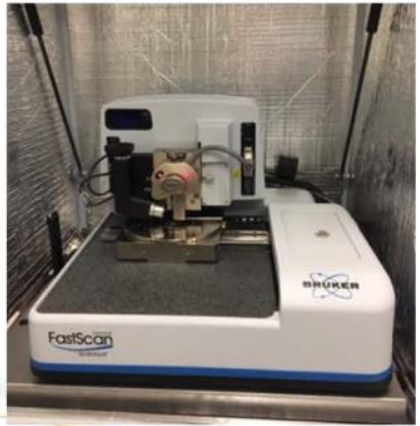

Bruker Dimension Icon Atomic Force Microscope

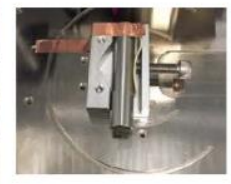




\section{Surface chemistry analysis}

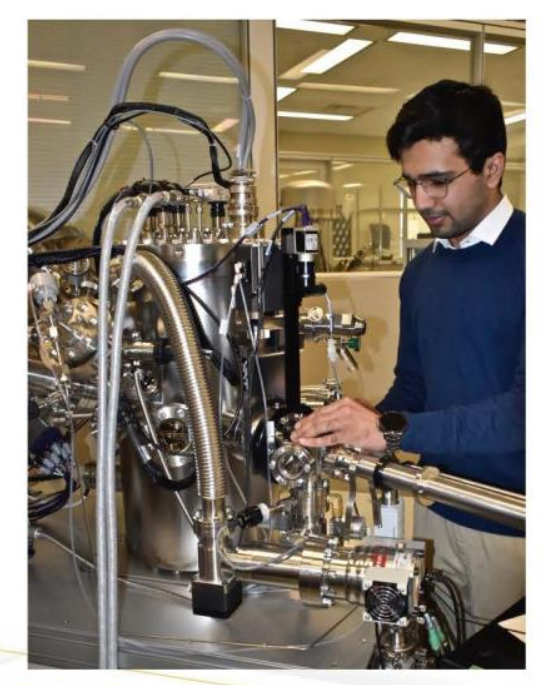

(iiii)

College of Engineering
PHI VersaProbe III Scanning XPS Microprobe

- Micro-focused, scanning x-ray source which provides excellent large area and superior micro-area spectroscopy performance.

- Spectroscopy, depth profiling and imaging can all be performed over the full range of $\mathrm{x}$-ray beam sizes including the minimum $\mathrm{x}$-ray beam size of less than $10 \mu \mathrm{m}$.

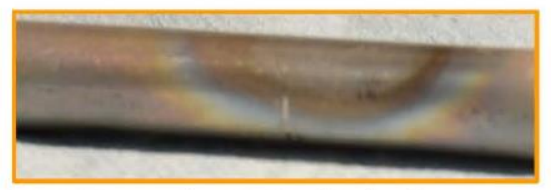

FeCrAl APMT tested at UW. Optical appearance may be associated with surface chemistry

\section{CHF test facilities}

- UW Madison has two facilities for studying CHF

- Near-atmospheric pressures

- Pressures up to Supercritical

- Flexible in operating conditions and test section design
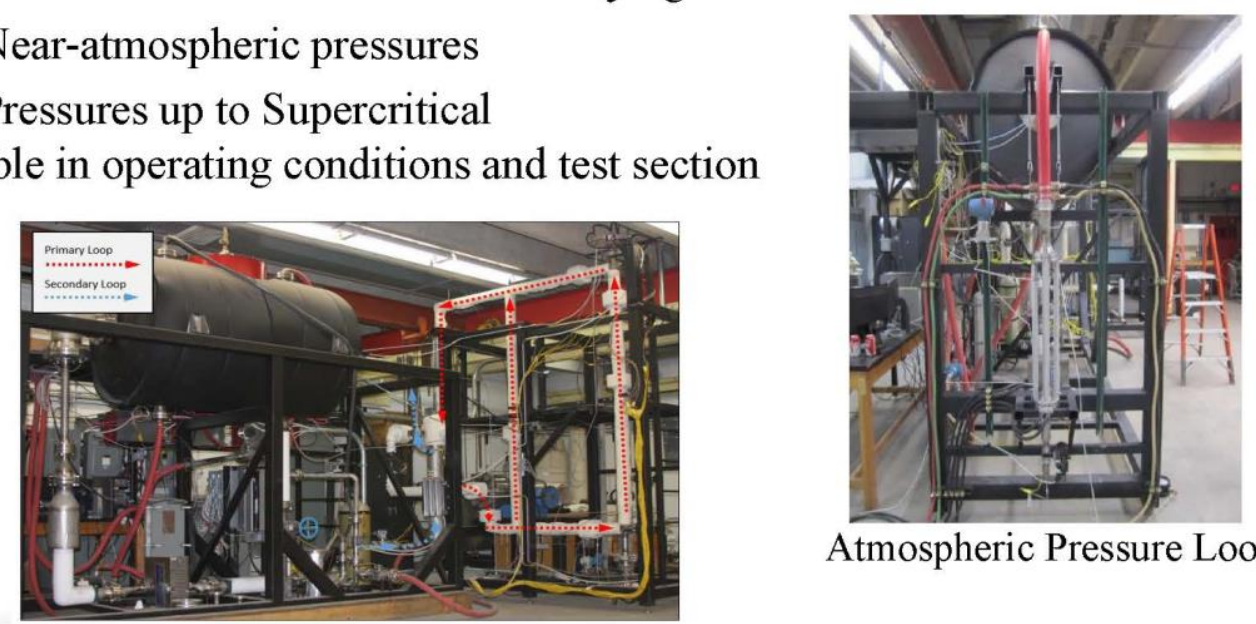

High Pressure Loop

Atmospheric Pressure Loop

Courtesy from University of Wisconsin (iii) $\mathrm{V} / U_{\text {College of Engineering }}$ 


\section{Modeling and Simulation}

- The Modeling and Simulation component of this project is being conducted with computational tools provided by FRAMATOME

- COBRA-U University package

- Non-Disclosure agreement was signed with the company

- Software transfer and training was conducted (April 2019)

- This stage was substantially delayed from our original plan as

FRAMATOME needed to conduct modifications of their code

- One graduate and one undergraduate student as well as 2 Nuclear Engineering faculty (PI and support faculty) were trained

- Software has already been installed in our computer laboratory and preliminary tests are under process.

(iii) $\mathrm{V} / U_{\text {College of Engineering }}$

\section{Methodology}

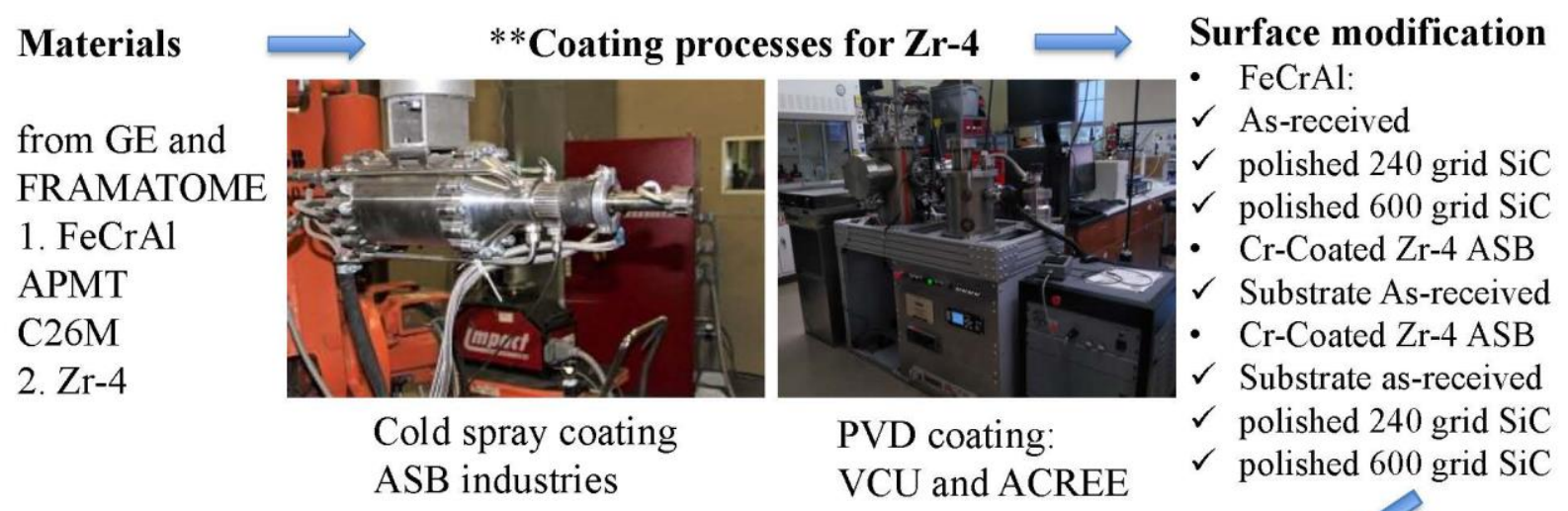

\section{Modeling/simulation}

- Codes will be developed and tested with experimental work

\section{CHF testing at UW}

- FeCrAl: full-length and $60 \mathrm{~cm}$ tubes will be tested

- Cr-coated $\mathrm{Zr}$ only $60 \mathrm{~cm}$ long tubes

**Framatome was going to provide $\mathrm{Cr}$-coated $\mathrm{Zr}$ however due to technology disclosure issues, only $\mathrm{Zr}-4$ was provided 


\section{Data-QA plan}

Following the QA program description document, we are:

1. Providing our students with the necessary training and documenting it.

2. Performing standard characterization of samples received from GE and Framatome as a verification point.

3. Managing documents and records, this includes, characterization and testing raw data, developed tests plans, verifying records keeping continuously. Meeting notes are being created and stored. Encrypted drives are being used to store related information

4. Created an ID system for all the samples received and processed for further characterization and results analysis

5. Tracked all the handling, storing, and shipping processes to avoid materials losses and samples being damaged.

6. Control over services being provided by external parties (ASB, ACREE).

Documentation of agreements and warranties are stored as well as technical data provided by company

7. All measurement and testing equipment is being calibrated as needed

\section{(1iii) $/ \mathrm{CU}$ College of Engineering}

\section{RESULTS}

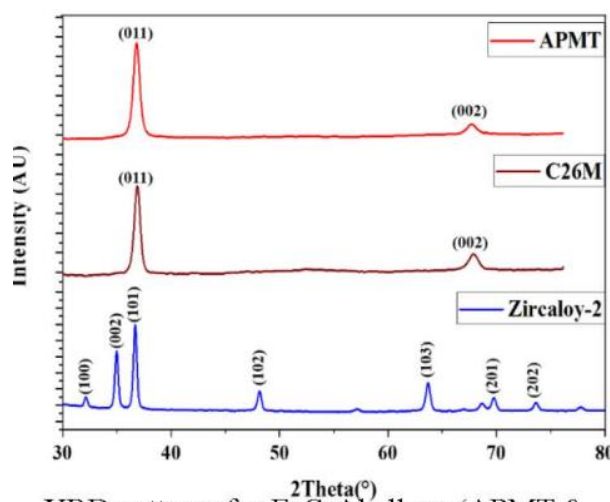

XRD patterns for FeCrAl alloys (APMT \& $\mathrm{C} 26 \mathrm{M}$ ) and Zircaloy-2
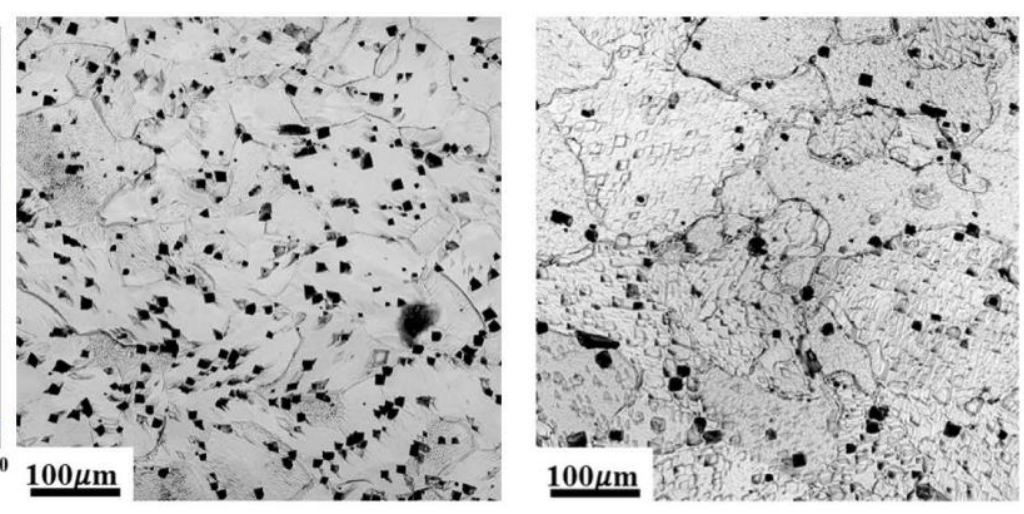

Figure 3. SEM micrographs of etched $\mathrm{FeCrAl}$ alloys: a) $\mathrm{C} 26 \mathrm{M}$ and b) APMT

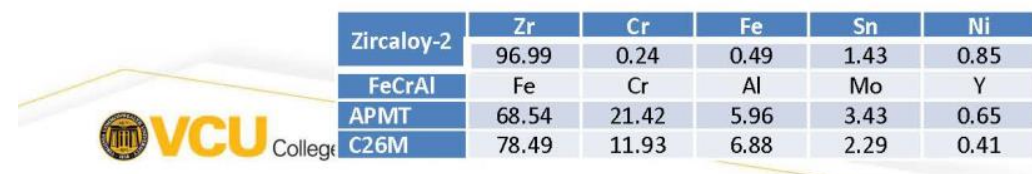

EDS analysis of $\mathrm{FeCrAl}$ alloys (APMT \& C26M) and Zircaloy-2 


\section{Contact angle and SEM}
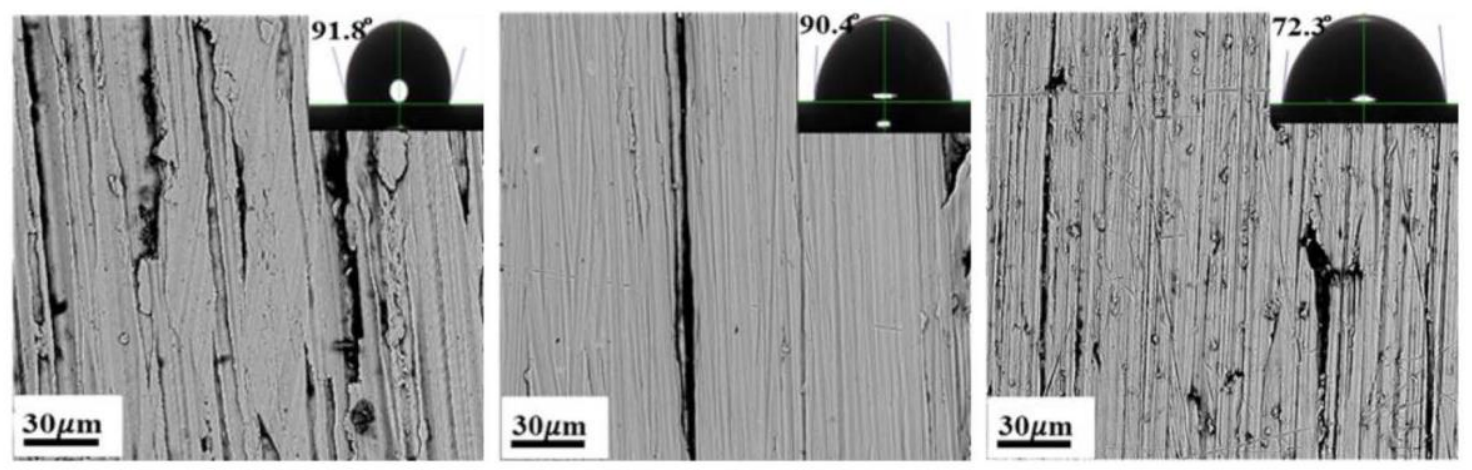

Surface characteristics, including the static contact angle and surface morphologies at microscale for: a) APMT, b) C26M, and c) Zircaloy-2

(iiii) $/ \mathrm{CU}$ College of Engineering

\section{Dynamic Contact angle - Roughness}
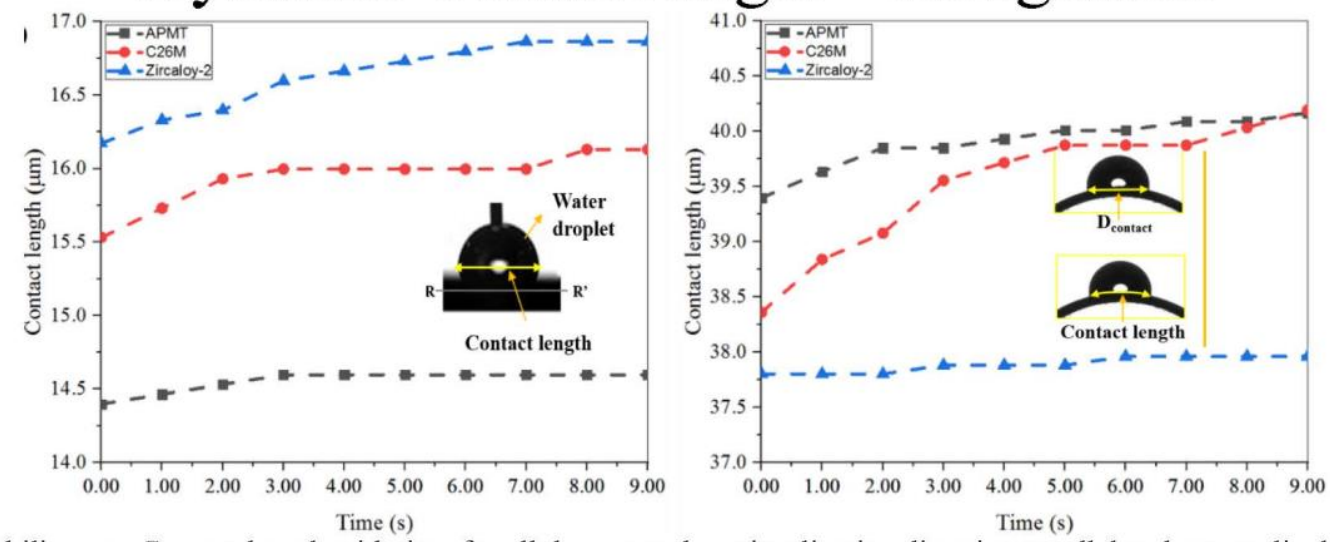

Spreadability test: Contact length with time for all three samples, visualization direction parallel and perpendicular to axial direction

\begin{tabular}{|c|c|c|c|c|c|c|c|}
\hline \multirow{3}{*}{ Material } & \multicolumn{6}{|c|}{ Roughness } & \multirow{3}{*}{$\begin{array}{c}\text { Contact } \\
\text { angle } \\
\text { (degree) }\end{array}$} \\
\hline & \multicolumn{4}{|c|}{ SJ-410 Profilometer } & \multicolumn{2}{|c|}{ AFM } & \\
\hline & $\operatorname{Ra}(\mu \mathrm{m})$ & $\mathrm{Rz}(\mu \mathrm{m})$ & Rsk & Rku & $\begin{array}{c}\text { Roughness } \\
\text { factor (r) }\end{array}$ & $\begin{array}{l}\text { Rsm } \\
(\mu \mathrm{m})\end{array}$ & \\
\hline Zircaloy-2 & $0.36 \pm 0.04$ & $4.46 \pm 1.08$ & $0.01 \pm 0.32$ & $4.46 \pm 1.79$ & 1.02 & 0.18 & $72.33 \pm 4.28$ \\
\hline APMT & $0.68 \pm 0.07$ & $5.94 \pm 0.84$ & $-0.47 \pm 0.12$ & $3.17 \pm 0.29$ & 1.07 & 0.49 & $91.97 \pm 2.78$ \\
\hline C26M & $0.69 \pm 0.07$ & $8.59 \pm 1.34$ & $-1.05 \pm 0.31$ & $6.23 \pm 1.76$ & 1.02 & 0.38 & $90.43 \pm 2.28$ \\
\hline
\end{tabular}




\section{Optical microscopy (APMT) Surface roughness modification}

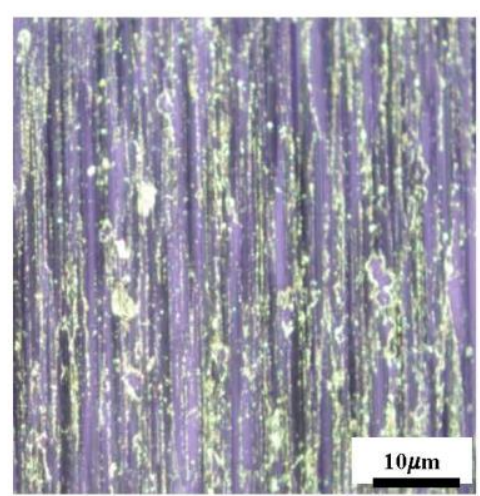

As received

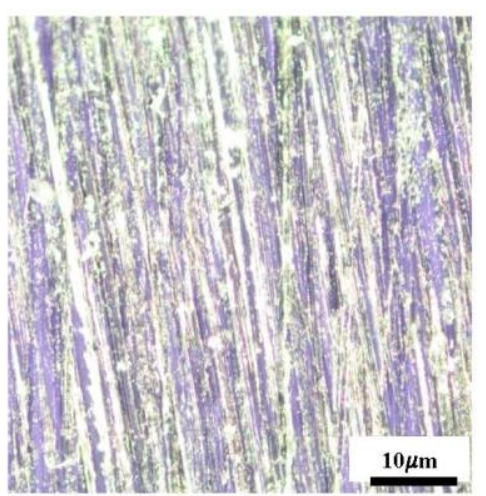

120 Grit

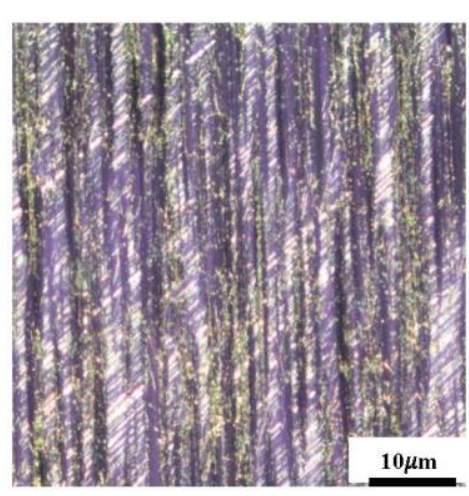

1200 Grit

(iiii) $/ \mathrm{C} U$ College of Engineering

\section{Optical microscopy (C26M)}

Surface roughness modification

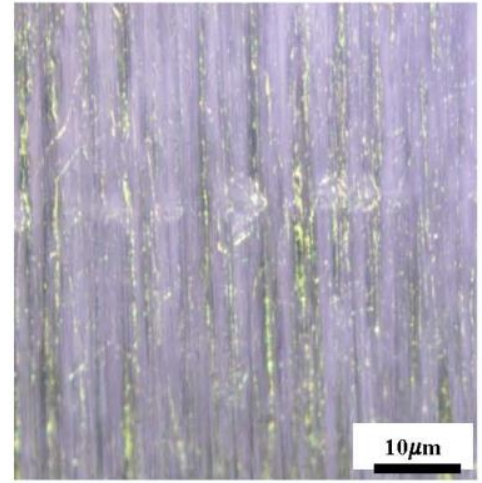

As received

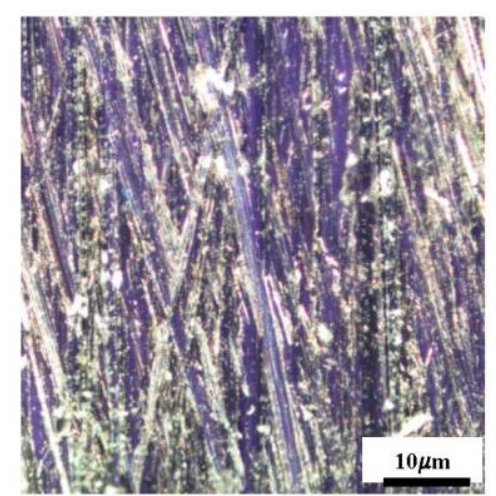

120 Grit

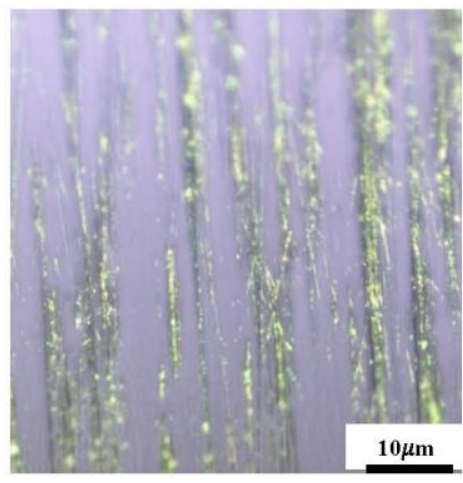

1200 Grit

(iiii) $/ \mathrm{Cl}$ College of Engineering 


\section{Roughness parameters FeCrAl}

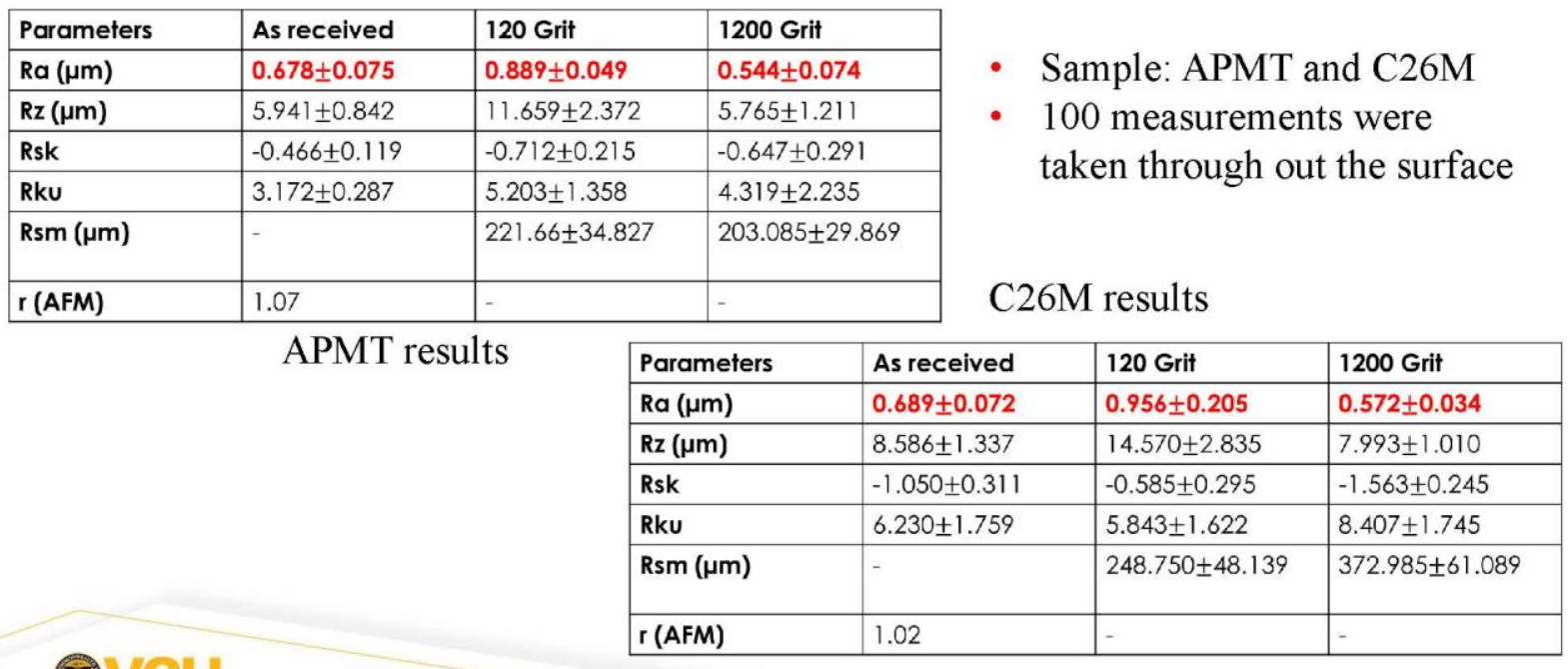

(Iiii) College of Engineering

\section{AFM characterization of C26M}
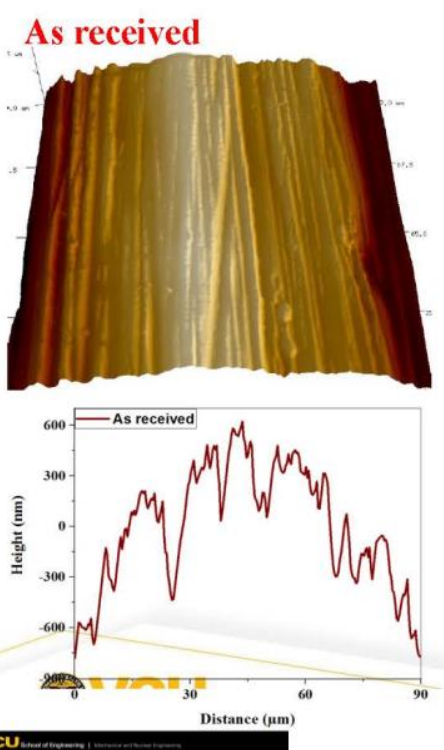

1200 Grit
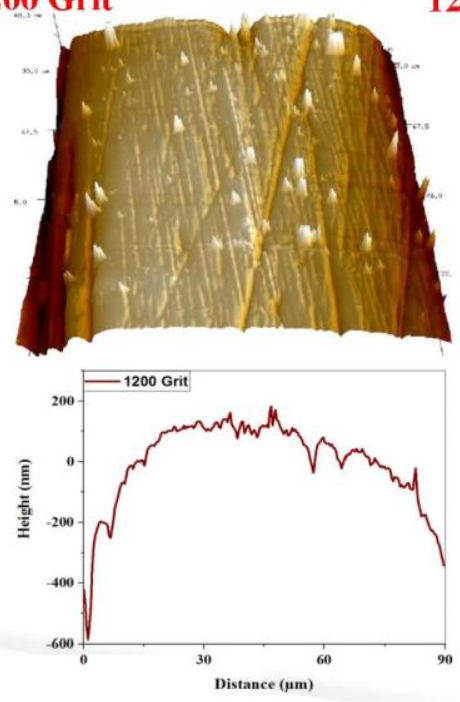

120 Grit
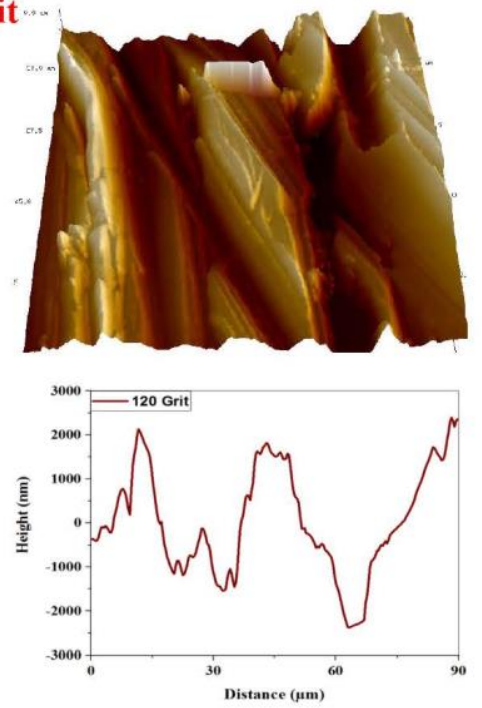


\section{Preliminary results Cr-Coated Zr-4}

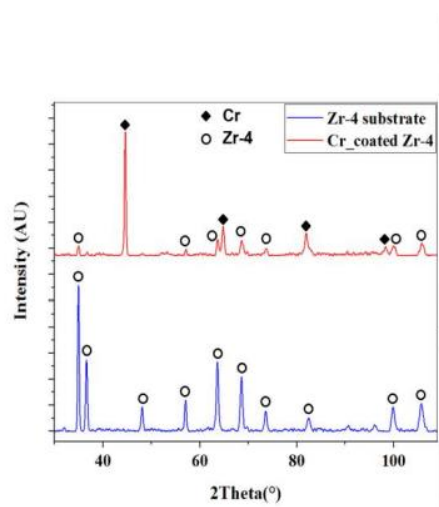

XRD patterns and Crosssectional SEM view (Top-Right) and SEM surface micrograph (Bottom-Right)

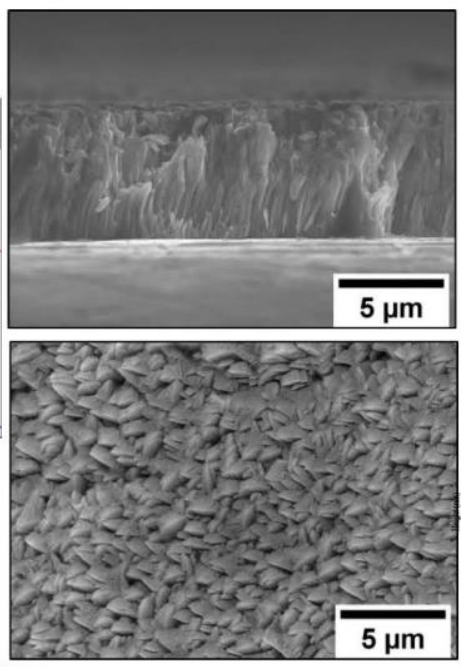

$5 \mu \mathrm{m}$
TABLE I. Surface roughness measurements

Roughness

Parameters ( $\mu m$ )

$\mathrm{Ra}$

Substrate

Zircaloy-4

0.399

31.420

2.715

$\mathrm{Rz}$

$\mathrm{Rq}$

0.494
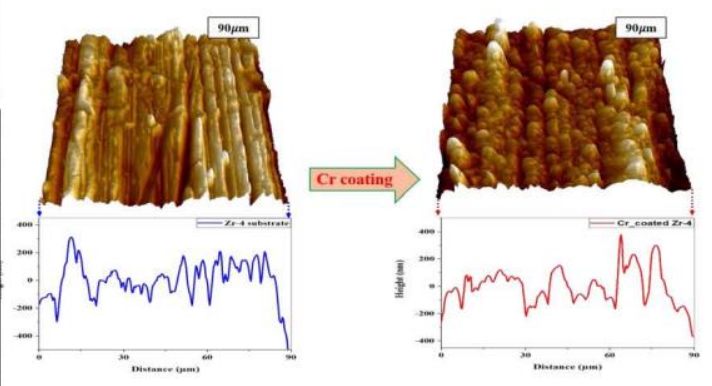

AFM surface morphology and roughness distribution of as received Zircaloy- 4 before (Left) and after (Right) Cr coating

\section{Acree Cr-coating PVD}

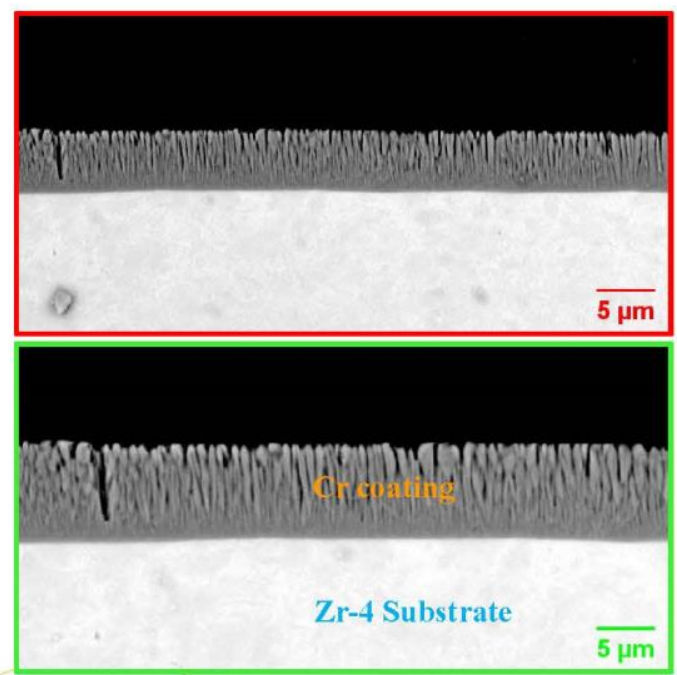

SEM micrographs showing a uniform $\mathrm{Cr}$ coating 6.5 um thick

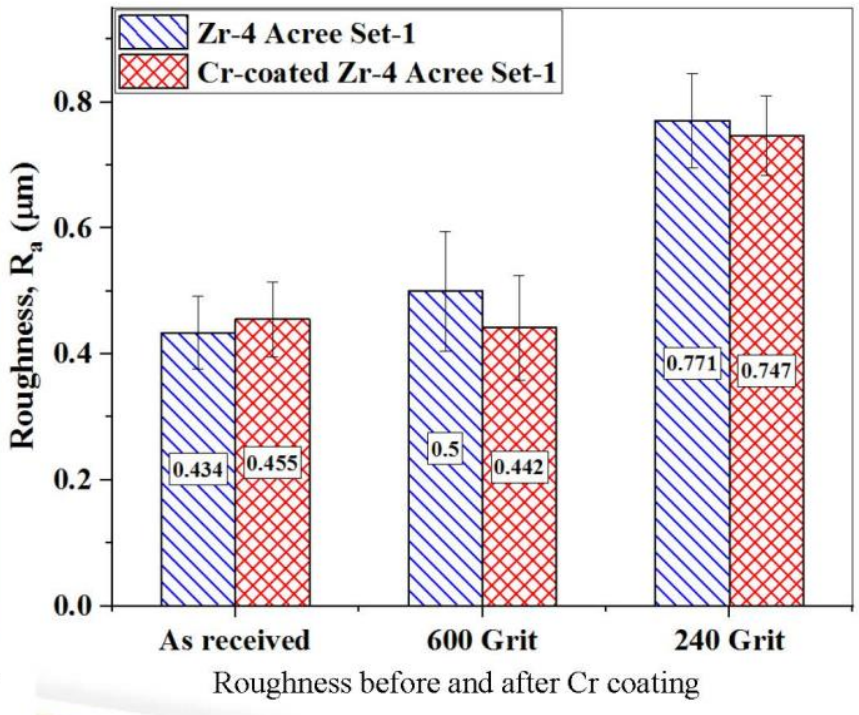




\section{Contact angle Cr-coated $\mathrm{Zr}-4$}

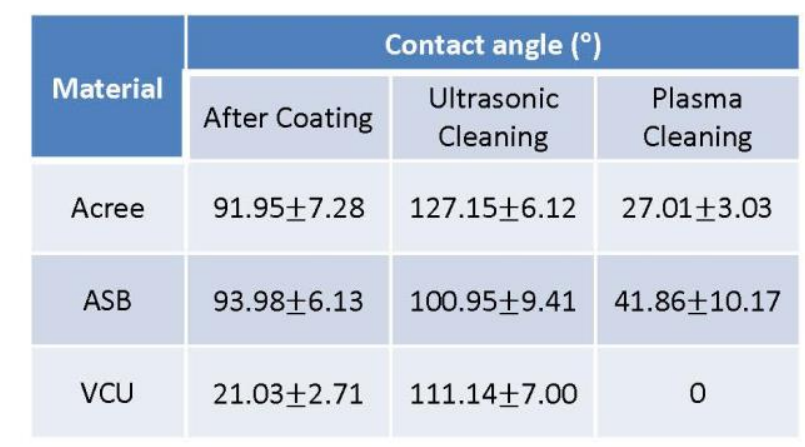

Contact angle comparison for As received Samples

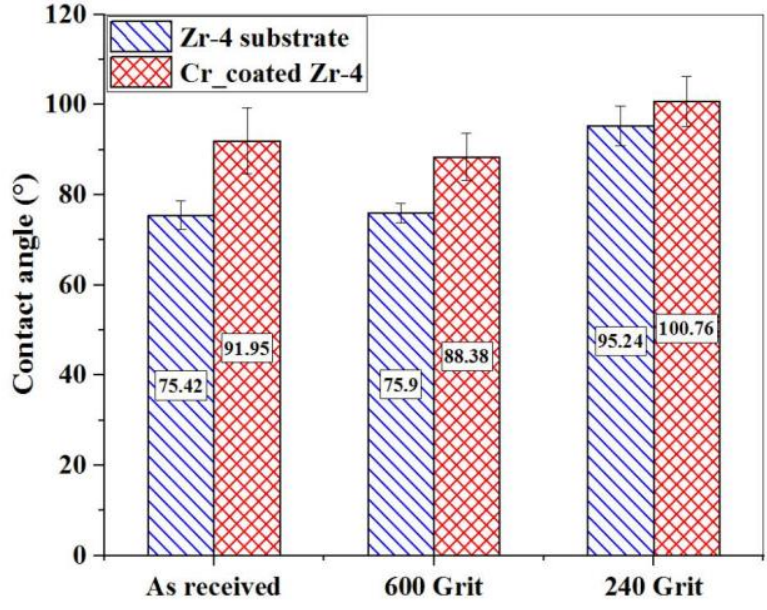

Contact angle before and after $\mathrm{Cr}$ coating (PVD (Acree))

\section{Surface behavior with aging}
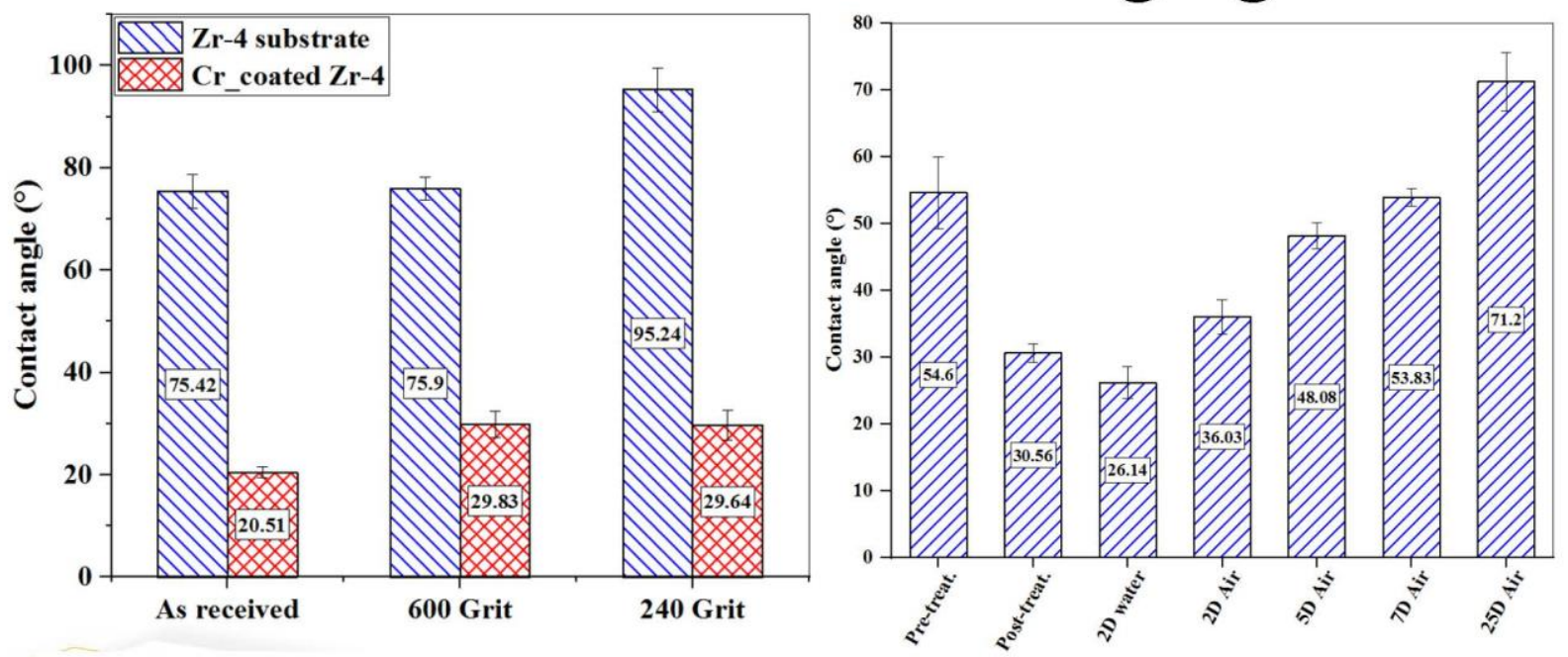

a)Cr-Coated $\mathrm{Zr}-4$, coating performed at VCU and analysis done right after coating b) contact angle evolution with water/air exposure 


\section{Surface Chemistry}
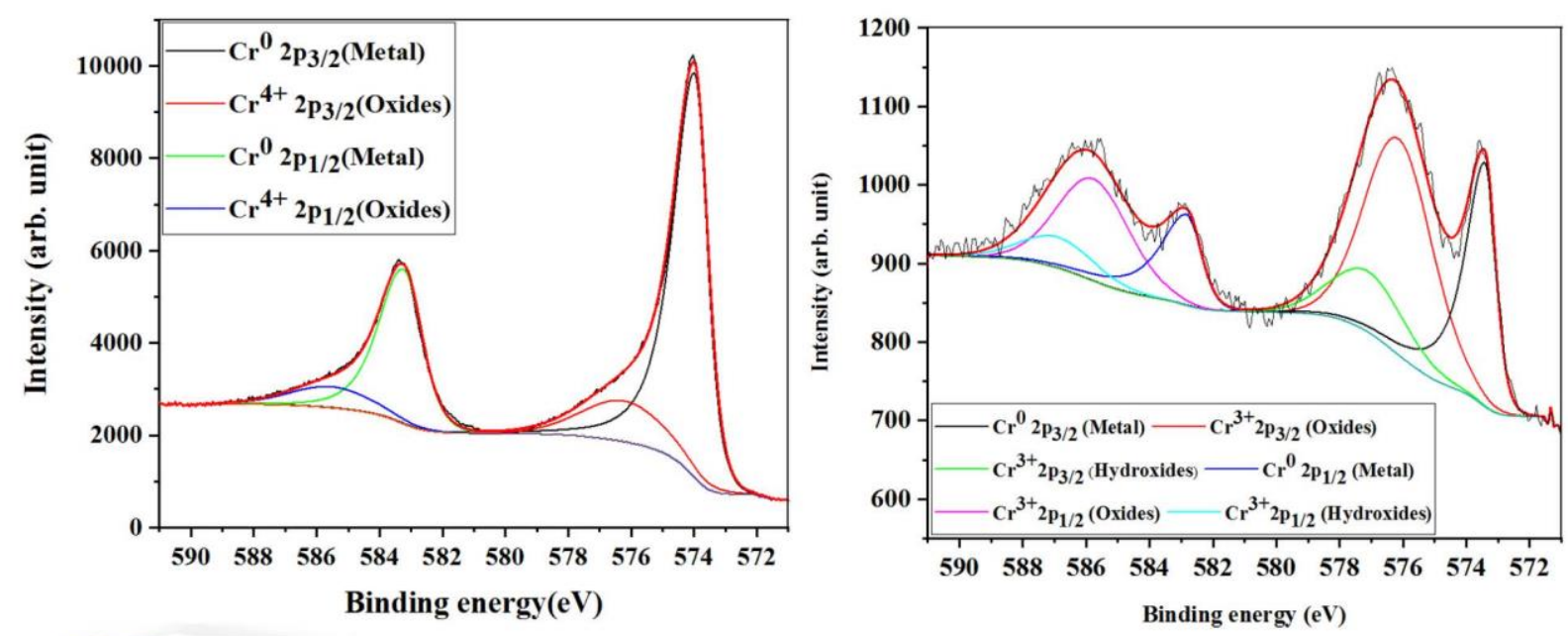

Cr 2p XPS spectrum of 240 grit Cr-coated Zr-4 (a) Reference sample (after coating) and (b)

(iii) DI Water (2 days) and Air (25 days) exposed

\section{Optical Microscopy (Cr-coated Zr-4-ASB)}
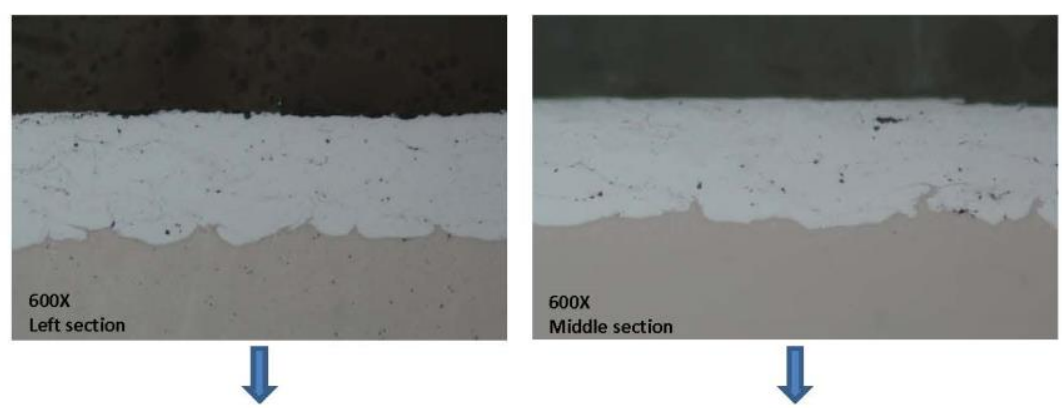

Middle section

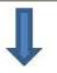

\begin{tabular}{|c|c|c|c|c|c|c|c|}
\hline \multirow{2}{*}{$\begin{array}{l}\text { Spot } \\
\text { Length }\end{array}$} & \multicolumn{3}{|c|}{ Diameler before Spray $(\mathrm{mm})$} & \multicolumn{3}{|c|}{ Diameler offer Spray $(\mathrm{mm})$} & \multirow{2}{*}{$\begin{array}{l}\text { Final } \\
\text { Cooling } \\
\text { Thickness } \\
\text { (xim) }\end{array}$} \\
\hline & O Deg & 120 Deg & 240 Deg & O Deg & 120 Deg & 240 Deg & \\
\hline 5" & 9.498 & 9.501 & 9.500 & 9.560 & 9.556 & 9.554 & 28.46 \\
\hline 9" & 9.501 & 9.499 & 9.500 & 9.565 & 9.560 & 9.560 & 30.84 \\
\hline 13" & 9.500 & 9.500 & 9.501 & 9.561 & 9.556 & 9.558 & 28.97 \\
\hline $17 "$ & 9.499 & 9.499 & 9.499 & 9.559 & 9.573 & 9.557 & 28.65 \\
\hline
\end{tabular}

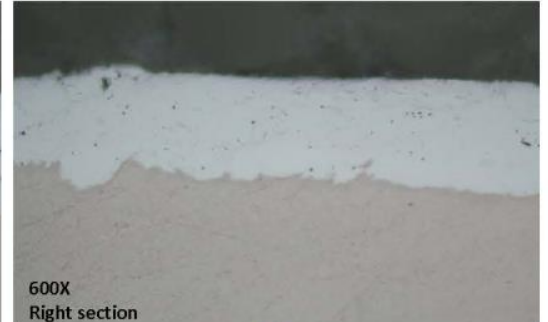

$\rrbracket$

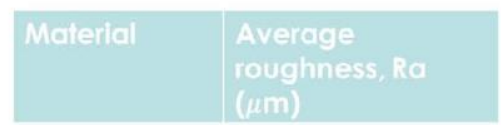

Substrate $\quad 0.434 \pm 0.058$

Cr-coating $\quad 1.332 \pm 0.352$ 


\section{Challenges}

- The challenges associated with the execution of this work have been mainly associated with delayed materials from our partner companies.

- GE delivered samples for preliminary experiments and test plans in June 2018.

- Framatome decided not to provide the $\mathrm{Cr}$-coated $\mathrm{Zr}-4$ due to technical reasons. This affected our timeline and schedule.

- The team arranged with Framatome the delivery of $\mathrm{Zr}-4$ and $\mathrm{VCU}$ will handle coting service from external providers. Acree and ASB were selected. The team received Zr-4 at the beginning of 2019.

- The delivery of COBRA-U was also delayed due to NDA needed to be produced and signed.

- The team received the code in April 2019.

(iiii) $/ \mathrm{C}$ College of Engineering

\section{Future Work}

- Near term efforts (Path Forward)

- Finalize the surface characterization of the $\mathrm{Cr}$-coated $\mathrm{Zr}$-4. We are planning to benchmark our coatings with the ones being produced by Framatome with regards to thickness.

- VCU has provided bare $\mathrm{Zr}-4$ and $\mathrm{Cr}$-coated $\mathrm{Zr}$ to UW. The next step in this work will focus on preparing and running CHF test in the atmospheric pressure loop.

- Acquire full length FeCrAl tubes from GE. Once they are sent, their surface will be modified following the procedures developed previously.

- Long term efforts (Path Forward)

- Start modeling and simulation efforts as we continue with our experimental work. 


\section{Publication and students involved}

Graduate students:

- At VCU: Rajnikant Umretiya: $3^{\text {rd }}$ Year PhD student (already passed QE)

- At UW: Barret Elward

Undergraduate students:

Robert Uhorchuk: Junior student in Mechanical and Nuclear Engineering, funded partially by the Dean Undergraduate Research Initiative (DERI)

\section{Publications:}

2019 ANS Winter Meeting \& Expo

1. Surface Characterization of Chromium Coated Zircaloy-4 Accident Tolerant Fuel Cladding Material.

Rajnikant Umretiya, Robert Uhorchuk, Santiago Vargas, Carlos E. Castano, Jessika Rojas

2. Aging Effect of Chromium Coated Zircaloy-4 Accident Tolerant Fuel Cladding Material

Authors: Rajnikant Umretiya, Santiago Vargas, Robert Uhorchuk, Carlos E. Castano, Jessika Rojas

3. Evaluation of Surface Characteristics of FeCrAl alloy Accident Tolerant Fuel Cladding Material after

Critical Heat Flux Testing under Atmospheric Pressure. Rajnikant Umretiya, Robert Uhorchuk, Mark Anderson,

Barret Elward, Sama Bilbao y Leon, Raul B. Rebak, Jessika Rojas

\section{Publications:}

NURETH 2019

Surface Characteristics od Accident Tolerant Fuel Claddings and their potential impact in Critical Heat Flux Rajnikant Umretiya, Daniel Ginestro, Sama Bilbao y Leon, Barret Elward, Mark Anderson, Raul B. Rebak, Jessika Rojas.

TMS 2020 (149th Annual Meeting \& Exhibition) (Submitted)

1. Evaluation of Surface Characteristics of Cr-coated Zr-4 Accident Tolerant Fuel Cladding Material after Critical Heat Flux Testing under Atmospheric Pressure. Rajnikant Umretiya, Mark Anderson, Barret Elward, Sama Bilbao y Leon, Raul B. Rebak, Jessika Rojas. Status: Under Review

2. Surface Characterization of FeCrAl Accident Tolerant Fuel Cladding Material after Flow Boiling Testing under Atmospheric Pressure. Rajnikant Umretiya, Mark Anderson, Barret Elward, Sama Bilbao y Leon, Raul B. Rebak, Jessika Rojas. Status: Under Review

3. Surface Characterization and Mechanical Properties of Cr-coated Zr-4 Accident Tolerant Fuels Cladding prepared using different Coating Techniques. Authors: Rajnikant Umretiya, Santiago Vargas, Carlos E. Castano, Reza Mohammadi, Jessika Rojas. Status: Under Review 


\section{Summary}

- The issues with materials availability were resolved

- The team has carried out an extensive characterization and analysis of surface medication on $\mathrm{FeCrAl}$ alloys.

- We received the Cr-coated $\mathrm{Zr}-4$ from both ASB and Acree and materials characterization is in process.

- Preliminary results on CHF for APMT were produced at UW and VCU has started identifying changes associated with surface characteristics related to both morphology and chemistry.

(iii) VCU College of Engineering

\section{Questions?}




\section{Appendix H}

\section{Investigation of Droplet Quenching on Accident-Tolerant Coating Using Infrared Thermometry}




\section{Appendix $\mathbf{H}$}

\section{Investigation of Droplet Quenching on Accident Tolerant Coating Using Infrared Thermometry}

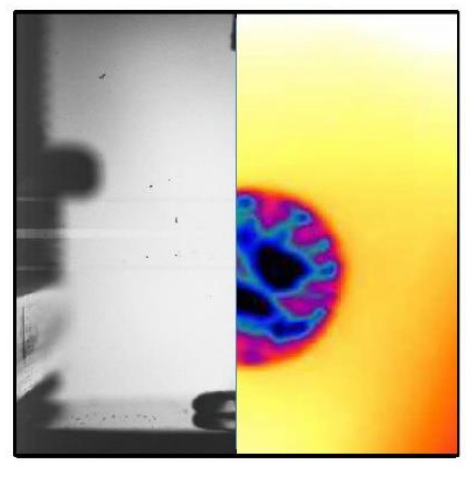

Investigation of Droplet Quenching on Accident Tolerant Coatings Using Infrared Thermometry

Understanding Leidenfrost phenomena on ATF materials

H. Kim, W. McGee, A. Kossolapov, B. Phillips, M. Bucci Massachusetts Institute of Technology

Department of Nuclear Science and Engineering 


\section{Introduction and significance of the work}

- Spray cooling (BWR)

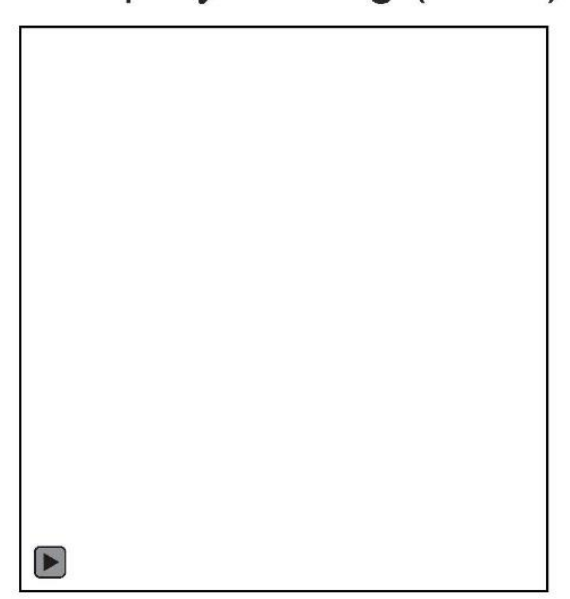

- Boiling curve

$D_{\text {avg }}=1 \sim 2 \mathrm{~mm}$
$W e_{n}=\frac{\rho v_{n}^{2} D}{\sigma}<30$

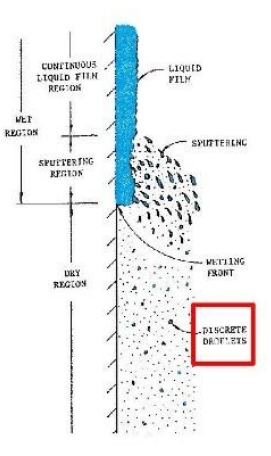

Leidenfrost temperature

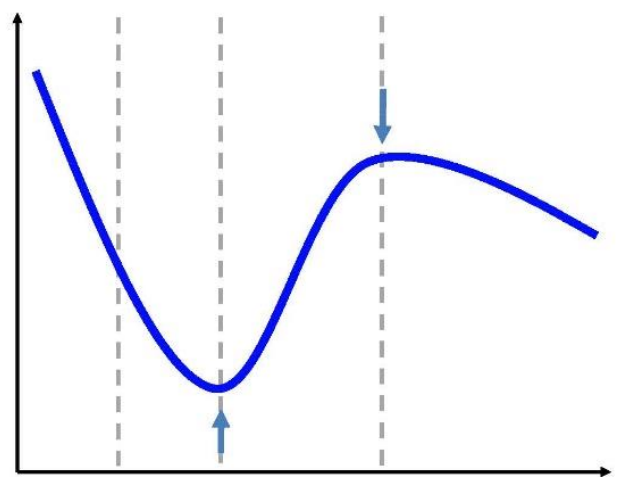

\section{Background}

- ATF quenching experiments and $T_{M F B}$

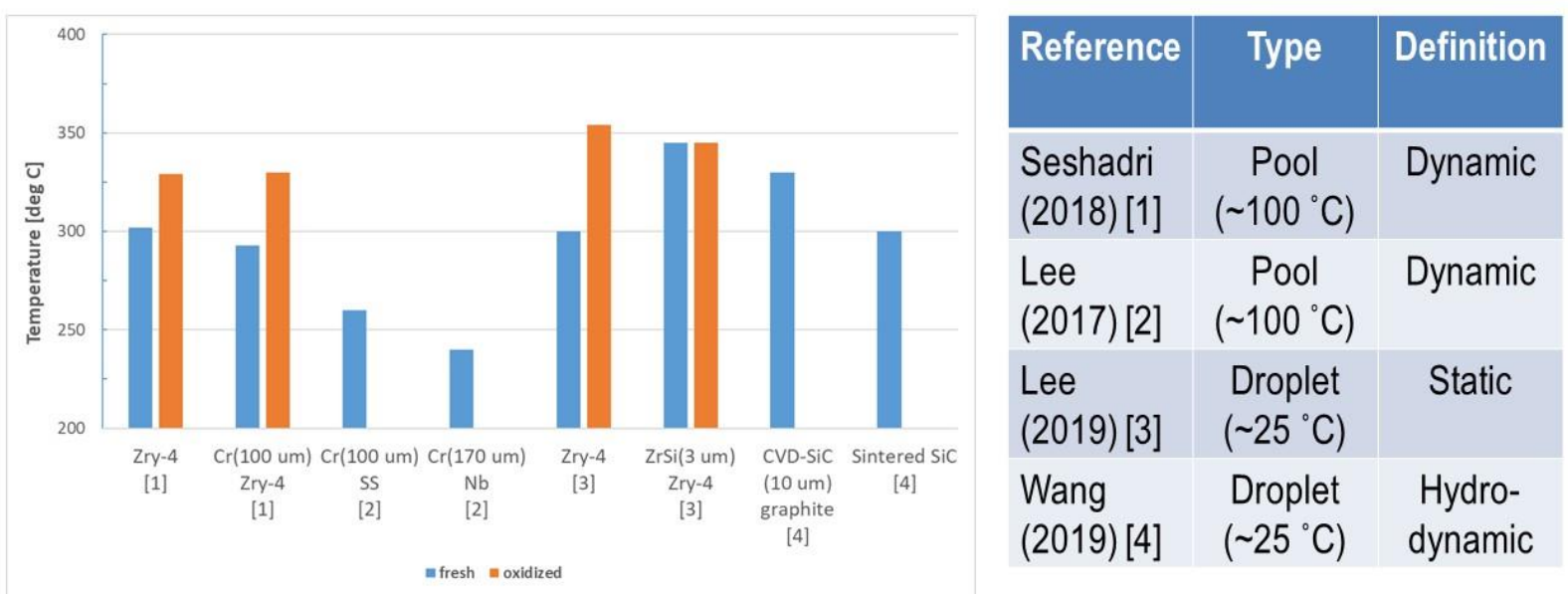




\section{Background}

\section{Quenching}

Experiments

- Materials

Pool

Droplet

Zry, Cr, FeCrAl, SiC ...

Effect of oxidation

ATF material

- Surface parameters thermal properties, roughness, wettability, porosity ...

- System parameters pressure, subcooling ...

Other material

Various materials (Si, metal, ... )

Micro/nano structured surfaces

- Few available

ZrSi (Lee, 2019)

SiC (Wang, 2019)

This work

\section{Objectives}

- Quantify Leidenfrost temperature of potential ATF coating materials under BWR spray quenching conditions:

Surface material: unoxidized and oxidized Zircaloy, SiC-, Cr-, and FeCrAl-coated

Surface finish: nano-smooth and rough (same as PWR claddings)

as a function of droplet subcooling and droplet Weber number

- Develop ATF-material-specific correlations to be implemented 


\section{Methodology: sample preparation}

- PVD sputtering

$\mathrm{Ti}(\sim 100 \mathrm{~nm})$ and $\mathrm{Cr}(\sim 300 \mathrm{~nm})$ layer

- Change in colors

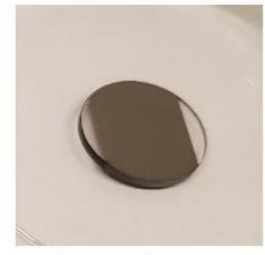

As fabricated

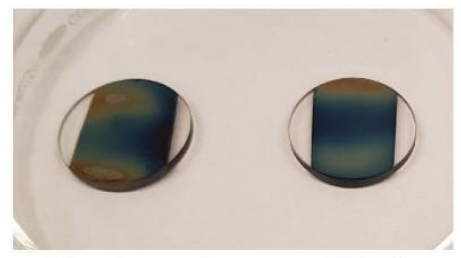

After heated up to $\sim 500{ }^{\circ} \mathrm{C}$
Air

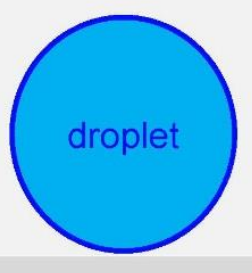

Cr surface layer

Ti bonding layer

Sapphire

\section{Methodology: Droplet quenching facility}

- $2 \mathrm{~mm}$ droplet

Weber number $\sim$ falling height

- Up to $\sim 500{ }^{\circ} \mathrm{C}$

- Target area $\sim 0.6 \times 0.6 \mathrm{~cm}^{2}$

IR field of view

- IR and HSV diagnostics

IR: 30 um/pixel, $3000 \mathrm{fps}$

HSV: 20 um/pixel, 3000 fps
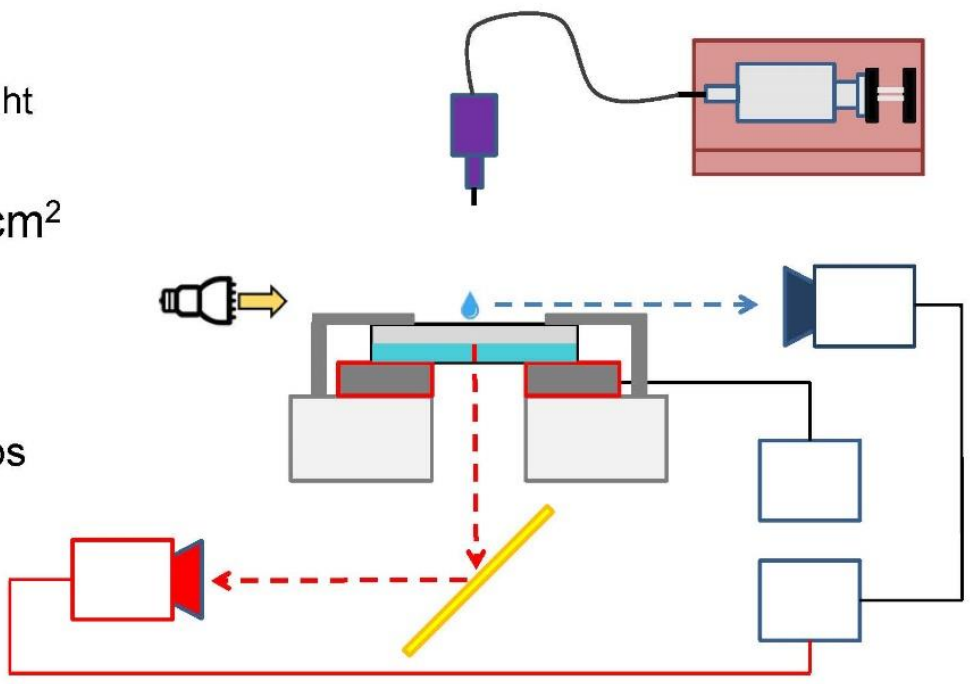


\section{Methodology: Droplet quenching facility}

- $2 \mathrm{~mm}$ droplet

Weber number $\sim$ falling height

- Up to $\sim 500{ }^{\circ} \mathrm{C}$

- Target area $\sim 0.6 \times 0.6 \mathrm{~cm}^{2}$ IR field of view

- IR and HSV diagnostics

IR: 30 um/pixel, $3000 \mathrm{fps}$ HSV: 20 um/pixel, 3000 fps

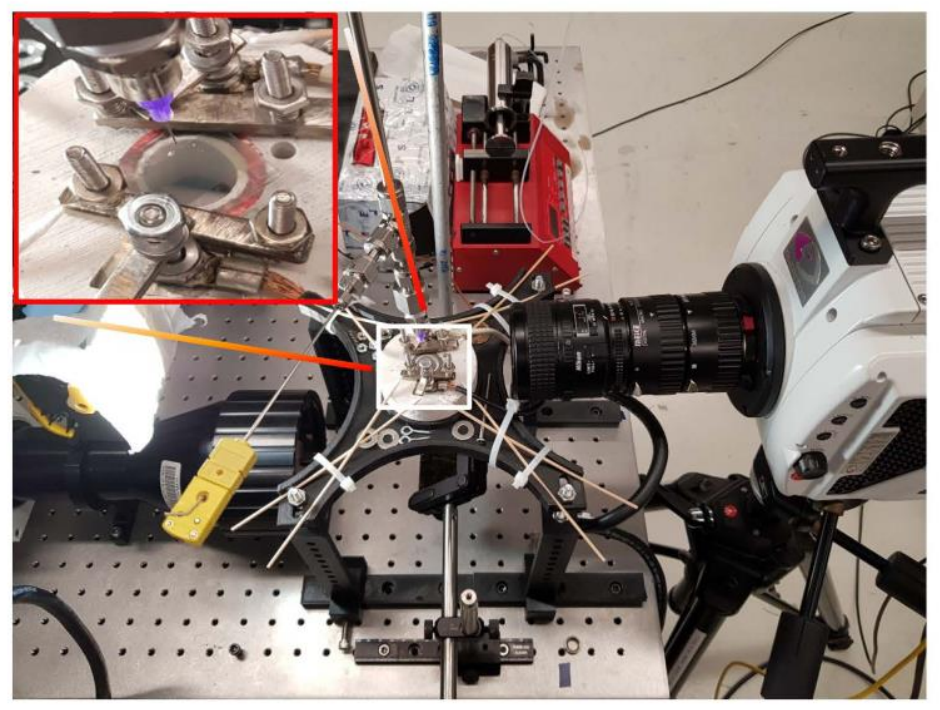

\section{Methodology: IR data post-processing}

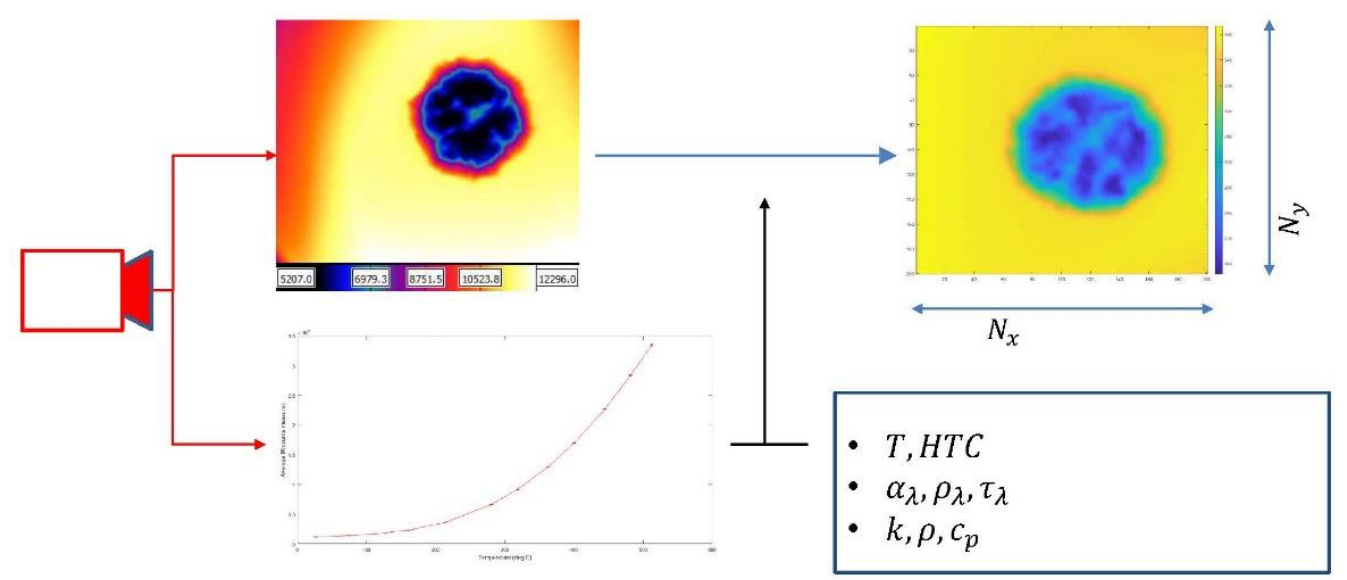




\section{Result}

- Nucleate boiling $\left(\sim 140{ }^{\circ} \mathrm{C}\right)$

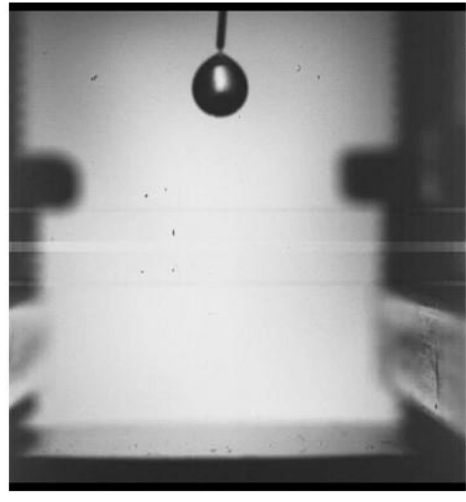

HSV

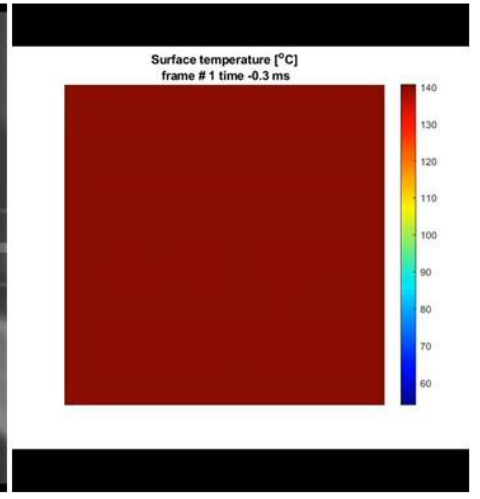

Surface temperature

\section{Result}

- Transient boiling $\left(\sim 240{ }^{\circ} \mathrm{C}\right)$

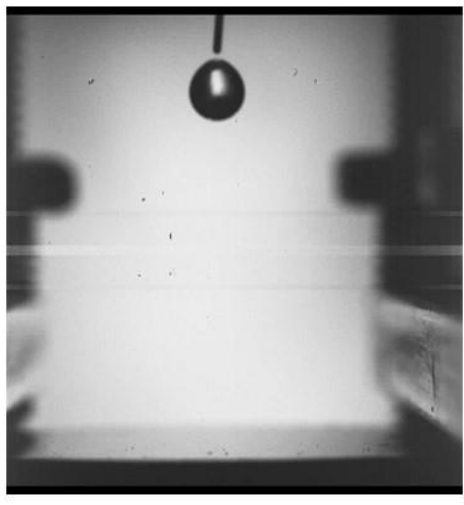

HSV

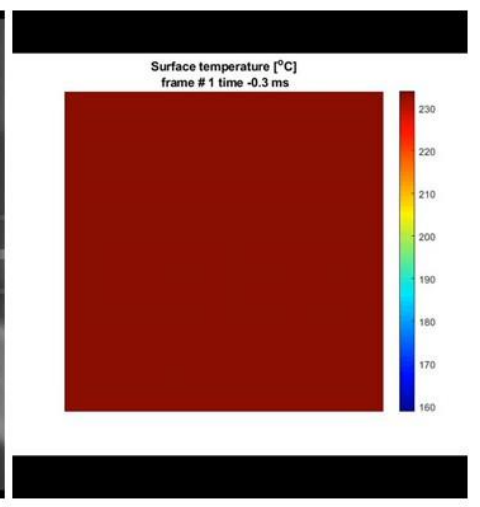

Surface temperature 


\section{Analysis}

- Leidenfrost temperature (hydrodynamic)

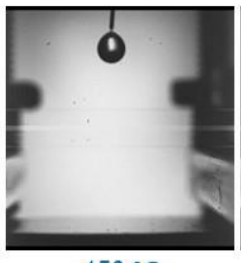

$150^{\circ} \mathrm{C}$

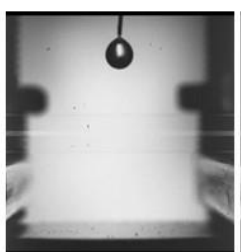

$400{ }^{\circ} \mathrm{C}$

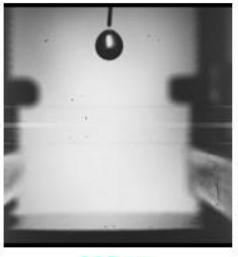

$235^{\circ} \mathrm{C}$

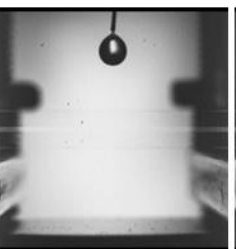

$435^{\circ} \mathrm{C}$

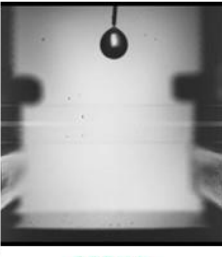

$380^{\circ} \mathrm{C}$

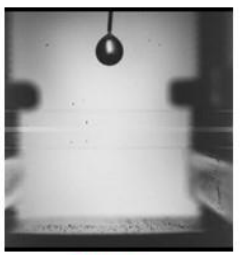

$525^{\circ} \mathrm{C}$

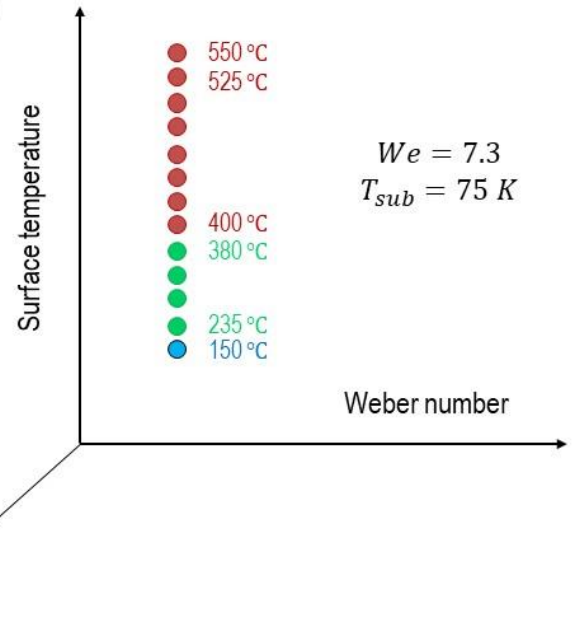

Result

- Film boiling $\left(\sim 520^{\circ} \mathrm{C}\right)$

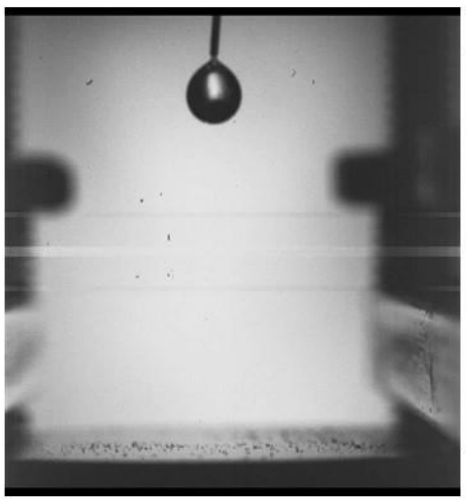

HSV

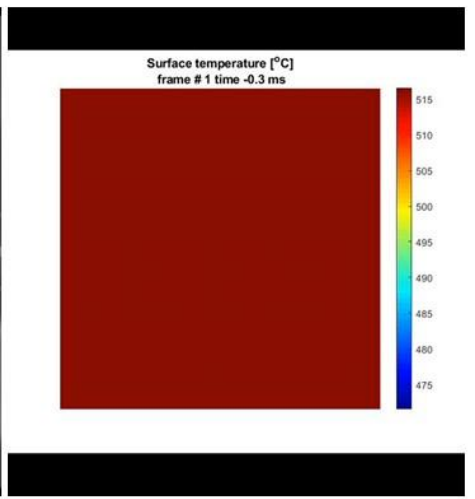

Surface temperature 


\section{Methodology: further IR data post-processing}

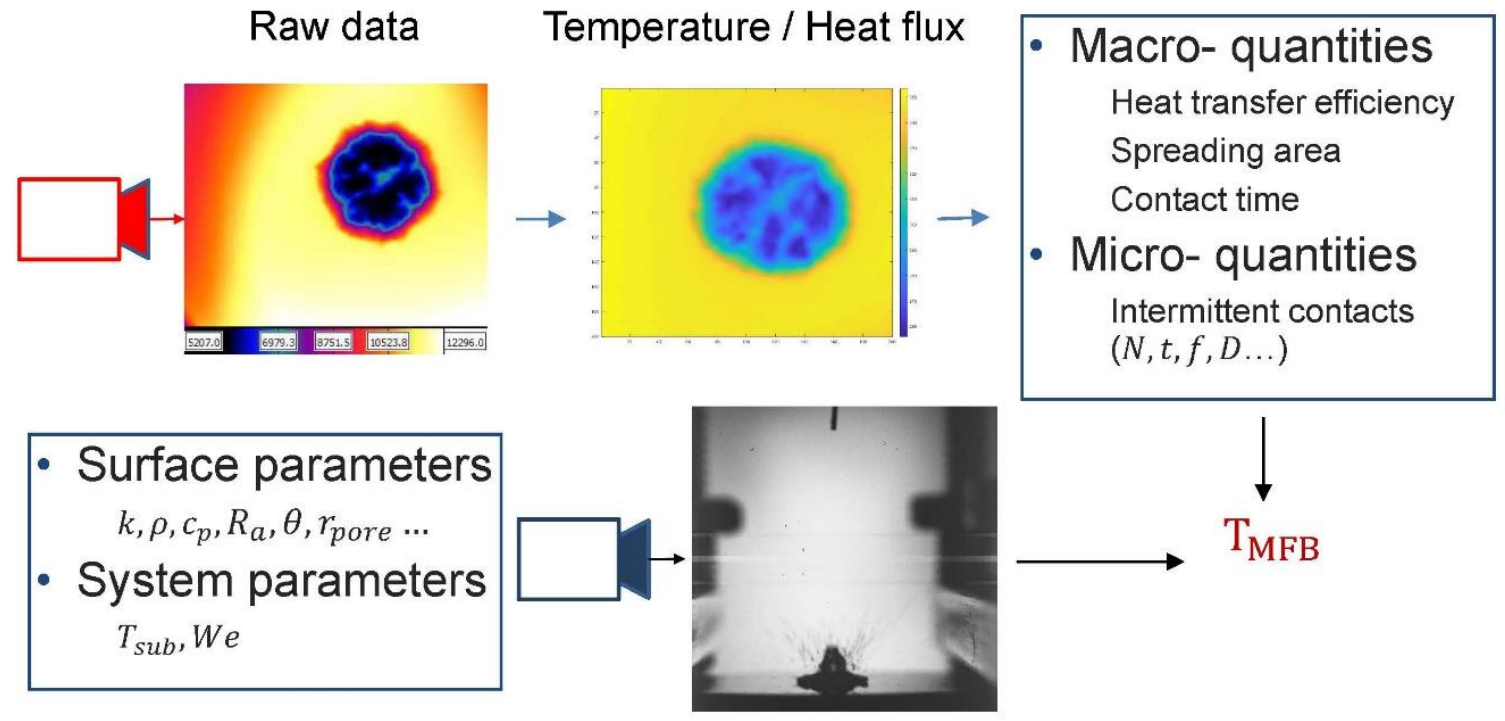

\section{Path forward}

Quantify Leidenfrost temperature of potential ATF coating materials under BWR spray quenching conditions:

Surface material: unoxidized and oxidized Zircaloy, SiC-, Cr-, and FeCrAl-coated Surface finish: nano-smooth and rough (same as PWR claddings) as a function of droplet Weber number and droplet subcooling

\section{Priority}

1. Surface material

2. Surface finish

3. Droplet subcooling

4. Droplet weber number 


\section{Backup slides}

\section{Star CCM+ calculation}

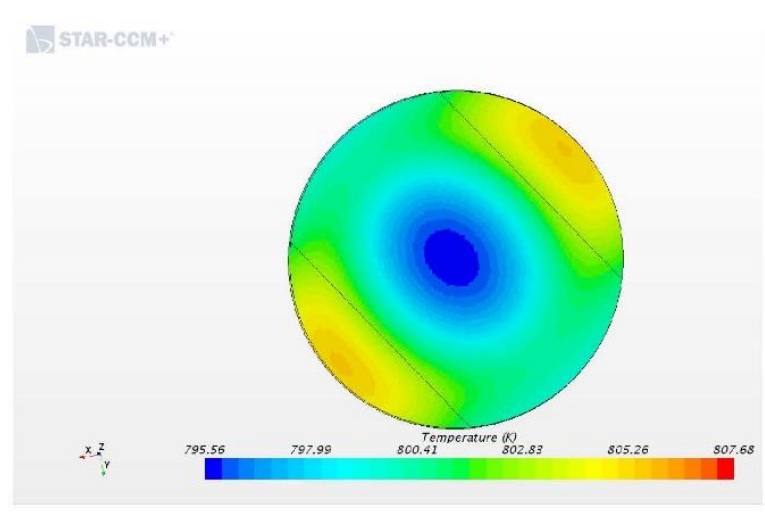

Top view

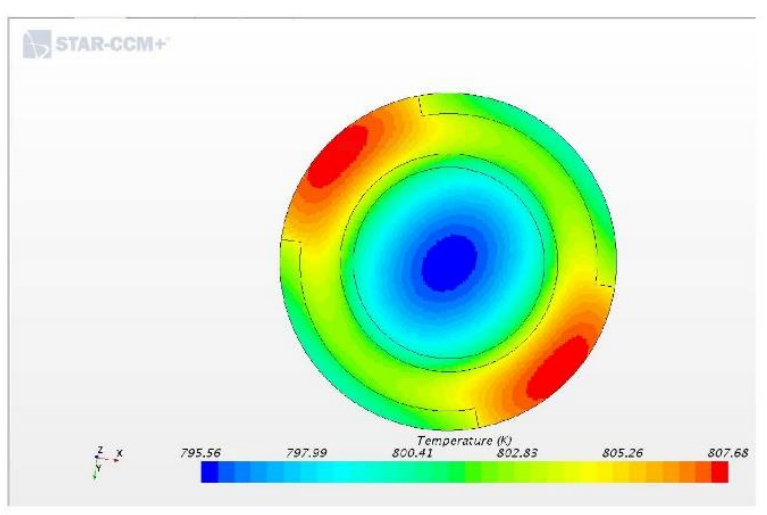

Bottom view

Heat flux $=10 \mathrm{~W}, \mathrm{HTC}=20 \mathrm{~W} / \mathrm{m}^{2} \mathrm{~K}$ 


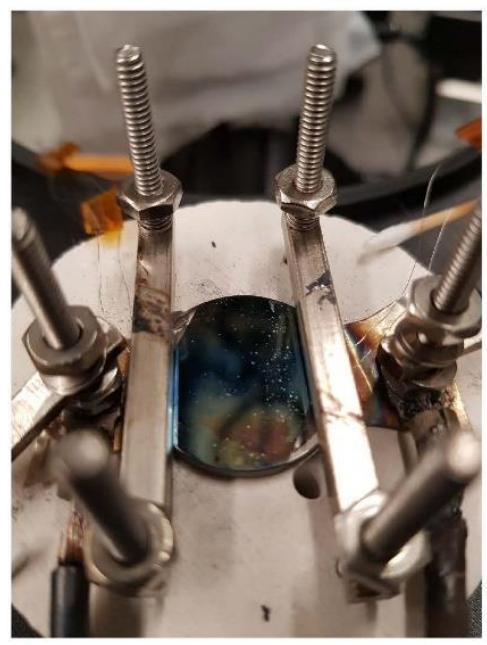

\section{Thermocouple installation}
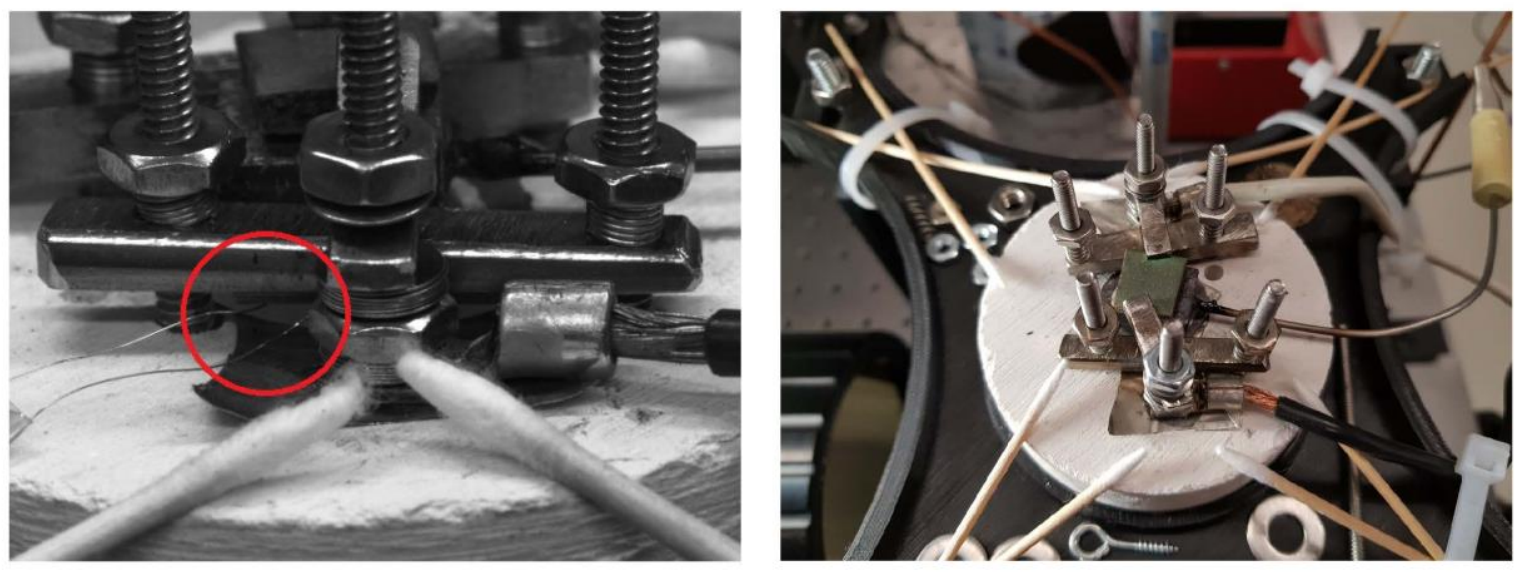


\section{Appendix I}

\section{CHF and CRUD WALT Loop Measurements for Westinghouse Accident-Tolerant Fuel}




\section{Appendix I}

\section{CHF and CRUD WALT Loop Measurements for Westinghouse Accident-Tolerant Fuel}

CHF and CRUD WALT Loop Measurements for Westinghouse Accident Tolerant Fuel

Zeses E. Karoutas, Guoqiang Wang, William A. Byers

${ }^{1}$ Westinghouse Electric Company, LLC

NEUP ATF CHF Meeting at MIT, August 13, 2019

Boston, MA

(2) Westinghouse 


\section{Outline}

- Introduction

- Westinghouse ${ }^{1}$ Encore ${ }^{\circledR}$ Fuel

- Description of WALT Loop Test Facility

- WALT CHF Test Method and Procedure

- WALT Loop CHF Test Results

- CRUD Adherence Testing

- Conclusions and Recommendations

${ }^{1} \mathrm{EnCore}$ is a registered trademark of Westinghouse Electric Company LLC, its affiliates and/or its subsidiaries in the United States of America and may be registered in other

countries throughout the world. All rights reserved. Unauthorized use is strictly prohibited.

Westinghouse Other names may be trademarks of their respective owners."

2

\section{Introduction}

- Westinghouse is developing ATF fuel products which change the cladding surface

- Chromium coated cladding and SiC cladding

- Testing has begun in the WALT loop to evaluate the heat transfer and $\mathrm{CHF}$ performance with and without coating and CRUD relative to current cladding materials

- Testing also being performed to assess adherence of CRUD deposits

(20) Westinghouse 


\section{Westinghouse's EnCore ${ }^{\circledR}$ Fuel}

EnCore ${ }^{\circledR}$ includes both incremental and game changing products to enable a sensible path to achieve full ATF benefits.

EnCore ${ }^{\circledR}$ Products:

$\checkmark$ Advanced Cladding

$\checkmark$ Cr-coated zirconium

$\checkmark \mathrm{SiC}$

$\checkmark$ Advanced Fuel

$\checkmark$ ADOPT ${ }^{\mathrm{TM}}$ doped fuel pellets

$\checkmark \mathrm{U}_{3} \mathrm{Si}_{2}$ pellets

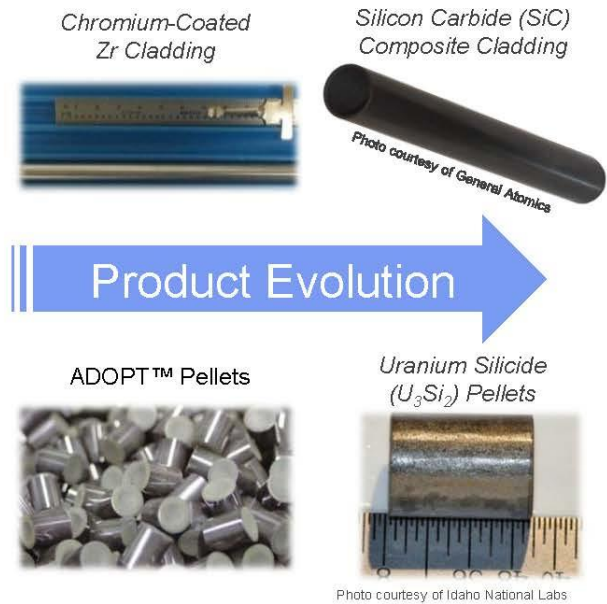

(2) Westinghouse

ADOPT ${ }^{\mathrm{TM}}$, EnCore ${ }^{\circledR}$ ZIRLO ${ }^{\otimes}$ are trademarks or registered trademarks of Westinghouse Electric Company LLC, its affiliates and/or its subsidiaries in the United States of America and may be registered in other countries throughout the world. All rights reserved. Unauthorized use is strictly prohibited. Other names may be trademarks of their respective owners. 4

\section{Description of WALT Loop Test Facility -} Simulate Top Grid Span of PWR Fuel

Westinghouse

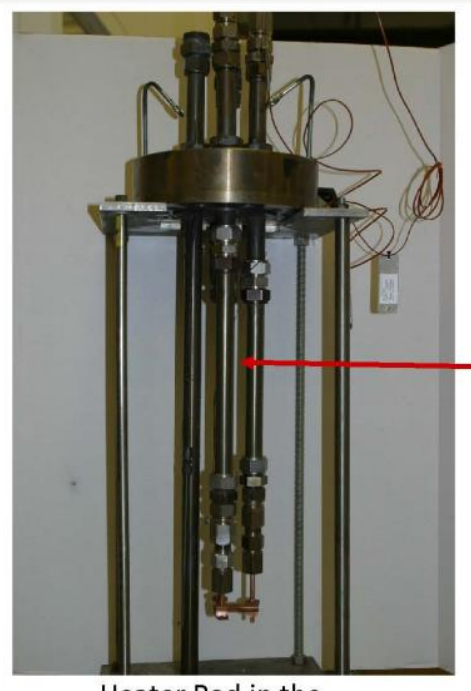

Heater Rod in the

WALT Test Loop

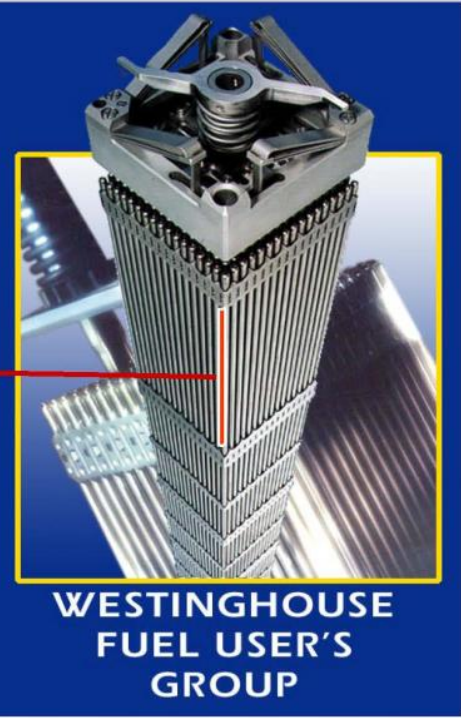

PWR Fuel Assembly 


\section{Description of WALT Loop Test Facility -}

\section{Loop Layout}

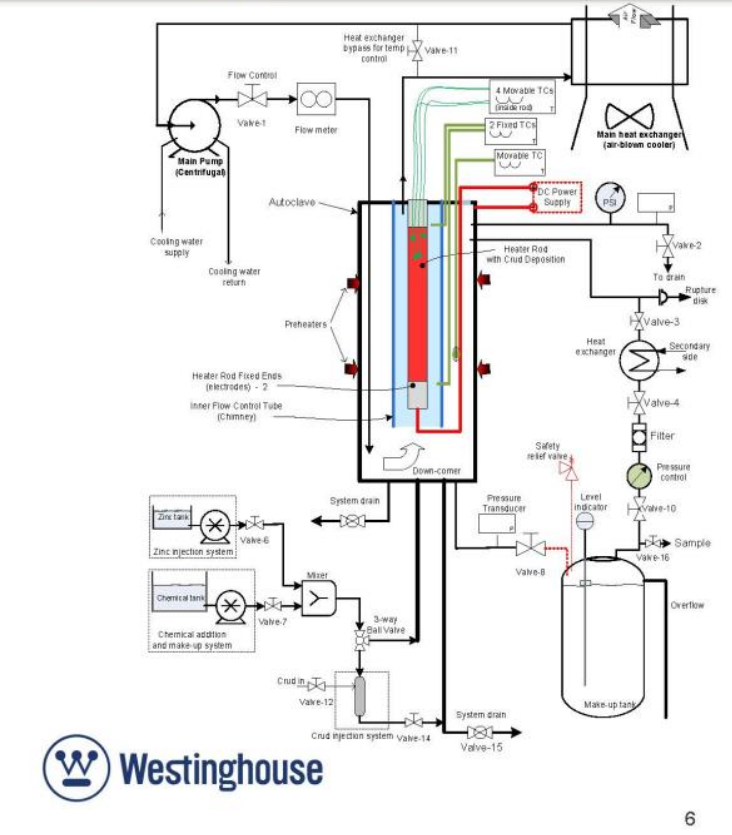

Westinghouse Non-Proprietary Class 3

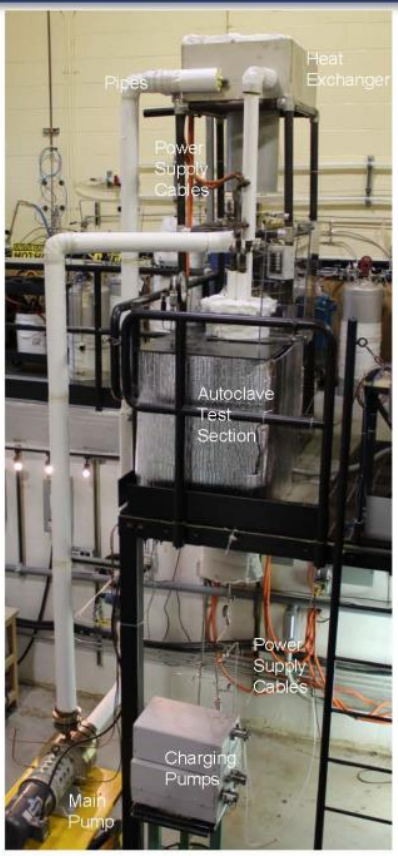

(๑) 2019 Westinghouse Electric Company LLC. All Rights Reserved.

\section{Heater Rod Design - Direct Heating}

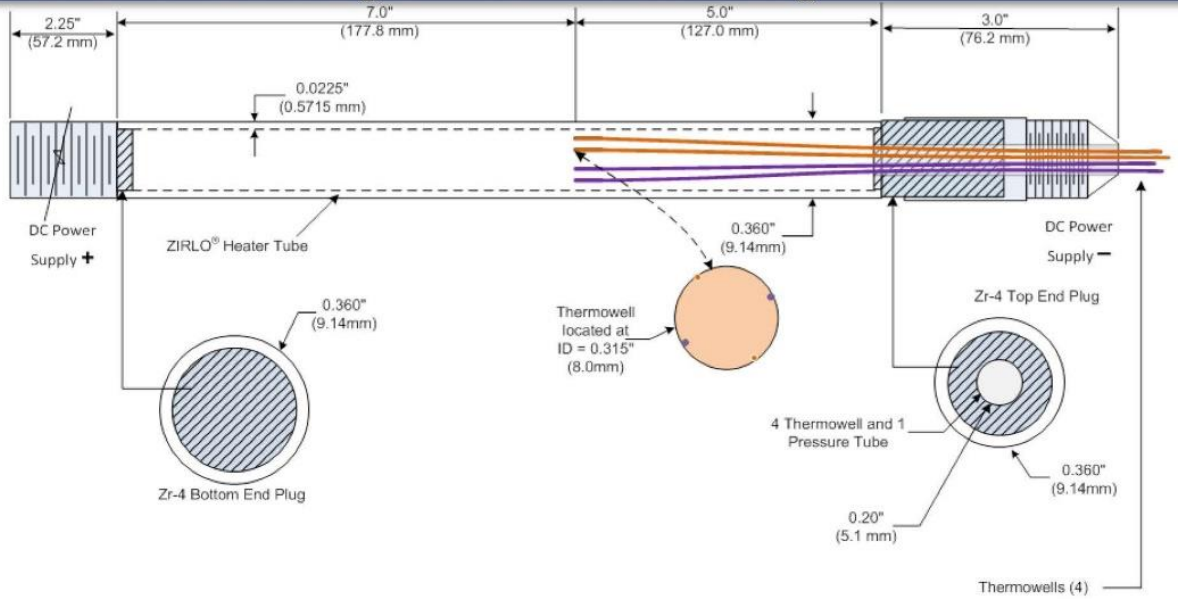

NOT TO SCALE

(20) Westinghouse 


\section{Key Parameters of WALT Loop}

\begin{tabular}{|l|l|}
\hline PARAMETERS & UPPER LIMITS \\
\hline System pressure, $\mathrm{MPa}$ & 17.22 \\
\hline DC power supply, $\mathrm{kW}$ & 90 \\
\hline DC power supply, Amps & 1800 \\
\hline DC power supply, Volts & 100 \\
\hline Heat exchanger, $\mathrm{kW}$ & 31.8 \\
\hline Flow velocity, $\mathrm{m} / \mathrm{s}$ & 6.00 \\
\hline Inlet temperature, ${ }^{\circ} \mathrm{C}$ & $<$ Tsat \\
\hline Axial Power Shape & Uniform \\
\hline Heater rod materials & Inconel, Zr-4, ZIRLO \\
\hline Heater rod length, $\mathrm{m}$ & $<1.35$ (0.33 heated typical) \\
\hline Heater rod OD, $\mathrm{mm}$ & 9.50 \\
\hline Heater rod ID, $\mathrm{mm}$ & $8.35 \sim 9.2$ \\
\hline Test section shroud ID, $\mathrm{mm}^{\circ}$ & 20.96 \\
\hline Test section flow area, $\mathrm{mm}^{2}$ & 274.0 \\
\hline
\end{tabular}

\section{WALT CHF Test Method and Procedure}

\section{DNB Test Procedures:}

- Establish Initial DNB Test Conditions $\square$ Setup desired Flow, exit pressure, and inlet temperature

-Setup 75 80\% predicted CHF power

- Slowly increase power

$\square$ About 5 6 amps per step (for the current WALT loop design)

- Monitor heater rod cladding temperatures

- Observe the temperature excursion

$\square$ See the figures in the left column

- Record DNB conditions

$\square$ Maximum power

(2v) Westinghouse

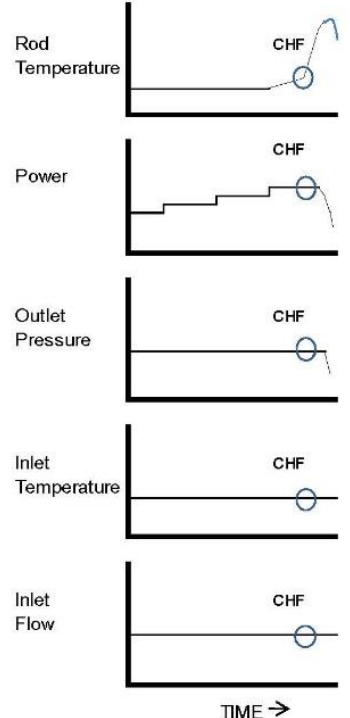




\section{Electrical Resistance Measurement}

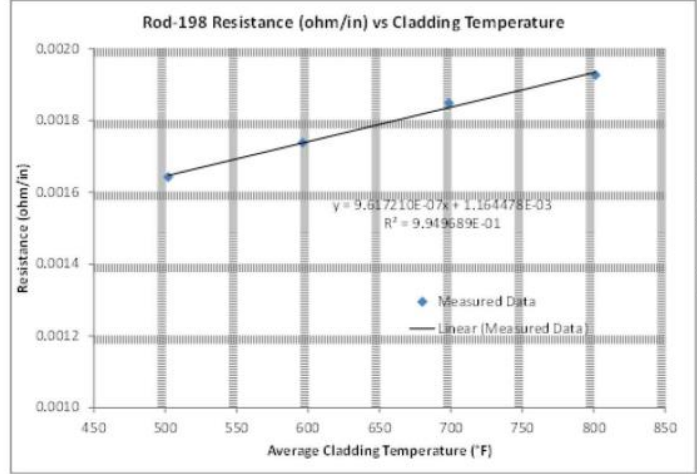

Uncoated Cladding

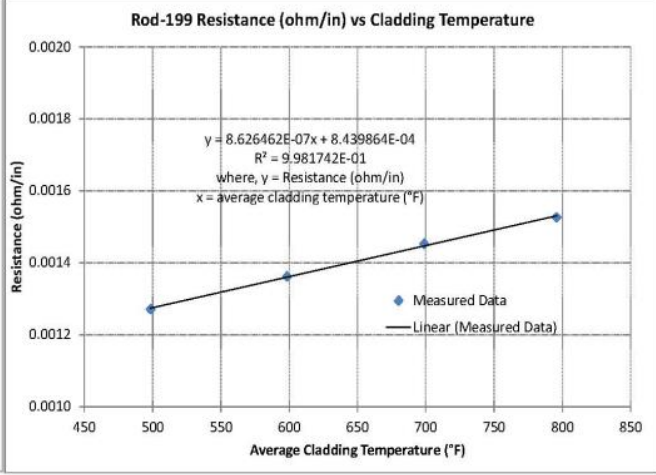

Coated Cladding

Chromium coating had a noticeable impact on measured resistance

\section{(2) Westinghouse}

10

\section{WALT Loop CHF Test Results}

- CHF Tests performed with and without coating

- Test results grouped according to approximate constant $\mathrm{TH}$ conditions

- CRUD was deposited on some tests

- $\mathrm{CHF}$ variation in each region approximately $+/-6 \%$ (w) Westinghouse

\begin{tabular}{|c|c|c|c|c|c|c|c|c|}
\hline Rod \# & Run \# & Cr-Coating & $\begin{array}{l}\text { Average } \\
\text { Crud } \\
\text { Thickness }\end{array}$ & $\begin{array}{c}\text { Inlet } \\
\text { Temperature }\end{array}$ & Flow & Pressure & CHF & $\begin{array}{c}\text { Relative } \\
\text { Change in } \\
\text { CHF } \\
\text { compared } \\
\text { to Average }\end{array}$ \\
\hline & & & Microns & Deg-C & $\mathrm{m}^{3} / \mathrm{hr}$ & bars & $\mathrm{W} / \mathrm{cm}^{2}$ & $\%$ \\
\hline 198 & $1 \mathrm{a}$ & No & 0 & 336.8 & 2.42 & 152.63 & 233.12 & 4.74 \\
\hline 198 & $1 \mathrm{~b}$ & No & 0 & 339.5 & 2.37 & 154.05 & 208.94 & -6.12 \\
\hline 198 & $1 \mathrm{c}$ & No & 0 & 338.7 & 2.42 & 156.58 & 221.22 & -0.60 \\
\hline 193 & $1 \mathrm{a}$ & Yes & 0 & 338.1 & 2.38 & 148.78 & 231.16 & 3.86 \\
\hline 193 & $1 \mathrm{~b}$ & Yes & 0 & 338.1 & 2.40 & 158.99 & 218.37 & -1.88 \\
\hline Average & & & & 338.2 & 2.40 & 154.21 & 222.56 & \\
\hline 198 & $2 a$ & No & 0 & 339.9 & 3.49 & 156.21 & 245.91 & -1.37 \\
\hline 198 & $2 b$ & No & 0 & 340.6 & 3.49 & 156.72 & 256.16 & 2.74 \\
\hline 194 & 1a & Yes & 0 & 339.9 & 3.39 & 153.88 & 241.95 & -2.96 \\
\hline 195 & 1a & Yes & 0 & 339.6 & 3.37 & 151.78 & 249.99 & 0.26 \\
\hline 200 & 1a & Yes & 0 & 338.8 & 3.39 & 153.46 & 239.53 & -3.93 \\
\hline 200 & $1 \mathrm{~b}$ & Yes & 43 & 341.7 & 3.38 & 155.16 & 249.97 & 0.26 \\
\hline 201 & 1a & Yes & 0 & 339.2 & 3.38 & 156.94 & 247.82 & -0.61 \\
\hline 201 & $1 b$ & Yes & 40 & 339.4 & 3.41 & 156.86 & 263.32 & 5.61 \\
\hline Average & & & & 339.9 & 3.41 & 155.13 & 249.33 & \\
\hline 198 & $3 a$ & No & 0 & 329.1 & 3.34 & 128.57 & 258.74 & 0.92 \\
\hline 198 & $3 b$ & No & 0 & 328.3 & 3.41 & 125.08 & 257.88 & 0.58 \\
\hline 199 & 1a & Yes & 0 & 328.7 & 3.22 & 126.78 & 275.70 & 7.53 \\
\hline 202 & 1a & Yes & 0 & 330.6 & 3.00 & 127.90 & 238.65 & -6.92 \\
\hline 202 & $1 b$ & Yes & 21 & 331.1 & 3.25 & 130.52 & 250.97 & -2.11 \\
\hline Average & & & & 329.5 & 3.24 & 127.77 & 256.39 & \\
\hline
\end{tabular}




\section{Typical CHF Test for Rod 198 2b Uncoated No Crud}

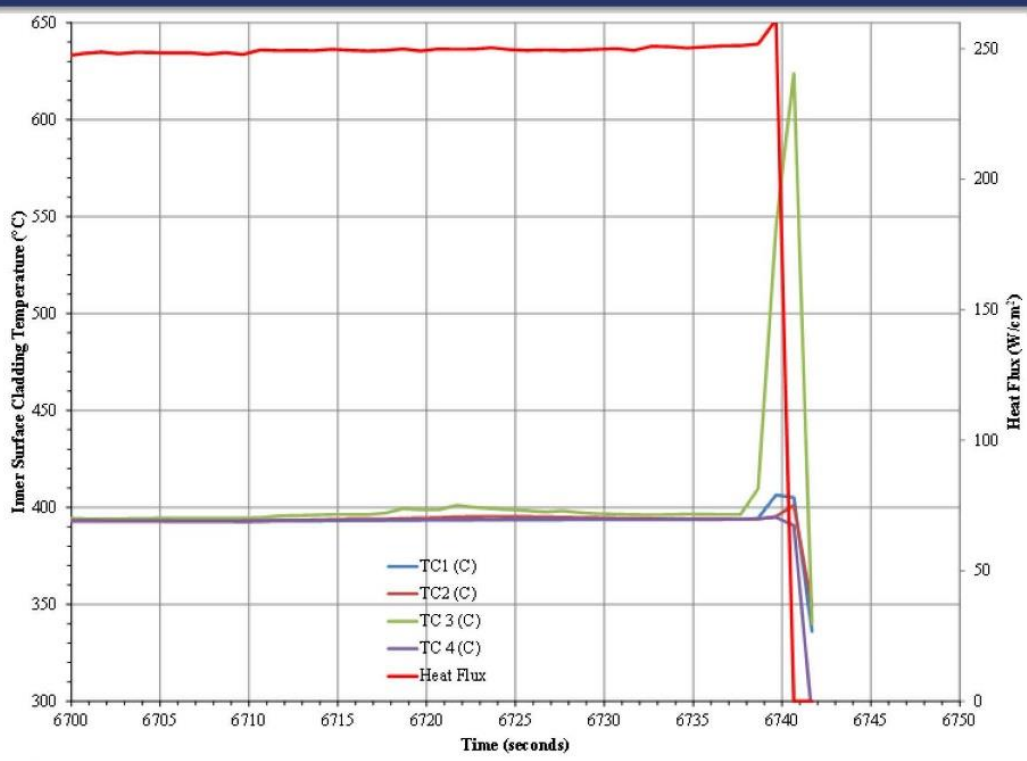

(w) Westinghouse

12

CHF measurements for approximate average $\mathrm{T}-\mathrm{H}$ conditions (Tinlet $338.2^{\circ} \mathrm{C}$, Flow $2.40 \mathrm{~m} 3 / \mathrm{hr}$, Pressure 154.21 bar)

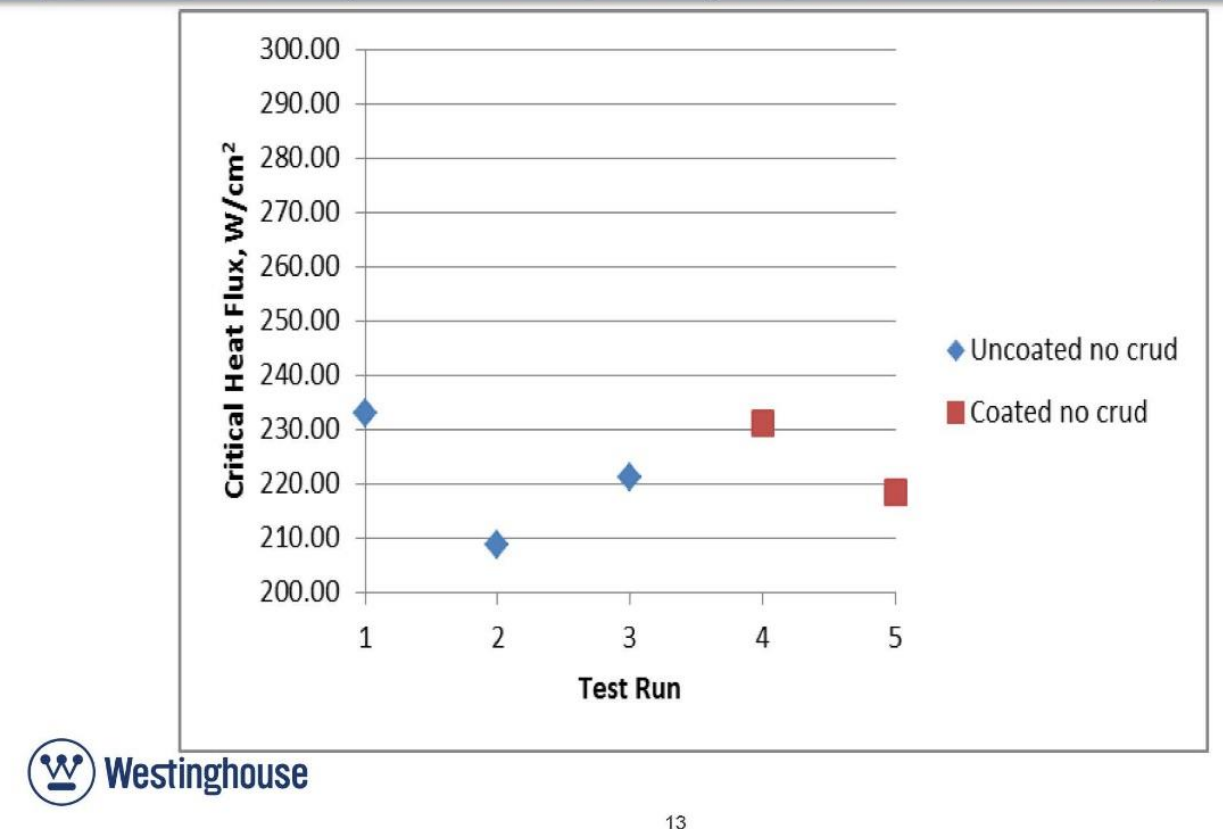


CHF measurements for approximate average $\mathrm{T}-\mathrm{H}$ conditions (Tinlet $339.9^{\circ} \mathrm{C}$, Flow $3.41 \mathrm{~m} 3 / \mathrm{hr}$, Pressure $155.13 \mathrm{bar}$ )

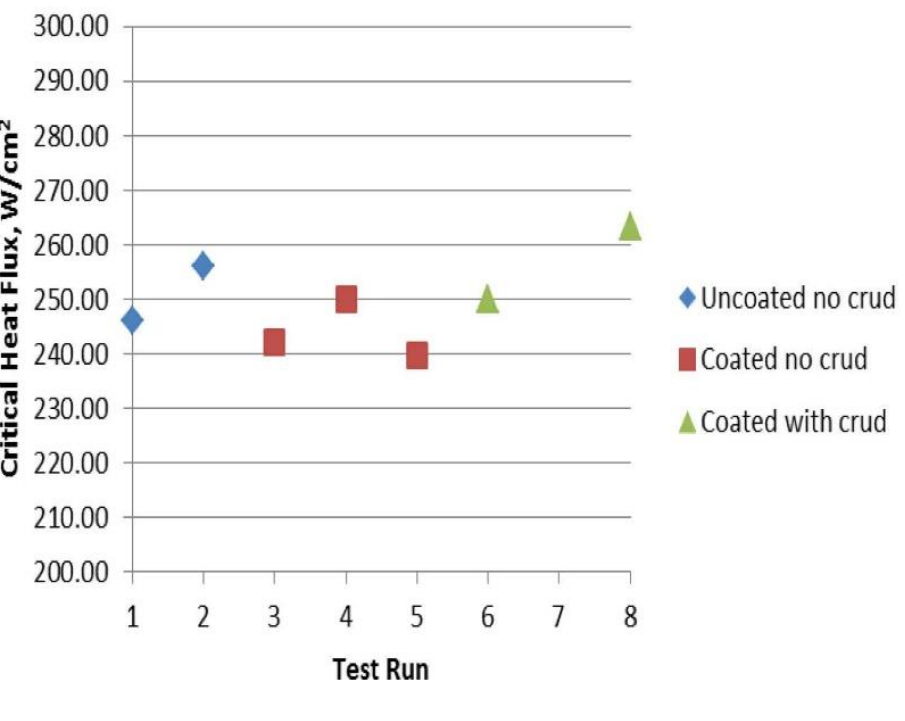

We Westinghouse

14

CHF measurements for approximate average T-H conditions (Tinlet $329.5^{\circ} \mathrm{C}$, Flow $3.24 \mathrm{~m} 3 / \mathrm{hr}$, Pressure 127.77 bar)

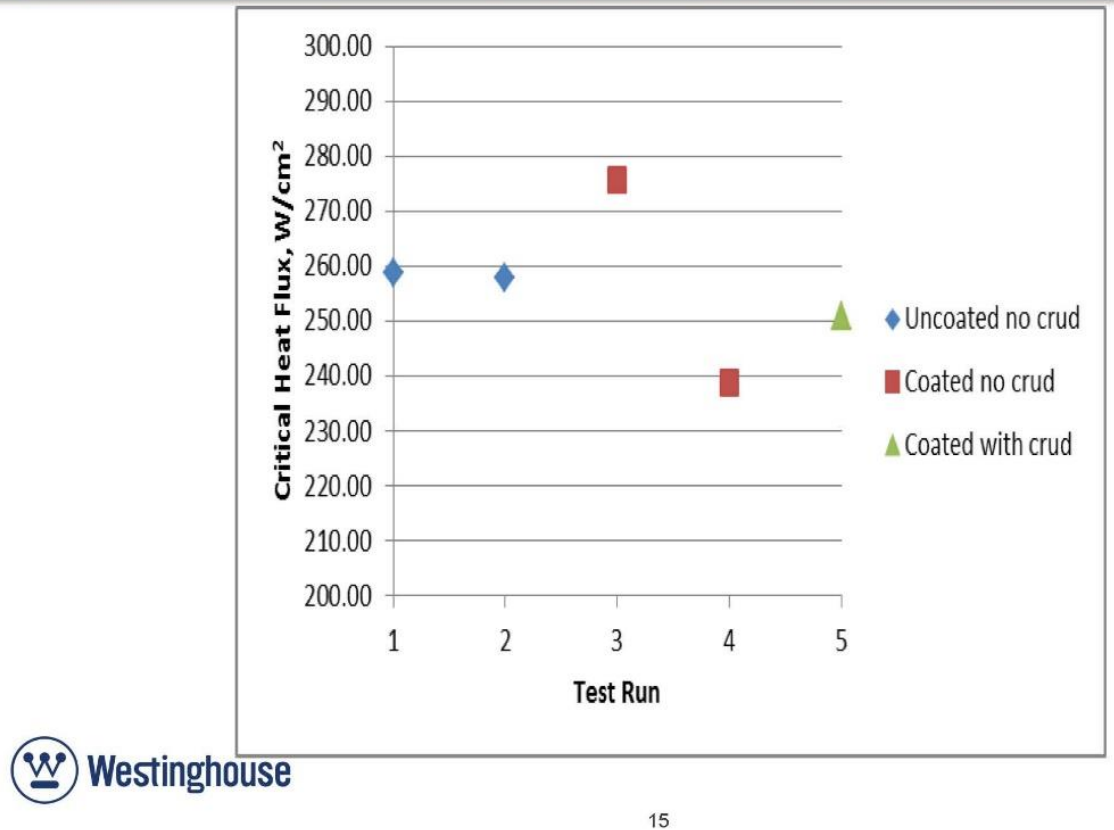




\section{CRUD Testing}

- CHF impact due to coating and/or CRUD deposit appeared to be within the normal variation observed for a clean surface without coating

- CRUD was deposited on coated rods 200, 201 and 202 where CRUD adhered on average of $\sim 5.1$ microns per injection, where CRUD adhered on an uncoated rod $\sim 6.75$ microns suggesting that the coated surface did not increase CRUD adherence

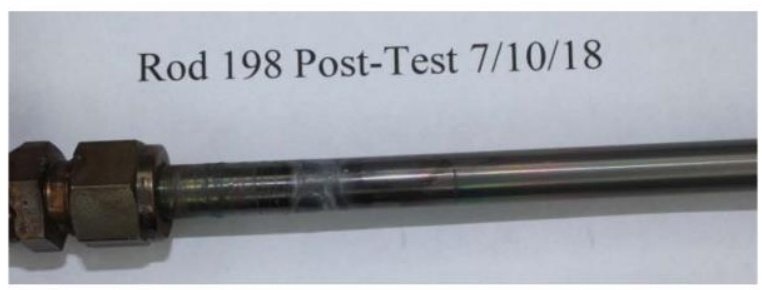

Post-test observation of Rod 198 uncoated surface no crud

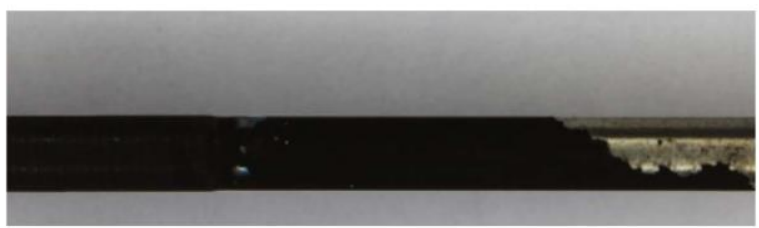

Post-test observation of Rod 200 coated surface with crud

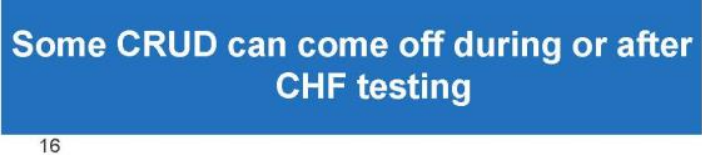

\section{Conclusions and Recommendations}

- Current CHF test data for Cr-coated and crud surfaces using direct type heating suggest $\mathrm{CHF}$ performance is within $\mathrm{CHF}$ variation for clean uncoated cladding surfaces therefore no adverse $\mathrm{CHF}$ impact is expected due to the Westinghouse $\mathrm{Cr}$ coating application.

- The variation observed in WALT loop CHF tests for uncoated and $\mathrm{Cr}$ coated surfaces appear to be somewhat large possibly due to use of direct type heating and not being able to keep T-H conditions close to target for making relative comparisons. It is recommended that future $\mathrm{CHF}$ tests be performed with indirect type heater or more accurate direct heating to possibly reduce scatter and modify loop instrumentation to better control T-H conditions.

- The application of $\mathrm{Cr}$-coating significantly affects electrical resistance. This large change in electrical resistance can introduce more uncertainty in CHF measurements. The use of indirect type heating may help reduce this uncertainty. Some improvement in $\mathrm{CHF}$ maybe observed due to $\mathrm{Cr}$ coated and crud surfaces as a result of using indirect heating. 


\section{Conclusions and Recommendations (Cont.)}

- Further testing is recommended on crud adherence for uncoated and coated surfaces using indirect heating on a single heater rod. The use of electrical current through cladding may have an impact on CRUD deposits and CHF measurements

- Future CHF testing is recommended to be performed to determine how long an ATF cladding surface can stay in DNB without damage to the cladding. These tests shall be performed for $\mathrm{Cr}$ coated and $\mathrm{SiC}$ cladding type surfaces.

Current CHF testing of ATF surfaces at reactor conditions and chemistry appear to show no adverse impact

\section{(20) Westinghouse}

18

(20) Westinghouse 


\section{Heater Rod Design - Direct Heating}

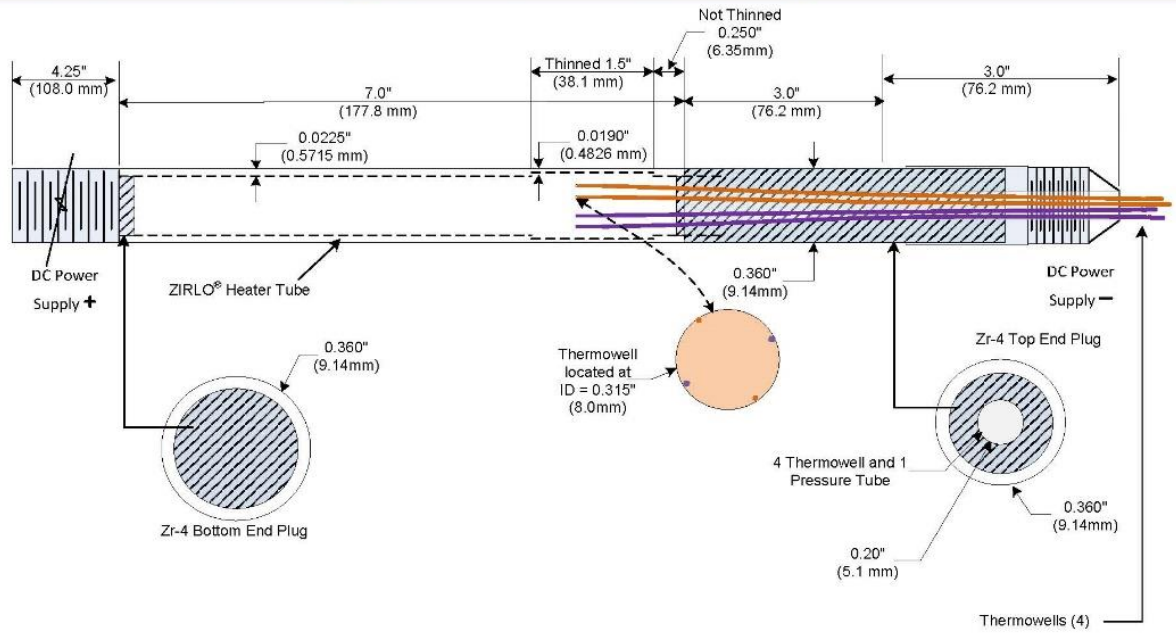

\section{WALT DNB Tests - High Level Planning}

- WALT DNB/CHF Test Planning

$\square$ Low Flow Cases To provide benefits for DNB limiting cases of a loss of flow or locked rotor event, with a transient time of a few seconds

$\square$ Core Limit Cases: To cover a pressure range from 1800 psia to close to 2400 psia Tinlet Cases: To cover a range of inlet temperatures

$\square$ Crud Cases: Perform DNB tests before and after crud deposition

$\square$ Selected Cases: Listed on next table

W. Westinghouse 


\section{WALT DNB Test Matrix - Selected Cases}

\begin{tabular}{|c|c|c|c|c|c|c|}
\hline & \multicolumn{2}{|c|}{$\begin{array}{l}\text { Flow } \\
\text { (gpm) }\end{array}$} & \multicolumn{2}{|c|}{$\begin{array}{c}\text { Pressure } \\
\text { (psia) }\end{array}$} & \multicolumn{2}{|c|}{$\begin{array}{l}\text { Tinlet } \\
\left({ }^{\circ} \mathrm{F}\right)\end{array}$} \\
\hline & $60 \%$ & Normal & 1800 & 2250 & 605 & 635 \\
\hline Tube-1 & $\checkmark$ & & & $\checkmark$ & & $\checkmark$ \\
\hline Tube-2 & & $\checkmark$ & & $\checkmark$ & & $\checkmark$ \\
\hline Tube-3 & & $\checkmark$ & $\checkmark$ & & $\checkmark$ & \\
\hline Crud & & $\checkmark$ & & $\checkmark$ & & $\checkmark$ \\
\hline Transient & $\checkmark$ & & & $\checkmark$ & & $\checkmark$ \\
\hline
\end{tabular}

(2) Westinghouse

22

Westinghouse Non-Proprietary Class 3

๑) 2019 Westinghouse Electric Company LLC. All Rights Reserved.

\section{DNB Test Results for Rod\#239 - With Clean} Optimized Zirlo Tube

\begin{tabular}{|c|c|c|c|}
\hline Parameters & Rod239-Casel & Rod239-Case2 & Rod239-Case3 \\
\hline System Pressure, MPa & 15.5 & 15.5 & 15.5 \\
\hline $\begin{array}{l}\text { Chimney Inlet } \\
\text { Temperature, }{ }^{\circ} \mathrm{F}\end{array}$ & 636.0 & 635.0 & 635.0 \\
\hline $\begin{array}{l}\text { Chimney Inlet Flow } \\
\text { Velocity, } \mathrm{m}^{3} / \mathrm{h}\end{array}$ & 3.27 & 3.29 & 3.21 \\
\hline $\begin{array}{l}\text { Heat Flux (main center } \\
\text { section), W/ } \mathrm{cm}^{2}\end{array}$ & 399.3 & 367.3 & 374.3 \\
\hline (2) Westinghouse & & $\begin{array}{l}\text { the initial DN } \\
\text { peated CHF r }\end{array}$ & $\begin{array}{l}n \text {, the } 2^{\text {nd }} \text { and } 3^{\text {rd }} \\
\text { ts are within } 2 \%\end{array}$ \\
\hline
\end{tabular}




\section{CHF Test Results for Rod 239 Uncoated No Crud}

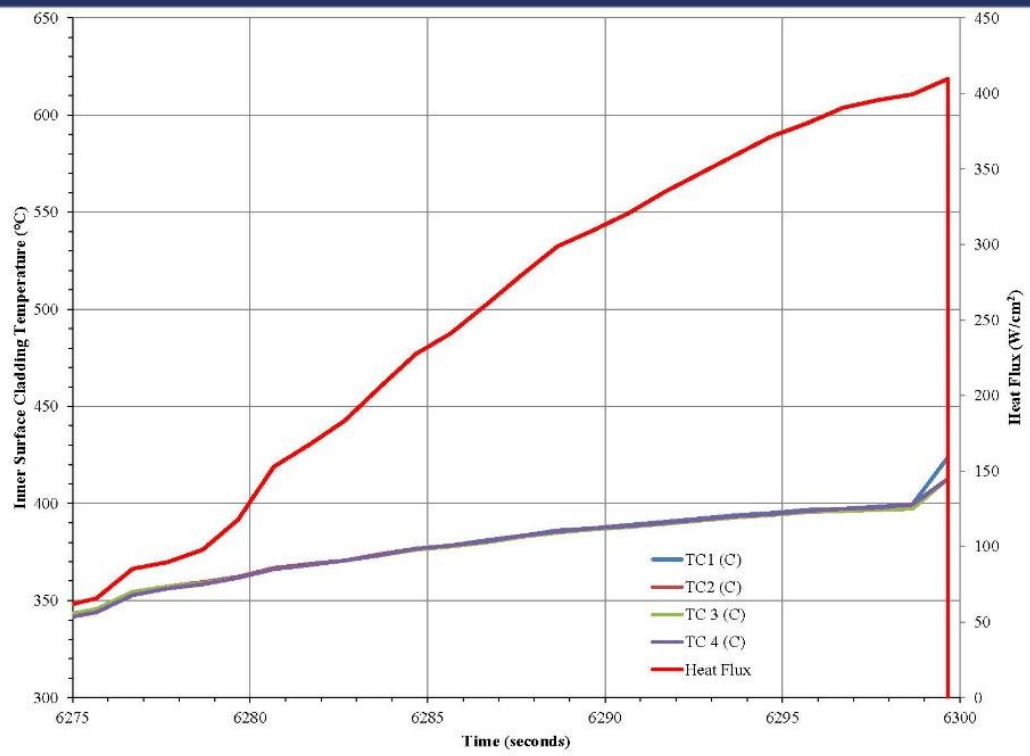

(W) Westinghouse

24

Westinghouse Non-Proprietary Class 3

๑๑ 2019 Westinghouse Electric Company LLC. All Rights Reserved.

\section{DNB Test Results for Rod\#242 - With Cr-Coated} Optimized Zirlo Tube (Flow was higher than the Ref.)

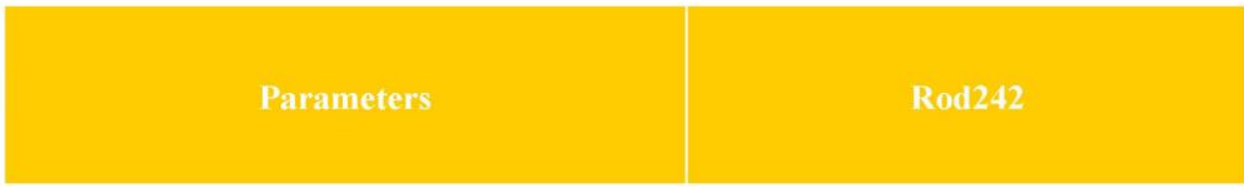

System Pressure, MPa

Chimney Inlet Temperature, ${ }^{\circ} \mathrm{F}$

Chimney Inlet Flow Velocity, $\mathrm{m}^{3} / \mathrm{h}$

Heat Flux (main center section), W/ $\mathrm{cm}^{2}$
450.2

15.5

634.0

3.52

Comparing with the Optimized Zirlo Tube, the CHF results are increased by $12.7 \%$

We Westinghouse 


\section{CHF Test Results for Rod 242 Cr-coated}

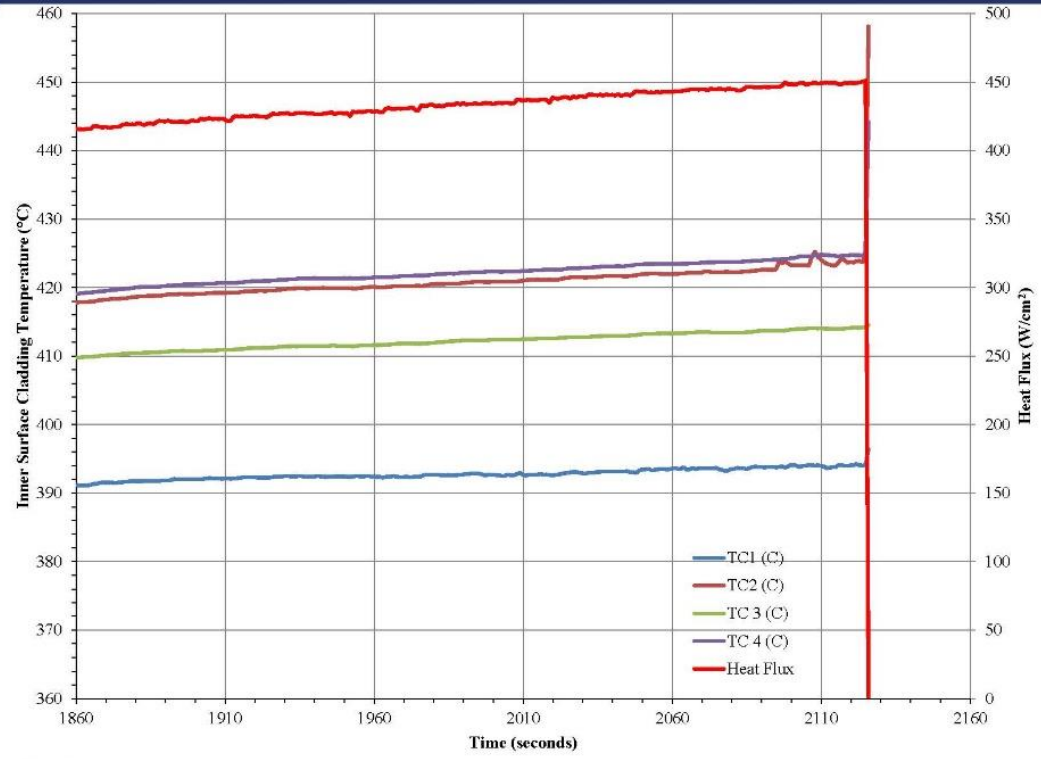

We Westinghouse 
Appendix $\mathbf{J}$

\section{In-Pile CHF Experiments at TREAT and Related CHF Activities}




\section{Appendix $\mathbf{J}$}

\section{In-Pile CHF Experiments at TREAT and Related CHF Activities}

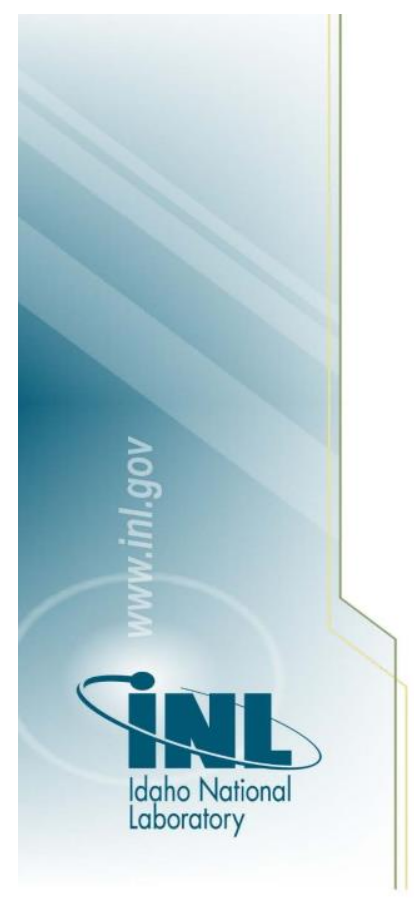

\section{In-Pile CHF Experiments at TREAT and Related CHF Activities}

C. Folsom, C. Jensen, N. Woolstenhulme, N. Smith, K. Condie Idaho National Laboratory

K. Terrill, R. Christensen

University of Idaho

N. Brown, R. Hernandez

University of Tennessee, Knoxville

NEUP-ATF Meeting

August 13, 2019

Cambridge, MA

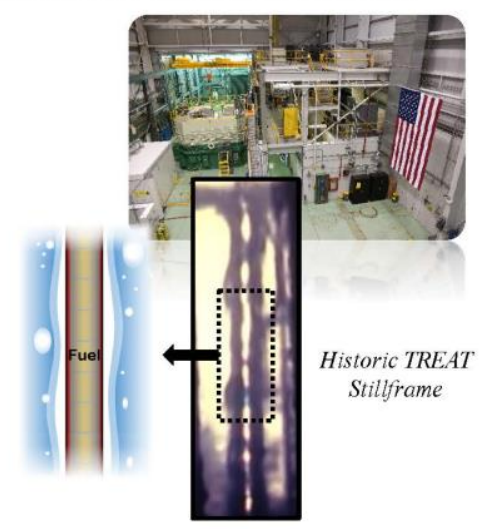




\section{Introduction}

- Cladding-to-coolant heat transfer during transient irradiation conditions remains a critical area of uncertainty in fuel performance predictive capability

- Key safety limits for LWRs are intended to avoid critical heat flux (CHF)

In the US a limiting DNBR is defined such that fuel rods will not experience CHF during normal or expected operation (Condition I and II events). This limit is also used to indicate fuel failures for some postulated accidents (Condition III and IV events) in evaluating off-site dose rates.

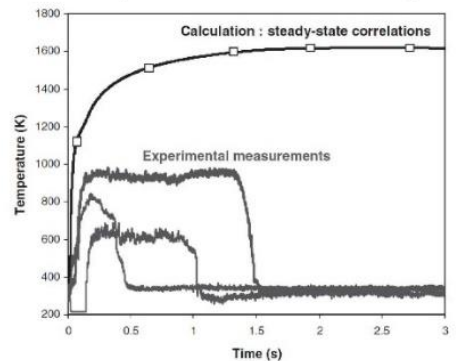

Experimental measured cladding surface temperature during RIA experiments in NSRR V. Bessiron, (2007) J. Nucl. Sci. Technol. 44 (5) $723-732$

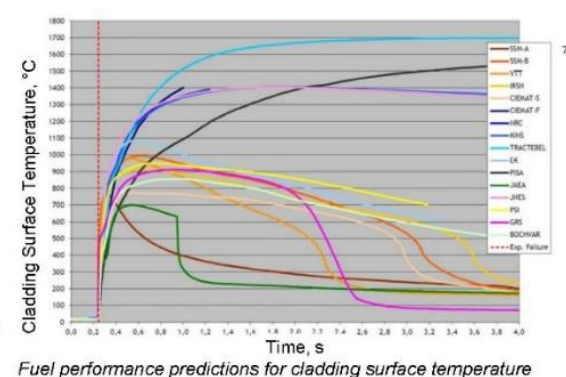

Fuel performance predictions for cladding surface temperature during RIA (NEAVCSNI/R(2013)7)

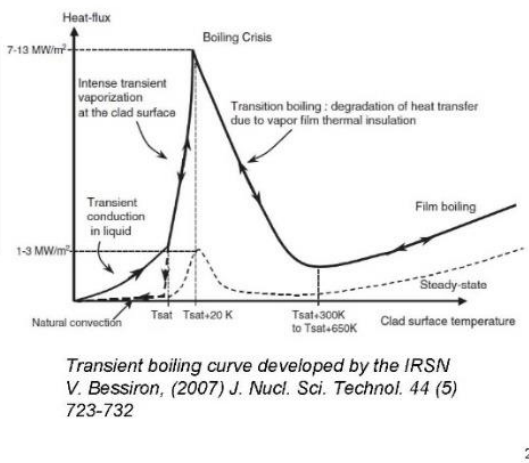

Idaho National Laboratory

\section{Experimental Background}

- Few relevant out-of-pile experimental transient boiling studies (exponentially escalating heat input) Primarily ribbons and wires over a very limited range of pressures ${ }^{[1]}$

- Noteworthy studies for relevant geometry and conditions:

NSRR in-pile tests

JMTR study on radiation induced surface activation (RISA)[2]

- PATRICIA facility - out-of-pile with prototypic thermal-hydraulic capability (few data) ${ }^{[3]}$

- For RIA transients, data shows small dependence on mass flux and subcooling - important effect from irradiation

Pre-irradiation effect on transient boiling performance in NSRR experiments, Udagawa et al., Proc. of WRFPM 2014

[1] Su G., et al. Int. J. Heat Mass [2] Sibamoto $Y$, et at, NuCl $\mathrm{SCl}$ Technol., Vol. 44, NNo. 2, 2007, pp. 183 193.

[3] Bessiron, $V$, et al, J. NuCl. Sol. Technol, Vol. 44, No. 5, 2007, pp. 723
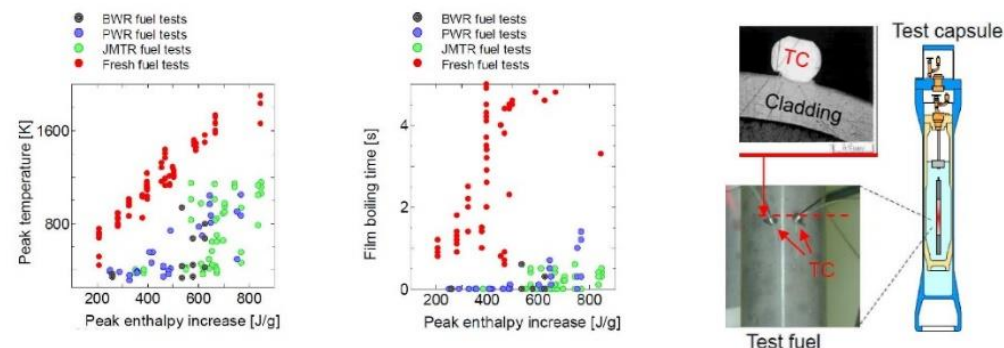


\section{TIDIdaho National Laboratory}

\section{Impacts on Fuel Performance}

- Bison uncertainty quantification and sensitivity analysis using 21 inputs on fuel rod geometry, thermal-hydraulic boundary conditions, core power conditions, and physical properties/models $\pm 25 \%$ factor on HTC

- One sided factor on CHF varied from 1-2 (SD of $50 \%$ )

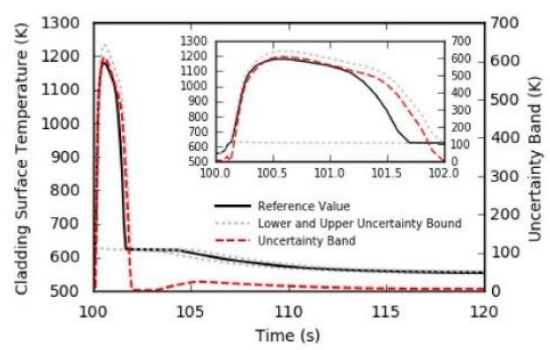

\begin{tabular}{|c|c|c|c|c|c|c|c|c|c|c|c|}
\hline \multicolumn{12}{|c|}{ Sobol Indices } \\
\hline \begin{tabular}{|l} 
NPUT paramater \\
\end{tabular} & RAE & TFC & TFO & $\mathrm{TCl}$ & TCO & CTHS & CHS & FOR & PHS & GAP & $\mathrm{HFC}$ \\
\hline Cladding outside diameter & 0.009 & 0.010 & 0.003 & 0.003 & 0.003 & 0.007 & 0.004 & 0.005 & 0.005 & 0.003 & 0.003 \\
\hline Cladding inside diameter & 0.004 & 0.003 & 0.010 & 0.003 & 0.003 & 0.329 & 0.198 & 0.009 & 0.132 & 0.110 & 0.002 \\
\hline Fvel outer diameter & 0.008 & 0.007 & 0.007 & 0.002 & 0.002 & 0.080 & 0.042 & 0.135 & 0.030 & 0.034 & 0.007 \\
\hline Fuel porosity & 0.014 & 0.015 & 0.004 & 0.004 & 0.003 & 0.003 & 0.003 & 0.005 & 0.004 & 0.003 & 0.004 \\
\hline Cladding roughness & 0.009 & 0.007 & 0.076 & 0.014 & 0.010 & 0.007 & 0.017 & 0.007 & 0.011 & 0.005 & 0.421 \\
\hline Fuel roughness & 0.005 & 0.004 & 0.063 & 0.016 & 0.011 & 0.000 & 0.021 & 0.001 & 0.005 & 0.000 & 0.431 \\
\hline Filling gas pressure & 0.001 & 0.001 & 0.001 & 0.002 & 0.001 & 0.002 & 0.002 & 0.002 & 0.001 & 0.001 & 0.001 \\
\hline Coolant pressure & 0.004 & 0.004 & 0.005 & 0.007 & 0.006 & 0.005 & 0.005 & 0.001 & 0.004 & 0.003 & 0.003 \\
\hline Coolant inlet temperature & 0.006 & 0.006 & 0.008 & 0.011 & 0.011 & 0.004 & 0.008 & 0.005 & 0.005 & 0.001 & 0.003 \\
\hline Coolant velocity & 0.005 & 0.005 & 0.001 & 0.001 & 0.001 & 0.009 & 0.003 & 0.010 & 0.005 & 0.004 & 0.006 \\
\hline Injected energy in the rod & 0.863 & 0.868 & 0.228 & 0.096 & 0.060 & 0.185 & 0.012 & 0.273 & 0.176 & 0.156 & 0.008 \\
\hline FWHM pulse width & 0.009 & 0.004 & 0.015 & 0.005 & 0.003 & 0.004 & 0.001 & 0.003 & 0.004 & 0.003 & 0.005 \\
\hline Fuel thermal conductivity model & 0.005 & 0.005 & 0.036 & 0.015 & 0.010 & 0.003 & 0.013 & 0.004 & 0.004 & 0.001 & 0.003 \\
\hline Clad thermal conductivity model & 0.006 & 0.006 & 0.008 & 0.007 & 0.005 & 0.006 & 0.002 & 0.005 & 0.007 & 0.004 & 0.006 \\
\hline Fuel thermal expansion model & 0.002 & 0.002 & 0.006 & 0.004 & 0.004 & 0.327 & 0.160 & 0.507 & 0.123 & 0.208 & 0.002 \\
\hline Clad thermal expansion model & 0.003 & 0.003 & 0.002 & 0.002 & 0.002 & 0.002 & 0.003 & 0.002 & 0.005 & 0.008 & 0.002 \\
\hline Clad Yield stress & 0.003 & 0.003 & 0.001 & 0.002 & 0.002 & 0.001 & 0.008 & 0.002 & 0.005 & 0.003 & 0.001 \\
\hline Fuel enthalpy & 0.079 & 0.091 & 0.010 & 0.006 & 0.005 & 0.019 & 0.010 & 0.031 & 0.012 & 0.034 & 0.003 \\
\hline clad toc & 0.004 & 0.003 & 0.111 & 0.162 & & & & & & & \\
\hline Coolant CHF factor & 0.012 & 0.009 & 0.370 & 0.643 & 0.702 & 0.013 & 0.350 & 0.013 & 0.312 & 0.056 & 0.007 \\
\hline Gas conductivity facto & -0.004 & -0.003 & 0.016 & 0.003 & - & -0.04 & -0.003 & -0.008 & 0.010 & 0.002 & 0.060 \\
\hline $\mathrm{mm}$ & $100 \times$ & 1 & & 1007 & 1014 & & & & & & \\
\hline
\end{tabular}

Fin. Idaho National Laboratory

\section{How to capture early phase RIA Thermal Hydraulics?}

- Coolant flow-rate has no clear effect on the CHF from RIA experiments

- Pool conditions in autoclave and MARCH-SERTTA capsules will be adequate to assess early phase (pre-DNB) transient boiling behavior
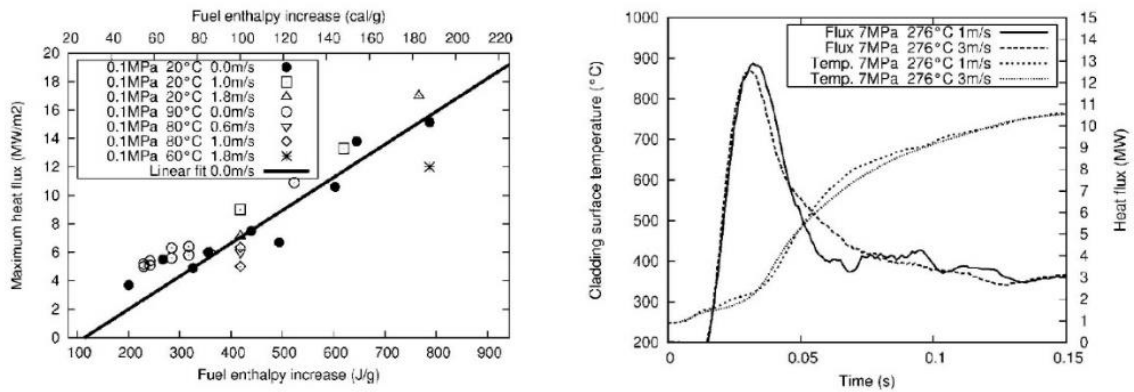


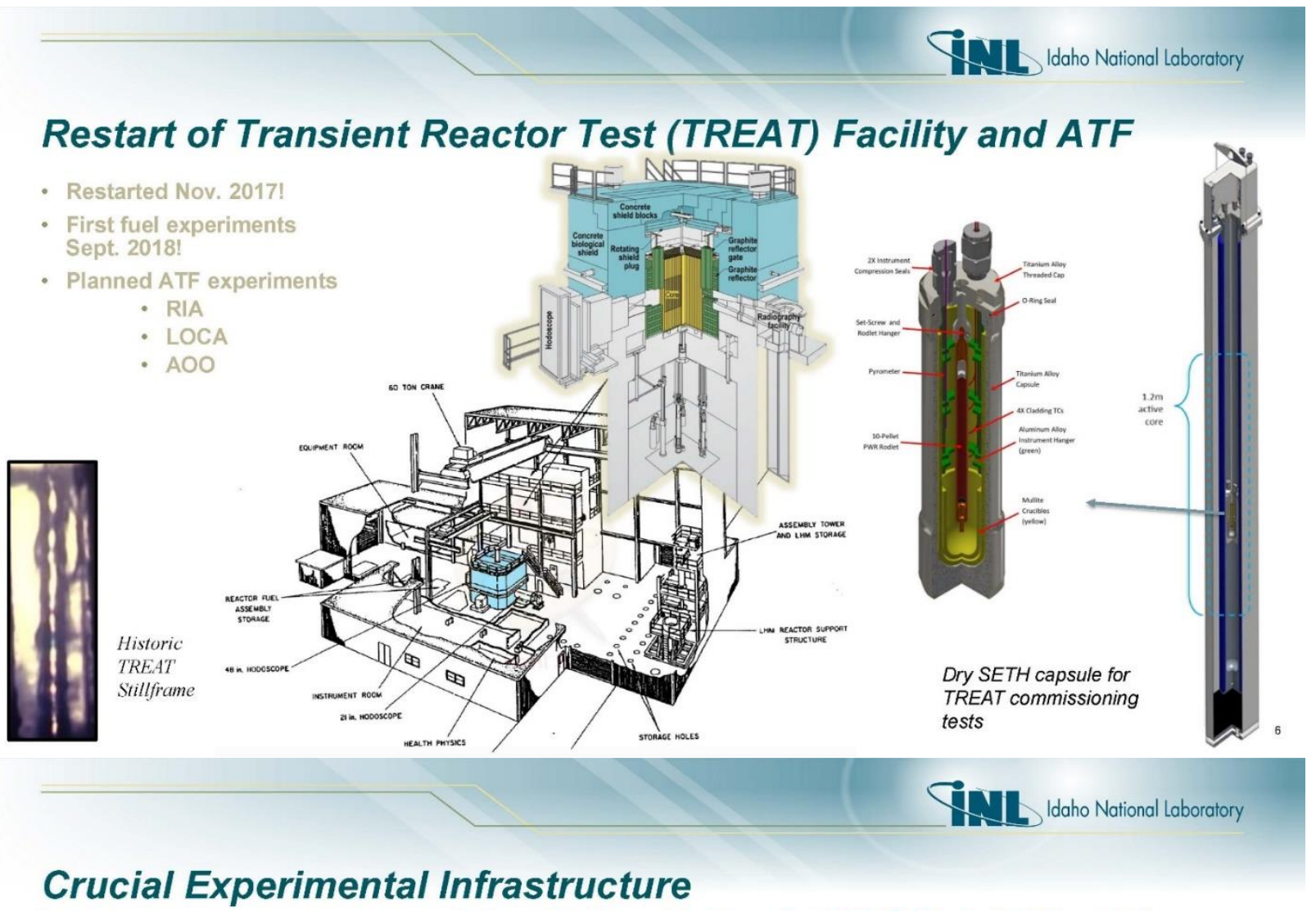

- TREAT is open for business running experiments since 2018!

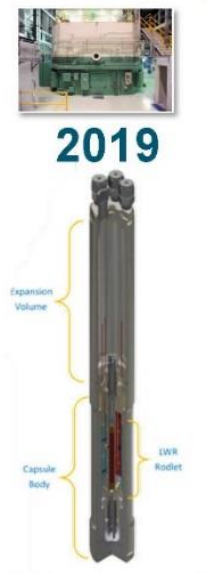

Static water capsule

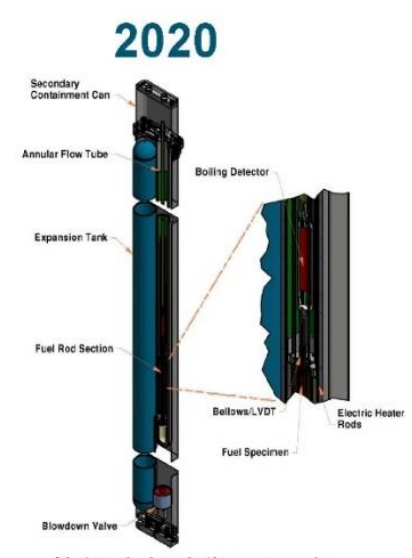

Natural circulation capsule with blowdown capability Full PWR/BWR pressures and temperatures - varying by flow

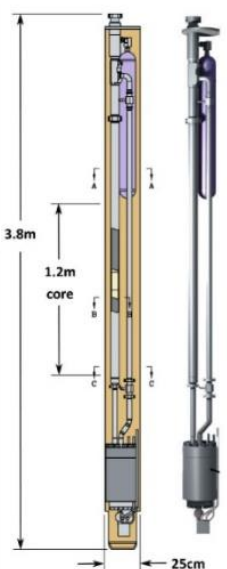

Full flow recirculating loop

2023
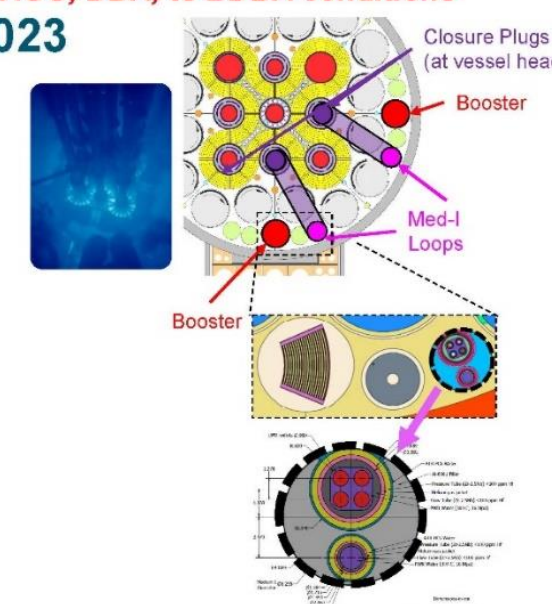

Proposed i-loop in ATR includes dryout studies 


\section{In-Pile CHF-SERTTA Experiment Design}

- Planned to utilized MARCHSERTTA module for watersubmerged rodlet testing

- Conaxes for up to $12 \mathrm{X} 1 \mathrm{~mm}$ leads

- Enables significant instrumentation opportunity

Boiling detector

Dual IR pyrometer (rod internal)

- Surface TC's

Acoustic sensor

- Planned experiment in $1^{\text {st }}$ half FY20

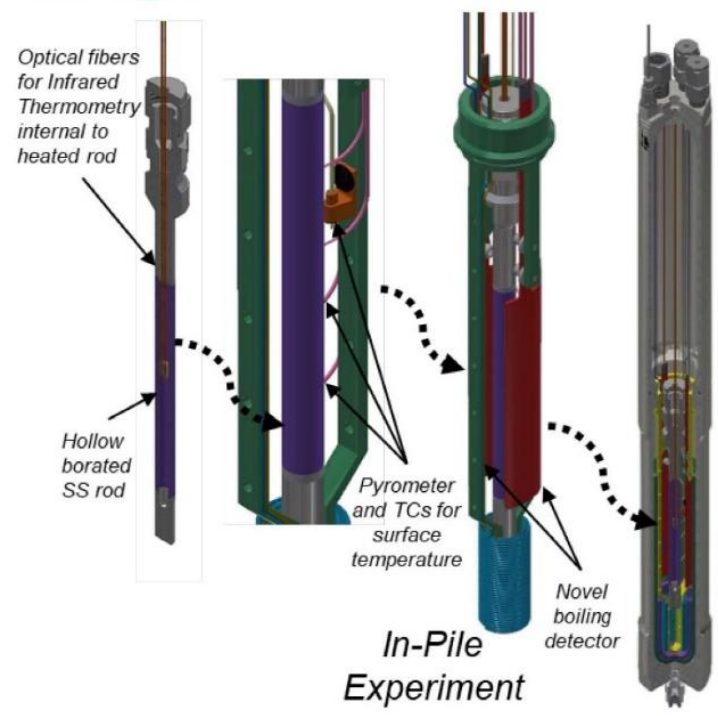

Idaho National Laboratory

\section{In-Pile Experiment Design:} Nuclear-Heated Simulator Rod - N-alpha heater inside cladding

- Hampers internal instrumentation options

- Complicated by gap, but more prototypic

- Offers the ability to test different cladding types

Empty n-alpha-heated tube

- More direct comparison to joule-heated out-of-pile tube tests

- Much easier to instrument inside the tube

- Solid rod

- Off-the-shelf rods, easier fabrication

- Extra mass needed for gamma heat only option

\begin{tabular}{|c|c|}
\hline & $\mathrm{J} / \mathrm{gMJ}$ \\
\hline NUO2 pellet & 0.77 \\
\hline B4C pellet & 0.65 \\
\hline BN pellet & 0.56 \\
\hline Bor SST tube $0.45 \% \mathrm{~B}$ & 0.16 \\
\hline Bor SST tube $0.97 \% \mathrm{~B}$ & 0.26 \\
\hline Bor SST tube $1.48 \% \mathrm{~B}$ & 0.32 \\
\hline Bor SST tube $2.03 \%$ B & 0.37 \\
\hline Li-Cu & TBD \\
\hline Tungsten & TBD \\
\hline
\end{tabular}

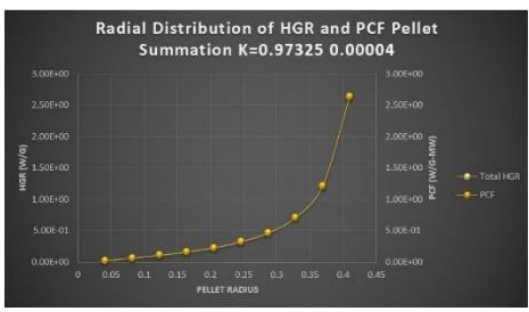


In-Pile Experiment Design:

Nuclear-Heated Simulator Rod

- Nuclear-heated simulator rod has gone through some design iterations to provide the right axial energy deposition

Finalized on an hourglass shape

Works neutronically, thermal studies are underway

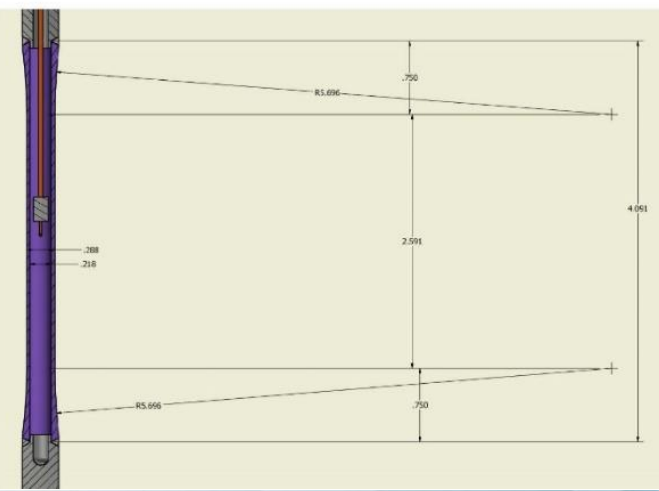

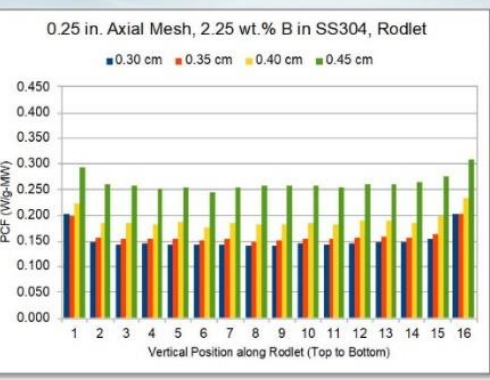

0.25 in. Axial Mesh, 2.25 wt.\% B in SS304 Hourglass

$=0.30 \mathrm{~cm}=0.35 \mathrm{~cm}=0.40 \mathrm{~cm}=0.45 \mathrm{~cm}$

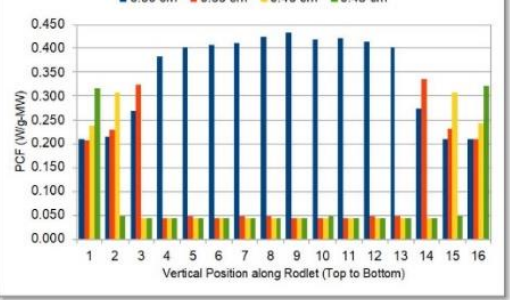

Rivi

\section{How to Validate System Performance outside of TREAT?}

- In-pile experiment offers a lot of flexibility for a R\&D sandbox with instrumentation and power control

1. Advanced instrumentation requires sufficient validation out-of-pile to maximize efficiency of in-pile testing with validated uncertainty

2. Even with great flexibility, out-of-pile facility offers opportunity to extend study parameter space to wider range of heating rates (overlap with NSRR/CABRI)

3. Advantage for separate effects evaluation excluding effects of irradiation with experiment as identical as possible

$\rightarrow$ Need out-of-pile companion facility to support TH evaluations 


\section{Out-of-Pile Transient Boiling System Design}

- Desire up to full PWR thermal hydraulic conditions (mass flux control is < priority objective), desire ability to simulate NSRR to TREAT heating rates (bounding commercial LWR RIA)

- Utilize existing water autoclaves

Stay within design specification

Support feedthroughs for gas lines, electrical feeds, instrumentation, imaging, ...

- Build custom, controllable power delivery system to simulate reactor transients

- Off the shelf components
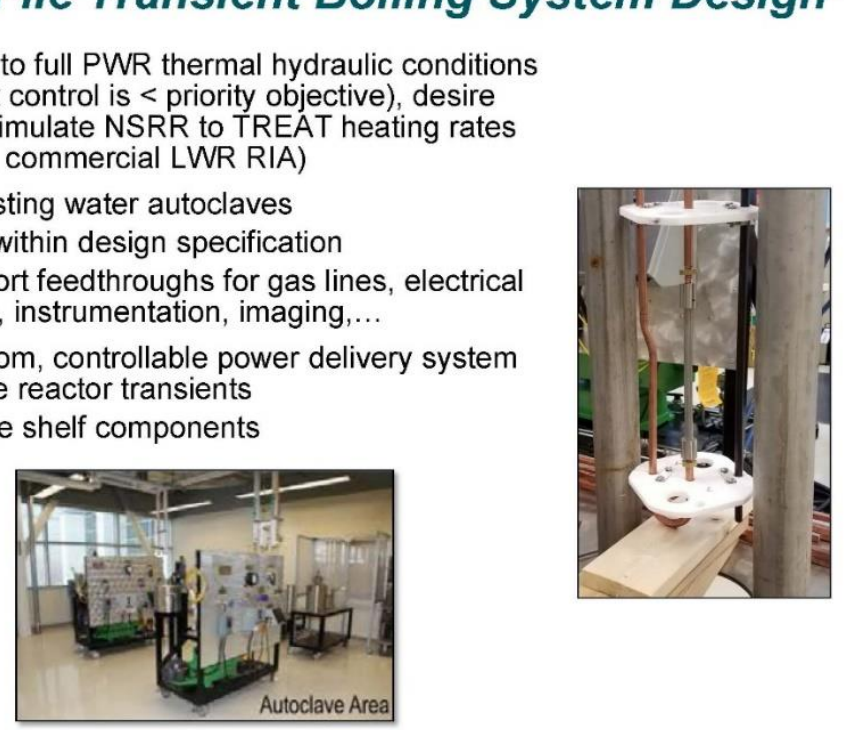

\section{Fivl Idaho National Lat pratgy}
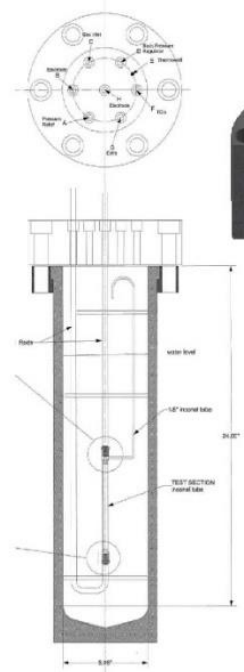

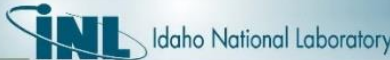

\section{Capacitor Banks}

- Electrical heating will be driven by 4 capacitor banks (>220 kW max power, $760 \mathrm{~kJ}$ total stored energy, $<20 \mathrm{~kJ}$ max experiment)

- Each with an independent switch and current probe

- Flexible system data acquisition and control

- Switching system enables power shaping; e.g. ramps, pulses (10ms-200ms FWHM)

- Full electrical model to predict electrical performance
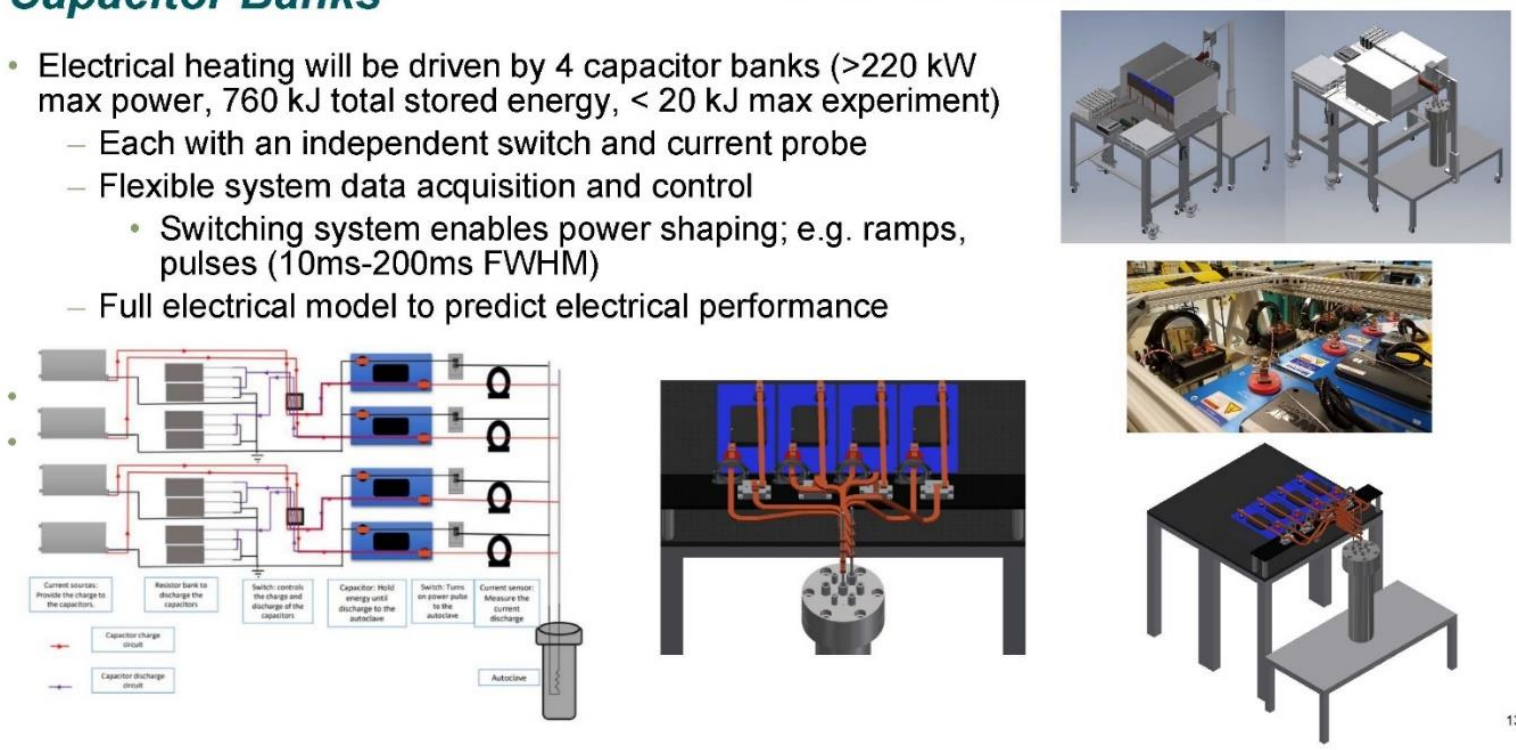


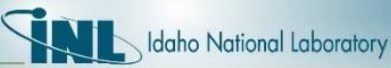

\section{Instrumentation is the key!}

- Incorporate the same instrumentation planned for inpile testing and more...

- Infrared pyrometers for inner and outer heater tube temperatures

- Thermocouples on heater surface

- Capacitive boiling detector

- Fast response pressure transducer

- High speed underwater imaging system
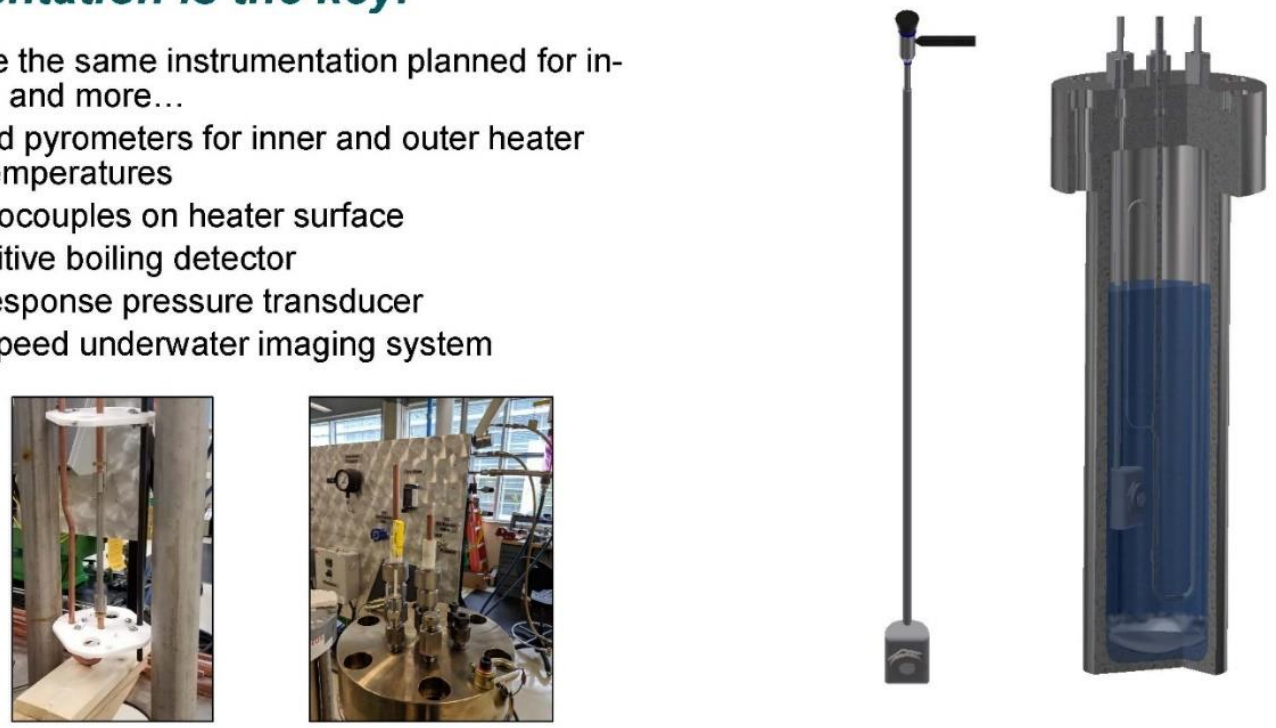

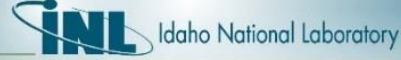

\section{Targeted Power Cases}

- RELAP5 model built from autoclave dimensions

- Power modeled as an RC decay circuit with power terminated at specified pulse width

- Initial conditions set at $300^{\circ} \mathrm{C}$ and 15.5 $\mathrm{MPa}$

- Modeled a range of pulse widths

- 11 ms (narrowest SPERT/NSRR/CABRI)

- $90 \mathrm{~ms}$ (TREAT)

$40 \mathrm{~ms}$ (PWR)

$-200 \mathrm{~ms}(36 \mathrm{~V})$
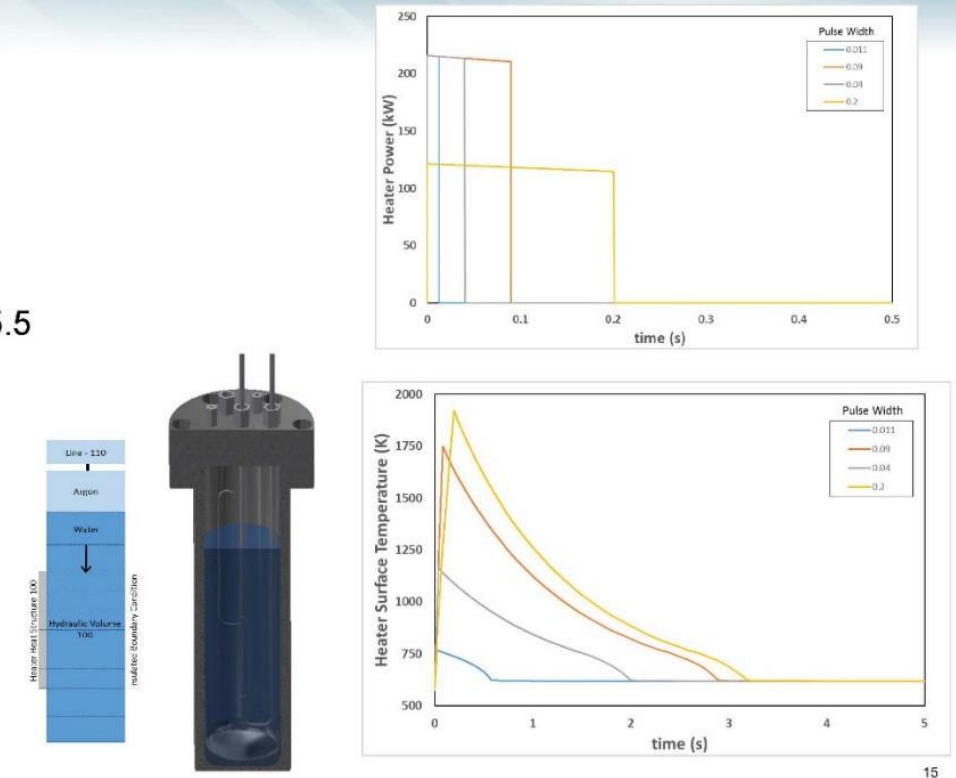


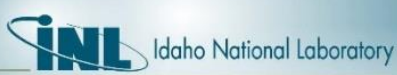

\section{... Targeted Power Cases Cont.}

- Narrowest pulse with current configuration is $\sim 0.011 \mathrm{~s}$

- A factor of 5 on CHF increases the narrowest pulse to $0.025 \mathrm{~s}$

- All cases reach $\mathrm{CHF}$ with default correlations in Relap5

- Pressure increases in water is negligible ( 10 psi)
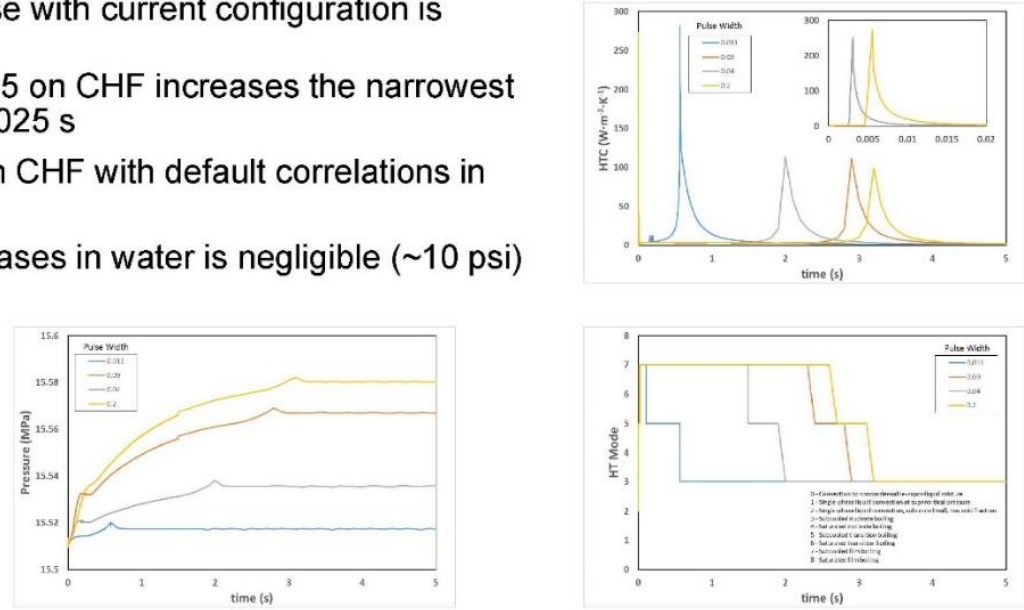

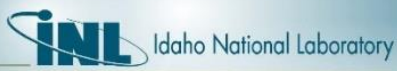

\section{Additional Topics}

- BWR AOO Event

- Boiling transition effects on irradiated fuel from test or commercial reactor

- Perform "integral" experiments on irradiated fuel rods that create appropriate temperature vs time history

MARCH-SERTTA capsule shows promising results

\section{- Coated Cladding PIRT}

Introduction of coated cladding might lead to additional questions that need to be answered

- Changes to hydraulic diameter due to the coating thickness

- Changes to boiling crisis behavior, including effects of surface roughness

- For boiling water reactor applications, changes to rewet temperature following dryout (i.e. Tmin)

- Potential for defects such as cracks and delamination

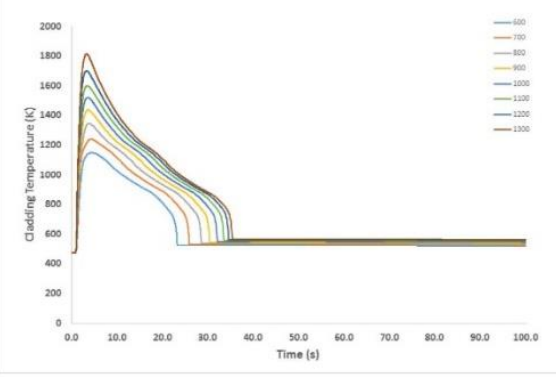




\section{Conclusions}

- In-pile transient boiling remains an area of uncertainty in fundamental understanding and predictive capability for RIA conditions

- Restart of TREAT provides ideal opportunity to investigate AOO and DBA transients

- Out-of-pile facility designed to complment in-pile experiments and extend experimental database for pre-DNB conditions

- Simple design, based on capacitive discharge system

- Facility can extend range of heating rates bridging integral test facilities and commercial LWR

- System operational this month!

- Support in-pile testing - ATF, AOO studies, etc., with collaboration with universities, EPRI, GE, IRSN, JAEA
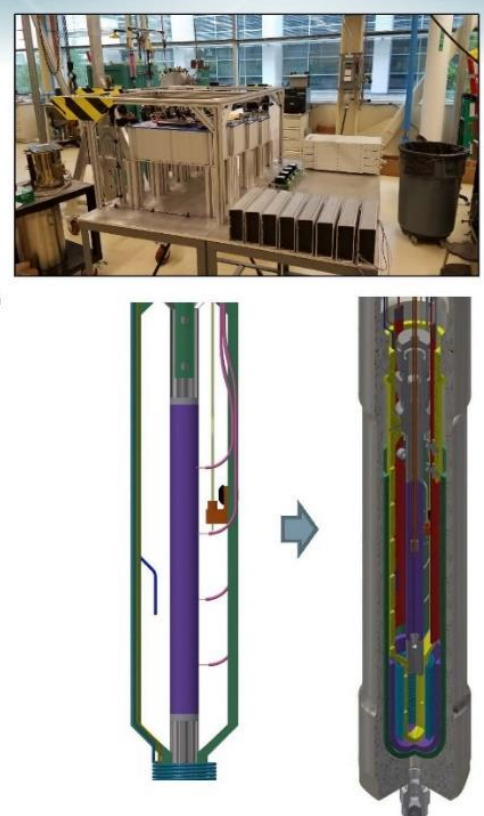

\section{Thank you for your attention!}




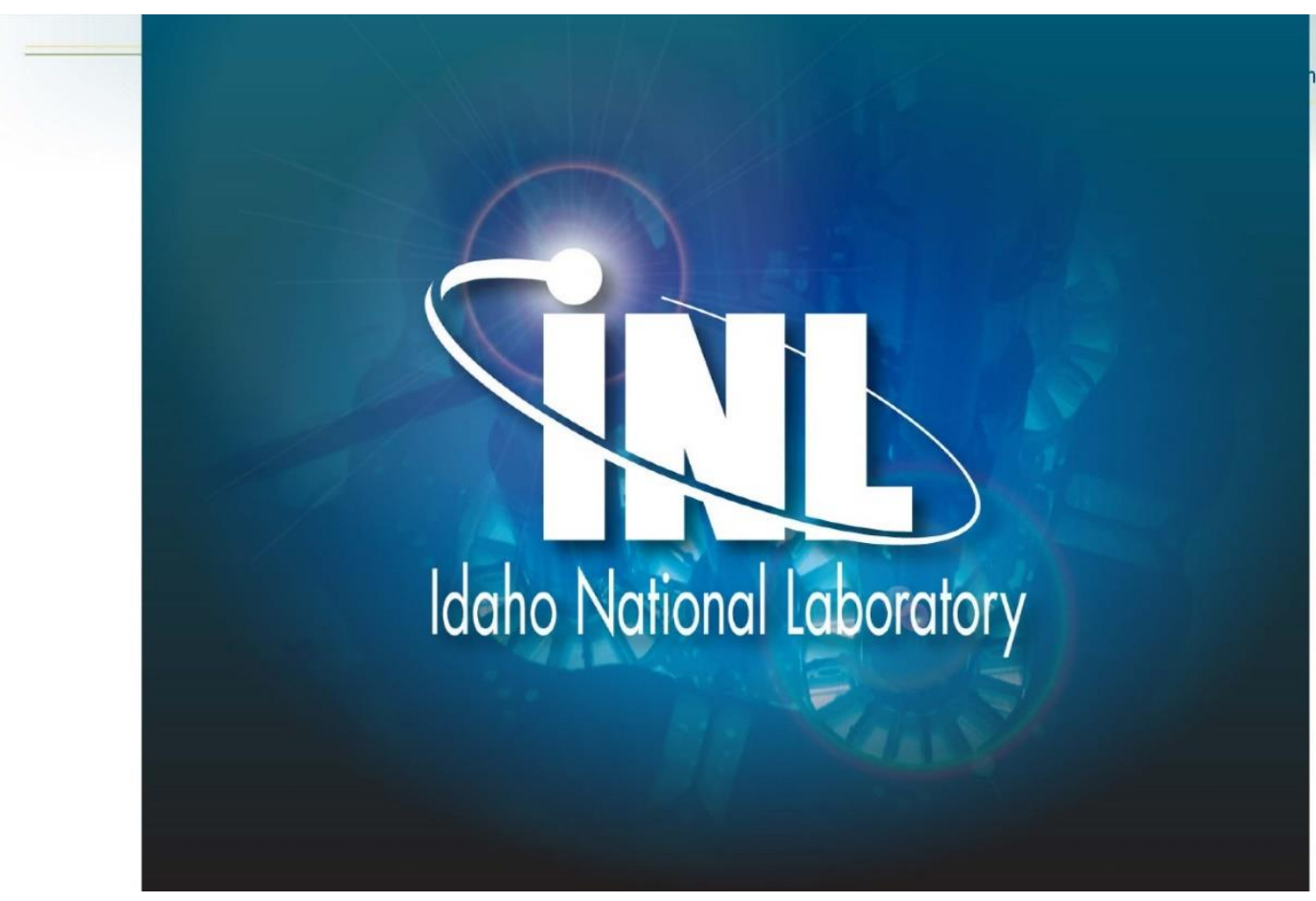




\section{Appendix K}

\section{Thermal-Hydraulics of ATF Cladding Materials, NEUP-ATF Meeting}




\section{Appendix K}

\section{Thermal-Hydraulics of ATF Cladding Materials, NEUP-ATF Meeting}

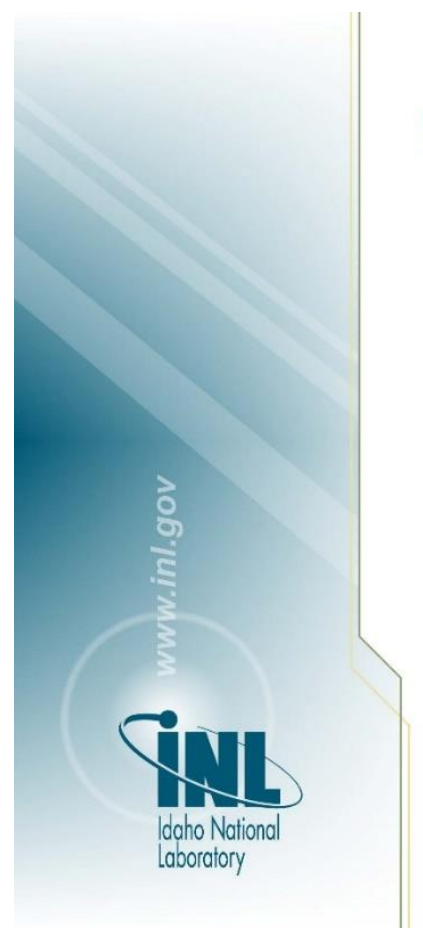

Thermal-Hydraulics of ATF Cladding Materials

NEUP - ATF Meeting

Organizers: Matteo Bucci (MIT) \& Piyush Sabharwall (INL)

August $13^{\text {th }} 2019$ 


\section{Overview}

$\begin{gathered}\text { NEUP Project } \\ \text { Number }\end{gathered}$
$17-12647$
$17-12688$
$17-13019$
$17-12549$

Title

Determination of Critical Heat Flux and Leidenfrost Temperature on Candidate Accident Tolerant Fuel Materials

An Experimental and Analytical Investigation into Critical Heat Flux (CHF) Implications for Accident Tolerant Fuel (ATF) Concepts

Evaluation of Accident Tolerant Fuels Surface Characteristics in Critical Heat Flux Performance Critical Heat Flux Studies for Innovative Accident Tolerant Fuel Cladding Surfaces

MIT

UWM

Project PIs

ZIRLO + Cr Spray Coating (WEC)

SiC Cladding (GA)

ZIRLO + FeCrAl Coating (WEC)

$\mathrm{SiC} / \mathrm{SiC}(\mathrm{GA})$

ZIRLO + Cr PVD

ZIRLO + FeCrAl Cold Spray

CVD SiC Cladding

ZIRLO + ZrSi PVD

FeCrAl Cladding

Zirc-4 + Cr PVD (AREVA)

SiC (AREVA)
University

PI

MIT Matteo Bucci

UNM Youho Lee

Sama Bilbao y

VCU León

UW Michael Corradini

VCU

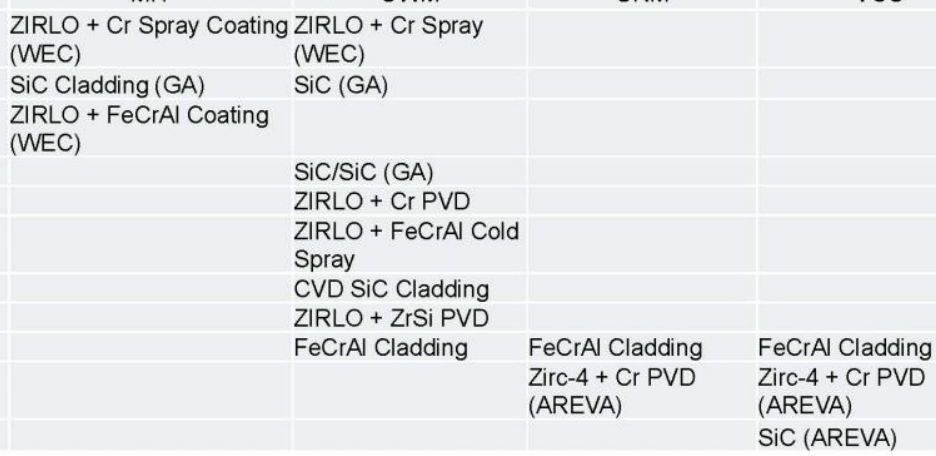

FeCrAl Cladding Zirc-4 + Cr PVD (AREVA)

FeCrAl Cladding Zirc-4 + Cr PVD (AREVA)

$\mathrm{SiC}$ (AREVA)

\section{Participants}

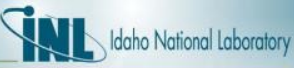

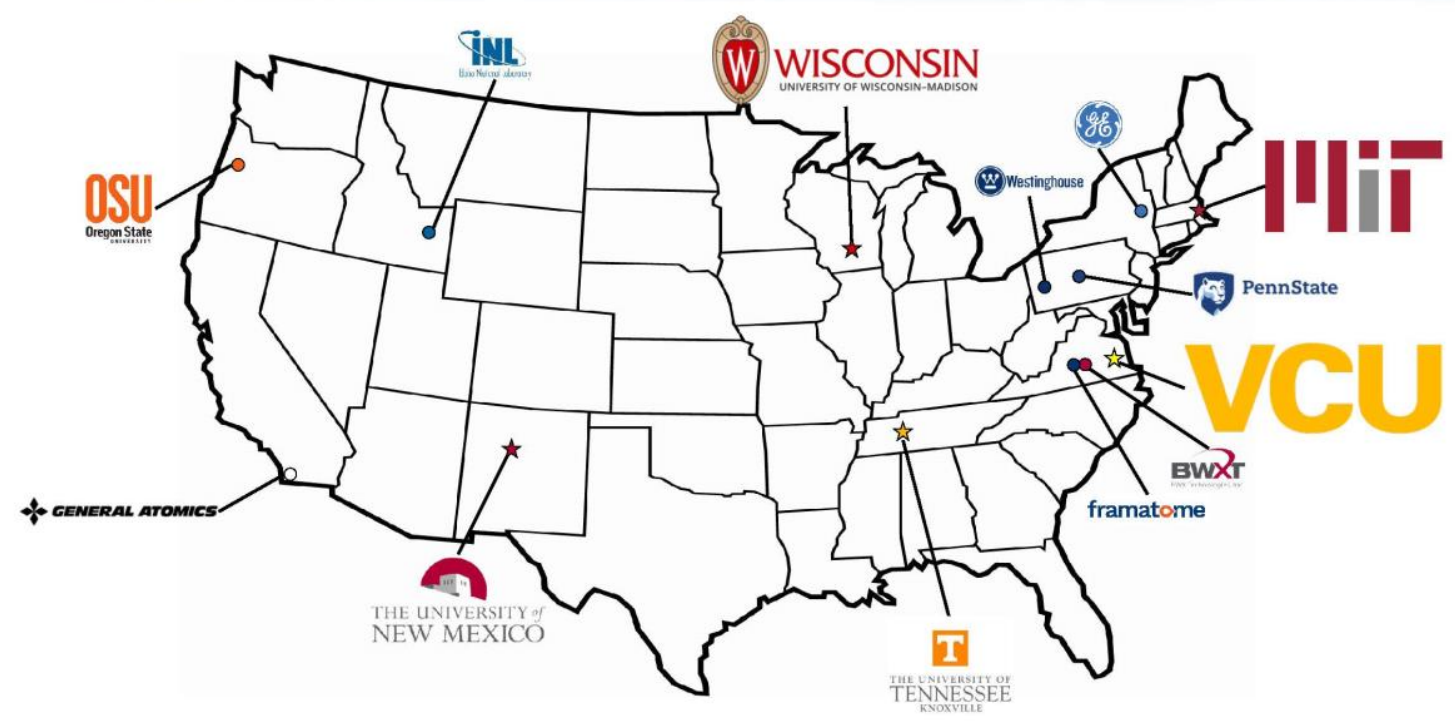




\section{Project Overviews}

VCU

- Perform separate-effects experiments to characterize surface properties

- System-wide tests

- Develop enhanced models \& correlations to predict $\mathrm{CHF}$, and implement in sub-channel codes

MIT

- Characterize CHF properties for 3 candidate ATF cladding materials

- Measure CHF under both steady-state and transient conditions

- Quantify the effects of CRUD deposition on CHF
UWM

- Study surface coating methods

- Characterize surface properties

- Pool boiling experiments

- Flow boiling experiments

UNM

- Determine change in CHF for candidate claddings

- Assess impact on reactor performance, design, and safety characteristics

- Conduct low \& high pressure boiling experiments

- System simulations

- Boiling modeling

\section{Integrating Efforts - CHF}

- Completed a survey of the different cladding/coating systems to be analyzed. Several potential areas for collaboration were identified.

While multiple entities may be investigating the same or similar systems, they are often looking at different properties or using different methods.

- MIT and UWM have areas of synergy for WEC systems.

- UNM and VCU have areas of synergy with Framatome (AREVA) systems.
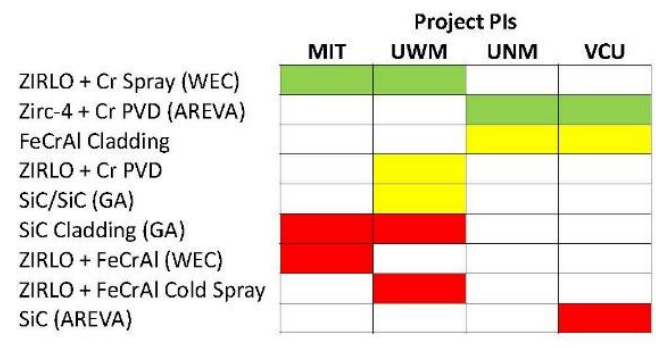

- Pls noted the relative priority of the various systems, based on their interactions with vendors.

- INL is working to facilitate collaborations among the researchers.

\section{- Importance of NQ-1 Data}

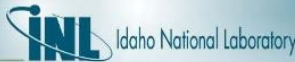

High Priority

No Priority Specified

Low Priority 


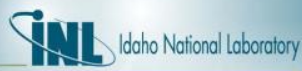

\section{Combined/ Integrated Report on Findings}

Thermal-hydraulics of Accident Tolerant Fuel cladding materials

(Coordination of NEUP projects)

- Introduction and Significance of Work

- Overall Objective

- Methodology (details)

- Experiment and modeling

- Verification and validation

- Data (gathering, quality assurance)

- Overall Challenges

- Path Forward Near term efforts Long term efforts

- Publications (if any)

- Main Conclusions and Summary

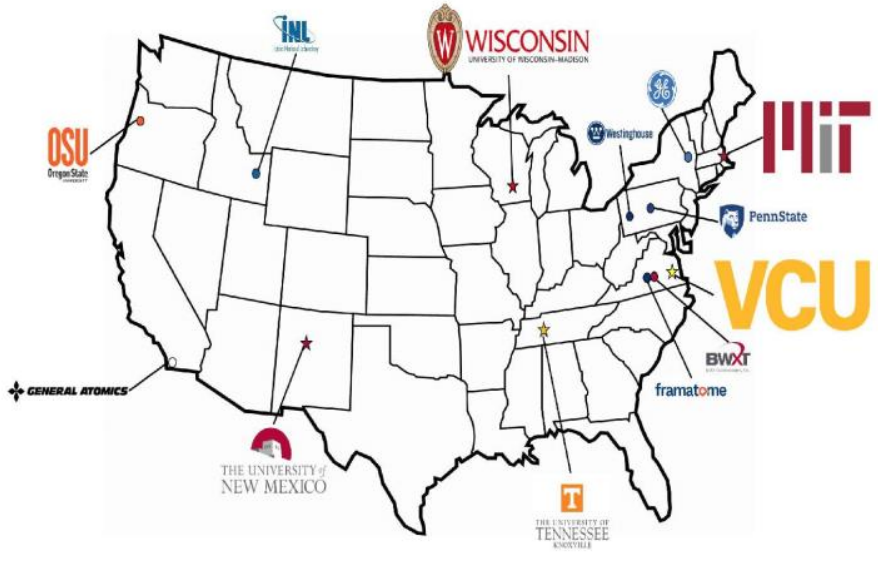




\section{Appendix L}

\section{The Red Lab and ATF Facilities in NSE, MIT}




\section{Appendix L}

\section{The Red Lab and ATF Facilities in NSE, MIT}

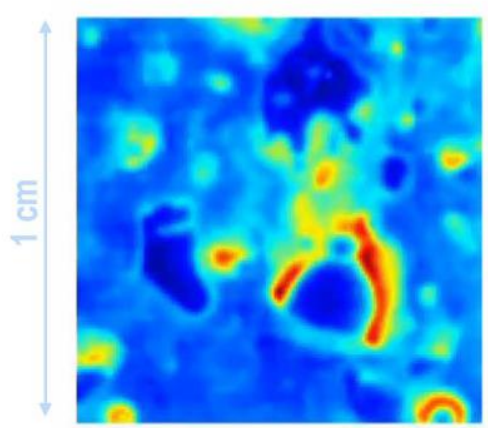

Heat flux on a boiling surface (approaching the boiling crisis)
The Red Lab and "ATF" Facilities in NSE, MIT

The study of thermal-hydraulics of accident tolerant fuel cladding materials

Matteo Bucci

Massachusetts Institute of Technology

Department of Nuclear Science and Engineering 


\section{Flow loop \#1 - Test section \#1: Pressurized}

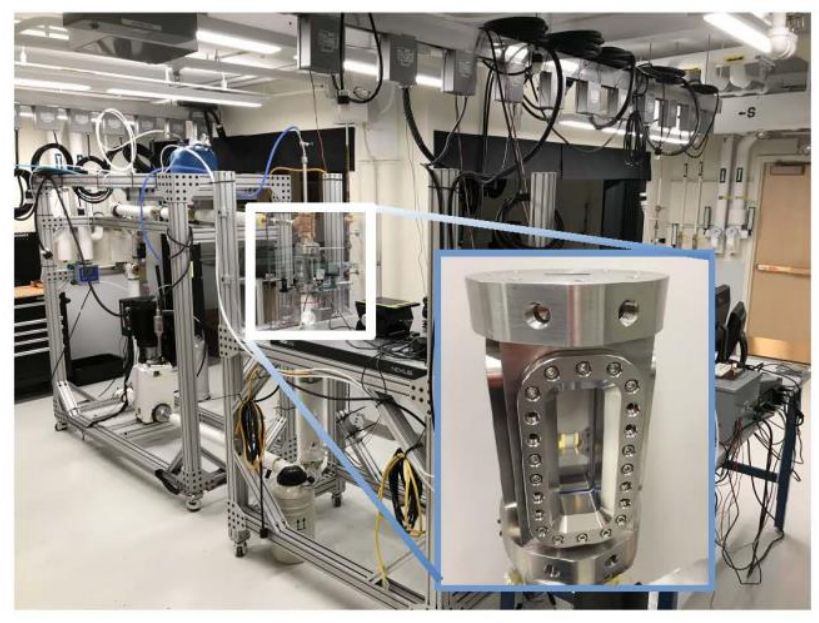

$P E T h E R$

\section{NSE}

Nuclear Science

and Engineering

- DI water

- Up to 14 bars

- Ambient temperature to saturation

- 400 to $2500 \mathrm{~kg} / \mathrm{m}^{2} / \mathrm{s}$

- $\mathrm{Dh} \sim 1.5 \mathrm{~cm}\left(1 \times 3 \mathrm{~cm}^{2}\right)$

- Up to CHF

- Diagnostics

\section{Flow loop \#1 - Test section \#2: Pressurized}

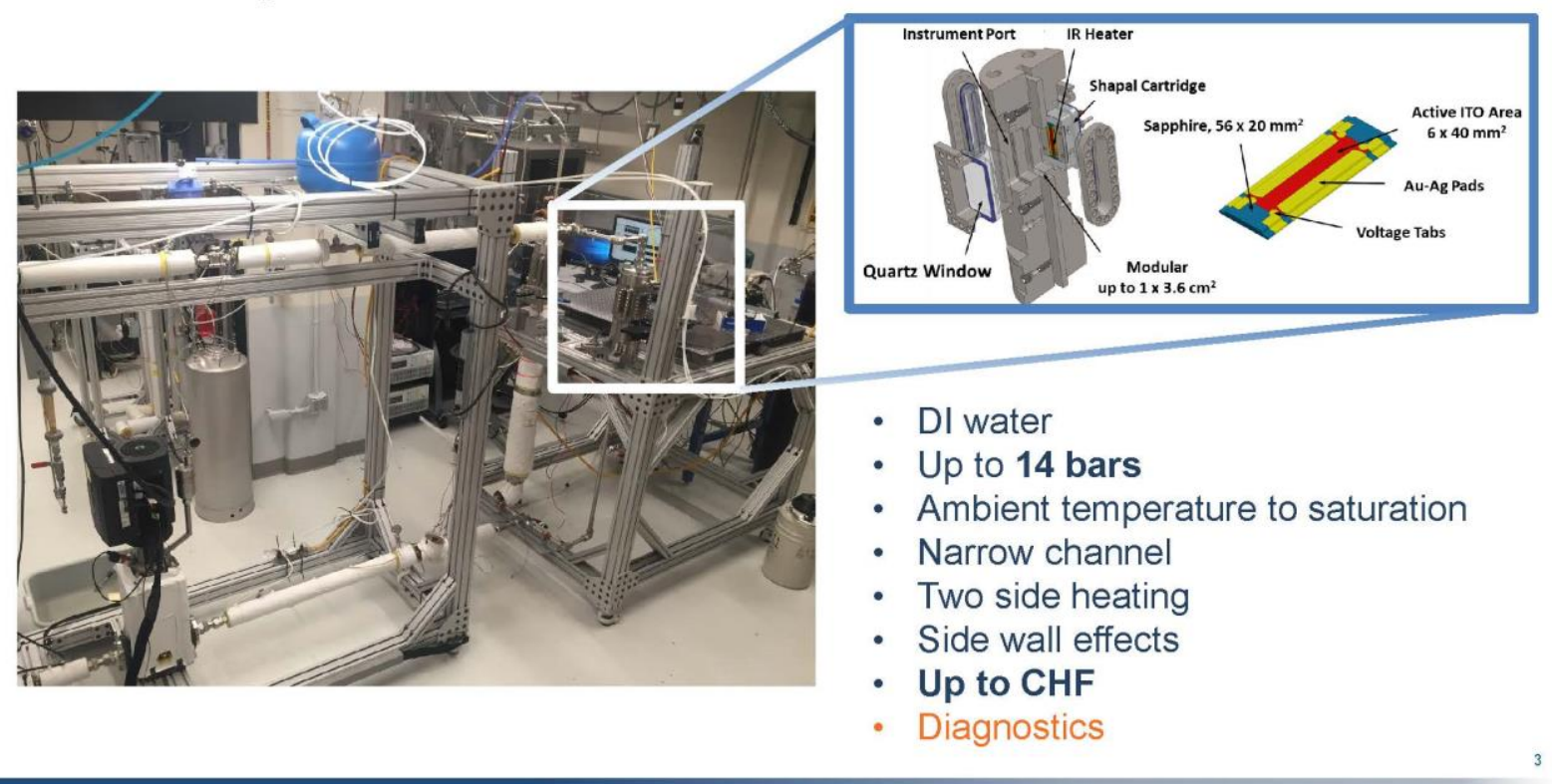




\section{Flow loop \#2: Full PWR}

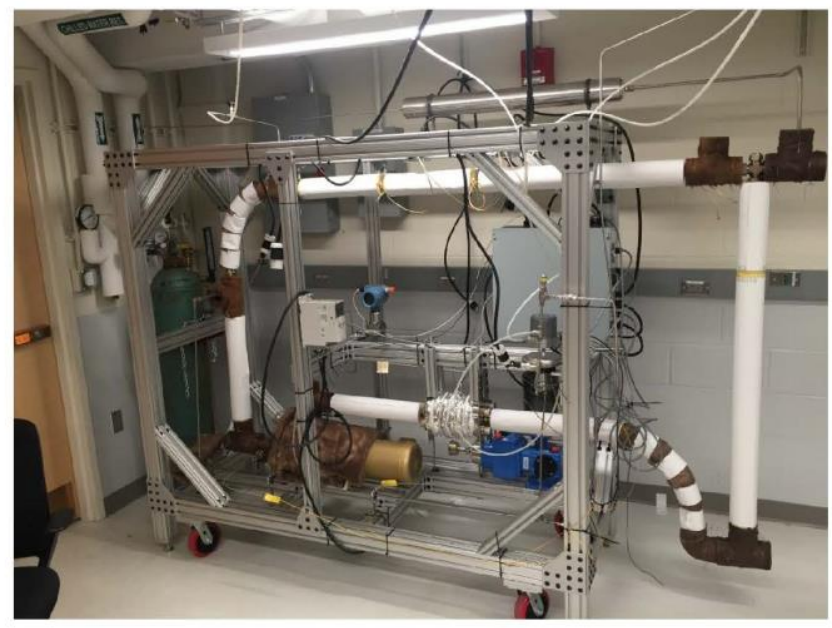

LWR

NSE

Nuclear Science

and Engineering

- DI water

- Up to PWR pressure

- Ambient temperature to saturation

- Up to $3600 \mathrm{~kg} / \mathrm{m}^{2} / \mathrm{s}$

- Up to CHF

- Dh Dh PWR

- Mixing obstacles

- Diagnostics

- Rod heaters / annular flow

\section{Flow loop \#2 - Test section: Full PWR}

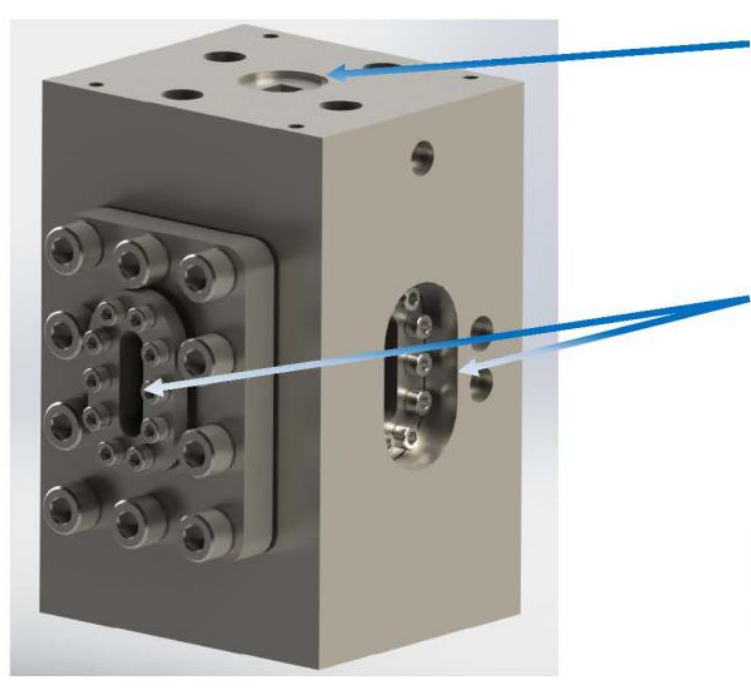

Square channel matches the hydraulic diameter of the inner PWR subchannel

Can accommodate upstream obstacles to mimic mixing grids

Multiple openings provide the view of the boiling process from all perspectives

The test section is designed to operate at full reactor pressure (155 bar) and up to the saturation temperature of water $\left(345^{\circ} \mathrm{C}\right)$ 


\section{Autoclave contact angle measurement}
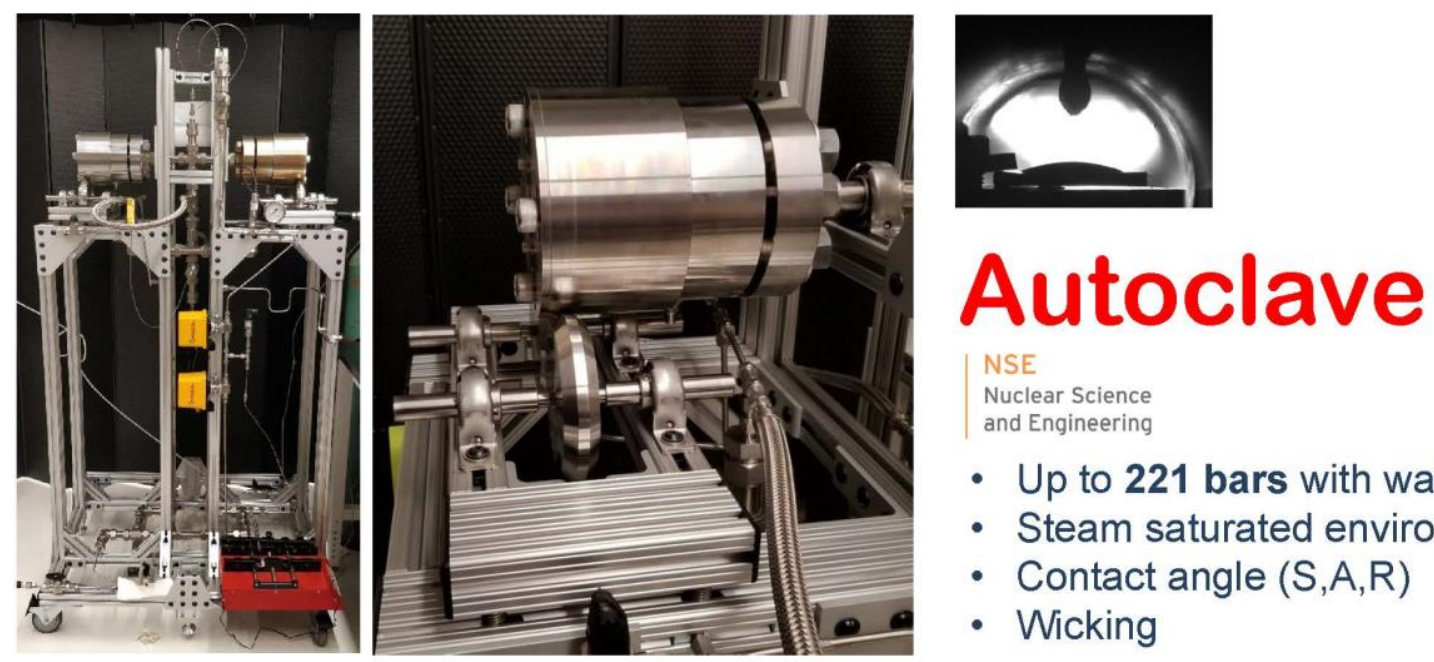

\section{NSE}

Nuclear Science

and Engineering

- Up to 221 bars with water

- Steam saturated environment

- Contact angle $(S, A, R)$

- Wicking

\section{Droplet quenching on ATF material}

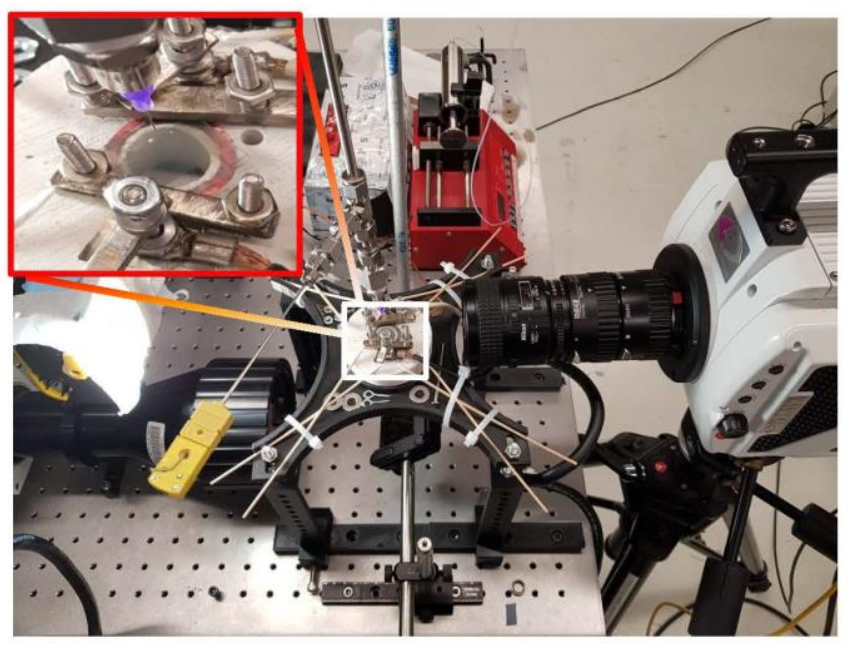

Quenching

NSE

Nuclear Science

and Engineering

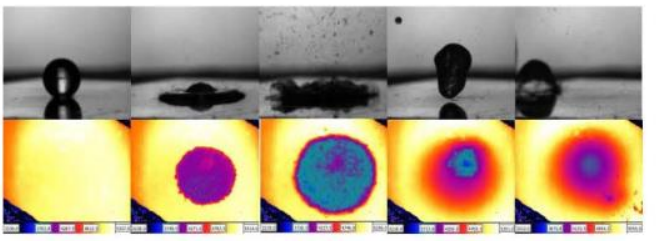

- $\sim 2 \mathrm{~mm}$ droplet

- Up to $500^{\circ} \mathrm{C}$ (Film boiling)

- Heating area $\sim 1 \mathrm{~cm}^{2}$

- IR and HSV diagnostics 


\section{Flow loop \#3: BWR or accident condition}

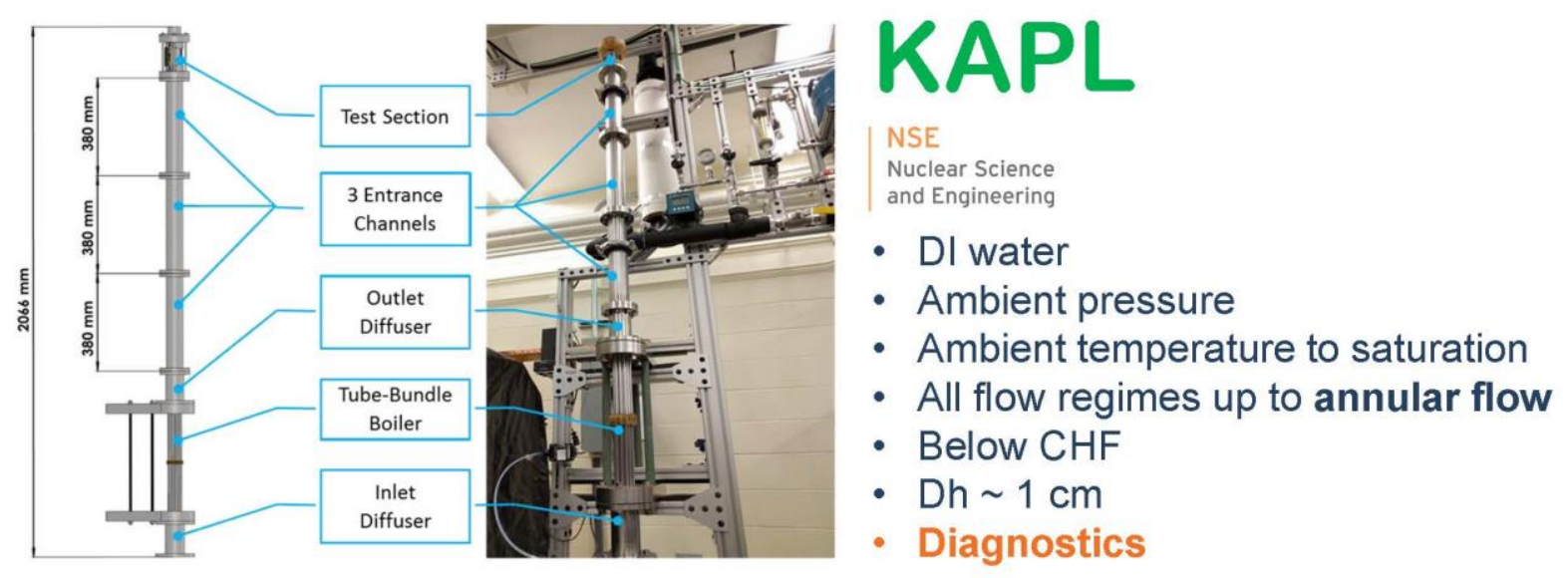

Impact of superheated steam on ATF material

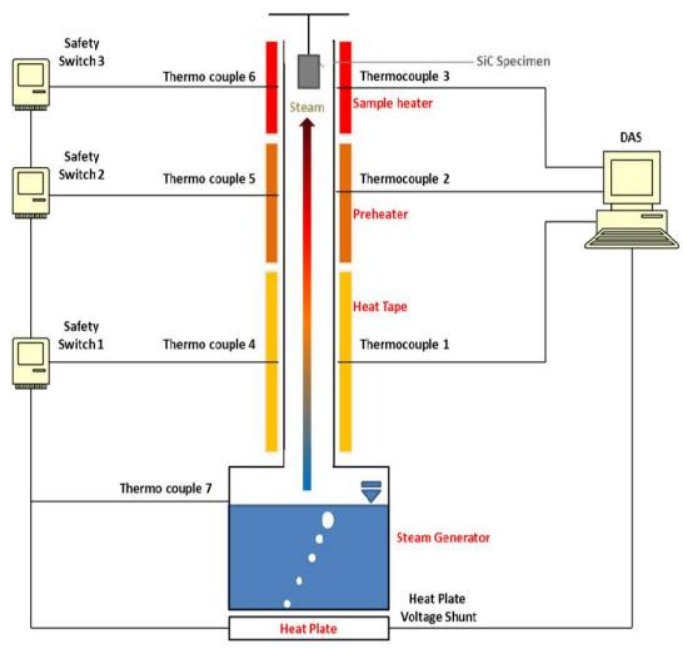

Oxidation Column NSE

Nuclear Science and Engineering

Duplicate post-LOCA conditions

- Steam T: $1140^{\circ} \mathrm{C} \sim 1500^{\circ} \mathrm{C}$

- Re: 40 300

- V: 1 9m/sec

- Ambient pressure 